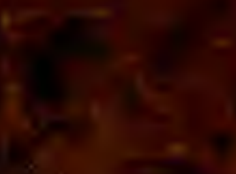




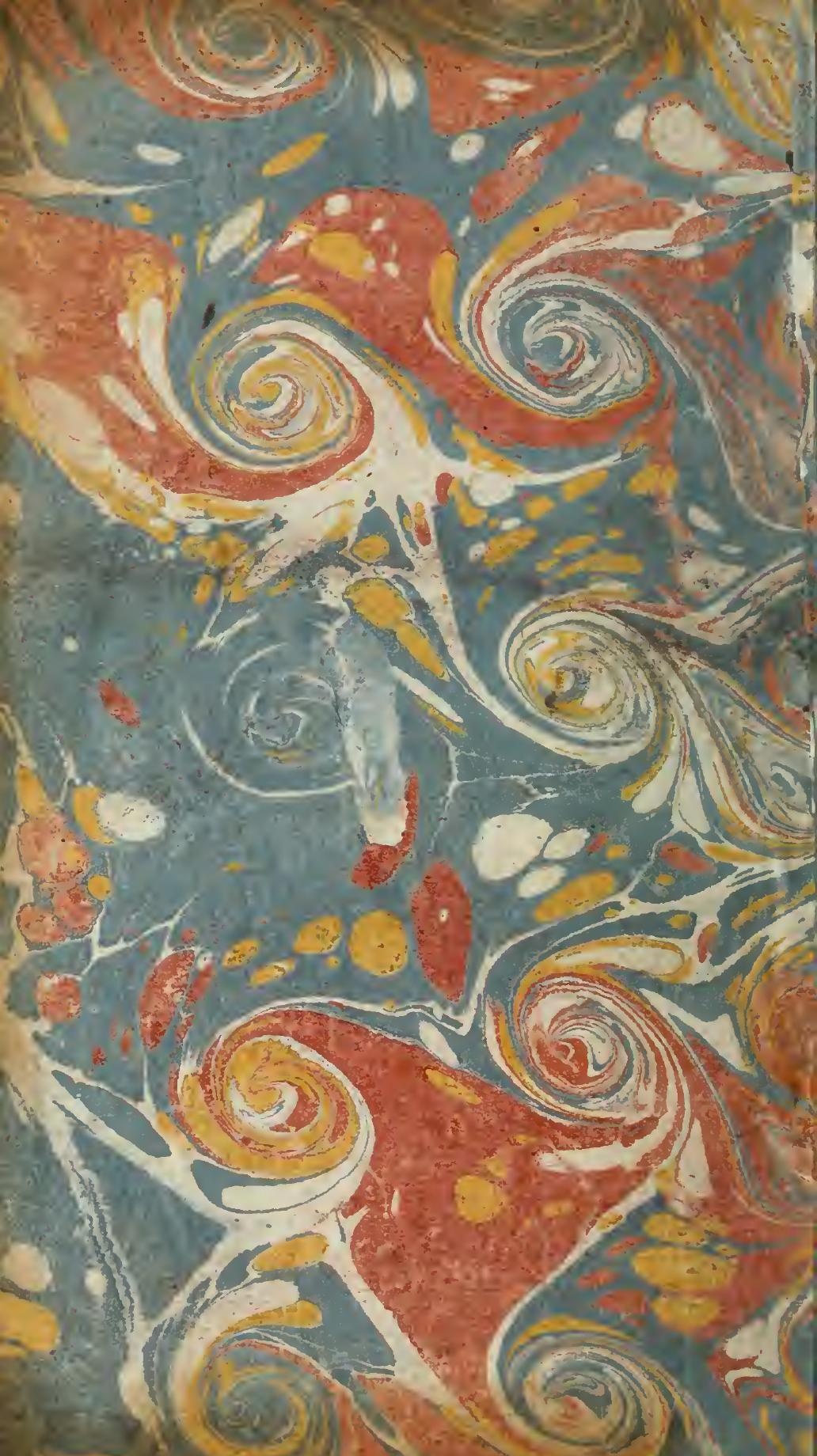


(3)

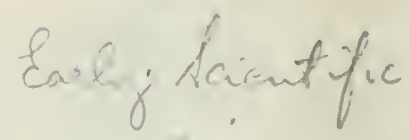

lecermonds te

$$
\text { Sim/- }
$$




$$
\text { form Youtar }
$$





\section{CONSIDERA TIONS P H I L O S O P H I QUES.}


2WOHTHACIEMSO

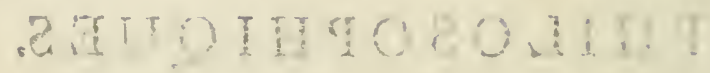




\section{CONSIDERATIONS PHILOSOPHIQUES \\ D E L A}

\section{GRADATION NATURELLE}

DES FORMES DE L'ETRE,

O U

L E S E S S A I S D E L A

N A T U R E QUI APPREND A FAIRE LHOMME. PAR J. B. ROBINET.

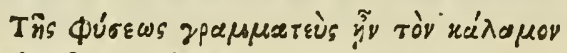
¿'To $\beta_{p o ́} \chi \omega \nu$ šureuv. SUID. de ARIST.

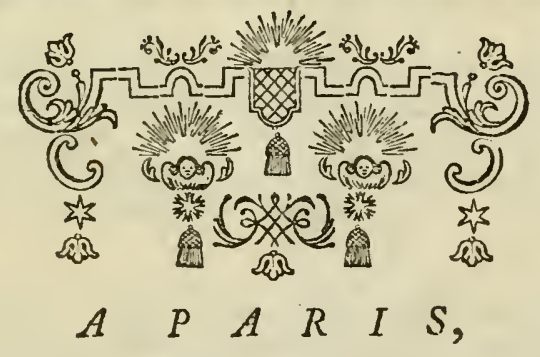

Chez CHARLES SAILLANT. MDCCLXVIII. 
tienment les unes aux autres d'aufi près qu'il fe ceut, giroique la fomme des dilerences accumulées le long de l'ćchelle univerfelle des Etres, puilìe rípandre du doute \& de l'incertitude fur la liaifon des plus élevés arec les plus bas. Clnacun a fon exiltence à part, \& aucun n'eft ifolé ou indépendant. Clacun a des rapports plus ou moins proches avec tous les autres, \& les extrêmes fe communiquent encore. Ils procedent les uns des autres d'une manière fi intime \& fi nécesfaire que chacun a la raifon fuffifante de fon exiftence dans celui qui le précede, comme il eft lui-n!ême la raifon fuffifante de l'exiftence de celui qui le fuit.

Qu'on me permette de rappeller ici cet cnchainement de tous les Ltres, fuffifamment établi \& développé ailleurs, qui fait de la Nature enticre un tout, continu d'exiftences variées, oul l'imperfection de nos connoifanes nous fait appercevoir des interruptions $\&$ des lacunes, quoiqu'il n'y cn ait point, \& qu'il ne puific pas y en avoir.

La Nature n'cit qu'un feul acte. Cet acte comprend les phénomènes paffés, piéfens \& futurs; fa permanence fait la duréc des chofes.

Quand je contemple la multitude innombrable d'individus épars fur la furface de la terie, dans fes entrailles $\&$ dans fon athmofphere, quand je compare la picrre à la plante, la plante à l'infecte, l'infecte au reptile, le reptile au quadrupede, j'apperçois au travers des différences qui caractérifent chacun d'cux, des rapports d'analogie qui me perfuadent qu'ils ont tous été concus \& tormés d'après un deffein unique dont ils font des variations graduées à l'infini. Ils m'offient tous des traits frappans de ce modele, de cet exemplaire original, de ce prototype, qui, en fe réaJifunt, a levêtu fucceflivement les formes infiniment multipliées \& diférenciées, fous lefquelles l'Etre fe manifelte à nos yeux.

Ces traits n’ont point échappé aux génies obfervateurs; \& fi j'entreprends aujourd'hui de mettre dans un plus grand jour une penfée que d'autres ont eur 


\section{P II I L O S O P II I Q U⿺ S \&c.}

avant moi, content de donner quelques nouveaux degrés de certitude, felon ma foible capacité, à ce qui a été propofé plûtôt comme une conjecture ou un doute, que comme une vérité, je me fais un devoir de rapporter la gloire de la découverte à ceux à qui elle appartient.

A la tête de cette grande échelle des habitans de la terre, paroît l'homme le plus parfait de tous:il réunit, non pas toutes les qualités des autres, mais tout ce qu'elles ont de compatible cn une même eflence, élevé à un plus haut degré de perfection. C'eft le chefd'ouvie de la Nature, que la progrefion graduelle des Etres devoit aroir pour dernier terme; au noins nous lc prenons ici pour le dernicr, parce que c'eltà luique fe termine notre échelle naturellc des Etres.

Dans la fuite prodigicufement variée des animaux inlérieurs à l'homme, je vois la Nature en travail avancer en tâtonmant vers cet Etre excellent qui couronne fon œuvi'c. Quelque imperceptible que foit le progrès qu'elle fait à chaque pas, c'eft-à-dire à chaque production nouvelle, à chaque variation réalifée du desfein primitif; il devient très-fenfible après ùn certain nombre de métamorphofes. Si, par exemple, la nuance entre deux quadrupedes voifins, tels que le cheval \& le zebre, eft trop délicate pour que nous puiflions juger lequel des deux, dans l'échelle, approche plus de l'homme que l'autre; cependant le Zoologifte qui paffe des bipedes aux bimanes, puis aux quadrupedes, folipedes, pieds-fourchus, fiffipedes, \& de ceux-ci aux quadrumanes, s'apperçoit qu'il monte par degrés ver's le fommet de l'échelle où il trouve le feul animal qui foit à la fois bimane \& bipede. Venant enfuite à lui comparer ces différens animaux., il reconnoît fans peinc qu'un quadrumane, tel que le magot ou l'Orangoutang, reflemble beaucoup plus à l'homme; qu'un quadrupede quelconque fiffipede; \& un folipede beaucoup moins qu'un fiflipede, fur-tout de ceux qui fe fervent de leurs pieds de devant comme de mains. Pour peu que notre Zoologifte veuille bien fe rendrs A 2 
attentif à tous les traits de la comparaifon, il découvrira encorc que l'orang-outang rcfiemble plus à l'homme, qu'à aucun autre animal.

Autant il y a de variations intermédiaires du prototype à l'homme, autant je compte d'eflais de la Nature qui, vifant au plus parfait, ne potivoit cependant y parvenil que par cette fuite innombrable d'ébauches. Car la perfection naturelle confite dans l'unité combinéc avec la plus grande varieté poffible: c'eft done l'extrême de la variation de la forme originale, qui peut donner la forme la plus parfaite; $\&$; cet cxtrême terminant la féric des variations intermédiaires, il falloit épuifer celle-ci pour avoir ce dernier terme.

La Nature ne pouvoit réalifer la forme humaine qu'en combinant de toutes les manières imaginables chacun des traits qui devoient y entrer. Si elle cût fauté une feule combinaifon, ils n'auroient point eu ce jufte degré de convenance qu'ils ont acquis en pasfant par toutes les nuances.

Sous ce point de vue, je me figure chaque variation de l'enveloppe du frototype, comme une étude de la forme humaine que la Nature méditoit; \& je crois pouvoir appeller la collection de ces études, l'apprentiffage de la Nature, ou les effais de la Nature qui ap. prend à faire l'homme (*).

Ce que je dis de l'homme par rapport à tous les autres Etres, eft peut-être également appliquable à un terme quelconque de l'échelle relativement à ceux qui le précedent. Mais l'homme étant ce que nous connoiffons de plus excellent fur notre planete, nous n'aurions point une idée de toute la richeffe de la Nature, fi nous nous bornions à la contempler dans un Etre inféricul.

Lorfqu’on étudie la machine humaine, cette multitude jmmenfe de fyltêmes combinés en un feul, cette

(*) Pline a appelle le lizeron, petite fleur fort refiemblante a 15s, l'apprentiffage de la Nature qui apprend a faire un lys, Corvolvulus tyrocinimm Natuia lilisin formbits difcentis. 


\section{P HIL O S O P H I Q UES \&c.}

énorme quantité de piéces, de refforts, de puiffances, de rapports, de nouvemens, dont le nombre ascable l'efprit, quoiqu'il n'en connoiffe que la moindre partie, on ne sétonne pas qu'il ait fallu une fi longue fucceffion d'arrangemens \& de déplacemens, de compofitions \& de diffolutions, d'additions \& de fuppresfions, d'altérations, d'oblitérations, de transformations de tous les genres, pour amencr une organifation auff favante \& aufin merveilleufe.

Mais quel œil affez pénétrant pourra reconnoître une ébauche de l'homme, je ne dis pas dans la première réalifation du prototype, à laquelle nos fens ne fiuroient atteindre \& que nous ne pouvons imaginer, mais dans le moindre des animaux fenfibles, déja fi éloigné du prototype, \& par cela même d'autant plus proche de l'homme? Qui fera capable de fuivre cette cbauche dans tous fes accroiffemens? Qui pourra faire violence à la Nature, lui arracher fon fecret, nous la montrer perfectionnant fans ceffe fon ouvrage, ajoutant des,facultés à des facultés, des organes à des organes; variant ces organes fous toutes les formes dont jls font fufceptibles, tantôt les prolongeant \& tantôt les reflerrant, les enveloppant dans un individu pour les développer dans un autre, les fupprimant quelquefois pour les reproduire enfuite avec un nouvel appareil; en un mot faifant tout l'homme en détail \&2 par piéces, travaillant \& multipliant chaque piéce comme à l'infini fans fe copier jamais, pour en compofer une infinité d'Etres différens; imprimant à chaque Etre fa fécondité inépuifable poul en former ce que nos méthodiftes appellent des efpeces, monumens durables de la gradation de fa marche; \& enfin par ces procédés générateurs obtenant le chef-d'œuyre qu'elle avoit projetté?

L'homme (j'entends l'homme pris dans un fens général \& abftrait pour le modele de l'efpece) eft le prototype, plus le réfultat de toutes les combinaifons que le prototype a fibies en paffant par tous les termes de la progreflion univerfelle de l'Etre. Si quelque génie

$$
\text { A } 3
$$


affez au fait de la marche de la Nature pour reconnoítre ce que le prototype a acquis à cliaque pas, fouvoit en dépotiller l'homme dans la niême progreflion defcendante \& avec la même inverlion des phenomènes, il le feroit rétrograder vers le bas de l'échelle où il fe réduiroit à la fimple enveloppe primitive du prototype. Mais dès le premicr pas de fa dégradation, il auroit ceffé d'être homme: car l'Etre, le plus voifin de l'homme, elt prefque un homme; mais il n'en eft pas un.

Puifuc l'homme eft le prototype, plus le réfultat de toutes les combinaifons que le prototype a fubies en paflant par tous les degrés de la progreflion univerfelle de l'Etre; pourquoi le prototype ne feroit-il pas l'homme, moins ce même réfultat? c'eft que ce réfultat eft précifément la différence qui conftitue l'homme. Dire que le prototype eft l'homme, moins ce réfultat, c'eft dire que le prototype eft l'homme, moins ce qui fait l'homme. Et que fignifie un tel langgge, fi non que le prototype n'eft pas l'homme?

Le prototype eft un modele qui repréfente l'Etre réduit à fes moindres termes: c'clt un fond inépuifable de variations. Chaçue variation réalifée, donne un Etrc, \& peut être appelléc une métamorphofe du prototype, ou plutôt de fá première enveloppe qui en a été la première réalifation. Le prototype eft un principe intellectuel qui ne s'altere qu'en fe léalifant dans la matière.

Une caverne, une grotte, une hutte de fauvage, une cabane de berger, une maifon, un palais, peuvent être confidérès comme des variations graduées d'un mêne plan d'architeeture qui commença à s'exé. cuter par les moindres élémens poffibles. Une hutte de fauvage, une cabane de berger, une maifon, ne font point un Ficurial, un Louvre; mais elles en peurent ĉtre regardés comme des types plus ou moins éloignés, en ce que celles - là comme ceux-ci fe rapportent à un même deflein primitif, $s+$ quils font tolss le produit d'une nême idée plusou moins développce. 
On trouve dans la plus chétive cabane, les mêmes pićces effentielles, que dans le plus magnifique palais: toute la difiérence entre la cabane \& le palais, confifte dans le nombie des piéces, leur travail, leur proportion, leul fite, leur's ornemens, toutes chofes qui fe. tirent du plan original, pour-ainfi-dire, par voie d'évolution, Non-feulement tous les bâtimens des hommes, quoique fi variés chez une même nation, \& cncore plus diffemblables chez des nations différentes, fe rapportent à un même plan; mais ce plan renferme encore toutes les habitations groffières que les animaux favent fe confturire felon leurs befoins \&t la portée de leur inftinet.

Une picrre, un chûne, un cheval, un finge, un homme, font des variations graduées du prototype qui a commencé à fe réalifer par les moindres élémens poffibles. Une pierre, un chêne, un cheval, ne font point des hommes; mais ils en peuvent ctre regardés comme des types plus ou moins grofliers en ce qu'ils fe rapportent à un même defiein primitif, \& qu'ils font tous le produit d'tune même idée plus ou moins développée. On trouve dans la pierre \& dans la plante, les mêmes principes effentiels à la vie, que dans la machine humaine: toute la différence confifte dans la combinaifon de ces principes, le nombre, la proportion, l'ordre, \& la forme des organes.

Envifageant la fuite des individus, quelque nom qu'on leur donne, comme autant de progrc̀s de l'être ver's l'humanité, nous allons les comparer d'abord à la forme humaine tant extérieure qu'intéricure, ou à l'lomme phyfique, puis aux facultés d'un ordre fupérieur, c'cft-à-dire à l'homme doué de raifon.

Cette nouvelle manière de contempler la Nature \& fes productions, qui les rappelle toutes à mine feule idée génératrice du monde, eft fondée furr le principe de continuité qui lie toutes les parties de ce grand tout. Chaque méchanifme, pris en particulier, ne tend proprement \& immédiatement qu'á produire celui qu'il engendre en effet; mais la fomme de ces méA 4 
chanifmes tend au dernier réfultat, \& nous prenons ici l'homme pour le dernier réfultat, afin de nous borner aux Etres terreftres, les feuls à notre portée.

\section{$\begin{array}{llllllllll}\text { C } & H & A & P & \text { I } & T & R & E & \text { II. }\end{array}$}

Oit lon recbercbe fic'eft la Matière ou la force qui confitue te fond de l' Etre.

T male. Une matière inorganique, morte, inaniméc, eft une chimère, une impoflibilité.

Se nourrir, fe développer, fe reproduire, font les cffets généraux de l'aetivité vitale ou animale, inhérente à la matière.

Nous croyons awoir quelque droit d'admettre ces propofitions pour des données.

Réalifer ces trois chofes, mutrition, accroiffement, geproduction, avec le plus \& le moins d'apparcil ponible, c'eft pour ainfi dire le problême univerfel que la Nature avoit à réfoudre. L'bomme en eft la folution la plus élégante, la plus fublime, la plus compliquée, celle où l'érudition ćclatte avec le plus de pompe \& de fafte. . . .

Quand on médite profondément fur les opérations fecretes de la Nature, il s'éleve un doute important qui embarraffe l'efprit, favoir, fi, dans les Etres, le fujet eft la matière ou l'aetivité.

A certains égards la puiffance active, paroît réfider dans la maucre, '\& en être une qualité effentielle, tandis que d'un autre côté l'activité femble être la fubftance, \& la matic̀re feulement un inftrument dont cet a fubltance fe fert pour déployer fon énergie.

Vans les Etres inferieurs, tels que les mineraux \& les végétaux, on rapporte tous les Phénomènes à la macière comine au fond principal de ces Etres; on ne 


\section{PH IL OSO PH I Q UES \&}

foupçonne pas même qu'il puiffe y avoir en eux autre chofe que le fujet matériel.

Un peu plus haut, on commence à douter: on eft indécis. On remarque une fpontanéité de mouvemens \& d'opérations qui décélent un principe actif, auquel on ne peut s'empêcher de les attribuel. Cependant on voit encore cette activité entraincée \& déterminée invinciblement par la matière: deforte que dans de tels fyftêmes, la matière \& l'activitć paroiffent dominer tour-à-tour, être fuccenivement le principal \& l'acceffoire, felon les circonftances. On diroit que la priffance active fait des efforts pour s'élever au deffus de la mafie étendue, folide, impénétrable., à laquelle elle eft enchaînée, mais qu"elle eft fouvent obligée d'en fubir le joug.

Dans l'homme au contraire, il eft évident que la matière n'eft que l'organe par lequel le principe aetif deploie fes facultés. C'eft une enveloppe qui modifie fon action, fans laquelle peut-être il agiroit plus li.brement, fans laquelle aufli peut-être il ne fauroit agir, \& fans laquelle furement il ne rendroit pas fes operations fenfibles.

Ne femble-t-il pas encore que plus la puiflance active croît \& fe perfectionne dans l'Etre, plus elle s'éleve au deffus de la matière? Ne pourroit-elle point parvenir naturellement à un tel degré de perfection, qu'elle n'eût plus abfolument aucun befoin de l'organe matériel pour opérer, deforte qu'alors elle le rejettcroit comme un inftrument inutile, pour paffer dans le monde des intelligences pures?

Telle feroit, fuivant cette hypothefe, la progreffion de la force active inhérente à la matière. Elle ne feroit d'abord que la moindre portion de l'Etre. Par des efforts multipliés \& des développemens progresfifs, elle parviendroit à en faire la principale partie. Enfin elle fe dématérialiferoit entiérement, fi j’ofe ainfi m'exprimer, \& pour dernière métamorphofe elle fe transtormeroit en une pure intelligence.

Quoi qu'on puiffe penfer de cette conjecture hardie A 5 
que je donne pour ce qu'clle peut être, je ferois aflez porté à croire que cette force dont je parle eft l'attribut le p'us eflenticl, le plus univerfel, difons mieux, le fond de l'Ltre, \& que le matériel eft l'organe ou le moyen par lequel cette force manifeftefes operations.

Si l'on me demande quelle notion j'ai d'une telle force, je rćpondrai avec plufieurs Philolophes, que je me lil leprefente comme une tendance à un changement en micux, qui s'cxerce fins celie nécellairement, farce que chaque changemont cit la diffefition la plus prochanc à un autre necilleur: chaque nourel état cft la raifon fuffifante d'un ćtat plus parfait, \& conféquemment il doit l'opérer.

Accontumés à jugcr da la réalité des chofes par les apparences qui fraprent nos fens, nous ne voulons admettre dans le monde que de la maticre, parce que nous ne voyons que de la matière. Lt, pour cmprunter les paroles d'un Auteur moderne, comme toutes les modifications, que nos fens obfervent dans la Mature, confiftent dans la fimple variation des limites de l'étendue, dès qu'il futut abjurer cette étcndue, on croit rentrel dans le néant, on s'arrête, comme s'il ne pouvoit y avoir rien au-delà.

Nous ne faifons pas attention que le monde matériel ou vifible eft un affemblage dephénomènes, \& rien autre chole; qu'il doit nćccftarrement y avoir un mon. de invilible qui foit le fondement, le fujet du monde vifible, \& auquel on doire ramener tout ce qu'il y al de réel \& de fubfanticl dans la Nature.

Ce monde invifible eft la collection de toutes les forces cui tendent continuellement à améliorer leur exifience, qui l'améliorent en effet, en étendant \& perfectionnant fans ceffe leur action, felon la proportion convenable à chacune d'elles:

Il y a une gradation de forces dans le monde invifible, comme une progreffion de formes dans le monde étendu ou vifible. Les forces actives s'engendrent à. ]eur manière, comme les formes matériclles. Si même l'on conçoit bien ce que je viens de dire, on fen- 
tira que les formes matérielles ne procadent les unes des autres, que parce qu'un certain degré de force en anime un autre, celui-ci un autre, \& ainfi de fuite.

On conclut de ces notions que le prototype repréfente la furce prototype, jointe à la forme prototype, c'eft-à-dire la force \& la forme réduites à leur etat élénentairce, \& que le progrrès nćccflaire de cesélémens Icmplit l'ćchelle univerfelle des Etres.

Il y a quelques particularités à obferver dans cette progreflion.

A chaque terme la matic̀re fe dégroflit, \& devient moins maffive, moins matérielle en quelque forte, au lieu que la foree devient de plus en plus aetive en tous fens. Le moindre degré de force n'a befoin que de l'organe le plus obtus, le plus informe, pour fe déployer. Un degré fupéricur de force exige un inftrumient d'un ordre proportionné à fon énergie, poul l'exérer convenablement \& totalement.

La moindre force fe trouvant ainfi alliée à la mafliveté la plus matérielle, \&r la forme la plus déliće à la plus grande activité, on voit la raifon pourquoi, dans la partic inférieure de l'échelle, Jes Ltres femblent tenil plus de la matière que de la force; tandis que c'elt le contraire dans la partic fupérieure.

Dans les foffiles, par excmple, la force agit d'une manière fourde \& enveloppée que des yeux vulgaires ne faififent point, \& que par conféquent ils regardent comme nulile. Ainfi les foffiles font réputés de la matière inanimée, infenfible \& morte, parce que les fens groffiers n'y voient que de la matiere fans action.

Un peu audeffus, la force commence à fe faire appercevoir; comme néanmoins fon action eft bornée à faire croître la matière qu'clle anime, à cn augmentcr le volume, à en développer la forme, elle fe confond aifément avec le matériel. On la nomme force végétative, \&z on la regarde comme la moindre partie d'un tel fyftême où la matière femble dominer.

Avancez de quelques degrés, yous trouverez l'empirc partagé dans les animaux. 
Au fommet de l'échelle on trouve un Etre qui ne paroît plus avoir avec la matière que les rapports généraux \& communs de l'étendue, de la folidité, de l'impénétrabilité, \&c. tant la perfection du principe actif qui fait proprement fon exiltence, I'éleve au deffus de la portion de matic̀e qui lui fert d'organe.

La progreflion n'eft pas finic. Il peut y aroir des formes plis fubtiles, des puiflances plus actives, que celles qui compofent l'homme. La force pourroit bien cncore fe défare infentiblement de toute matérialité pour commencer un nouveau monde . . . mais nous ne devons pas nous égarer dans les vaftes régions du pollible.

Que ce fuit la force ou la matière qui conftitue le fond de l'Etre, il eft toûjours fùr que tout Etre a une forme \& de l'actirité. L'enfemb'e de la Nature ofire done à nozre contemplation deux grands objets: la progreftion des forces \& le développement ces formes. Nous coutemplerons aujourd'luui les formes.

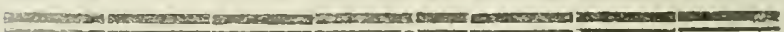

\section{II $\Lambda$ P I $\quad \mathrm{T} \quad \mathrm{R} \quad \mathrm{E}$ III.}

De la première ébaucbe de la Forme Humaine danis les Foliles.

t.

ART, le finge de la Nature, nous aidera à conce. voir comment les formes les plus fimples \& les plus grosfières peurent, en fe perfectionnant, amener les formes les plus compofées \& les plus élégantes, des formes qui ne paroiffoient avoir aucune analogic avec les premières, en un mot les formes les plus difparates en apparence.

Confidérons les commencemens de l'Art. Dans les temps les plus reculés, la Gréce adora trente Idoles, ou Divinités vifibles, qui n'avoient point de figure 
humaine. C'étoient des blocs irréguliers, des pielres quarrées, ou des colonnes. Telle fut longtemps Junon à Thefpis, telle Diane à Icare, Jupiter à Corinthe, \& la première Venus à Paphos: teis furent encore dans d'autres Villes, Bacchus, l'Amour \& les Graces. A Sparte, Caftor \& Pollux avoient la figure de deux morceaux de bois attachés enfemble par deux autres pićces mifes en travers, figure qui s'eft confervée jufqu’à ce jour pour défigner les Gemeaux fur le Zodiaque de nos fpheres.

- On mit dans la fuite des têtes grofièrement ćbau. chées fur les pierres \& les colonnes dont je viens de parler. On voyoit en Arcadie un Neptune \& un Jupiter de cettc forme, l'un à Tricoloni, l'autre à Tegée.

Longtemps après on s'avifa de féparer en deux la partic inférieure de ces maffes informes pour indiquer les jambes \& les cuifles.

Tels furent les foibles commencemens de l'Art, chez les Egyptiens, les Etrufques \& les Grees qui le portèrent dans la fuité à une perfection qu'on n'a point atteint depuis cux (*).

Prenons cette pierre à fon origine, quelque fyftême que l'on admette pour' la formation des fubitances picrreufes. Quelle analogic découvre-t - on entre les premiers rudimens d'un bloc de marbre qui commence à croître dans les entrailles de la terre, \& les belles formes que faura lui donner la nain d'un Phidjas? Combien de changemens \& d'accroiffemens ne doit-il pas fubir avant même que de devenil propre à recevoir les preniers coups du cifeau?

La première ftatue fut une colonne, ou une pierre encore plús informe, fans aucune apparence de traits humains, fans diftinction nii de tête, ni de bras, ni de jambes $(t)$.

(*) Voyez l'Hiftoire de l'Are chez les Ancieus, par Mr. J. Winclielmânn.

$(t)$ Le mot Grec xic'v, colonne, fignifioit aufli une fata'e, meme dans les meilleurs temps. 
Tntrez dans les cabinets des curieux antiquaires, ouvrez les Recueils des Gori, des Montfaucon, des Caylus, \& vorez par combien de degrés l'Art s'éleva d'une forme li groflicre it la perfection de l'Antinoüs, ou de la Venus de Medicis.

Voyez combien d'ćbauches en argilc, en bois, en ivoire, en pierre, en métal! Combien d'efquifes en grand st en petit, de toutes les dimenfions depuis les plus énormes colofles jufqu'aux plus petites figures des pierres gravées, telles que celles du cachet de MichelAnge! Combien d'eflais en buftes, en ftatues, en basreliefs, en gravure creufe! Les monumens qui nous reftent, st qui caractérifent les différens âges de l'Art, font innombrables, \&r ce n'eft rien en comparaifon des ouvrages que le temps a confumés, ou que la malice $\&$ la ftupidite humaines ont détruits.

Combien l'on tailla de têtes avant que de parvenir a'z bel ovale des têtes Grecques! Combicn l'on fit, d'veux applattis $\&$ obliquement tirés! Combien de nez éciales on "une longueur démefurée, combien de bouches mal iendues et tirées en-haut! Combien de mentons rijdiculement pointus, d'oreilles mal placécs! Combien de mains contrefaites fans diftinction de doigts, \& de doigts fans articulations! Combien de pieds larges \& plats, ou maigres \& grêles, de jambes ¿'c de genoux mal tournés, de corps fans aucune incicution des os \& des mufeles, ou au contraire avec mo expreflion forcée des os \& des mufcles, des nerfs \& des reines! Combien l'Art enfanta de figures étroites \& refferrées, ou pefantes \&r manives, d'attitudes outrées, de proportions monftrueufes, de formes angulaires \& quarrées, avant que de produire Niobé \& fes fillics, l'Apollon ciu Vatican, ou le Génic âle de la Vigne Borghefe, modeles éternels du vrai beau!

Ce fut pai une infinité de degrés \&x de nuances que l'ancien ftyle, ce ftyle dur, roide \& deftitue de graces, changea le faillant des parties trop fortement marquées, cn des contours arrondis, moëlleux \& coulans, pour fe transformer d'abord en un fyle grand 
Qx fublime, allicr cufuite le gracieux au fublime, \& parvenir enfin à la plus grande vérité d'imitation dans Praxiteles, Lyfippe \& $\Lambda$ pellès.

Les fiécles s'ecoulèrent, des générations nombrenfes d'artiftes fe fuccédièrent, ies effais fe multiplièrent à l'infini, avant que l'on trouvât la jufte proportion des parties, \& cette multiplication des centres qui fait que les formes d'un bean co:ps font compolées de lignes mobiles qui changent continuellement de point central, parce qu'elles s'écoulent fans ceffe l'une dans l'autre comme des ondes.

Cette marche lente \& graduée de l'Art eft une image imparfaite de celle de la Nature. Il y a bien moins loin de ce bloc de marbre arraché violemment du fein de la terre, à la plus belle ftatue qu'il n'y a de la première réalifation àu prototype à l'homme. Fille en eft pourtant le première ébanche.

La Nature commença à préparer, dans le moindre atôme, ce chef-d'œuvre de mechanique qui me devoit être porté à fa perfection qu'après un nombre infini de combinaifons. Si clles ne faifoit pas encore des têtes, ni des bras, ni des mains, ni des pieds, ni des chairs, ni des os, ni des mufeles, elle travailloit les matériaux; clle étoit occupéc à d'autres formes moins compofées qui, par une gradation imperceptible, devoient amener celles-là.

Les Etres produits au commencement avoient déja une vie particulière, convenable à leur fimplicité: ils fe nourrifoient, fe développoient, fe reproduifoient; \& quoique ces importantes fonctions s'cxécutaffent avec le moindre appareil poffible, clles fuppofent tô̂. jours des organes proportionnés à leur efpece, \& ces oroganes, quels qu'ils fuffent, étoient un acheminement vers leurs analogues, tels qu'ils devoient être dans le roi des animaux.

Quelle production naturelle n'eft pas un fyftême de folides arrofés par un fluide! La vue la plus générale de l'univers nous offre de grands corps qui nagent dans un fluide d'autant plus fubtil qu'ils font eux- 
mêmes plus maflifs. Si nous jugcons des autres gio. bles par celui que nous habitons, chacun eft un fyltê. me particulicr de folides qu'un fluide particulier pénetre de toutes parts. Chaque fubftance foflile offre une ćconomie fenblable. Tous ces fyftêmes, grands \& petits, fi multipliés \& $\mathrm{fi}$ variés, feront regardés à jufte titre comme les premières ébauches de la machine humaine, entant qu'elle clt compofée de folides \& de fluides dont l'action réciproque entretient la vic.

Le trone, cette partic du corps qui renferme les organes de la circulation \&t de la refpiration, méritoit, par fon importance, d'être projetté le premier. Mais, dira-t-on, que voyez-vous dans une pierre qui foit analogue au cœur $\&$ aux poumons de l'animal?

Je conviens que l'analogic eft au delà de nos fens. Eft-ce une raifon pour refufer de l'admettre? Suivons la dégradation de ces parties, fans fortir des bornes où l'on a reflerré le règne animal, \& nous jugerons jusqu'où elle peut être portée.

Le cour \& les poumons des grands animaux reflemblent parfaitement au coul \& aux poumons de l'homme: au moins la différence eft fi peu-de-chofe qu'on la néglige. Cependant cette différence fe charge en defcendant l'échelle; après un certain nombre de degl'és, elle fe rend très-fenfible dans quelques efpeces qui s'éloignent d'autant plus de l'homme. Le cœut commence par perdre graduellement ce riche appareil d'organes \& de vaificaux qui l'accompagnent dans l'homme; puis il perd une oreillette; plus bas fa forme s'altere, ce n'eft bientôt plus qu'une longue artère ; immédiatement au deflous, dans plafieurs infectes, il n'y a plus ni coeur ni poumons, mais feulement des viferes d'une autre ftructure, qui en font les fonetions, en quoi ils leur font analogues.

Nous fommes encore dans le règne animal, \& déja ces organes reputés fi eflentiels, font fi étrangement altérés. Quc dis-je? ils ne font plus: la Nature leur a fubftitué des analogues d'une toute autre conformation. L'analogie s'atfoiblira par degrés, \& ces analo- 
gुues feront fupprimés à lcur tour, ou du moins fi bizarrement traveftis, qu'ils feront plûtôt foupçonnés qu'apperçus.

La Nature a formé un animal fingulier qui n'crt qu'un boyau ramifié, dont le tiffu eft partont uni. forme, qu'on retourne en fartant de l'intérieur de l'unimal l'extérieur, fans quc ce retournement nuife aux fonctions vitales.

Sous quelle forme exiftent, dans une machine fi fimple, les analogues du cœur \& des poumons? Ils ne peuvent guere y exifter que fous la forme d'utricules \& de trachées, comme dans les plantes avec lesquelles le polype confine de très près. Cette conjes cture eft confirmée par les obfervations microfcopiques: on a découvert fur le tilfu dont le polype eft tormé, une infinité de petits grains qui font vraifemblabiement les vifcères ou les principaux organes de la vie d'un tel animal.

Quand nous ne retrouverions ni titricules ni trachées dans les minéraux, tout ce qu'on en pourroit légitimement conclure, c'elt qu'un appareil organique plus fimple fuffit à ce àegré de l'Etre.

De quelle fineffe, de quelle fimplicité ne doivent pas être les organes d'une vie ti fimple dans des corps aufil purs que l'or \& le diamant? Leur extrême ténuité les dèrobe à nos fens, \& nous ne faurions nous former une idée de leur ftrueture. Parce que nus yeux \& nos microfcopes, beaucoup meilleurs que nos yeux, ne les apperçoivent point, nous en nions la réalité. C'eft outrager la Nature, que de renfermer ainfi la réalité de l'Etre dans la Sphere étroite de nos fens, ou de nos inftrumens.

Perfuadé que le foffiles vivent, finon d'une vic extérieure, parce qu'ils manquent peut-être de membres, $\&$ de fens, ce que je n'oferois pointant afturer, au moins d'une vie interne, enveloppée, mais très reelle en fon efpece, quoique beaucoup au deffous de celle de l'animal endormi, \& de la plante; je n'ai garde de leur refufer les organes néceflaires aux fonctions de leur 
ćconomie vitale; \&r quelque forme qu'ils aient, je la conçois comme un progrès vers la forme de leurs analogues dans les végétaux, dans les infectes, dans les glunds animaux, \& finalement dans l'homme.

Il y a dans l'homme un cour, un toie, des pou. mons, un eftomac, \&c. Il y a dans les infectes un loner vaifieau fort délié en forme d'artère, un fac inteftinal \& des trachées. Il n'y a dans les picrites que des utricules, des vafes propies \& des trachees. Bes Etres placés au deflous de la plante doivent avoir un appareil d'organes encore plus limple; fu fimplicité n'empêche pas qu'il ne loit le type d'un appareil plus compofé.

Tout le monde n'eft pas en état d'apprécier des généralités un peu vagues. On exige des raifonnemens plus fenfibles, des pleuves plus frappantes. La même clafie des Etres nous les tournira. Ces preuves nous feroient fufpectes de toute autre part. Nous n'avons point ici d'illufion ni de fraude à crainàre.

Voyez comme la Nature à empreint, fur les folfiles, Jes differentes formes du corps humain! Il y a des pierres qui repréfentent le coenr de l'homme, d'autres imitent le cerveau, le crânc, la machoire, des os, un picd, une main, un rein, wne oreillc, un ceil; d'autres encore repréfentent les parties fexuelles de l'homme \& de la femme. La Nature pouvoit-ellenous annoncer d'une manière plus intelligible, où tendoient les premières métamorphofes de l'Etre?

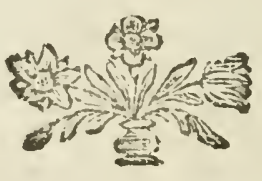




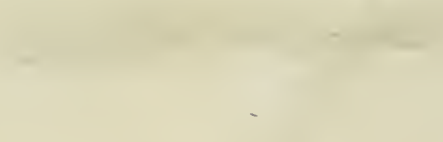


Mlanche $T$. Tage to.

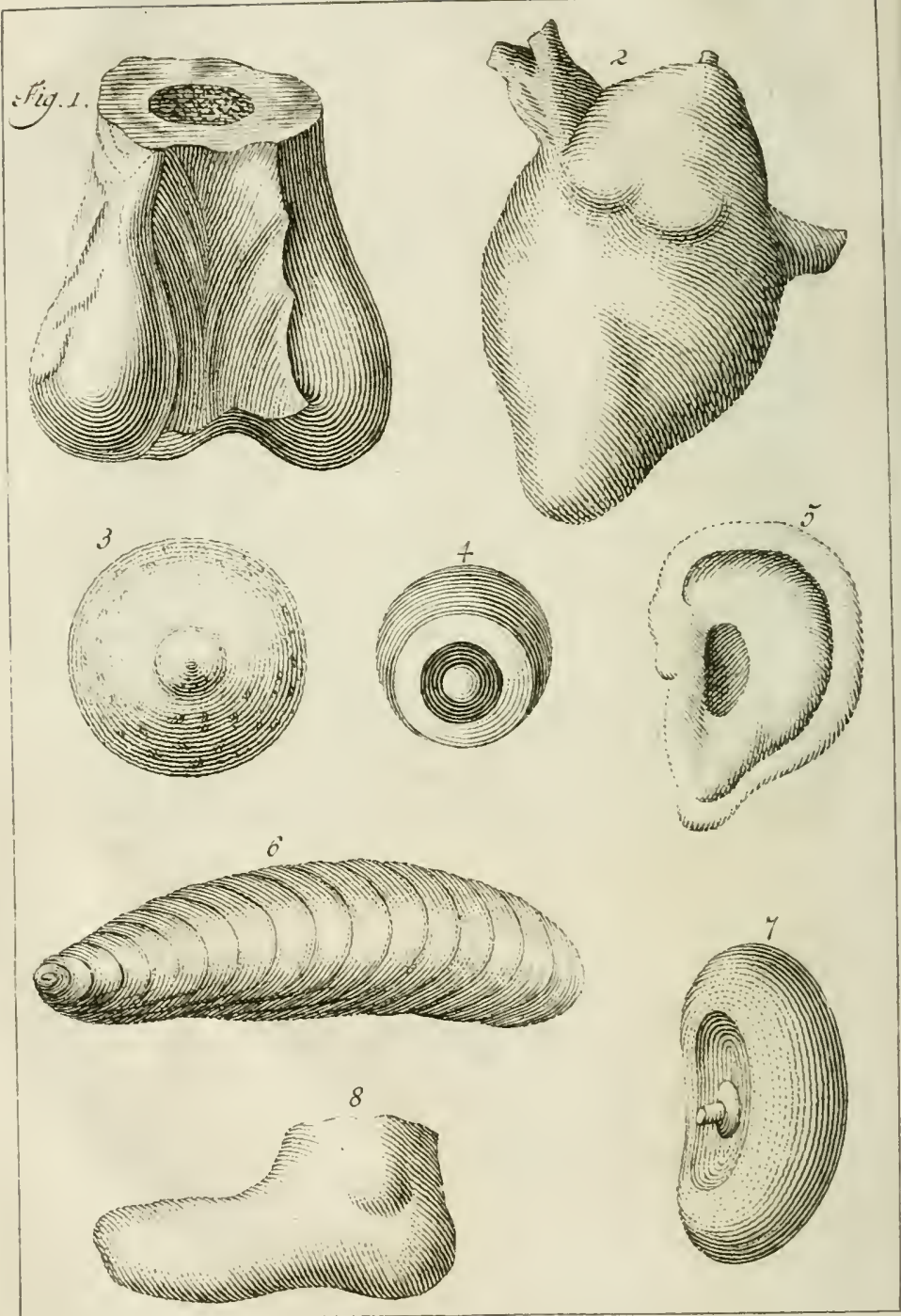

T. 7 s. direx $^{2}$ 


\section{$\begin{array}{lllllllll}C & H & A & P & I & T & R & E & I V .\end{array}$}

Des Litbocardites \& Bucardites. Des Antropo: cardittes, ou efpeces de pierres qui ont la figure d'un Ceur bumain.

\section{Litbocardites \& Bucardites.}

$P_{1}$

\& Busreurs Naturaliftes parlent des Lithocardites peces leste peces. Peut-ête n'elt-il aucune contréc de la terre qui ne produife quantité de ces pierres qui repréfen: tent plus ou moins parfaitement la figure d'un cœur. Il n'eft pas étonnant, que la Nature ait multiplić, avec tant de profution, les exemplaires ébauchés d'une fi noble partie animale, le fiége du mouvenient vital. En comparant les diffërentes fortes de Lithocardites que produit chaque pays, on remarque entre elles une gradation de refiembiance qui plaît à l'imagination.

\section{Antbropocardites.}

L'efpece qui reffemble le plus au cœur humain, 8 qu'on nomme pour cela Anthropocardite, eltrcelle dont je donne ici la figure (Plancbe T. Fig. 2.) d'après le Dodteur Brookes (*). Elle mérite une artention particulière. Sa fubfiance eft un caillou bleuâtre en dedans. La forme d'un cœur eft aufí bien imitéc qu'elle puifie l'être. On y diftingue le trône de la veine cave, avec portion de fes deux branches. On voit fortir auffi du ventricule gauche le trone de la grande artère, avec fa partie inférieure ou defcendante, bien indiquée. Cette pierre elt rare. On diroit que laNa-

(*) Natural Hiftory, Vol. $\mathrm{V}$. 
sure, contente de cette eqquifle, en arrêta le trait, Ss fe mit peu en peine d'en multiplier les modeles.

\section{$\begin{array}{llllllllll}\text { C } & \text { H } & \text { A } & \text { P } & \text { I } & \text { T } & \text { R } & \text { E } & \text { V. }\end{array}$}

\section{Des pierres qui imitent le Ceroeau bumain.}

\section{$T$}

ES Auteurs nomment ces pierres Encepbalö̈des (*) ou Encepbalitbes. Elles imitent fi bien le cerveau humain, qu'on les prendroit prefque pour des cerveaux humains pétrifiés, fi l'oul pouvoit croire à de pareilles pétrifications. Ellies font graveleufes, argilleufes, \& d'une couleur tirant fur le blanc $(t)$.

Le Docteur Plott $(\S)$ parle d'une Encephaloide très fingulière qu'il dit avoir vue. Elle reflembloit à la bale d'un cerveau humain, ou au cervelet renfermé dans la dure-mère. On en voyoit fortir des portions de plufieurs paires de nerfs coupés, $\&$ de plus un prolongement de la même fubltance, d'où fortoient encore d'autres faires de nerfs.

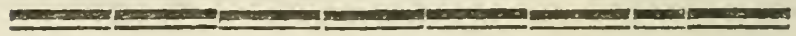

\section{$\begin{array}{lllllllllll}C & H & A & P & I & T & R & E & \text { VI. }\end{array}$}

Des Carniö̈des ou pierres qui repréfentent le crâne bumaino Des Hyppoceplaloüdes.

O.

iv trouve en plufieurs pays des pierres qui repréfentent divers fragmens du cräne humain. On en a trouvé auffi dans la Suiffe \& dans l'Ettrie, qui le repréfentent en entier, avec les os de la face.

(*) Mafxun Calceolarinm Settali.

( $t$ ) Oryctulogic de Mr. Dargenvillc.

(i) The Natural Hiftory of Oxfordshire. 
Les Actes ou Mémoires de l'Académie de Suéde fon: mention d'un parcil crâne pierreux dont la partie, qui repréfentoit la mâchoire fupérieure, portoit quelques petits os qui imiroient affez bien des dents. Aufi le Dr. Leyel prétend-il, dans une Differtation fur cette pierre, que e'eft un crâne véritable pétrifié; mais ce qui auroit du le détromper', c'eft qu'il a trouvé un offelct femblable dans une autre pierre qui avoit à peu près la forme de l'os de l'épaule d'un homme: car affurément l'omoplate n'eft du tout point faite pour porter des dents.

Scheuchzer parle d'une efpece de Carnioïdes dont on trouve quantité aux invirons de Bafic: ce font des pierres graveleufes \& argilleufes, de couleur jaunâtre, qui ont une future dans le milieu, \& qui imitent le crâne humain avec affez de reffemblance (*).

Le crâne de la fameufe tête prétendue pétrificée, trouvée fur les montagnes du village de Sacy, à deux lieues de Reims, n'eft qu'une pierre de la même efpece. Outre que l'épaiffeur monftrucufe \& inégale du crâne, \& le rétréciffement extraordinaire des orbites, des narrines, \& des autres ouvertures, trois fois plus étroites que dans les crânes véritables, prouvent évidemment que ce ne fauroit être une pétrification; le merveilleux d'une pareille production ceffe entièrement lorfque l'on vient à confidérer que dans les carrières de Heddington on a trouvé des Hyppocephaloìdes de différente grofleur, c'eft-à-dire des pierres qui repréfentent la tête d'un cheval, avec les oreilles, le toupet entre deux, un peu de nez, la place des yeux, $\&$ le refte de la tête, excepté la partic inférieure $(t)$. La groffeur de ces pierres eft fort au deflous de celle d'une tête de cheval ordinaire, \& on ne s'eft jamais avilé de les prendre pour des têtes pétrifiées de cet animal. Ces Hyppocephaloïdes font trop fingulières poul.

$\left.5^{*}\right)$ Specimen Lithographiæ Helvetic curiofic.

(t) Mufæum Wormianum. 
n'en pas donner ici la figure d'après les Auteurs qui ont vu ces furtes de picrres fingulières (Voyzz, Plancloe I1. Fin. I.)

On rencontre fouvent dans plufieurs montagnes d'Allemagne, diverfes efpeces de Carnioïdes plus ou moins parfaites.

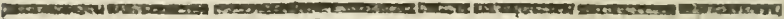

\section{$\begin{array}{lllllllll}\mathrm{C} & \mathrm{H} & \mathrm{A} & \mathrm{P} & \mathrm{I} & \mathrm{T} & \mathrm{R} & \mathrm{E} & \mathrm{VII} \text {. }\end{array}$}

Pirries qui repréfentent la Mácboire bumaine.

1

E font d'abord les deux mâchoires de la tête fosGle dont je viens de parler. Les mémoires de l'Académe de Suéde \& d'autres Livres font mention de pierres femblables reprélentant la mâchoire humaine, foit fupérieure, foit inférịcure, même avec les alvioles des deints.

\section{H A $\mathrm{P}$ I $\mathrm{T}$ R $\mathrm{E}$ VIII.}

Os bumains foljiles.

I

L n'eft pas rare de vois des picrres qui reffenblent à différens os du fqueletre humain. Il n'eft prefque pas de cabinet de curiofités naturelles, un peu afforti, qui n'en pofiede quelques-uns. Ici ce font des vertèbres, là des omoplates, ailicurs des os du bras ou do la cuiffe. On en voit dont l'intérieur eft rempli d'une efpece de fubftance afiez femblable à de la moëlle (**).

(*) Bayeri Oryctographia Norica; Mufcum Zachinelli, \&c. 

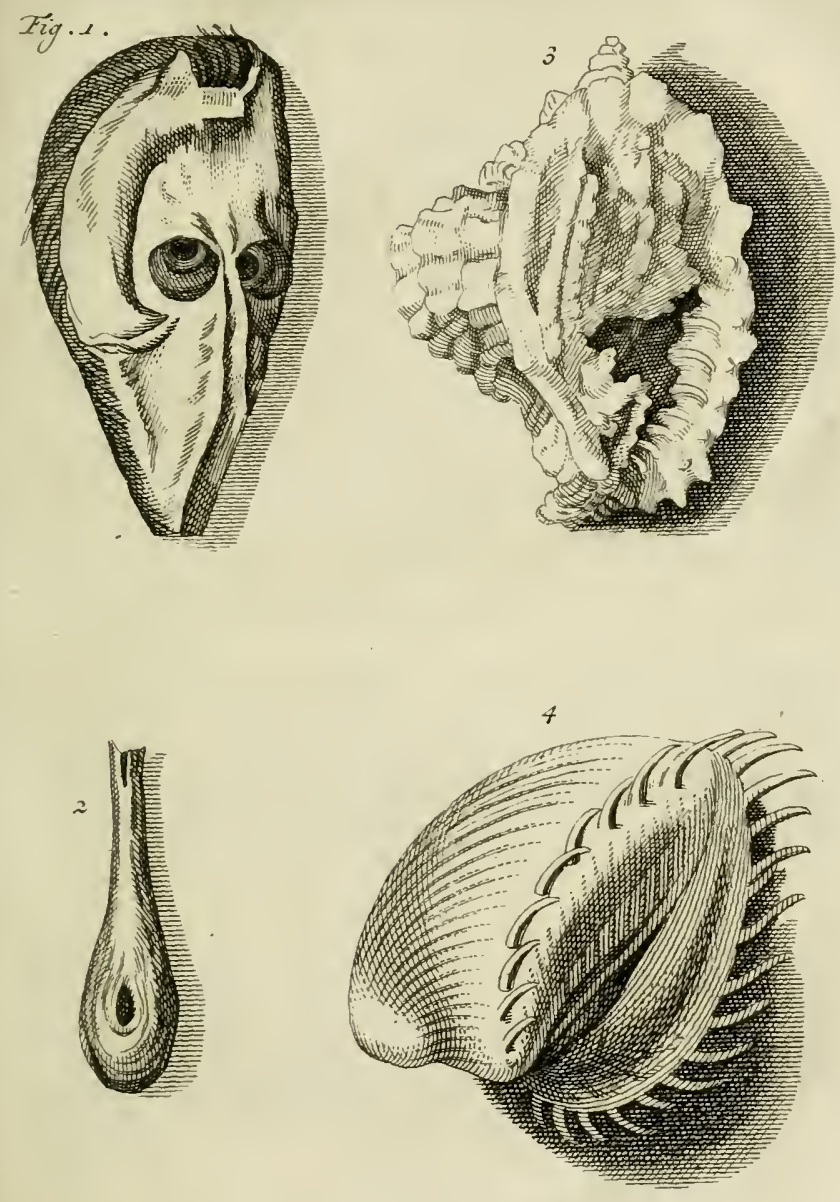


\section{$\begin{array}{llllllllll}C & H & A & P & I & T & R & E & I X .\end{array}$}

Piarres qui initent la forme du Pied de l'bomme.

I. Première ejpece.

$\mathrm{I}$

E Dr. Plott a trouvé dans une carrière, au pied du mont Shotover, des pierres qui repréfentent le pied humain coupé un peu a.u coffus de la cheville. Les doigts n'y funt point marqués, mais la cloville $\mathrm{y}$ eft très fenfible. On en voit la figure Plunche $I . n .3$. Le pied eft fort élevé, \& encore plus long, ayant plis de denx pieds Anglois de longueur. C'eft l'efpece la plus longue: on en trouve au même endroit de beaucoup plus petite. Ces picrres font de couleur cendrée ( $\%$.

2. Seconde efpece.

Le pes bunanus Saxeus, dont parle un autre Naturalifte, mérite encore à plus jufte tître le nom d' $A$ indiopodite. C'elt une pierre qui repréfente le pied gauche d'un jeune homme avec les articulations, les doigț \&r l'os anterieur de la jambe $(t)$.

\section{Troifrime efpece.}

UNE autre efpece fait voir la figure d'un pied humain, au point d'y reconnoître, les rotules \& les petits os. L'imitation eit fi cxacte qu'clle a fait dire qu'on feroit tenté de prendre ce pied pour celui d'un homme changé en pierre par la vertu pétrifiante de la tête de Medufe: ut diceres lafidofi bominis à Medufa permmtati (\$).

(*) The Natural Hifory of Oxfordshire.

(t) Mufieun Wormianuin.

(s) Mufaun Calceolarium Settali. 


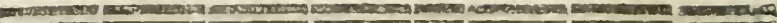

\section{$\begin{array}{lllllllllllllllllllll}C & H & A & P & I & T & R & E & X\end{array}$}

\section{Fierre de Rein.}

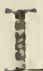

A figure 7 de la Planche 1. repréfentc une pierre de rein, ainfi nomméc parce qu'elle a la forme d'un rein, avec le tronc d'un des uretères qui fort de fa fartic concave. Cette pierre a cela de particulier, que, lor\{qu'elle eft fraîchenient déterréc, elle a la couleur d'un véritable rein, \& le tronc d'uretère qui en fort eit ii mou qu'on le coupe aifément avec un canif; mais en moins d'unc heurc il devient dur comme le refte de la nierre. Au moins c'eft ce qui arriva à celle dont paile le Dr. Brookes, dans fon Hiftoire Naturelle d'où j'ai tirai la figure que j'en donne.

xemsersecs

\section{$\begin{array}{llllllllll}C & H & A & P & I & T & R & E & X I .\end{array}$}

Olites, ou pierres Auriculaires.

$\mathrm{C}$

Es pierres reffemblent à une oreille humaine. Elles en repréfentent la forme extérieure: le creux de loreille y eft bien marqué. Ces olites font communes dans quelques carrières d'Angleterre, furtout dans celles du mont Shotover, \& aux environs de la ville de Somerton, où le Dr. Plott en a trouvé plufieurs. on en voit ici une fur la Plancbe I. Fing. 5 . 


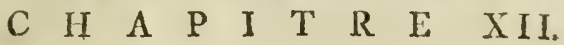

Picrres qui repréfentent tn coil.

I

y a plufieurs efpeces de pierres qui repréfentent un $œ i l$. Nous n'en rapporterons que quatre efpeccs.

\section{Première espece.}

La première efpece, celle que Pline a décrite \& nommée Leucophtalmos, eft blanchâtre, \& repréfente le blane de l'œil, felon Mr. Dargenville. Mais il paroît que le Naturalifte moderne a mal interpreté le nom que le Naturalifte ancien a donné à cette pierre. Pline n'a pas voulu dire qu'elle repréfentoit le blanc de l'œil, mais plûtôt qu'olle imitoit la figure d'un ail blanchâtre, ou marqué de blanc au centre de la prunclle, ce que nous expliquerons tout-à-l'heure en parlant de la quatriéme efpece de ces pierres.

2. Seconde efpece.

L'Ocyopbraimss ou Acyopbtalmos, comme l'écrivent quelques Auteurs, eft de la même couleur \& fait voir un petit œil faillant \& pointu.

\section{Troifiene efpece.}

Une troifiéme efpece de pierre de la même nature, qu"on nomme Tiropbtalmos, porte la figure de trois ycux, d'où lui vient fon nom.

\section{Quatriéme elpece.}

Celle dont on voit la figure Planche $1.1 \%$. 4. a nin ccrclc' extéricur blanchâtre, enfuite une Zone circt. 15 
laire de couleur foncée qui eft celle de la pierre, puis au centre un petit rond blane qui ne reffemble pas mal à une taic ou cataracte dont la prunclle feroit chargée. C'eft la penfée d'un Naturalitte Anglois qui l'a d'ćcrite d'après l'original. Il coniceture que ce pourroit bien être l'œil de Belus mentionné par Boot (*), \& que le Leucopbtalmos de Pline n'cn eft qu'tune varieté, qu'il nomme ainli à caufe du blanc qui couvre le centre de la prunelle $(t)$.

\section{Cinquiéme eppece.}

Une cinquiéme efpece repréfente deux yeux l'un à cotté de l'autre fur une ligne parailèle, avec une jufte diftance entre deux. On la nomme Diopbtalmos. C'eft une très belle onyx.

Q

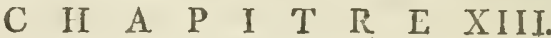

Pierres incinmillaires.

$\mathrm{C}$

Es pierres, qui ne font pas rares, repréfentent la mammelle d'une fèmme. Le bouton ou mammelon $\mathrm{y}$ eft bien deffiné \& très éminent. On y voit auffi l'aréole ou la couronne qui l'entoure, \& clle y paroît femce de petites protubérances, comme dans ic Naturel.

\section{Première efpece.}

J'n connois deux efpeces. Celle dont je donne ici la figure (Planche I. Figr. 3.) eft la plus refiemblante. Je l'ai vue, \& je puis prevenir le Leeteur que le burin n'a point affez exaetement copié la belle forme de l'original.

(*) De Lapidibns \& Cemmis.

t) The Natural Hitory of Oxfordshire by Rob. plott. 
3. seconde eppece.

On en voit une autre efpece dans l'Hiftoire Naturelle du Dr. Brookes (*). J'y renvoie le Lecteur.

\section{$\begin{array}{llllllllll}C & H & A & P & I & T & R & E & X I V .\end{array}$}

Pierre nommé Lapis Chirites, repréfentant une Mains bunaine.

ETTE pierre ftriée, de nature un peu gypfenie; repréfente la paume de la main avec des formes de doigts \& d'ongles de couleur de chair. C'elt un des plus beaux folliles que l'on puiffe voir.

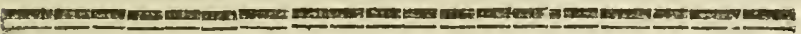

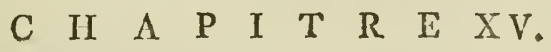

Pierres qui repréfentent un Mufcle.

$\mathrm{O}$

N en diftingue deux efpeces particulières, une grande \& une petite.

\section{Première efpece.}

La première efpece (même Plancbe Fig. 6.) eft fort Jongue à proportion de fa grofleur. L'interieur eft une forte de matière pierreufe jaunâtre; la furface extérieure eft d'un blanc poli \& luifant, \& légércment marquée de lignes quil'entourent en forme d'anneanx, comme les plis de l'enveloppe d'un mufcle ordinaire. L'un des deux bouts eft plus gros que l'autre. Llle

(f) Volume V, 
n'eft pas ronde, comme un cylindre, mais ovale $s ;$ tant foit peu applattie d'un côte.

\section{Seconde effece,}

La petite efpece ne differe de la grande, qu'en ce que l'ovale n'en eft point applatti.

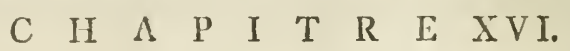

Pierres qui repréfentent le Nerf olfactoire.

$I_{1}$ l'on tire une quanić de petites pierres juund l'on tire une quantité de petites pierres jaunatres, longues, toutes femblables les unes aux autres, qui ont la forme exacte du nerf olfactoire entier. L'extérieur eft lifie \& poli: l'intéricur elt creux. On voit une de ces pieries Plancho II. Fig. 2.

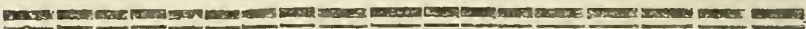

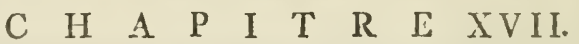

Des pierres appeiles Orchis, Diorchis ó Triorchis. $\mathrm{N}_{0}$ L o us voici parrenus aux modeles follies des organes de la génération. Quoique ce ne foient que des pierres, peut-être fe trouvera-t-il quelques Lecteurs dont la faufie délicatefle fera offenfée de ces repréfentations. Nous refpeetons affez leurs ferupules pour tâclè de les lever par ces belles remarques d'un Auteur mojerne:

" Ca n’elt pas fans raifon que les parties de la gé"nération ont été appellées les parties nobles, puisوqu'elles fervent à l'ouvrage le plus admirable que sorme la Nature; on leur rendoit autiefois les mê- 
5, mes hommagics qu'aux Dieux: le foleil \& les autres Atres ont cré mis avec moins de raifon au nombre des Divinités; leurs influences n'ofirent rien de fi merveilleux que la rofée féconde qui découle des parties maturelles; les Livres facrés ne nous infpirent que de la vénération pour ees organes; ils ordoninent qu'on coupe la main à qui ofe les outrager ; ils excluent du miniftère ficre les hommes mutilés, la nouvelle loi les éloigne de mêne de fes autels: les Caffres victorieux ne "grennent pour monumens de leur gloire que les parties nobles de leurs ennenis, ce font-la leurs ftatues, leurs hiltoires, leurs ares de triomphe; il en font des colliels à leurs femmes, ils en font des préfens à lcurs amis. Notrc hiltoire ne parle qu'avec horreur de Villandre qui ofa porter la main aux parties naturelles de Charles IX. Par ces farties l'ho:mme affermit fon empire fur la moitiédu genre humain, elles font le feeau de l'union \& de la paix qui rend les familles hemreufes. Dans la focieté clles font d'une néceflicé abfolue: l'homme \& la femme en fe mariant fe promettent une fidélité mutuelle, ils s'affurent l'un de l'autre par des fermens inviolables; mais les loix humaines, autorifées des loix divines, nous dégagent de ces "fermens quand nous fumn:es incapables de nous grendre les devoirs mutuels.

"Nous pourrions entrer ici dans des détails qui froient fufeeptibles d'explications curieufes: de vrais favans ne s'imagineroient pas qu'on fit une infulte à leur modeftie en les leur préfentant. Ils croient, avec raifon, qu'on peut porter fa curiofité fur tons les objets qu'étale la phyfique: les parties même qu'une bizarie contradiction a fait "2 appellar nobles \& honteufes, ne leur font pas dé"tourner les yeux; leur efprit qui y cherche le méchanisme du grand cuvre de la Nature, ne penfe qu'a s'inftruire; l'admiration qui fuit leurs recherclies ticnt tô̂jours leur cour en fureté. Mais tuus les 
"efprits ne penfent pas avec cette élération \& cette "g juftefle. Il y en a de foibles qui font doninés par "les fens \& par l'imagination; li petiteffe des ma" chines délicates, feches \& fragiles dans lefquelles , ils iont renfermès, forme une complexion facile à o, émouvoir, la moindre bluette y produit d'abord " un embrafement univerfel: comme tout eft contaפg gieux pour eux, tout les effarouche, ils voudroient و, que le nom des parties naturelles fùt retranché des "Livres de l'Alt; peut-être voudroient-ils encore "q que ces parties mémes fuftent retranchées descorps; " du moins leurs vains ferupules femblent accufer la פ Nature d'avoir choifi une voie honteufe pour mulפ tiplier le genre humain. Mais que ces efprits font פ extraordinaires. Cette foibleffe eft indigne d'un g) efprit raifonnable, $\&$ c. (*).".

11 feroic auffi ridicule de vouloir retrancher certaines matières de l'Hiftoire Naturelle, que de fupprimer dans la Nature les parties qui la renouvellent. Du refte, les Lecteurs fenfés comprendront aifement que les pierres que je vais mettre fous leurs yeux entrent nécellailement dans le plan de cet ouvrage, comme dans celui de l'échelle univerfelle des Erres. C'elt asfez pour juftifier la liberté que je prends de les décrire.

\section{Orcisid.}

L'Orcbis eft une pierre qui repréfente un tefticule de l'honme ou d'un animal quelconque. On a vu des individus humains qui n'en avolent pas plus d'un.

\section{Diorcbis.}

Lorfque cette pierre repréfente les deux tefticules, on la nomme Diorchis. C'eft l'efpece la plus commune.

(*) L'Auatonie de Heifter, Tome I. p. 555 . E firir. 
Il y a des Diorcbis d'une groffeur prodigieufe: telles font celles dont parle le Dr. Plott, \& qu'il a tronvées au côté occidental du mont Shotover : montagne fi feconde en ces fortes de productions, qu'on pourroit la comparer à un attelier oì la Nature a dépofé quantité de modeles des différentes parties du corps humain.

\section{Triorcbis.}

La pierre, nommé Triorcbis, repréfente trois tefticules; ainfi il fe rencontre quelquefois des hommes à qui la Nature libérale en a donné autant. N'eft -ce pas un phénomène remarquable, que l'on tronlve dans les fofililes des types de cette monftruofité?

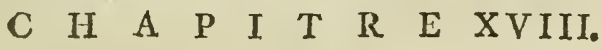

De la pierre nommée Scrotum humanum. Voyez Plancbe I. Fig. I.

8

ETTE pierre, qui repréfente le Scrotum, c'cft-àdire la bourfe contenant les tefticules, eft d'un blane fale, \& la furface en eft fort ridéc. Ce n'cit pas feulement par fa forme extel'ne qu'elle imite cette partic de l'homme. L'organifation interne paroît y être également analogue. En touchant ce Scrotum pierreux, on croit fentir que chaque tefticule eft contenu dans une bourfe particullière mufculeufe, comme fi l'intérieur en étoit divifé en deux par la cloifon formée de la duplicature du Dartos, ainfi que dans le véritable frotum humain. Une autre fingularité de cette pierre, c'eft qu'on voit à fa partie fupérieure une cfpece de canal, rempli d'une fubfance fpongieufe, aftez femblable à une portion de l'urethre, 


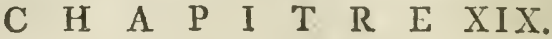

\section{Des Priapolites, Colites \&O Pballoïdes.}

(1)

font des pierres qui repréfentent le membre viril enflé avec fes tefticules. Il y $\mathrm{cn}$ a de plufieurs fortCS.

\section{Premiere efpece.}

Le plus beau de tous les Priapolites cft, fans contredit, celui dont je donne la figure Plancbe $J J T$. $n$. I. La reflemblance eft aufi parfaite qu'on puiffe la defirer. L'imagination n'a rien à y fuppléer. Sa couleur eft jaunâtre. On voit dans le milieu un canal rempli de matière criftalline, trés relatif au conduit del'urethre, le gland percé à fon extrémité, avec le prépuce qui le reçouvre, les deux tefticules bien formés \& pendans à la racine de la verge. Comme j'ai vu ce Priapolite, je puis infifter fur la fidélité de la figure \& de la deicription.

Ce foffile fe trouve en Saxe: ce qui fait que les Auteurs l'ont nommé Priapolites Saxonice cum appenfis tefiibus $(*)$.

\section{Seconde efpece.}

Il y a des Colites dans les Pyrénćes, mais ils n'ont point de tefticules. (e font des Cylindres de couleur jaunâtre, traverfés par un canal criftallifé, comme dans le précédent, imitant le canal de l'urethre, du refte fans aucune forme de gland ni de teiticules; il y a feulement une apparence d'ouverture à l'une de fes extrémités.

(*) Oryetologie de Mr. Dargenville. 


\section{Troiflisme elpece:}

Le Priapolite de Caftres en Languedoc, ñe diffèré ae celui des Pyrenées que par fa couleur qui eft grifàtre: la forme d'ailleurs eft la même ( ${ }^{*}$ ).

\section{$\begin{array}{lllllllll}C & H & A & P & I & T & R & E & X\end{array}$}

Pierre nommée Hifterapetra.

Luhisteri apetra que l'on voit même Planche Fig. 2. eft de forme ellyptique, un peu élevée en cône par deffus, \& plate en deffous: clle imite la vuive d'une femme. Cette pierre fe trouve dans le Rou,ffililon près du village de St. Lauren de Lerdans, dans la Vallée de Cuftuia $(t)$.

\section{$\begin{array}{llllllllll}C & H & A & P & I & T & R & E & X X & \text { X. }\end{array}$}

\section{De rHifterolithos, ou Diphys, ou Diphrys.}

\section{$\mathbf{N}$}

féparens venons de voir les deux rexes tepiétentés féparément par des pierres différentes: les voici réunis dans le même folfile; comme fi la Nature cût voulư en faire le type des hermaphrodites

L'Hiferolitbos, ou Dipbys; eft une pierre felon quelques uns, \& felon d'autres une coquille bivalve fófile, qui repréfente d'un côté le partie naturelle de la femme avec les grandes levres fort étendues \& élevées, \& de l'autre côté les parties de l'homme: Le\& unes \& les autres funt $f i$ bien imitées, dit Pline, qu'on

(*) Oryctologic de Mr. Dargenville:

(t) Lis-même. 
les croiroit propres à l'acte de la génération, fi elles n'étoient pas de picre: ut concubitui venereo aptum dixeris, nifi lapis efjet (").

Ce fotfile fe trouve en abondance en plufieurs endroits, dans la Gotlande en Sućde, dans l'Evêché de Treves, en France dans le Rouffillon, \& aux environs de la ville de Caftres. Il eft rare que l'on ne trouve qu'une feule de ces pierres. Il y en a ordinairement plufieurs accrues les unes auprès des autres dans la mêne roche.

Gefner, Agricola \& Wormius nomment ce folfile Dipbys $(t)$. Scheuchzer lui donne le nom de concba veneris lapidea ( $(0)$.

On en voit ici la figure même Plancbe Fig. 3 .

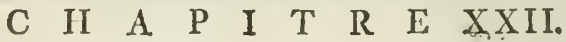

Caillou connu fous le nom de Puer in fafciis.

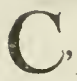

FST un caillou oriental oblong, dont la marbrure rouge renferme la figure bleuâtre d'un enfant en maillot, d'ou lui vient le nom de Puer in fafciis. La repréfentation n'eft pourtant pas fi exacte qu'il ne faille un peu s'y prêter. Mr. Dargenville en a donné la figure dans ion Oryctologie $(\$ S)$.

(*) Plin. Hift. I,iv. XXXvI. Chap. $\mathrm{x}$.

(†) Mufaum Wormianum.

(\$) Difcium Querelix.

(5ii) Page 208. Planche 6. n.5.

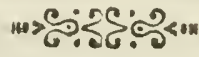




\section{C $\quad \begin{array}{llllllllll} & \text { A } & \text { P } & \text { I } & \text { T } & R & \text { E } & \text { XXIII. }\end{array}$}

Autre caillow repréfentant les feffes d' un enfant.

(1)

E caillou oriental eft rond \& repréfente, fur un fond brun, les feffes bien diftinctes d'un enfant dont les jupes feroient relevées. On en peut voir la figure dans l'ouvrage que je viens de citer (*).

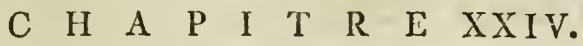

Des Figures bumaines empreintes fir des Agatbes, Ë autres pierres.

$\mathrm{O}$ $N$ voit, dans les cabinets des curieux, des agathes qui portent des empreintes naturelles d'une tête humaine très bien deffincéc. Tels font deux petits portraits de Negres, l'un avec la tête nue, l'autre coëffé d'un petit chapeau à l'Efpagnole. Tel eft encore un portrait noir dans la manière de Rembrant, où l'on voir très diftinctemient le nez, la bouche, l'cil, le front, le mentnn, les cheveux \& la draperic.

Wormius fait mention d'une pierre qui repréfentoit parfaitement un homme dont on voyoit toutes les partics.

Bartholin parle de certains cailloux qui femblent avoir été travaillés au tour, tant ils repréfentent délicatement les yeux, le nez, la bouche, les bras, les pieds \& les autres parties du corps humain.

(*) Mêne pagé, même Plancỉ. n. 4. 


\section{$\begin{array}{llllllllllll}C & H & A & P & I & T & R & E & X X V\end{array}$}

D'un Rocber appellé le Moine pendu.

\section{D} A N s l'Tfle de Malthe, fur une des côtes de la mer, paroît un rocher feparé du refte d'une montagne, tellement fulpendu, \& refiemblant fi fort à un Hermite, qu'on l'appelle communément. Il Frate impiccato, ou le Moine pendu (*). Il paroit que les pierres devoient repréfenter l'homme de toutes les manières, par parties \& en enticr, en grand \& en petit, en empreintes plates \& en relicf.

\section{$\begin{array}{llllllllllll}C & H & A & P & I & T & R & E & X & X & \text { VI. }\end{array}$}

Concluyson des Cbapitres précédens.

I

L me feroit aifé d'augmenter ce catalogue de curiofités naturelles d'un très grand nombre de piéces aufi fingulières, \& dont l'exiftence eft également confatcé. Je pourrois y joindre, par excmple, les cailloux dont parle Moncomp dans fes Voyages: il dit avoir trouvé, fur le chemin du Mont Sinaî au Caire, des cailloux qui repréfentoient de grands cœurs, \& qu'en ayant pris un qui paroifloit avoir une cicatrice, \& l'ayant fendu \& ouvert, il y avoit trouvé un cœur blefé dans chacun des côtés du caillou ( $\dagger^{`}$.

Mais c'en eft affez, je crois, pour faire voir que la Nature, en travaillant les pierres, modéloit véritablement les différentes formes du corps humain. La figure conftante de chaque efpéce de pierres que je viens

(*) Voyez le Journal des Savans a an. I6:?

(†) I丸 - meme. 
de mettre fous les yeux de mes Leeteurs, annonce de plus que ce ne font point des jeux du hazard, mais Jes produits d'autant de germes particulier's, des réalifations du modèle unique de tous les Etres, des animaux vivans, quoique dénués en apparence de fens \& conféquemment de mouvement progrefiff \& de vic extéricure. Je dis en apparence, car ils pourroient pofféder ces avantages à un degré fì foible qu'il ne nous fût pas fenfible, \& néanmoins fi réel qu'il pût fe faire appercevoir en prenant une teinte plus forte.

Ces Etres nous paroiflent placés bien bas dans l'échelle. Ils en ont cependant beaucoup d'autres, au. deffous d'eux. Les fels, les fouphres, les bitumes, les huiles font des degrés inférieurs aux métaux \& anx pierres. Au deffous des huiles il y a les animalcules aëriens, jgnés, aqueux, terreux, fyftêmes organiques les moins compofés que l'on connoiffe, \& réputés pour cela les premières préparations de l'efprit animal.

En contemp'ant l'Etre dans les picrres, nousdevons donc nous fouvenir que, pour atteindre ce degré, il a paffé par un nombre \& une varieté de transformations qui excédent la force de l'imagination la plus vafte, \& qui toutes preparoient de loin la forme humaine.

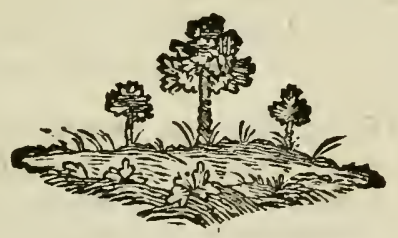




\section{CONSIDLRATIONS}

\section{SECONDE PARTIE.}

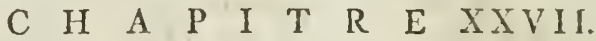

De l'intérieur des fofllis confideré comme un type de Purganifation bumaine.

I

A ftructure organique des foffiles n'eft plus un prob.ême. Ceux d'entre les Naturalittes qui s'obftinent, avec le vulgaire, à les regarder comme descorps bruts, ne peuvent difconvenir pourtant que leur tisfu intérieur ne foit compofe de fibres \& de veines entrelacée les unes dans les autres.

Les minéraux, dit Mr. Wallerius (*), font des fubftances qui croiflent fans paroitre avoir de vie, \& fans qu'on remarque qu'ancun fuc vilible circule ou foit contenu dans leurs fibres ou veines.

Que font ces fibres \& ces veines fenfibles dans un teces grand nombre de foffiles, finon des organes? L'organifation des os, des mufeles, des chairs, en un mot de tout le folide animal eft-il autre chofe qu'un entrelacement de fibres \& de fibrilles qui fe croifent en plufieurs fens, \& s'arrangent fous différentes combinailons, en paquets, en réfeaux, en cordons, en lames, en houppes, Ėc. avec différens degrés de tention $\&$ de roideur?

"Il y a des Naturaliftes qui prétendent que jes mi$\Rightarrow$ Jićrux ont une vie femblable à celle dont jourfént " 'es végétaux: mais perfonne n'ayant encore pu jus$\Rightarrow$ qu'à-préfent remarquer, même à l'arde des meil9, icurs microfcopes, que ces fubftances euflent un

(*) Minéralngie nu Defcruption générale des fubfances du Re. gne Minéral; au commencement. 
entenu dans des fibres ou vcines; perfonne n'ayant établi ce fentiment pal quelques preuves; \& d'ail"g leurs étant impoffible de fe former une idéc de la "vie en général fans un fuc qui circule, on ne voit "p pint fur quel fondement on attribueroit une vie " aux minéraux, à-moins qu'on ne voulût appeller "vivant tout ce qui a la faculté de croître \& de s'aug" menter: en admettant cette fuppofition, il n'eft pis "doutcux, qu'on ne puifle dire que les minéraux vi"vent (*)."

Si l'on n'a point d'autre railon pour refufer aux minéraux une vie particulière, que de nier qu'ils foient imprégnés d'un fuc vivifiant, ni d'autre railon de nier l'exiltence de ce fuc, que parce qu'on ne l'a pas encore apperçu, on peut aifément les réfuter l'une \& l'autre.

Quand il feroit vrai qu'on n'eût point apperçu de fluide circulant dans les vaiffeaux fibreux des foffiles, ni glandes, ni véficules, ni mammelons qui tinflent en ciffolution un fuc nourricier, ni traches qui en aidaffent la filtration, ce feroit moins une marque de la non exiftence de ce fiuide, que de fon extrême tinefle. Car, pour tirer nos exemples, des corps les pius purs \& du tiffu le plus ferré, ce qu'on nomme paille ou défaut dans les pierres fines, pourroit bien ctre un épanchement de ce fuc extravafé, qui en con-. ftateroit la réalité. Les cfprits animaux fonc un fluide prefque univerfellement reconnu, quoiqu'aucun Anatomifte ne l'ait vu, quoique perfonne mêne n'en ait apperçu les traces.

Je ne penfe pas qu'il faille un grand appareil de preuves pour perfuader que les foffiles contiennent un fuc qui en pénétre toutes les pa:ties. On voit l'eau diftiller des voutes des grottes, \& l'on ne furroit douter qu'elle ne fe filtre au traver's de la roche. Un caillon augmente de poids, après avoir refté quéque temps

(*) Minćralogie de Mr. Wallerius. 2. Gufervation,

$$
\text { C } 4
$$


dans l'eau, foit fur le rord d'une ririère ou de la mer, fans-doute parce qu'il s'en rft imbibi \& comme faoulé. . Monconys raprorte dans fes voyages, qu'ug ne pierre qu'on avoit mife dans un matras ou il $y$ " avoit de l'eau, \& qu"on avoit houchí très exacte9, ment, avott teliement augmenté de volumeau bout "de quelques annecs, qu'il 'uc impoffible de la reti", rer du matras fans le caffer (*)."? i'ai vu auffi dans nne bouteille une pierre qui n'y avoit fûrement pu. entrer dans l'etat ou elle étoit. Ces dernières expériences prouvent que ces pierres s'étoient nourries d'eau par intulufception, \& que, par une vertu interne affimilative, elies en avoient converti les parties en leur nropre fubltance.

Crmbien de pierres font graftes huileufes \& au toucher! D'oul vient cette tranpiration graffe \& huileufe, finon du fluide femblable qu'elles contiennent! Combien de pierres fe diftillent , \& donnent à la diftillation plus ou moins de liqueur! Combien de pierres fe durciffent au feu par l'evaporation du fluide qui les amoliffoit! En gineral toutes les pierres en fe refioidiffant après la fulion deviennent concaves à la furface, \& la mafre fonduc eit plus légère que n'étoit Ja pierre avant que d'entrer en fufion $(t)$. '"eft qu'à la fufion, le fuc contenu dans les fibres, \& les veines, s'évapore; les parnis des unes \& des autres s'affaiffent en fe rapprochant; la diminution du poids vient de la diffipation du fluide; \& la concavité de la furface de l'affaiffement des fibres \& des veines.

La coulleur des pierres précieules ne vient que da fuc métallique dont elles font imprégnées: fuc extrêmement fubril où font trés - finement dıffoutes des particules de fer pour donner la couleur rouge au rubis, de cuivre pour faire le bleu dans les fiphirs; de cuivre \& de plomb pour rendre la chripolite d'un jaune

(*) Metallique de Mr. Wallerius. 3. Obfervatien.
$(t)$ Là-méme, page 6. 
verdâtre; de cuivre \& de fer pour former le beau verd de l'éméraude \& du bérylle \& \& $c$

Il y a des pierres qui fembient être des ćponges pleines du fluide électrique. Lnfin tout nous confirme que nous avons raifon de regarder les picries conıme des fyftêmes de folides arrof̣és par un fiude, quel qu'il foit.

Nous ne prétendons pas qu'elles aient une vie femblable à celle des végétaux. Il n'eft dnnc pas néceffairc que le Suc qu'elles contiennent y ait une marche femblable à celle de la feve dans les plantes. Une finpie pénétration ou inbibition, un arrofement fuifit peut-être à l'efpéce de leur économic vitale. Ou peut-être encore elt-ce quelque chofe de plus fimple dan. les échellons les plus bas. Tout vit ; mais la vie eft réduite à fes moindres termes daris les prem ères réalifations du prototype (*).

Cependant les fibres \& les veines des foffiles ou on en déc uvre à la fimple vue, femblent deftinces à en filtrer un fuc nourricier: cette conjecture n'a rien d'étrarge.

L.es tales \& les ardoifes, l'or, l'argent \& tous les folfiu's lamineux ont leurs feuilles attachées par de petits fibres qui vont traniverfalement d'une feuille à l'autre, comme les fibres qui lient enfemble les lames dont les os font formés dans l'animal.

Parmi les fibres pierreufes \& métalliques, il y en a dont la ftructure imite celle de plufieurs fibres animales.' La numismale a des fibres tournées en forme de fpirales, comme celles du cœur; le plomb cn a de tortueufes \& d'annulaires, comme celles de la plevre; l'antimoine en a de plićes en $\mathrm{zig}$ - Zag, comme les fibres mufculaires, \&̈c. Qui connoîtroit l'intérieur de tous les foffiles, y verroit peit - ćtre des types de toutes les fibres animales.

Une pierre eft ordinairement un tout d'une ftruêure affez uniforme. Elle n'eft point compofée de

(*) Voyez dans le Livre incitule de la Nature, Tome IV. des prouves \& des faits fentiles concernant lin vie des folfiles

C 5 
folides d'une confiftance ou d'une efpece différente. Un métal a le même caractère d'unitormité dans fa texture. Ce n'eft pas qu'on ne voie aufli des foffiles dont le tiffu eft plus ferré dans une partie \& plus lâche dans une autre partic; d'autres qui ont une forte de noyau, ou de courr, à leur centre; d'autres dont l'intérieur eft rempli d'une apparence médullaisc. Ce font autant d'échellons qui s'élevent les uns au deflus des autres.

Le grand nombre des folfites font plus uniformes dans leur organifation, \& cette uniformité les met au deflous de ceux qui y font moins affervis. La Nature s'étudiant à tourner \& à tiffer la matière fibreufe, commença par les moindres ćlémens, par Jes combinaifons les plus aifées, pour s'élever graduellement à des compofés plus favans.

Il y a une gradation d'appareil fibrillaire dans les fofliles. Pour juger en combien de manières la Nature l'a varié, multiplié \& nuancé, il faudroit avoir une minćralogie complette, ure énumeration exacte de toutes les iubftances fofiles, \& de plus en voir le tiffu à découvert. Quand aurons - nous une Minéralogic complette? Alfurément il y a encore bien des Etres inconnus à ajoûter à celles de IVallerius \& de Bonare. Quand aurons-nous des inftrumens qui nous mettent en etat d'anatomifer tous les mincraux connus?

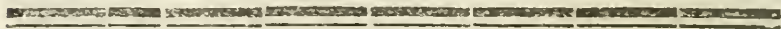

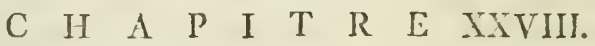

Pafage des Miníraux aux Plantes.

I

Es pierres fibreufes, c'eft-à-clire celles dont les fibres font fenfibles, forment le paftage des minéraux aux régétaux. Elles approchent fi près de ceux-ci, que, le préjugé mis a part, il feroit difficile de les en altinguer. 'iels font les mica, les tales, les pierres 


\section{P H I L OSO PHI QUES \&c.}

ollaires, les amiantes, les asbeftes, qui compofent des famill's confidérables. Nous alions entrer dans quelques détails fur ces pierres, autant qu'elles ont de rapport avec l'objet principal de cet Ouvrage.

\section{C}

\section{Les Mica.}

I

Es mica font des pierres compofées de particules en forme de petites écailles, ou lames, attachées les unes aux autres par des fibres tranfverfales de la manière que j'ai dite ci-deflus (*). Elles font ordinairement tendres \& friables.

Le feu defféchant leurs fibres \& en détruifant la frrueture, les raccornit \& le rend dures au toucher.

Ces pierres varient d'une efpece à l'autre pour la confiftance, la figure \& l'arrangement de leurs parties.

\section{Première espece.}

\section{Mica roide.}

Cetic première efpece a fes lames ou écailles roides, fans aucune flexibilité. La cotileur varie chez les individus: il y en a de blanes, de jaunes, ce verds, de rouges \& de noirs: mica rigida.

\section{Seconde eppece. \\ Mica fexible.}

Celle - ci a de grandes lames flexibles: fa couleur eft un blanc argente: mica faxilis argeiztea.

(*) Chapitre XXVII. 


\section{Troifiéme efpece.}

Mica écailleux à lames pointues.

Les écailles de ce mica font minces \& pointues: $m i-$ ea particulis temuioribus acuminatis.

\section{Quatriéme efpece. Mica brillant.}

Les lames de cette efpece font luifantes \& demitranfparentes: mica femi-pellucida.

\section{Cinquiéme efpece. \\ Verre de Mofcovie.}

Le verre de Mofcovie, vitrum Mofcovitum, a des lames auffi tranfparentes que du verre.

$$
\begin{aligned}
& \text { 6. Sixiéme efpece. } \\
& \text { Mica ftrié. }
\end{aligned}
$$

Ce mica paroît plûtôt compofé de filets parallèles, arrangés en faifceaux, que d'écailles, tant elles font fines \& allongées: mica particulis oblongis.

\section{Septiéme efpece.}

Mica demi-sphérique.

Les lames de cette efpece font rangées circulairement autour d'un centre commun, où elles viennent Se réunir pour la plûpart. Ce mica demi-fphérique fe trouve à Spogol en Finlande ( $)$ : mica bamijpberica.

(*) Minéralogie de Wallerius. Ce Naturalifte fait une autre diftribution des mica, peur-être meilleure que la miennc, mais je ne fais pas une méthode. 
PHIL O S O PHI Q UES \&c.

8. Huitiéme efpece.

Mica irrégulier.

C'eft celui dont les parties lamineufes femblent ne garder aucune régularite dans leur figure ni dans leur arrangement: mica Squammulis inordinatè mixtis.

\section{$\begin{array}{llllllllll}\text { C } & H & A & P & \text { I } & T & R & E & X X X & \end{array}$}

L

\section{Les Tales.}

talcs mas montrent, à-pet-près, les mênes phénomènes, feulement avec des variations finement graduées dans la forme, la confiftance, \& le calibre des petits feuillets qui les compofent. Le tiffu en eft plus ferré, ce qui leur donne plus de maffiveté.

Plus on compare la ftructure des nica \& des tales à celle des os, plus on fe convainc que l'une eft une ćtude de l'autre.

\section{$\begin{array}{llllllllll}C & H & A & P & I & T & R & E & X X X I \text {. }\end{array}$}

\section{Les Pierres Ollaires.}

1

INTÉRIEUR des pierres ollaires offre à la première vue des amas confus \& irréguliers de petits feuillets, de filamens \& de petits grains: ce font des paquets de fibres, comme l'Anatomic en fait voir urie infinité de plus ou moins gros dans le corps animal. 


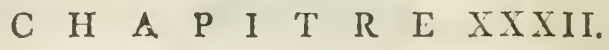 \\ Les Racbes de corne.}

$\mathrm{O}$

$\mathrm{N}$ appelle roche de corne une pierre qui par fa ftrueture feuilletée eft analogue à la corne des animaux, à laquelle elle reffemble auffi par fa conleur. On fait que la couleur des corps provient du fluide qui les pénétre \& les teint en les pénétrant: ce qui rend l'analogie entre cette pierre \&r la corne animale plus complette. Nous verrons dans la fuite que nos ongles font des extraits perfectionnés de la corne des quadrupedes.

II y a furtout une efpece de roche de corne dure \& noire, qui reffemble plus que toutes les autres au fabot du cheval, comme l'ont obfervé les Naturaliftes; les autres cfpeces en approchent plus ou moins. Les feuilles de celles - là fe levent \& fe détachent comme les fetilles de la corne.

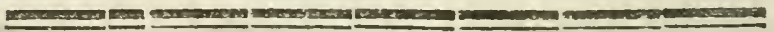

\section{C $\mathrm{H}$ A $\mathrm{P}$ I $\mathrm{T}$ R $\mathrm{E}$ XXX̃III.}

\section{Les Amiantes.}

N s'apperçoit, en confidélant les amiantes \& les asbeftes, que la Nature, parvenue à ce genre de productions, a déja confidérablement perfectionné le fyftême fibrillaire.

Les amiantes font compofées de fibres dures \& coriaces qui ont beaucoup de rapport avec celles des fubftances charnues. Elies font ou difpofés parallèlement, ou elles fe croifent \& s'entrelacent pour former des couches ou membranes réticulaires.

„2 Les difierentes efpeces damiantes, dit Mr. MTal- 
"lerius, font les plus molles de toutes les picrres; " elles font ordinairement flexibles jufqu'à un certain פg point; on peut même les filer \& en faire de la toi"le; ce font aufii les plus légères des pierres, atten" du qu'elles nagent à la furtace de l'eau; il n'y en a "point qui aient plus d'analogic avec le règne ani" mal \& végétal par leur molleffe \& leur légereté, \& "furtout par leur organifation". Je vais parler de quelques efpeces dans l'ordre où elles fe préfenteront.

\section{Premiere espece.}

Amiante de chypre, oul lin folfile.

Ce lin fofile reffemble beaucoup, pour la couleur \& la fubftance, à un paquet ou faifceau de cheveux gris. On l'appelle auffi laine de montagne: lana montana.

\section{Seconde elpece.}

Cuir folfole.

Le cuir foffile, ou cuir de montagne, a des fibres molles, étroitement unics les unes aux autres, entrelacées par d'autres fibres, dont la texture eft tout-àfait coriacée. Il reffemble parfaitement a du cuir, dont il prend le nom: corium montantm.

\section{Troiféme efpece.}

Chair foljile. Caro montana.

La chair foflile eft encore une amiante compofée de l'alfemblage de plufieurs membranes epaiffes \& folides, \& fi analogues a des membranes charnues qu'on n'a pu lui en refufer le nom. Il eft à remarquer que ce nom lui a été donné avant toute idée d'un fyftême femblable à celui que j'expofe, \& par des Naturaliftes qui étoient fort éloignés d'envifager la Nature fous ls 


\section{CONSIDERATION S}

même point de vue que je la confidere à ce momert. Frappés de la reflemblance, ils on rendu bommage a la verité, même en la contredilant; \&, en furvant une route contraire à celle qui devoit les conduire au vraì fyltême, ils nous l'ont indiquee.

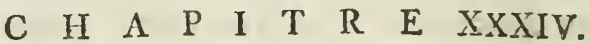 Les Asbeftes.}

Tes asbeftes, comporés de fibres appliquées longitudinalement les unes contre les autres par faifceaux; ont avec les nerfs \& les mufcles les mêmes rapports organiques que les amiantes ont avec les chairs, fi ce n'eft que les fibres des asbeftes n'ont pas la flexibilité des fibres nerveufes \& mufculaires, comme celles des amiantes ont la fouplefle des fibres charnues.

On diftingue l'asbefte mûr de celui qui ne l'eft pas encore, en ce que les fibres de celui - ci font fi tendres qu'on les caffe plûtôt que de les féparer, au-lieu que lorfqu'elles ont acquis de la confifrence en mûriffant, on les détache facilement les une: des autres fuivant leur longueul. On peut auffi filer \& tiffer l'asbefte mûr comme l'amiante.

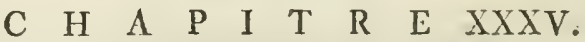

Si les Amiantes \&O les Asbefles divent être mis aù rang des minéraux, ou des vigétaux.

UELQUES Auteurs (*) ont foutenu que l'2miante \& l'asbefte n'étoient point aes finfiles, mais

(*) Voỵez Rieger, Lexicon IIifl. Nar, au mot aminntus: 
mais plûtôt des végétaux. La méprife, fi c'en eft une, eft bien pardonnable. Ils ont pu croire fans abfurdité que des fubftances filamenteufes, flexibles \& légères comme les racines des piantes, propres, comme le lin vćgétal, a être filées \& manufacturées en toile, pouvoient appartenir au même regne.

Il eft vrai qu'elles le tirent des montagnes, \& qu'on ne les voit point s'élever au deffus de la furface du fol. Que s'enfuit-il? Qu'elles pourroient ĉtre des plantes toutes en racines: feroit - ce une chofe fi itrange? D'ailleurs la truffe ne fort point non plus de desfous la terre; on peut l'appeller à cet égard une plante foffile.

L'amiante \& l'asbefte font incombuttibles, \& fedurciffent au feu aulieu de s'y confumer. N'y $a-t-$ il pas quantité de racines qui ont la même vercu, celles du Sodda des Indes, l'Antrofaces de Diofcoride, l'Umbilicus marinus Monfpelienfinm?

C'eft un fait que les amiantes \& les asbeftes particicipent plus de la Nature \& des propriétés des végétaux, que de celles des minéraux. Il y a de la discrétion \& de la retenue à les regarder feulement comme deftinés à remplir le paffage du minéral au végétal. On les appellera fi l'on veut, des foffiles qui fe métamorphofent en plantes, pour commencer le regne végétal, dont l'autre extrémité eft pleuplée do plantes qui s'animalifent.

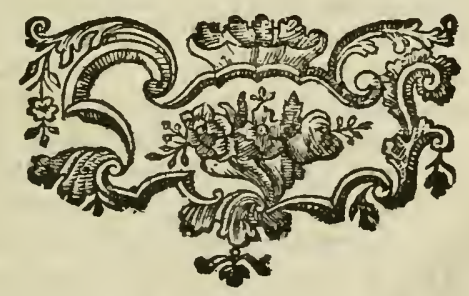




\section{T ROISIEME PAR T IE.}

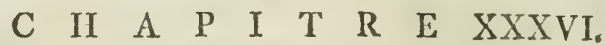

Sommaire des rapports organiques de la Plants avec l'Homme.

No excroifra navons vi jufques -ici que des malcs fans excroifances, des troncs fans rameaux, des corps fans membres. Les premières plantes, telles que la truffe \& le: noftoch, funt aufi dénuées de branches, de tiges \& de feuilles. Le champignon a des racines: fa tête, gronfle fur fon pédicule, s'évade de tous côtés en forme de chapiteau convexe en deffus, concave en cleflous; cetie dernic̀re furface cit feuilletce , ou fiftuleufe; ceft-à-dire garnie de petits tuyaux. Les lichens fuivent les champignons. Viennent enfuite les plantes herbacées, les arbrillcaux \& les grands arbres.

Ainfi la matière, qui ne s'étoit montrée jufqu'à ce degié de l'ćchelle des Etres, que fous des formes resferrées fans ramifications extérieures, fait ici de ces troncs autant de centres d'où fortent progreffivement d'un côté des racines, de l'autre des branches, \& des feuilles. Nous verrons, dans la fuite, les nouvelles formes que prendront les unes \& les autres.

Mon deffein n'eft.pas de m'arrêter ici à contempler la nuultitude immenfe des plantes, ou la varieté infinie de leurs figures. Nous connoiffons un peu plus de vingt mille efpeces de plantes, \& ce n'eft pas fansdoute la vingtiéme partie de ce qu'il nous en refte à connoître. Qui pourroit feulement compter le peuple nombreux des mouffes, des lichens, des champignons? Notre botanique eft peut - être à celle de 12 
Nature, comme un à cent-mille: Je me trompe; nous ne fommes pas fi avancés. La diverlité des formes végétales qui fait line gradation de nuances depuis le noftoch jufqu'au cedre \& au fapin, n'elt pas noins étonnante. Mais ce qui doit fixer notre attention, ce font les rapports organiques de la plante avec l'homme.

L'homme n'eft point une plante: la plante n'eft point un homme. J'apperçois feulement entre la plante \& l'homme une analogie de formes \& de parties qui nie dit que ce font deux métamorphofes du prototype, dont l'une, quelque éloignée qu'elle foit de l'autre, pent nćanmoins l'amener par une fuite d'altcrations, d'accroiffemens \& d'approximations.

Je ne veux pas dire qu'une plante puifie devenir un homme. On m'auroit mal compris, fi on l'entendoit ainfi. Je me fuis afiez expliqué: j'entends uniquement que le deffein d'après lequel la Nature a travaillé le végétal, peut être perfectionné jufqu'à devenir le modele de la machine humaine, conme le plar de l'organifation des plantes eft une variation perfectionnée du plan des machines minérales.

Je vois dans les plantes une diftinction de fexes, \& des parties fexuelles qui ne s'éloignent pas beaucoup, pour la forme, des parties naturelles de l'homme \& de la femme. Les étamines, parties mâles des plantes, font des filets ou petites colonnes qui portent des gouffes fpermatiques, analogues aux tefticules. La différence entre ces parties \& celles de l'homme, confitte en ce que, dans l'homme les tefticules pendent au deffous \& à la racine de la verge, aulieu que, dans la plante, les tefticules font au fommet ou à la tête des petites verges.

Leș plantes ont une femence continue dans des véficules, d'où elle eft éjaculće dans un lieu propre à la fécondation. Ce lieu eft le peftile, \&t ce peftile a fa bafe, fes conduits \& fon fommet, qui repréfentent la matrice, les tronipes \& la vulve de la femme.

Le fortus plante a des filets ombilicaux, des lober

D 2 
qui lui fervent de placenta \& des envelnpres qui répondent au choriun \& à l'amnios où le tatul: humain eft conteris. C t aflortiment de partics fe forne, pour l'un comme puur l'autre, du fupertu de la fimence. L'in \& l'autre fe noulriflent, dans ce premicr état, pai le cordun ombilical.

On diftingnc dans l'homme le corps \& les extrémitćs: la têtc, les bras, les cuifres \& leurs dépend: nces font les extrémités. La divition eft la méme pour la plante: on y ditingue le tronc \& les extremités qui font les racines \& les branches. Il n'eft pas encore temps de roir les racines fe raccourcir, la partic inférieure du tronc fe jivifer en deux portions cgales, toutes les branches fe réunir de côté \&r d'autre en deux? grofies feulement, mais nous pouvons remarquer en pafrant, que les doigts ou ramifications des pieds \& des mains font des reftes dégulifes de l'ancienne forme.

Toutes les parties folides du corps humain font de deux fortes, ofieufes ou charnues. De-même toutes les parties folides des plantes, les racincs, les tiges, des brancizes, les feuilles, les fleurs, les fruits, les graines, font compofées de deux fortes de corps. Les parties ligneufes, c'eft - à - dire les fibres \& les filets repondent aux 0s. Les écorces, les peaux, les moëlles, les pulpes, les parenchymes font leurs chairs. La moëlIe végétale eit contenue dans le bois, comme la moël2e animale dans l'os.

L'écorce de l'arbre eft compoféc de trois menbranes: favoir la fine ćcorce, la grofie écorce \& l'śpidelme. La peau de l'homme eft de-même formec de trois menibranes, la peau intéricure, lia furpeau \& l'epiderme.

Il y à dans le corps humain deux fluides généraux, le fang \& la lymphe. Il y a dans les plantes deux fluides, la feve \& une liqueur vifqueufe analogue à la lymphe. Si la feve ne circule point réellement dans la plante, comine le fang dans l'homme, elic ne lais. fe pas d'y avoir un cours reglé; st quelyue nous qu'il 
mérite, c"eft toûjours une idke de la circtiation du fang (*).

La plante pompe par fes racines \& par ies pores de fes feuilles, qui tont comme antant de bouches, un fuc qui eft porté dans des utricules, comme dans des eftomacs. Là il fermente $\&$ fe digère: il pafe en îte dans les fibres ligneufes, lefquelles f́quivalent anx yeines lactées. Il eft verfé de là dans les vafes pronjes, analogues aux vaiffeaux fanguins, où il fe montre fous la forme d'une feve colorée convenable à s'incorporer à la plante. Les ramifications des vafes propres la difribuent en effet à toutes les parties de la machine, pour les nourrir.

Il y a auffi, dans la plante, comme dans l'homme, des organes excrétoires pour l'évacuation des matières peu propres à faire corps avec clle.

Les feuilles de la plante font fes poumons. Leur fubftance eft fpongieufe. Elles font garnies de trachées qui lui fervent à refpirer. D'autres trachées femblables accompagnent les fibres ligneufes avec lefquelles elles communiquent, y introduifant fans ceffe l'air de la refpiration pour atténuer la feve \& en faciliter le mouvement. De pareils tuyaux, tournés en firirale, accompagnent dans l'homme les vaifeaux fanguins \& y fouffent fans ceffe un nouvel air qui fe mêle au fang pour le fubtilifer \& en faciliter la circulation.

Dans les plantes encore. . mais qu'eft-il befoin de m'appefantir fur ce parallèle \& de répéter ici ce que tant d'Auteurs ont obfervé \& publić fur l'anatomie des plantes, leur nutrition, leur accroiffement, leur génération, \& les organes de toutes ces fonctions? Les plantes vivent, elles refpirent, elles tranfpirent. Elles tranfpirent beaucoup plus que l'homme; elles refpirent d'autant plus facilement que leurs poumons font à l'extrémité de leurs membres, au lieu que les

${ }^{*}$ ) Je prends ici le mot ile dans fa fignification propre, pour image. Voyez le Chapitre fuivant au fujet de la circulation de la feye.

D 3 
nôtres font refferrés vers le centre de notre corps. II y a, dans les maclines végutales, une intufiufception de matière nourricière qui y eft préparće \&z digérée; il y a une aflimilation de parties propres, \& une excrétion de matières impropres ou hétérogènes. Les plantes ont un temps de veille \& de fommeil; elles ont encore un grand nombre de nos maladies: elles font fujettes aux wifules, aux engorgemens, obfructions, abcès, infiammations, à la gengrenc, à une efpèce de fièvie, \&c.

Voilà, ce me fimble, un aflez grand nombre des appanages de l'humanité. A peine les plantes pourroient-elles en avoir davantaye, fans être des hommes. Ce n'en font pourtant que des ébauches bien imparfaites.

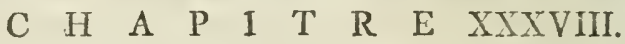

De la circulation de la Seve dans les Plantes. 9 des filtre pafie à triverés contre le corps linfertions (qui font , ler de l'ćcorce ver's la moëlle. Dans le haut de la gr racine, les infertions s'oppofent à ce paffage ; parg, ce que la moëlle qui eft vis-à-vis, étant fort large, s, la fermentation du fuc y eft très-forte, \& par cons, féquent l'oppofition qu'il fait au nouveau fuc eft as"fez grande; mais dans le bas de la racine le fuc paffe : plus facilement à travers les infertions, foit parce 5) que n'y ayant que peu ou point de moëlle; il ne ", trouve prefque pas d'obftacle, foit parce que les , infertions y étant plus petites, \& preflant par con"réquent moins les fibres du corps ligneux, le che"s min eft plus ouvert; de forte que bien que le fue " trouve quelque refiftance, même dans cet endroit, " comme elle y eft fort petite, il nourrit en paffant s) le carps ligneux, \& il arrive enfin dans la moëlle. 
Slanche 11: Mage 54.

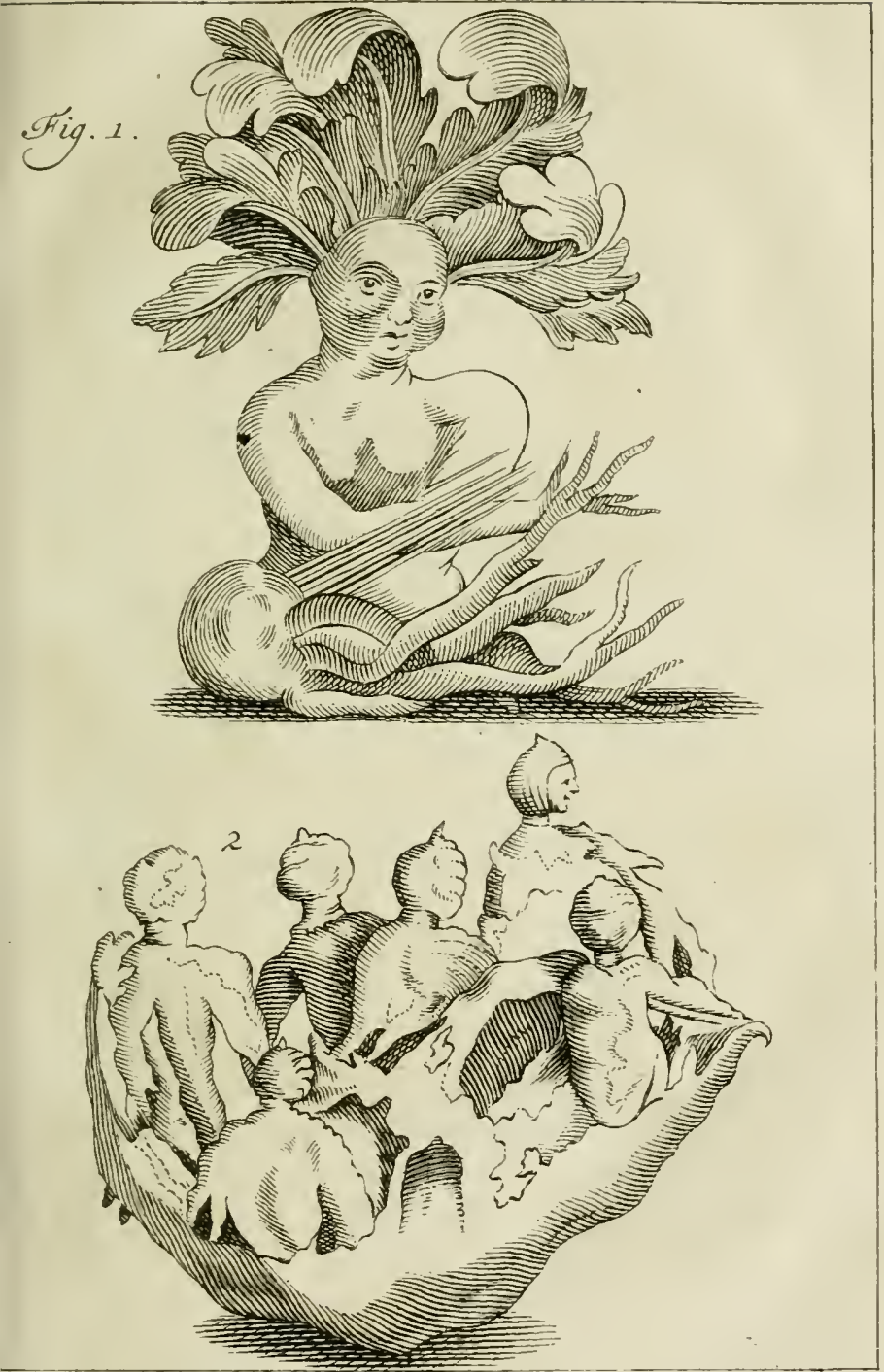

T. ग. Sinex. 



\section{P H I L O S O P H IQ UES \&c.}

2) Il y entre enfuite de notveau fuc, \& cclui gui eft

" vcul le promier n'étant plus ni trop crud, ni trop "groflier; mais au contraire étant purifić \& affine, "g il s'éleve facilement dans la moëlle, comme dans " la grande artère, juf दqu'à la hauteur des infertions "les plus élevées. Lorfqu'il y eft arrivé, les parties "les plus volatiles continuent à monter en droite li"gne vers la tige de la plante; celles qui ne font pas פf fi propres à monter ne pouvant pas auffi defcendre, " parce qu'elles font plus légères que cel'es qui font ", au deflous d'elles, prennent un mouvement moyen „entre l'un \& l'autre, \& retournent de la moëlle " dans les infertions. Elles nourrifient en paflant le " corps ligneux, \& ce qui en refte étant poufié par $\Rightarrow$ d'autre firc qui le fuit, va fe rendre pour la fecon" de fois dans l'écorce qui eft comme la veine cave. "Il y eft encore pouffé en dehors par le fuc qui " vient de la moëlle; mais étant rencontré par d’au" tre fuc qui va de la circonfére ce vers le centre, "il eft obligé de redefcendre vers le bas de la racion ne, \& d'y repaffer dans la moëlle à travcr's les in" fertions, en fe joignant au nouveau fuc qui $y$ " entre dans la terre. Enfuite les parties les plus " crues retournent encore de la même manière dins g, l'ćcorce \& reviennent dans la mnëlle; \& celles ", qui fe trouvent affez volatiles n'aysnt plus befoin " cie circulation, montent en droite ligne vers la ti"ge de la plante (*)."

C'ef́ ainfi qu'un célèbre Anglois, un des premicrs Naturaliftes qui ont traité avec quelque méthode de l'Anatomie des plantes, concevoit la circulation de la feve: il voyoit dans les végétaux des partics analogtres ì la grande artère \& à la veine cave.

Un Médecin François, qui a fait un Traité de lame des plantes, s'explique ainfi fur la même matic̀re:

(*) Anatomie des Plantes, par IIr. N. Grew, trad. de l'Anglois. 
"Un efprit acide chargé de que'ques particules de g) terre, s'infinue dans la tige des plantes, où fe mế, lant avec les fucs qui montent par les lacines, \& פ, ccux qui defcendent du réfidu de la nourriture des " partics, ils fe fermentent, ils fe cuifent cnfemble, , \& re rendent enfin propres \& fuffifans à nourrir la "plante.

, Ces fucs, ainfi cuits \& préparés, circulent dans " toute la plante. Sortant de la tige ils montent dans "le trone, dans les branches \& dans les feuilles; \& "2 après avoir laifié ce qu'ils ont de meilleur pour la "nourriture \& pour l'accroifement des partics, le "refte qui eft inutile defcend dans la tige pour y \% être cuit \& preparć de nouveau, après quoi il fe "diftrubue derechef dans toute la plante; de-même و que dans les animaux le fang arteriel fort ducœur, g \& fe diftribue dans tout le corps qui retient ce que , le fang a de propre pour l'entretenir, \& renvoie le , refte au cour qui, après l'avoir préparé, le poutte ", de rechef vers les parties. \& entretient par ce moyen g, une circulation continuelle.

, Cette dofirine n'eft pas moins füre pour être פ, nouvelle (en I685.); il eft bien aifé de le démong, trer, puifque les ralions qui prouvent que le fang " circule dans les animaux, établifient auti la circuפ, lation de la feve dans les plantes: en voici quelg, ques - unes.

2) I. Le flux inćvitable \& continuel de la fubftance 2, de tout ce qui fe nourrit a befoin d'être prompteg, ment \& continuellement réparé.

9,2 . Cette réparation ne peut fe faire que par un ", fuc cuit \& préparé par les parties deftinées à cet פ, ufage.

,3. Il eft impoflible que cette prćparation, fi importante \& li difficile, fe faffe la première fois, puisque le fuc ne s'arrête qu'un moment dans les parties; il faut donc qu'elle fe fafle à plufieurs reprifes.

9, 4. Dans la nourriture la partic inutile cft tou- 


\section{P H I L O S O P H I Q U E S \& . 57}

99 jours féparéc d’avec l'utile, \& par conféquent la „ partic inutile doit être renvoyéc aux parties qui g, peuvent la rendre utile, en lui procurant les bon" nes qualitćs que toute la malle avoit avant que la פportion utile en en̂t été féparće.

"Toutes ces conditions qui rendent la circulation , néceflaire aux animaux, fe rencontrenc dans les plantes; leur fubftance le diffipe commece.le des ani" maux; elle eft réparcé, comme dans les animaux, , par la nourriture où le bon eft féparé d'avec le " nuauvais, l'utile d'avec l'inutile; entin la tige eft a "Ja plante ce que le cœur eft aux animiux; tous les פ deux reçoivent \& donnent, tous les deux préparent , \& digerent.

"On m'objectera peut-être que les organes de la circulation paroiffent évidemment dans les anj, maux, qu'il n'en eft pas de-même des plantes. Je "réponds à cette objection que, comme il y a des " animaux où les vailfeaux paroiffent diftinctement, "\& d'autres moins parfaits (tels que font la plûpart " des infectes) oul l'on ne voit non feulement ni vei" nes ni artères, mais dans lefquels on ne diftingue ni " cour ni foie; on peut dire aufi qu'cntre les plan"tes il y en a où les organes de la circulation fon. diftincts \& vifibles, comme les vieux chênes dan. l'écorce defquels on trouve de gros \& de petits filets, \& d'autres où les vaificaux \& les routes font cachées \& inconnucs. Si l'on veut que la nourriture des infectes circule, \& qu'ils aicnt des organcs diitincts comme les animaux parfaits, - parce que les fonctions de ces animaux fournifient des conjectures de l'exiftence de ces organes; ne poulrois-je pas dire la même chofe des plantes où il ne paroît point de vaiffeau (*)."

On pouvoit raifonner ainf dans le dernier fiécle, di-

(*) De l’âme des Plantes, par MIr. Dedu Doĉteur en Medecine de la faculté de Miontpellicr. 
ront les Naturaliftes du nôtre; mais des ob?crvations plus récentes prouvent incon eltablement qu'il n’y a point de circulation de la feve dans les flantes, J'en conviendrai aifément avec eux. En rapportant les deux partages qu'on vicnt de lire, je n'ai eu pour but que de faire voir jufju'où l'analogie entre lia plante \& l'animal avoit éré por'ee il y : longtemps.

Il n'y a point de circulition proprement aite dans les plantes: il n'y en a qu'un effai, lequel fe perfectionnera d'abord dans les infestes par le moyen àu long vaifleau qui ne fera pas un cœur, mais qui fe contractera \& fe dilatera alternativement comme le cceur. Quelques échellons plus haut, ce vaifieau, ou grande artère, prendra une forme pyramidale; ce cour ébauché n'ayant encore qu'une orcillette; il n'y aura uuffi qu'une circulation mparfaite. Lnfin ce cocur acquérant fucceflivement deux ventricules, deux oreillettes, \& un grand nombre de vaifleaux, la circulation conplette aura lieu.

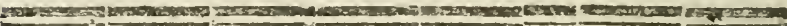

\section{I}

Navet fingulierrepréfentant une femme (Voy. Planche IV. Fig. I.

$\mathbf{L}_{\mathrm{B}}$

navet monfrueux, dont on donne ici la defeription \& la figure, a été trouvé tel qu'on le voit, dans ım jardin au lieu nommé $W$ eiden à deux miles de Juliers, fur le chemin de Bonn. L'herbe, ou, pour micux dire, les feuilles qui font pour l'ordinaire au haut du navet, repréfentent en celui-ci des cheveux dreflés en haut, \& forment un panache des plus beaux \& des mieux garnis que l'on puille voir. Au delfous de ce panache, la Nature a formé une tête avec des yeux, un nez, une bouche, des levres \& un menton. On y voit même le fein bien marqué, la poitrine entière; \& les racines qui fe trouvent ordinaire- 
ment dans cette efpece de plantes, font ici tellement difpofées qu'on croit voir des bras \& des pieds. Ainfi tout lc navet repréfente une femme nue, aljie fur fes pieds, à peu près à la manière des tailleurs, \& ayant les bras croifés au deffous de la poitrine $\left({ }^{*}\right)$.

Je laifle aux Philofophes à expliquer, s'ils le peuvent, comment la fubftance de ce navet a pu prendre une forme fi fingulière. Pour moi j'admire les crreurs de la Nature, fi l'on peut dire qu'elle fe trompe quelquefois. Ses écarts font pour nous une fource d'inftructions. On diroit, en contemplant cette production fingulière, que la Nature voulut effayer fi la forme humaine pourroit s'allier avec la fubitance végétale \& comment elles figureroient enfemble.

Ce que je difois dans l'inftant $(t)$ de la réunion des branclies \& des racines pour faire des bras \& des pieds, commence à fa réalifer dans ce naver. La métamorphofe eft bien avancée. On voit qu'elle n'a pas mal réufli pour un premier effai,

\section{C $\quad$ H}

Cbampignon repréfentant fix figures bumaines (Voy. Plancibe IV. Fin.2.)

$\bigcup_{0}$ UE champignon extraordinalre merite de fervir de pencant au navet dont on vient de parles. Il fut trouvé par un payfan en I66I, au pied d'un arbre, dans la forêt d'Altdorff. Il repréfente affez au naturel fix figures humaines plus ou moins bien deffinées. Il y en a furtout une, dont la tête de profil fait voir un oxil, le nez, la bouche \& le menton aufi exactement

(*) Voyez le Journal des Savans, annéc 16 \%

(t) $\mathrm{Ci}$-devant Chapitre IXXYI, 
travaillés qu'ils pourroient l'être par une main habile. Les cinq autres tigures ne montrent que le dos (*).

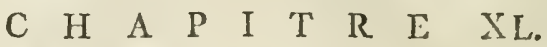

\section{Mandragore repréfentant la figure d'une fomme.}

\section{C}

Es productions étranges me font fouvenir d'avoir lu quelque part ou'en 1687 on trouva, fous une potance allez près du grand chemin. une mandragore qui avoit la figure d'une femme auffi bien formée par la Nature, que fi l'Art y ent travaillé; que cette mandragore fut prérentée au Roi Louis XIV. qui l'acheta, $\&$ en fit graver une belle eftampe, laquelle doit fe trouver dans la troiliéme partic des Mémzoires \& Elampes pour fervir aे I Hifioite des Plantes de Dodart $(t)$. La relation de cette mandragore elt contenue dans unc lettre d'un nommé Mr. de Jolly en date du 4 Mai 1687 . c'eft tout ce que j'en fais, n'ayant vu ni la relation, ni la figure de ce phónomène.

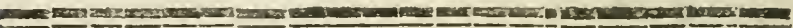

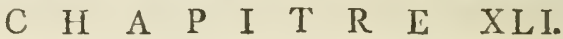

Rave aygint in forme d"une main bumaine.

\section{C}

ETTE rave ne faroîtra pas fort fingulière, après ce qu'on a rapporté dans les Chapitres précédens. Elle reprérente une main humaine tres bien formée: on voit fur le pouce la trace d'un ongle de grandeur naturelie. Les feuilles arrangées autour du poignet, compolent uu: clpece de garniture qui inite une manchette. On en peut voir la figure dans le Journal des Savans annec 1679.

$\left(^{*}\right)$ Journal des Savans, année i6-3.

(t) Paris i 701. de l'lmprimerie Royale, in fol, 


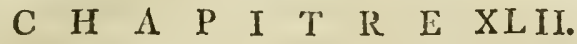

\section{Les Zoopbytes, ou Plantes animales (*). Infecies aquatiques.}

\section{L}

A Nature travaille au fond des eaux des corps tendres \& mollaffes, d'une fubftance muqueufe organifée, couverte d'une peau plus ou moins délicate. Ce font les Zoophytes, peuple nombreux \& varié, par lequel eile s'éleve du regne végétal au regne animal. Nous avons dit que les amiantes \& les asbeftes étoient des pierres métamorphofées en plantes. Quel-

(*) On appelle de ce nom certains poifons, ou animaux aquatiques, privés de fang, qui tiennent de la plante \& de l'animal: ce font l'Ortie de mer, nommée en Latin Urtica, parce que, quand on la touche, elle brule \& pique comme les orties; le Poumon marin, en Latin Pulmo marinus, qui a la figure de nos poumons; l'Holothurie, appellé en Latin Holothuriunn; la Tethye, nommée en Latin Terhya ou Tethaa, qui eft une cfpece de coquillage \& dont quelques Naturaliftes comptent fix différentes efpeces; la Verge marine, ell Latin Nentuli marina; la Pomme de Grenade, Malum Granatum; le Champignon marin, en Latin Fungus marinus; la Poire marine, Pyrun murinun; $l^{3}$ Aile ou lse Plume de mer, en Latin Penna marina, qui brille la nuit; le Raifin de mer Uya marina; la pomme folle de mer, nommée en Latin Malum infanum marinum; la Mdin de mer, Hanus marina; \& le Concombre marin, en Latin Cucumer marimus. Voilà les cfpeces de Zoophytes rapportécs par Aldrovande \& aprìs lui par Ruyfch qui l'a copié. On voit que ces poiflons tirent leurs noms de lcurs figures. Ces Naruriliftes 11'ont point parlé des diverfes efpeces de Polype, parce qui le Polype n'étoit pas encore connu dc leur temps.

M. Limæus (Syft. Nat. Edit. 6. p. 72.) divife les différentes efpeces de Zoophytes en plufieurs genres: favoir, fous le nom d'Amphitrite il comprend TAdamus marinus; fous celui de Tetliys, le Tethya \& THolothurie; fous celui de Nereis, la Scolopendre narine; fous celui de Limax, les différentes efpeces de Linaces, conme la Limace noire qui fe trouve dans les bois, la Limace ronfe qui fe trouve dans les lieux ombrigés, la Linace cendrée C'alende commune dans les lieux humides d'Oelande, une autre petite Limaie cendrée qui fe trouve dans les près $\&$ dans les jardins parni les plantes potagères; une autre Limace jaune \& taclocice qui fe trouve dais les lieux unbragés ce parmi les plantes. 
ques Zoophytes pourroient être appellés des plantes métamorphofies en animaux.

Parmi ces plantes animalifées je vois de petits arbres touffis. Du tronc s'ilevent piufieurs branches; ces branches en pouffent d'autres qui fe ramifient encore. Ces branches fonc tout-à-la-fois des bouches, des jambes \& des bras. Le polype qui les poflede s'en fert à marcher, à fe faifir de fa proie \& à l'avaler. L'intérieur ne montre à l'obfervateur que des vaisfeaux féveux, des utricules \& des trachées, comme dans les plantes; ie puis bien dire des vaifjeaux féveux, puilqu'une caraeteriftique de cette efpece d'animaux, eft de n'avoir point de fung.

Les Zoophytes branchus ou rameux font les plus nombreux. On en connoitt cependant d'autres efpeces dans qui la Nature a fupprimé les extrénités. Elle leur a donné, en revanche, une organifation intérieure, un peu plus avancée vers celle des grands animaux: Les vers d'eau douce, par exemple, dont le corps eft formé d'une fuite d'anneaux, ont, je ne dis pas un cœur, mais un très grand nombre de pe. tits coeturs, mis bout -à-bout, dont chacun a tion mourement alternatif de dilatation \& de contraction pour recevoir le fluide \& le chaffer de l'un à l'au!tre, \& de plus un bel affortiment de vaificaux \& de veines. Au deffous de cette continuite de ps-

Le favant Naturalifte Suédois comprend fous le nom de Lernad, le Lierye marin, mn perit infecte de mer qui fuce le fang, \& un petit poifion blanc, qui fe trouve dans les lacs bourbeux de Sucde, où il eft appellé Rulla. Ce poiflon nninmé par M1. Limneeus

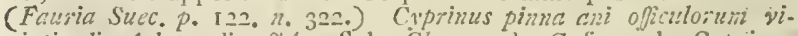
ginti, lined laterali rectd, eft le Clnarax de Gefner, le Cyprinus iatus alins des antres Nacuraliftes, \& le Carcfius de ikay. Les autres Zoophytes, iclon M. Linnerus, comnus fous différens noms, font ceux qui fuivent: il comprend fous le nom d'Hylra, l'Hyrtre nommée vulgairement Polype; fous celui de s'pit:, la Seche \& le Cornet; fous celui de Triton, le Triten; fous celui de Salacia le Phrspahus; fous cclui d'Aphrodita, on Ml:s merinus, l'Aphrodite, efpece de clienille de mer; fous celui de Medufe, l'Ortie de mer, le Poumon marin, l'Ortie cheyclue, etr l'oric Aftro. thyre; fous celui d'alferias, les differentes efpeces d'Etoilio dé 
tits coeurs eft un conduit inteftinal dont les portions d'un diamétre inégal fonc les fonctions de l'xlophage, de l'eftomac \& des inteltins.

Avant que de fuivre plus loin la progreffion des fơmes organiques, arrêtons nous un moment à contempler l'exterieur de quelques Zoophytes. Nous y verrons de nouveaux modèles des mains, des poumons, des reins \& des parties fexuelles de l'homme, La Nature a femé les formes humaines le long de l'échelle des Etres: nous en trouvons quelques-unes prefque à chaque degré.

mer, \& la Conete marine; ¿ différentes efpeces d'Ourfins de mer.

M. Donati (dans fon Hiftoire Naturelle de la Mer Adriatique p. 54.) divife la claffe des Zoophytes en deux légions particulières. La premiere contient les Zoophytes immobiles; ce font ceux qui ne peuvent pas fe tranfporter d'eux-mêmes d'un lieu à un autre. Cette légion eft divilée en trois centuries: la première comprend les Zoophytes dont la fubfance eft entierement charnue: la fe. conde centurie embraffe les Zoophytes qui font compofés de deux fubltances dont l'une eft molle \& charnue, \& l'autre ferme \& tendineufe: la troifiéme centurie eft pour les Zoophytes qui font charnus \& offeux. La feconde légion contient les Zoophytes inobiles ou qui ont la faculté de fe inouvoir \& de fe tranfporter d'un Lieu à un autre. Dičionnaire des Animaur.

On découvre tous les jours de nouveaux Zoophytes.

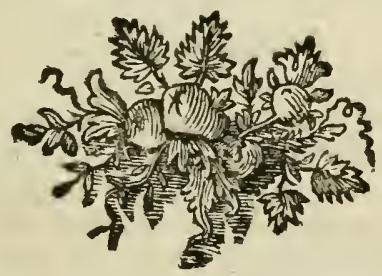




\section{QUATRIEME PAR TIE.}

\section{C $\quad$ H}

De quelques formes du corps bumain ébaucbées dans. lis Zoophytes.

\section{La Main de mer.}

M

un 'Zuophyte mou \& rameux qui a la figure d'une main, non pas aufí reftemblante que la rave du Chapitre $\$ L I$, aflez neanmoins pour lui en avoir fait donner le nom par les Naturaliftes. C'eft l' Alcyonium rameux, mou, dont les ramifications font en forme de doigts, \& qui eft entiérement étoilé.

Alcyonium ramofo-digitatum, molle, afcerifis undique ornatum.

\section{$\begin{array}{llllllllll}C & H & A & P & I & T & R & E & X L I V .\end{array}$}

\section{Le Poumon marin.}

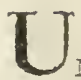

N autre zoophyte couvert d'un cuir dur eft appeilé poumon marin, parce qu'il reffemble au poumon humain, tant par fa forme extéricure que par fa ftruéture interne. Pulmo marinus dicitur ita vel a pulinonum arofrorum figurâ, vel ab corumden fubfanwia taxâ É molit, foraminulis plend (*).

C H A-

(*) Ruyfch. Da Exanguibus aquaticis Lib. IV. De Zoophytis feu ऐ]zut+animalibus Cap. U. 


\section{$\begin{array}{lllllllllll}C & H & A & P & I & T & R & E & X L V & \end{array}$ \\ Le Rein de mer.}

$Q_{E}$

E zoophyte, connu depuis peu de temps, a la forme d'un rein comprimé. Voyez en la figure \& la defcription dans le Livre cité au bas de la page (*).

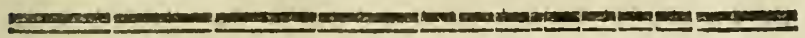

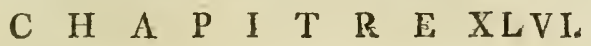

Des Holothuries ou Verges marines; en Latin Ho. lothurium.

$\mathrm{I}_{1}$ plus ou moins de reflemblance avec lo membre vit: ce qui leur a fait donner, par les Auteurs Grecs le non de ßopas, Genitura.

\section{Première espece. Mentula marina.}

La première efpece reffemble prefque au piftile d'uine fleur: car on y voit comme une petule \& un calice qui fortent de fa partic fupérieurc. Elle n'eft pas auffi belle que la fuivante. Elle a pourtant mérité d'être appellée mentula marina.

\section{Seconde efpece. Epipetrum.}

La partie antéricure de celle-ci reffemble parfaitement à l'extrémité du gland de la verge découvert. On y voit l'ouverture du conduit de l'Urethre, qui eft la bouche \& en même temps l'anus de l'animal. Sa fubftance eft tendre, molle \& polie à cette extrémité, mais ridée fur tout le refte du corps dont l'au(*) De la Nature, Tom. IV. Planche IV. Fig. 3, 
tre bout fe termine en cone obtus. Cette verge marine eft connue des Naturaliftes fous le inom d'epipetrum. On cn voit la figure dans le grand Ouvrage de Seba qui en avoit l'original dans fon cabinet (*).

$$
\text { 3. } 7 \text { roifréme espece. Mentula alata. }
$$

Il y en a une troifiéme efpece, forte de panache de mer, dont la furtic fupéricure elt garnie d'un rang de plumes de chaque côte, qui font les bouches ou fucoirs de ce zoophyte; \& dont le buut nud, liffe, mollafie $S$ percé d'un trou à l'extrémité, montre quelque contormité avec le membre vilir; ce qui lui a fait donner le nom de mentulu alata pifcatorum,

\section{H A P I $\mathrm{T} \quad \mathrm{R} \quad \mathrm{E}$ XII.}

Champignon thavin dont la partie fupérieure repréfente la vulve d'unie femmin.

A même clafie des animaux marins qui nous a donné la repréfentation d'une verge, nous offie ici celie de-la vulve d'une fenme. Ce zoophyte eft une forte de Champignon de mer: du moins voici comme les Auteurs le nomment \& le caraeterient.

Fungus, pileslo lato orbiculari, candicans, marinus, fuperin parte veram vulve muibbris forman gerens $(t)$.

Ceux qui trouveront cetie ébauche un peu groflière, doivent fe fouvenir que c'eft la feconde feulement, qu'elle eft déja plus refemblante que la première dont nous avons fait mention, \& que la mer nous en fournira une troifieme plus parfaite, dans les coquillages $(0)$.

(*) On retrouve la même figure dans le Livre de la Note précédente. Planche VI. fig. 1.

$(t)$ Voyez on la figure dans le tivre intitule de la Nature, Tome IV. Planche VI. fig. 2 .

(\$) Nous en parlerons bientòt. Cliap. LI. 


\section{CINQUIEME PARTIE。}

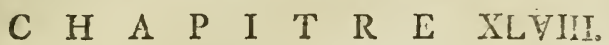

\section{Des Infectes terreftre:}

\section{L}

ES zoophytes, qui font des infectes aquatiques nous conduirent aux infeetcs terreftres. Le paftage des uns aux autres eft marqué par le rapport des vers d'eau douce aux vers de terre.

Quand on entre dans ee qu'on appelle l'empire des animaux, on fe croit tranfplante dans un nouveat monde. On fe trompe; c'eit le même regne qui prend Q'autres formes: c'eft le même plan d'être avec des variations différentes. Ces différences qui paroiffent fi grandes lor'qu'on les confidère dans des dégrés ëloignés, font à peine fenfibles dans les points de contact:

Le monde animal à des habitans branchus \& en = racinés dont les vifcères ne different de ceux des plantes, qu'autant qu'il faut pour n'en être pas la répetition, \& quiont l'admirable propriété végétale de multiplicr de bouture ou par rejettons, de pouvoir êtré greffés, enfin de fe redonner les parties, qu'on leur ôte. Soit qu'ils n'aient que des vaiffeaux féveux, des utricules \&r des trachées à la manière des végétaux, foit que l'Etre en s'élevant ait changé cette fimplicité de vifceres en une organifation un peu plus compofée, en leur donnant un cordon de petitscœurs, \& un fac membraneux en forme d'eftomac; foit qu'ils aient des membres ou qu'ils n'en aient point, les organes etientiels à la vie y font fi multipliés \& tellement répandus dans toute l'habitude de leur corps qu'ils ont autant de cœurs; d'eftomacs \& de véficules pulmonaires qu'il y a de points dans leur fubftance

$$
E \approx
$$


deforteque chaque portion ćtant un abrégé du tout, ils confervent, fous l'une \&r l'autre forme, cette facultéde fe reproduire par leurs parties coupées, \& de fe réintégrer, de quelque manıère qu'on les mutile. Les polypes, les ortics \& les étoiles de mer, les ver's apodes $x$ les mille-pieds, les tania \& les ver's de terre, \&r beaucoup d'autres jouiffent de cet avantage.

En comparant en général l'intérieur des infectes à celui des plantes, on reconnoît que la moëlle fpinale, ce trone principal des nerfs, avec fes nouds, elt une métamorphofe de la moëlle végétale: que la longue artère qui fe contracte \& fe dilate, avce fes veines \& vaifieaux a remplacé les vafes propres \&z les autres vaifleaux réveux \& leurs ramifications; que le fac intefrinal efti une réunion des utricules cn un feul boyau. La feve n'eft pas encore changée en fang. Quant aux trachées, elles fe trouvent parfaitement iemblables dans les infeites \& les plantes, avec même ftructure, nnême ufage \& même diftribution: car les infectes ont auffi leurs poumons à l'extéricur, foit à la tête, fur le corcelet, le long des côtés, ì la partie poftéricure, ou même au bout d'une corne. Ce font les ftigmates, ouvertures cxternes qui repondent t̀ autant de troncs ou de paquets de trachées (*).

L'écorce, tantôt unic \& tantôt rabotcufe, eft cievenue un cuir dur, ou une cnveloppe écailleufe qui recouvre certains infectes crrtiérement ou en partic. La tige garnic de nouds repréfente affez bien le corps cylindrique des vers formé d'une contintité d'anneaux. Ce cylindre divifé en trois parties inégales par deux

(*) Les ftigmates font des ouvertures en forme de bouche, que l'on voit à l'extéricur des infectes. Ce font leurs poumuns ou orzanes de la refpiration, comme les ouvertures extéricures des trachées dans les plantes. Un caractire efloutiel des infectes eft qu'ils ne refpirent pas l'air par la bouche, mais qu'ils le pon1pent \& l'exhalent par les ftigmates dont nots parlons. I.al différence n'eft que dans le nombre \& la place. Les niouches les ont fur le corcclet \& les anncanx; le vers ì foic \& les autres infectes de fon elpece cn ont dix-liuit le long des cotes du corps; 
étranglomens, donnc la tête le corcelet \& le ventre.

Les formes faillantes ne font guère plus altérćcs. La métamorphofe des racines en picds plus ou moins nombreux $\left({ }^{*}\right)$ eft fenfible. Le pied du limaçon eft un paquet de racines mufculaires. Suppofez les raccourcies \& diftribuées par paires fous le corps de l'animal dans la longueur, vous aurez un polypode. Le nombre des pieds diminuera; ils changeront de figure, \& en paffant par ces mutations diverfes ils prendront des crochets, des pinces, une corne, puis des ongles.

Voyez les chenilles épineufes, dont il y a tant d'efpeces. Elles font chargées d'une forêt de branches en forme de buifons. Voilà des Etres d'une nature fingulière: des buiftons ambulans. De vcritables pieds fervent de racines à des arbriffeaux, dont le trone eft le corps d'un animal.

Les ailes font les feuilles des infeetes; ils en ont deux ou quatre, mais clles font ordinairement très. grandes relativement au volume de leur corps, deforte que la grandeur compenfe le nombre.

On remarque à l'extrémité antérieure des vers, une petite ouverture circulaire; c'eft le premici rudiment d'une tête qui commence par la bouche. Elle fe garnit fucceflivement de petites fcies, d'une trompe, d'un aiguillon. Ces piéces préparent \& annoncent le bee des oifeaux \& les machoires des grands animaux.

Les yeux entrent comme partie effentielle dans les nouvelles variations du prototype: ils y font même

d'autres en ont jufqu'd vingt. Il y a des vers qui portent leurs poumons au botit d'une corne. Ces ftigmates fe prolongent \& fe ramifient en dedans du corps en une infinité de petits canaux formés de fibres fpirales ou trachées qui portent l'air dans toutes les parties de l'économie animale; cet ail reffort enluite par les pores de la peau, comme dans les plantes.

(*) Les infectes ont fix, huit, quatorze pieds \& davantage. Quclques-uns en ont un fi grand nombre qu'on les appelle certo pieds, \& mille-pieds. 
prodigicufement multipliés (*). Ils compofent une petice maffe demi-fpherique fur chaque côté de la tête. On s'éronne qu'avec deux yeux nous voyions les obiets fimples. Cette fimplicité de la vifion eft bien plus etrange dans les infectes qui ont des milliers d'yeux. Ici la Nature fe joue du principe de la moindre aftion, en multip.iant les moyens pour un feul St même effec. Quelque chofe de plus remarquable encore e'eft le foin qu'clle a pris de couvrir ces yeux ce poils deftinés, comme les cils des nôtres, à détourner une trop grande quantité de rayons delumièIc, qui nuiroient à la vuc en caufant un éblouificment. Cet organe eft prefque parfait dès la première ćbauche. Il ne lui manque que de la mobilité.

Si les yeux des infectes ne font pas mobiles, leute tête l'eft à un tel point dans plufieurs efpeces, que la forme n'en eft pas confante, puifque l'animal peut l'allonger \& la raccourcir, la refferrer \& l'enfler; cu

(*) L.cs plus grands obfervateurs microfcopiques ipont pas manqué d"étudicr la ftrtcture fingulière de ces yeux. Ceux des mouches des fearabes . des papillons $\mathbb{E}$ de divers autres infectes, ne diffircut en rien deipinticl. Ces yeux font tous à peu près des pertions de fphìe, leur cuveloppe cxtérieure pent être regardée comme la cornce. Elle a une forte de luifant qui fait voir fnurent des conleuis aufi varicies que celles de l'are-en-ciel. Slle parrit. a la fimple vue, unie comme une glace, mais lorsciu'on la regarde à lil loupe, clle paroit taillée à facettes comme des diam jis; ecs facertes font difpofées avec une régnlarite admirahles, di dans nu nombie prodigieux. "Leuwculock a calculé

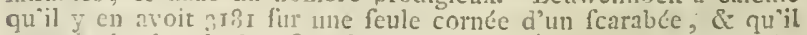
$y$ en vorit plus de 800 fur cliacune de celles d'une monche. Ce qu'il y a cie pius inerveilleur, c'eft que toutes ces faceltes font. traifomblabiement autant d'yeux; de forte qu'an lien de deux yeux que quclques-uns ont peine ì accorder aux papillons, nous devozs iel'r en recommôtre fur les deux cornées 34650 , aux mouches 1600 ; $a$ aux autres plus ou moins, mais tonjours dans un gombre auffi furpronant. J,e même Naturalifte a poufié l'art de I"nnatomie de ces netits animanx, jutqu'ł faire voir que chaque facette eft lai cryftallin, que chaque cryfallin a tout $c c$ qui faut pour faice un wil complet, \& furtout que cluacun a fon nerf cptique.

Ninlgré ces milliers d'ycux qui compofent les deux orbites, 12. plingart des monclies en snt cucore trois autres, placés en trianfie fiur la tête, cntre de crine di le cou. Ces trois ycux qui fort 
an mot la faire difparoître \& reparoîtrc à fon gré. Ces infectes, acephales, quand ils veulent, feroient-ils des modeles de ces bommes fans tête dont parlenț plufieurs Auteurs Grecs (*).

Les organes de la génération, cachés \& peut-être fupprimés dans certains Zoophytes, fe iemontrent dans les infeetes terreftres avec tant de fafte que plufieurs réuniffent les deux fexes. Nous avons vu que les plantes avoient aufii leurs hermaphrodites.

\section{H A P I T R E XLIX. \\ Les Coquillages:}

\section{I \\ $\mathrm{s}$ infeetes à écailles font voifins des infeetesà co- quililes. Les teltacés ne font, aux yeux de plufieurs}

auffi des cryftallins, ne font point à ficettes, mais liffes \& refiemblants à des points. Ces différentes grofreur's des yeux dans le méme infcete, les différentes places accorlées anx uns \& aux auties, font préfumer avec quelque vrailemblare, que la Nature a favorifé les infectes d'yeux proples à voir les objets qui font près d'eux, \& d'autres pour voir les objets ćloignés'; qu'elle a, pour ainfi dire, pourvus de microf́copes \& de téléfcopes. Dič́ionzaire d"Ilifoire Naturelle, au inot Infecte.

(*) Cependant, ces hommes acephales pourroient bien être des hommes fabuleux. Aule-Gclle, qui en parle d'apres plufieurs Auteurs Grecs, ne paroît pas fort convaincu de leur exiftence. Pline (Hift. Nat. Lib. V. Cap. VIII.) dit que l'on croyoir comnunsment que les Blemyes n’avoient poinc' de tête, \& qu' ils avoient les ymix, \& la bouche attachés à l'cftamac; inais il ne fe rend pas garant de cette opinion. Vopifcus, en décrivant le triomplo d'Aurelien, met des Blemyes au nombre des captifs qui fuivoiont le char; il dit que Probus fubjugna cette Nation, \& que le Peulle Romain regarda avec étonnement des hommes fans tête. Le témoignage de Vopifcus n'eft pas fuffifant pour accréliter un pléenomene fi étrange. L'Auteur dı $3-\mathrm{me}$. Sermon aux Frères du clefert, racconte-qu'étane allé prêcher en Ethiopie, il y vit des hommes \& des femmes qui n'avoient point de tête; \& qui nvoient les yeux à l'eftomac. D2 Laet parle de certains hommes qui ont le cout cxtrêmement court \&̇ la tête enfoncée entre le : épulles. IIiftoria Merlica de Acephalis. Autore Marco Depto. H. D. Profes. Sore \& Archiatro Argentinenfi.

\section{E 4}


Naturaliftes, que des vers de mer, de rivière, ou de terre, logés dans des cọulles univalves, bivalves, ou mulcivalves (*).

Si la matière des écailles d'un fcarabée venoit à furabonder, toutes les piéces s'uniroient pour former une feule taie dans laquelle l'animal feroit obligé de fe refferer, \& vous auriez un linacon. Les mouvemens qu'il fe donneroit en fe roulant fur lui-même, tourneroient fa coquille en fpirale: fes pieds dépouillés de leur enveloppe écailleure réunic à la coque, deviendroient un ou plufieurs mufeles par où il y adhéreroit. Les antennes fe changeroient en cornes au bout defquelles fervient placés les yeux. Il conferveroit quelques trachées avec leurs ftigmates: les autres commenceroicnt à fe transformer en quatre petites ouies, Exc.

I'explique dans un Etre particulier comment a pu fe faire la métamorphofe du type Général.

\section{$\begin{array}{lllllllllllll}C & H & A & P & I & T & R & E & L\end{array}$}

Buccin appellé Oreille de mer. Auris marina.

N connoît le buccin appellé Oreille, parce qu'il en a la forme. Il a été décrit par Lifter, Rumphius \& d'autres; mais les figures qu'ils cn ont données m'ont paru au deffous du Naturel; ce qui m'a engagé à en faire graver une autre d'après l'original confervé dans un des plus beaux Coquillers que l'on puifle voir $(t)$. Voyez Plancbe II. Fig. 3 .

(*) Mr. Linneus les met dans la claffe des vers,

(t) Celui de Mrs. 


\section{$\begin{array}{llllllllll}C & H & A & P & I & T & R & E & L I\end{array}$}

Conque de Venus. Concha Venerea (Planche IT. Fig. 4.)

$\mathrm{C}$

'EsT le nom que l'on donne à une enquille bivalve de la famille des cames. Elle eft prefque oviale, voutée, fillonnée tout autour par des lignes parallèles. Le devant de la coquille repréfente la vulve d'une femme, d'une manière bcaucoup pius partaite que les autres modeles rapportés ci-deffus $\left({ }^{*}\right)$. Cette partie eft d'un beau rouge. Les levres femblent un peu écartées \& l'on croit voir quelques apparences du clitoris \& des nymphes. Elle eft garnie tout autour de piguans plus ou moins forts \& un peu recourbés. En fuivant l'analogie de la repréfentation, on les prendroit pour des pinceaux de poils ainfi arrangés.

On ne doit pas être furpris de l'attention de la $\mathrm{Na}$ ture à multiplier les modeles des parties de la génération, vu l'importance de ces parties. Nous ne fommes cncore qu'aux petits animaux, \& déja elle a effayé toutes les manières de reproduction que nous connoilions. Par une magnificence admirable, elle en a réuni plufieurs dans un même individu. Le Polype eft un prodige à cet égard. L'hermaphrodifme de certonins coquillages eft peut-être aufî fingulier.

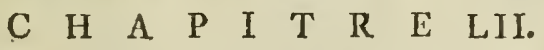

De l'Hermapbrodisme de quelques Coquillages. Dans quelques coquillages, le fexe eit diftingué;

(*) Chap, XX. \& XLViI. 
il y a des individus mâles \& des inđuividus femelles. Dans d'autres, les deux fexes font reunis; tutus les individus font hermaphrodites.

On peut, fuivant les curieufes obfervations de Mr. Adánfon que je vais copier, diftinguer trois fortes d'hermaphrodifme dans les coquillages I. Celui auque on n'apperçoit aucune des parties de la génération, parciculier aux conques. 2. Celui qui, réunisfint en lui les deux effeces des partics fexuelles, ne feut fe fuflire à lui même, mais a befoin du concours de deux indiviàus qui fe fécondent réciproquement \& en même temps, l'un fervant de mâle à l'autre, pendant qu'il fait à fon égard les fonetions de femelle: cet hermaphrodifme fe voit dans les limaçons terreftres. 3. Celui qui, poffédant les deux efpeces de parties génitales, a befoin de la jonction de deux individus, mais qui ne peuvent fe féconder en même temps, à caufe de l'eloignement de leurs olganes. Cette fituation defavantageufe les oblige de monter les lins fur les autres pendant l'accouplement. Si un incirvidu fuit à l'ćgarả de l'autre la fonßtion de mâle; ce mâle ne peut être en même temps fécondé par fà femelle, quoique hermaphroditc; it ne le peut être que par un troiliéme individu qui fe met fur lui vers les côtés en qualité de mâle.' C'eít pour cette raifon que l'on voit fouvent un grand nombre de ces animaux accouplés en chapelet les uns à la queue des autres. Le feul avantage que cette efpece d'hermaphrodíme ait fur les limaçons dont le fexe eft partagé, c'eft de pouvoir féconder, comme mâle, un fecond individu, SL être fécondé en même temps, comme femelle, par un troifíme individu. Il ne leur manqueroit plus, felon les reflexions de Mr. Adanfon, pour réunir toutes les cfpeces d'hermaphrodifmes, que de pouvoir fe féconder eux-mêmes, \& être en même témps le père \& la mère d'un animal. La chofe, ainfi que l'obferve ce favant Academicien, n'eft pas impolible, puifque plufieurs font pourvus des deux organes riéceffaires; \& peut-être quelque obervateur y decouvrira-t-il un 
jour cette forte de génération qui ne doit pas nons paroître plus étrange que celle des conques, dies polypes, \& de tant d'autres animaux femblables qui fe reproduifent fans accouplomcnt fentible, \& fan. ancun des olganes requis dans les autres animaux pour opérer la génération. Dans les limaçons, dont le fexe eft partage, l'ouverture de l'organe eft placée fur la di itte de l'animal. Dans les hermaphrodites de la reonde efpece, les parties mafeulines \& les parties feminines font unies enfemble: ciles ont une ouverture commune qui fe trouve fur le côté droit, à livrigine des corines. Dans les hermaphrodites de la troifiéme efpece, chaque organe a fon onverture diftinguéc: l'une à l'origine des cornes, \& l'autre brattcoup au deffous.

Il y a des plantes dont les parties mafculines naiffent \& croiftent naturelloment inférés dans les parties féminines. Voilà l'effece d'hermaphroủisme, qui manque aux coquillages, réalifé dans d'autres Etres. Mais ces différens hermaphrodismes, qui ont fi bien réufli dans les degrés de l'échelle que nous avons parcourus jufques-ici, la Nature les tentera en vain dons les échellons fupéricurs, comme nous le verrons dans la fuite.

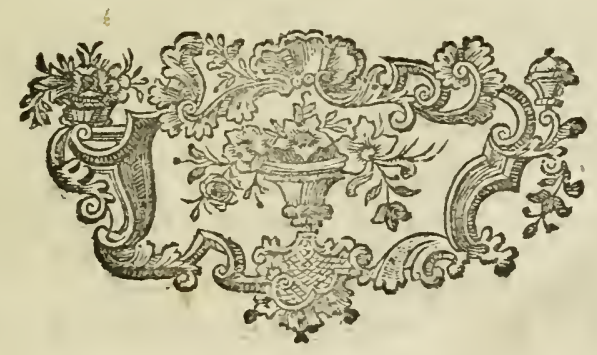




\section{SIXIEME PARTIE.}

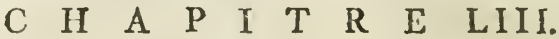

Paffage des Animaux Tefacés anx Cruffacés.

Le Cancre nommé vulgairemert. Le Soldat ou Bernard i' Hermite. Cancellus macrourus, cauda molli tefta cochlex inclufa, chcla dextra majore. Linn. Syfto Nat.

\section{A}

A Ux teftacés fuccedent les cruftacés qui font, comme cux, des infeetes marins ou fiuviaciles (*). Le coguille pierreufe des premiers eft attenuće \& ramollie pour former aux feccisus une enveloppe un reu moins àre. L'animal a pouffé des pieds \& des bras incruftés comme le refte cu corps. De là les cancres, les écreviffes, les cloportes de mer, êc.

Ce paffage eft marqué par l'efpece de cancre ou d'écrevifie qu'on nomme le Soldat ou Bernard l'bermite. On le prendroit pour une écreviffe dans une coguille de limaçon ou pour un limaçon qui a la tête, les pattes \& les bras d'une écreviffe. Cet animal, au corps naturellement nud, a l'inftinct de fe loger dans la première coquille en fpirale qu'il trouve vuide Eft-ce par un fouvenir de fon état précédent? Vient-jl revandiquer fon ancienne dépouillc, comme fi c'étoit un limaçon à moitić, métamorphofë? Cet inftinet nous indique toûjours combien les cruftacés font près des teftacés.!

Les uns \& les autres font privés de fang, comme

(*) Mrr. Linnaus les range parmi les infectes aptères, c'eft-àdire fans aîles. 
les infectes de terre; mais la tête, fi mobile dans les infectes, n'a aucun mouvement particulier dans les cruftacés, tenant immédiatcment au corps. Ils ont la propriété de fe redonner les membres qu'ils perdent par quelque accident que ce foit.

On commence à appercevoir une différence fenfibie entre les jambes antéricures, ou bras, \& les jambes de derrière. On fait que l'on appelle brasdans les écreviffes les deux groffes pattes ou pinces. C'eft par le moyen de ces bras que le Soldat fe eramponne fur le fable ou aux corps voifins, \& en repliant fon corps, il fait avancer fa coquilie à la rampe de laquelle il fe tient entortillé. Ce mouvement \& la manière dont il s'exécute font très analogues an mouvement progresfif de la moule de rivière. Les bras du foldat lui fervent encore à faifir les petits poifions \& les infectes dont il fait fa nourriture. Du refte il eft fi neuf fous cette forme d'écreviffe imparfaite, qu'il femble ignorer l'ufage de fes pieds.

L'animal cruftacé adhere à fon enveloppe, comme l'infecte à fon écaille, par un grand nombre de muscles répandus fur toute la furface interne, au lieu que l'animal teftacé n'eft attaché à fa coquille que par un, deux, ou quatre mufeles.au plus.

Les écailles, les coquilles, les croutes font les os de ces animaux. Les coquilles ont un périofte qui les recouvre extérieurement \& fert à leur confervation \& à leur accroiffement. Elles naiffent \& croiffent avec l'infecte: elles font partie de lui-même: clles font avec lui le produit d'un même germe. Elles font auffi la fonction des os qui eft de fervir de bafe \& de foutien aux parties molles. Les infeetes marins \& terreftres ont donc des os à l'extérieur, comme les autres animaux en ont à l'intérieur. Dans les uns ils font recouverts de mufcles \& de chairs; dans les autres, ils recouvrent les mufcles \& les chairs.

Que veulent dire ces côtes deflinées fur quelques coquilles, \& travaillées en relief fur d’autres? Et ces longs piquans inegaux qui s'élevent fur certaines con- 
ques, les ourlins \&t les araignćes de mer; \&c. que lign fient ils? Scroient-ce les premiers traits du fquelette les animaux qui ront fuivre?

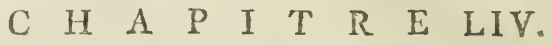

\section{Les Serpens.}

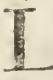

ES tuniques tendres \& fingiles des cruftacés préparent les écailles encore plus tendres desferpens. La propriété de changer tous les ans d'enveloppe, laquelle eft commune aux ferpens \& aux cruftacés, à l'exclufion de prefque tous les autres animatix, marque leur proximité dans l'échelle univerfelle des Etres. Les ferpens ne lunt-ils pas des crititacés?

Entiez dans un cabinet d'Hiftoire Naturelle. Confidérez attentivement la clafie des infectes cruftacés. Vous verrez les extrémités énormes de quelques efpe: ces diminuer graduellement dans les efpeces fuivantes, fe reflerter \& rentrer on ainfire dansle corps, jufqu'a s'effacer prefuue enticrement dans certains individus. Aldrovande \& Ruyfch nous connent les figures de que'ques cruftacés qu'ils mettent parmi les fquilles dont ils leur connent le nom, \&i qui n'ont ni cornes, ni pieds, ni aucunes parties firllantes. Le corps eft fort ong à proportion de fa groffeur. La diftunction de la quene d'avec la partic infërieure du corps, eft peu fenfible; ceile de la tête d'avec la partie fupericure du corps, l'eft un peu davantage. Ce lont comme des ferpens fous des croutes de fquililes.

Tandis que l'intérieur de lanimal fubit diffírentes altérations, la fubftance offeufe des croutes penétre en dedans du corps oì clle s'arrange fous une nouvelle forme qui n’eft pus tout- ̀̀-fait ćtrangère à celle qu'clle quitte: Le cafque \& les cornes font employ és à compofer les os de la tête, le crane, les michioires, ¿c. La cuirafte \& les tablettes de la queue fe rónlent iur- 
vanit leur longuetre, fe divifent \& fe façonnent en un très grand numbre de vertébres attachées bout à bout: Les fourreaux des pattes rentrés dans le corps vont s'unir aux vertebres do:fales, \& deviennent des côtes. Les croutes ainfi converties en os ne laiffent plus à l'extérieur, pour couvrir l'animal, que des lames de fubftance cornée, rettes de leur prenière forme.

Si mon plan ne me bornoit pas à des vues générales, j'entrerois ici dans l'énumération des différens ; apports du fquelette d'un ferpent avec le fquelette hulmain, qui prouvent combien ce modele en eft déja avancé. Il me fuffit d'y faire obferver une épine forméc d'une fuite de piéces emboittées les unes dans les autres, ces piéces percées de trous pour loger la moëlle, des arcs offeux attachés vers la partie lupéricure, \& faifant une caiffe deftinée à contenir les vifcères. Ce fond de ftructure fubfiftera deformais dans toutes les variations ultérieures, fe perfectionnera à chaque degré, \& recevra, dans l'homme, fa forme la plus élćgante.

\section{$\begin{array}{llllllllll}C & H & A & P & \text { I } & T & R & E & L V\end{array}$}

Serpent des Indes Orientales, appellé par les Portugais Cobra de Capelio, portant firr le dos un mafque ou une figure bumaine.

$\infty_{\mathrm{E}}$

EBA (*) donne la figure \& la defeription d'un Serpent des Indes Orientales qu'il confervoit dans fon cabinet fi riche en curiolités naturelles, lequel portc fur le dos une efpece de mafque ou de figure humaine avec un nez, une bouche \& des yeux, \& pour que le front \& le menton y foient indiqués, cette partie plus large en-haut qu'en-bas, femble imiter un ovale imparfait.

(*) Thef. Rerum Nat. Tom. II. p. ㄱ. Tab. XIIY. Fig. I. 
Les Portugais donnent à ce ferpent le nom de Cos bra de Capello; \& Scba le met au nombre des ferpens à lunettes, ce qui me fait croire que les lunettes, dont on charge le dos de tous les ferpens ainfi nommés, font des figures humaines commencées, où il n'y a encure que le nez \& les yeux de marqués.

\section{H A}

Réfexions fur les animaux qui n'ont point de membres, \& Jinr leur diffribution dans l'écbelle des Etres.

$\mathrm{O}^{2}$

N a du remarquel dans la progreffion des Etres, teile que nous arons pu la faifir \& la repréfenter, que la Nature, toutes les fois qu'elle veut donner une forme neuve aux extrémités, clle commence par lesfupprimer peu à peu, \& que, quand elle eft parvenue à les faire évanouir, clle produit quelques Etres intermédiaires qui n'en ont point. Aux plantes garnies de rucines \& de branches fuccedent les vers de terre \& d'eau qui n'ont point de membres; fuivent les infectes avec des pieds \& des ailles affez différens des ra-

- cines \&r des branches qu’ils remplacent. Les pieds difparoiffent dans la famille des conques pour fe reproduire avec un autre appareil dans les cancres. Les roici efracés de nnuveau dans les ferpens, parce qu'ils doivent prendre la figure de nageoires dans les poifions.

Si l'on cherche la raifon de ce phénomène, on le trouvera peut - ĉtre en obfervant ce qui fe paffe fous nos yeux dans la métamorphofe des chenilles. La différence eft grande de l'extérieur d'une chenille à celui d'un papilon. Dans l'animal qui rampe, le colps eft continu; dans l'infecte qui vole, le corps eft compofé de fegmens. Le premier a un grand nombre de jambes courtes, des mâchoires, une filière; le fecond a de longues pattes, des aìles, une trompe. Auffi faut-il, pour la transformation de ces parties, 
que le petit animal paffe par un état mitoyen où il foit privé des unes \&t des autres: état qui eft véritablement le milieu dans lequel la Nature opire la métamorphofe. L'infeete devient chryfalide en fe défaifant de fa peau, de fes jambes, de fil filière, fans parler des parties internes; \& 11 ne fort de cet etat que, lorsqu'ayant perdu les organes de fon premier corps, il a acquis ceux du nouveau.

Pour comparer ce changement d'un individu particulier à la métamorphofe continuelle de l'Ltire univerfel, on dira qu'un ver, une conque, un ferpent, font comme autant de Chryfalides du prototype qui paffe de l'état de plante.à celui de fearabée, de l'ćtat de fearabcé à celui de cruftacé, \& de l'état de cruftacé à celui de poiffon.

La comparaifon eft fort imparfaite. La chryfalide ordinaire eft dans une inaction totale, ou peu s'en faut; clle ne prend aucun aliment; l'animal fouffie une efpece de long fommeil léthargique au fortir duquel if fe trouve tout différent de lui-même. Un ver, une conque, un ferpent ne font rien moins que des animaux endormis ou léthargiques: ils fe nourrisfent, ils croiflent, ils produifent leurs femblables. C'eft que les métamorphofes du prototype ne fe font point dans les individus particuliers, mais feulement dans leur modèle univerfel dont ils font des réalifations toutes transformées; de forte que cet état d'engourdiffement, où les facultés de l'anumal femblent cnchainées, n'eft point néceffaire pour revêtir le prototype de nouvelles enveloppes.

Cette différence \& les autres que je n'anligne pas, n'empêchent point que la chryfalide d'une chenille qui fe change en papillon, n'ait quelque analogie avec les reptiles apodes \& fans membres, femés de diftar? ce en diftance fur la chaine des Etres, entre les char. gemens les plus notables des formes faillantes. 


\section{SEPTIEME PARTIE.}

\section{$\begin{array}{lllllllll}C & H & \Lambda & \mathrm{P} & \mathrm{I} & \mathrm{T} & \mathrm{R} & \mathrm{E} & \text { LVII. }\end{array}$}

\section{Les Poifons. L'Opbidion.}

L y a des poiffons que leur reflemblance avec les ferpens a fait nommer ferpens marins. Tels font les congres \& les murènes. On y voit la naiffance des nageoires dans les deux fetits aîlerons, placés au deffous des mâchoires ou plus bas, \& dans la bande cartilagineufe ou molle, prolongée uniformément le long du dos, \& qui, dans certaines efpeces, entoure la queue \& remonte fort haut fous le ventre. On conçoit que cette nageoire continue peut fe di. vifer, \& les portions diverfes fe placer par paires, ou ifolées, fur les flanes, fur le dos ou fous le ventre, fe prolonger ou fe raccourcir, être molles, ou fe garnir de rayons cartilagineux, ofleux, épincux.

L'Ophidion de Pline \& d'autres Naturalintes conferve la nageoire étroite des murènes; mais il a le corps plus ramaffé, applatti \& s'élargiffant depuis la queue jufqu'au ventre, fe refierrant un peu vers la tête qui n'eft plus celle d'un ferpent, mais d'un poifion parfait.

(*) "Quelques perfonmes prétendent que les poiflons rampent " E ferpentent, fe fondant fur la force de ces mots hébreux "Schare's \& Rrines qui fignifient Reptile \& Serpent. On lit dans " la Genefe I. 20. Oue le's écux produifent en abondance (à la " lettre, fafient remper) des animaux vivans qui rompent. Et au "vf. 2 r. Dicu crda les grand's poiffons \& tous les antmaux yivens "qui rampent (en Hébreu Haromefeth) que les eaux firent $\mathbf{5}$ am" per felon leurs gentes.

"St. Ambroife Haxam. Lib. V. se'xprime ainfi : "Tout ce qui „nage tient de l'efpece $\mathbb{S}$ de la nature du reptile : car, quoiqu'en 

Plandise T.

$\mathrm{Cog}_{2}$

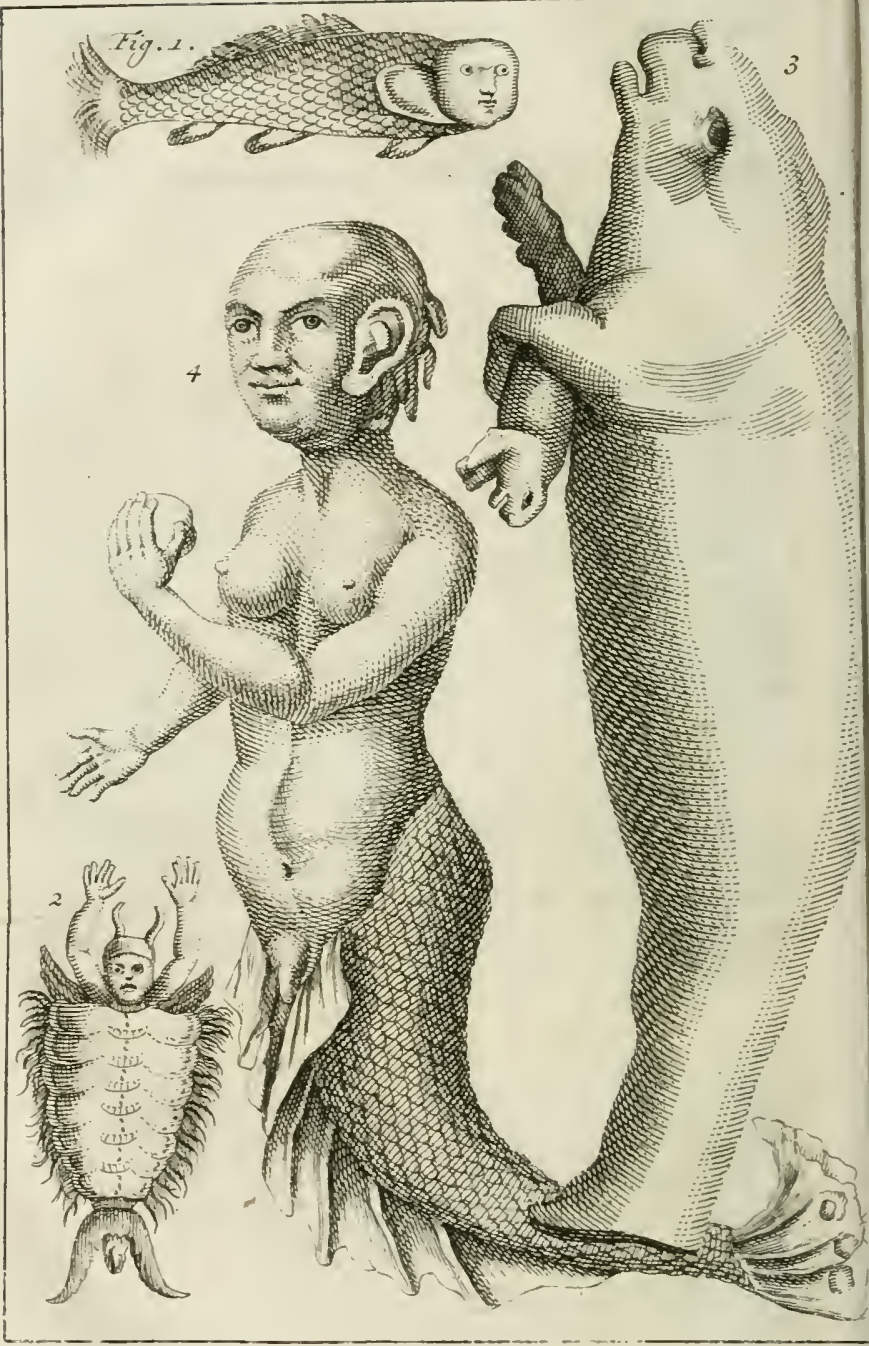




\section{P H L I O S O P H I Q U E S \&C.}

Les poiffons ont pour la plûpart des écailles qui ne diffërent pas beaucoup de celles des ferpens. L'ätion de nager a tant de rapport avec l'action de ramper, que des Auteurs, felon l'obfervation de Mr. Klein (**), foutiennent que les poifons rampent plûtôt qu'ils nc nagent.

\section{$\begin{array}{llllllllll}C & H & A & P & \text { I } & T & R & E & \text { LVIII. }\end{array}$}

Poiffons antbropomorpkes.

Carpe a figure bumaine. Cyprinus Anthropomorphos (Plancbe V. Fig. I.).

V

O I C I une production des plus fingulières \& dont la réalité eft conitatée par des autorités rcfpectables. C'eft un poiffon qui, par les nageoires, la queue, les écailles \& toute la partie inférieure du corps, reffemble parfaitement à une carpe, \& dont la tête ronde porte une face humaine où l'on diftingue les yeux, le ncz, la bouche, le menton: feulement les yeux paroiffent être plîtôt ceux d'un animal que d'un homme.

Rondelet parle d'une carpe femblable vivante, apportée fur le marché public de Lyon où elle fut vue de tout le peuple.

Gefner affure en avoir vu une pareille, prife en 1554. dans l'étang de Nozeret, que Gilbert Coufin a-

, plongeant il paroiffe fendre l'eau, cependant en remontant il „, rampe fur différentes furfaces d"eau: les Amphibies même qui ") ont des pieds \& qui marchent fur terre, ne marchent point, , mais nagent, lorfqu'ils font en pleine eau, \& $<$ leurs pieds ne , leur fervent point alors à faire des pas, mais ce font autant ", de rames dont ils s'aident pour ramper." Ces Autcurs penfent donc que c'eft parler plus jufte de dire que les poiffons rampent, que de dire qu'ils nagent. "Doutes ou Objeryations de $\Rightarrow$ Dr. Klicin sir la revue des animau.t "Ec."? 
cheta \& lui envoya après l'avoir gardce neuf jor rs vivante dans un vivier.

A l'occafion de cette carpe extraordinaire, le micme Naturalifte rapporte fur le témoignage d'un medecin \& d'un lurisconfulte, que l'on prit en 1545 . dans le lac de Conftance, un carpe à figure bunbine dont il donne la defeription en ces termes, telle qu'on da lui envora arec la figure. Faciem mon averfam, prout reliqui, vel obtufam, Jed repieflam, ab aliquo in planum alpectu tendente, cum temporibus utringue latis, oculis binis, ore, mandibula, ommia effigie bumana babuit. Pminis, lauammis, cauda, toto corpore poferiore, iplaqu? adeo magnitudine atque colore carpam pre je tubit. L'année fuivante, c'eit - à-dire en 1546. dit cncore Gefner, on rrefenta une carpe de lil même efpece à l'Empcreur Charles V. à A usbourg, comme une merveille digne d'un Empereur (*).

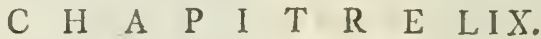

Poifon d'Amboine fort rare, nomme Anac Anac laoet jung terbongkocs, c'eft-d̀-dire l' Enfant de mer enmailioté (Planche V. Fig. 2. ).

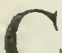

$U_{E}$ poiffon a véritablement la figure d'un enfant dans ion maillot. Ses deux mains jaunes portant chacune dinq doigts, font étendues en - haut. Les deux yeux, le nez, \& la bouche font peints en rouge; le defius de la tête \& le corps des deux côtés eft, d'un

(*) Voyez Aldrovande De Pifcibus Lib. V. Cap. XLI. \& R uyfch ce Pilcillns Tit. III. Cap. VII.

$(\dagger)$ Poiffons extraordinaires d'Amboine dans l'Hiftoire Générale des Voyages, Tome XTII. Edit. de Hollande.

(C) Peut-être le nomme-t - on ainfi, parce que la figure-humaine marquée fur la pierre qui s'engendre dans fon coips, re. prélente un veillard barbu tel qu'on peint St. Pierre. Il ne faut pas confondre ce poifion aree la dorée qu'on nomme auffi pois- 
verd céladon obfcur, feuilleté \& dentelé, ayant des raies rouges entre deux: le refte de la tête \& du corps jufqu'au bas a le fond jaune, fe ne partout de denilunes rouges \& bordées de points noirs. La queue eft comme la fleur du Pifang, ronde \& épaific vers ie corps, pointue en - bas, de coulcur rouge \& jaune. Il elt fort lure \& ne fe mange puint $(\dagger)$.

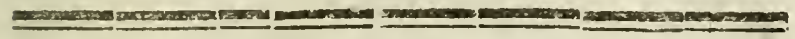

\section{$\begin{array}{llllllllll}C & H & A & P & I & T & R & E & L X .\end{array}$}

Poifon dans le corps duguel il s'engendre une pierre qui a la figisie d'une tête bumaine.

$\mathrm{O}$

N pếche fur les côtes de l'A mér:que un poiffon de la grandeur de notre merlu, qu'on nomme Poifjurn de st. Pierre $(\$)$, dans le corps duquel il s'engendre une pierre qui a la figure d'une rête' humaine.

11 fercit ingulier que les poiffons de cette efrece portafient tous une pierre ainfi figurée, \& qu'elle le formât par une coalition fortu'te de partics. Le ha- zard peut - il conner cunftanment des produits fi réguliers? faime mocux croire cette pierre le réfultat d'un germe développś, \& la figure d'une tête humai. ne qui y eft travaillee, un nouvel cfiai de la Nature qui a multiplié ces modeles à proportion de l'excellence du chcf d'œuvre qu'ils annoncent.

In America piscis deprebenditur, magnitudine Callarioe noftratis, d $S$. Petro nomen gerens, qui calculum fo-

fon de St. Pierre, \& qui a au milien du corps, une marque extérieure de la grandetir (¿゙ de la rondeur d'un denier. On lui a donné le non de poiffon de St. Pierre à caufe d'une pieufe tradition qui dit que cet Apdtre avoit pris un poiflon de cette efpece, par le commandement de Jefus-Chrift, \& avoit tiré de fa bouche une piéce de monnoie pour payer le tribut, $\&$ que St. Pierre, ayant mis cette piéce fur le corps du poiffon, l'em. preinte y eft reftés. 
vet effigie capitis bumani infgrnsm, didum Lapis pifcis $S$ : Petri Amsric onus (*)

\section{$\begin{array}{lllllllllll}C & H & A & P & I & T & R & E & L X & \end{array}$}

\section{Le Poiffon volant.}

I

Es nagcoires font aux poiffons ce que les aîles font aux oifeaux. A vec leurs aîles les oifeaux nagent dans l'air: avec leur's nagcoires les poiffons volent dans un élément plus denfe. Il y a des Phyficiens qui difent que l'eat n'ett qu'un air très denfe; \&z l'air une cau très rarcfiéc.

Mais les nageoires antérieures prolongées \& travaillées fur un plan approchant de celui des ailes, fervent à l'exocet à s'élancer dans l'air. Son vol, très-rapide, ne dure pas longtemps; fes ailes ne pouvant avoir de jeu qu'autant qu'elles font humeetées, \& les mouve-

(*) Alberti Seba I.ncuplet. Rerum Nat. Thef. Tom. II. p. I3o. (t) On lit dans l'lliftoirc Naturelle des Iles Antilles, ce qui fuit au fujet des Poiffons volans.

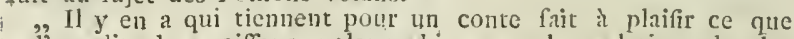
"lon dit des poiffons volans, bien que les relations de plu"fieurs faneux voyageurs on faffent foi. Mais, quelque opi9) nion qu'en puiffent avoir ceux qui ne veulent rien croire que 2) ce qu'ils ont vu, c'eft une vérité très conftante, qu'en navi"geant, des qu'on a paffé les Canaries, jufqu'd ce que l'on ap2) proche des Iles de.l'Amérique, on voit fortir touyent de la ") mer de grofies trouppes de poifions qui volent t̀ la hautenr os d'une pique \& prìs de cent pas lain; mais pas davantage, " parce que leurs aîles fe fechent an foleil. Ils font prefque 2, femblables aux harengs, mais ils ont la tête plus ronde, \& "2 ils font plus larges fuit le dos. Ils ont les ailes comme une ", chauve-fouris. qui commencent un peu au deffouș de la ") tête, \& sétendent prefque jufqu"à le queue. Il arrive fou"rent quils domment en volant contre les voiles des navires "\& qu'ils tombent meme en plein jour fur lo tillac. Cetix qui " en ont fait cuire \& qui en ont mangé, les trouvent fort déli" cats. Ce qui les oblige de quitter la mer qui eft leur élé"ment le plus ordinaire, eft qu'ils font pourfuivis par plufieurs 
mens violens qu'elles font pour voler les féchant bientôt, il eft obligé de replonger dans l'eau pour les humeeter $(t)$.

On compte pluficurs efpeces de poiflons volans qui ne different que par leurs ailles \& les couleurs de leur robe. Quelques uns n'ont que deux grandes ailes; d'autres en ont deux grandes \& deux petites: dans ces deux efpeces, les ailes font fortifieés d'efpace en efpace par des rayons offeux prolongés depuis la racine de l'aîle fous l'ouje jufqu'à fon extrêmité, \& recouverts d'une double membrane. Il y en a qui ont quatre aîles longues, étroites, unies \& fans arrêtes.

" grands poiffons qui en font curée. Pour efquiver leur rencontre, ils prennent une faufie route, faifant un bond en l'air, \& changeant leurs nageoires en ailes, pour éviter le danger; , mais ils trouvent des ennemis en l'air auff bien que dans les ", eaux. Car il y a de certains oifeaux marins, qui ne vivent "que de proic, lefquels leur font aufi tme cruelle guerre, \& " les prennent en volant. . .

"Il ne fera peut-être pas defagréable à ceux qui liront l'hi"ftoire de ces poiffons aîlés du nouveau monde, de nous y voir "ajouter pour enrichiffement les paroles de ce grand Poëte qui

2, daus fon Idyle hérö̈que nous témoigne qu'avec plaifir il a

"Vu mille fois fous les cercles brullans

2, Tomber comme des cieux de vrais poiflors volans:

"Qui courus dans les flots par des monftres avides,

"Et mettant leur refuge en leurs ailes timides

"Au fein du pill vogueur pleuvoięnt de tous còtés

Et jonchoient le tillac de leurs corps argentés.

Aujourd'hui on voit de cesfortes de poifons dans tous les a. vinets des Naturalifteș. 


\section{H U I T I E M E P A R T I E.}

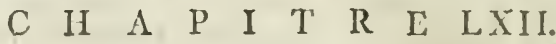

\section{Les Oiferux, ou Bipedes ailés.}

\section{9}

1 ANDIS que les mageoires antérieures achevent cie fe transtormer en ailes, les poftérieures, prenant une autre figure, deviennent des jambes avec des pieds palmés, c'ett-ì-vire dont les doigts font liés par une membrane; des piumes remplacent les écailles, le mufeau s'illonge, la matière des dents forme un bec, \& nous avons des vifeaux aquatiques, qui fe fervent de leurs picùs poul nager: le cygne, le canard, le cormoian, l'oie, la macreupe, la palette, \&c. nagent \& ne peuvent voler, foit par un défaut de force dans les mufles peotoraux, fuit à caufe d'un vice particulier de leurs ailes, ou peut-étre parce que ces piemiers oifeaux confervent fous leur enveloppe plumacée, les mœurs \& les inclinations du poiffon.

Les pieds perdent la membrane qui uniffoit les doigts, \&̇ les âlles acquièrent du reflort. Le pluvier, le hefon, le butor, le courlis, \& les autres de la même clafle ne nagent point. Cependant ils ont encore l'inftinct aquatique. Ils fréquentent le bord des rivières, \& les rivages de la mer, \& plongent dans l'eau avec une adrefle melreilleufe.

Tels font les degrés par lefquels l'Etre s'élève du fond des eaux qu'il a peuplées de toutes fortes de poillons en fubiflant diverfes métamorphofes, dans les plaines de l'air oui par des variations nouvelles il produit le peuple des vifeaux. Il orne les uns du plus riche plumage: il donne aux autres un ramage melodieux: quelques efpeces réunifient les deux avantages. 


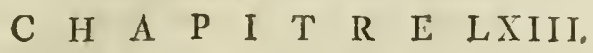

\section{L'Autrucbe.}

\section{I}

'AUTRUCHE eft remarquable par fes pieds de quadrupede, fes jambes couvertes d'écailles en tablettes; fes cuifies nues, fans écailles, fans poil \& fans plumes; fon corps couvert de plumes molles \& effilées, comme fi clles fe changeoient en poil; fes aîles armées d'ergots d'une fubftance cornée, lefquelles ne peuvent lui fervir à voler, mais feulement pour couril plus vîte; fes flancs nuds comme fes cuiffes; fon coul long \& velu, car le duret qui le couvre eft un poil fin, clair-femé \& luifant; la petiteffe de fa tête; la langue petite \& adhérente comme celle des poiffons. l'admire fur tout les yeux de l'autruche, prefque femblables à ceux de l'homme: ils font tirés en ovale, garnis de grands cils, \& la paupière fupérieure en eft mobilc.

\section{$\begin{array}{llllllllll}\text { C } & H & A & P & \text { I } & T & R & E & \text { LXIV. }\end{array}$}

La Chauve-fouris. La Rouffette. La Cbauve-fouris.

Q

UEL eft ce petit volatile hideux qui, vers le foir, fort de deffous le toit de ce château à de. mi-ruiné? Il n'ofe fe montrer pendant le jour. A-t-il honte de fa difformité. Sun vol eft gauche, incertain, inégal; fon cri cft aigre \& perçant. Son corps eft cou. vert de poil comme un quadrupede. Je lui croyois des aîles, \& je n'apperçois que des os montrueufement allongés, réunis par une membrane nue qui en F5 
s'attachant au corps enveloppe les jambes \& la queue. Il n'a point de nez: fes veux vont s'enfoncer dans les conques de fes oreilles: il a la gueule prodigicufement fendue, \& la tête furmontée de quatre oreillons. Ce monftre cit-il un oifeau défguré, ou un quadrupede informe? Ce n'eft point un quadrupeds: il n'a que deux pieds. Ce n'eft pas plus un oifeau que le poiffon volant. Il n'a que le vol de commun avec les oifeaux. La conformation intérieure du cour, des poumons \& des autres vifcères annonceroit un quadrupede. Il a même des rapports particuliers avec l'efpece humaine: le mâle a la verge pendante \& détachée, ce qui ne lui eft commun qu'avec le finge \& l'homme, la fémelle vivipare a deux mammelles fur la poitrine, dont elle allaite fes petits.

\section{La RoufJett,}

La Rouffette eft une efpece de chauve-fouvis, fuivant plufieurs Naturaliftes (*). Elle pourroit être une chauve fouris dégénérée, felon la conjecture de $\mathrm{Mr}$. de Buffon $(t)$. Seba $(\$)$ l'appelle un chien volant, feulement parce qu'elle elt plus grande \& qu'elle a la mureau plus allongé que la chauve-fouris: Cette différence n'eft pas la feule, ni la plus caractériftique. Elle en differe encore par le nombre \& la figure de fes dents incifives, \& par la partie inférieure du corps: la rouffette n'a point de queue, \& la membrane qui forme les aîles fe termine aux jambes de derrière, au lieu que dans la chauve-fouris cette membrane s'étend audelà des jambes pour envelopper la queue.

(*) Vefpertilio caudd nulld de Mr. Linnæus. Vespertilio Cynocephahus Ternatarius de Mr. Klein; $\mathcal{E}^{2} c$.

(t) Difcours fur la Dégénération des Animaux à la fin du Tome XIV. de l'Hift. Nat. Ec. Edit. in 4 to.

(\$) Canis yolans Ternatenus Orientelis. Albert. Scba Locuplet. Rerum Nat. Thef. Tom. I. 


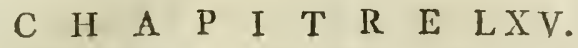

\section{Ecureuil volant. Singe volant. Chat volant.}

\section{l'Ecureuil volant.}

N compte plufieurs efpeces d'écureuils volans. Je parlerai du feul individu que j'ai vu. Il venoit de la Nouvelle Efpagne. Il n'avoit guère que la moitić de la grandeur de notre écureuil vulgaire. Sa queue étoit aufii longue que fon corps \& fa tête enfemble. Il avoit cinq doigts à chaque pied de devant \& de derrière; le pouce étoit féparé des quatre autres, \& tous les cinq étcient armés de petits ongles aigus \& recourbés. La peau des côtés prolongée \& attachée aux jambes de devant \& de derrière s'étendoit en forme de membrane très-molle, couverte d'un poil femblable à celui du. corps, feulement un peu plus ras. Le poil, rouflâtre par deffus le corps, blanchiffoit par deflous ou il étoit moins fourni. Quand il voloit, c'eft-à-dire quand il s'élançoit d'un lieu à l'autre, il déployoit la peau des côtés en étendant les pattes, fans leur donner aucun jeu qui imitât celui des aîles, Je l'ai vu s’élancer jusqu'à trente pas: peut-être cût-il fait un faut plus grand dans un cfpece moins bolné. Il voloit toûjours de haut en bas par une ligne oblique, \& jamais de bas en haut, ni horifontalement; mais il grimpoit avec beaucoup d'agilité. Ce que je lui ai trouvé de plus fingulier, ce font fes petites oreilles arrondies \& tour:nees comme celles du finge \& de l'homme.

\section{Singe volant.}

Helbigius \& d'autres Autcurs parlent d'une efpece de finge volant dont l'exiftence ne paroît pas bien conftatée. Ce fourroit bien n'être q̨u'un ćcurcuil rolant. 


\section{Cbat volent.}

Scba $\left({ }^{*}\right)$ donne la figure \& la defeription d'un animal dont toutes les excremités, les quatre pieds jusqu'aux ongles, la queue, \& la tête fe tiennent par le moyen du tiffu membraneux des ailles: c'eft une continuation de la peau du dos qui remonte jufqu'au cou, s'étend de chaque côté avec un contourdentelé, couvre les quarre pieds, \& va s'attacher à la queue. Sa tête paroît tenir du chat fauvage d'où lui vient le nom de chat volant. La femelle a des tettes grandes \& rondes, femblables aux mammelles d'tine femme.

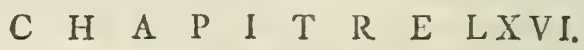

\section{Le Lezard volant, ou petit Dragon ailé.}

\section{T}

OICI un nouvel effai de quadrupede volant qui differe de tous ceux que nous avons vus jufqu'à prefent. C'eft un petit Lézard dont le deffus \& le desfous du corps font couverts de petites ćcailles très minces, ainfi que les pattes \& fa longue queue pointue. Il porte de chaque côté une aile cartilagineufe \& écailleufe comme le corps, dont la bafe s'etend de la cuiffe antérieure à celle de derrière fans adhérer à aucune des deux: au moins j'ai toûjours trouré les ailes ainfi détachées, avec les quatre cuiffes \& jambes libres dans trois efpeces diffèrentes que j'ai vus $(t)$. Ces aîles ont fix l'ayons, diminuant de grandeur vers le partie inferieure du corps, \& forment cing couplets. Le lézard volant d'Afrique, celui dont je parle, a fous

(*) Thef. Rer. Nac. T. I. Tab, LVIII. n. 2 Lt 3.

$F(\dagger)$ Cependant Seba donne la figure \& la defcription d'un Le. zard volant d'Amérique dont les ailes tenoient aux cuiffes des pattes de devani: celles de derriere avoint le joul libre. 
Ia machoire inférienre une. foche (ou un jabot) qui defeend jufqu'at cou vil elle s'attache Ceux d'Amérique n'en ont point. Cet animal ne vole pas reellement; il faute de branche en branche, \& d'un arbre à l'autre.

\section{C $\quad H \quad A \quad P \quad I \quad T \quad R \quad E$ LXVII.}

Objervation fur le pafjage des oifeaux aux Dua-

L diupedes.

nagcoire de poifron groffe patte d'écreviffe à une celle d'une aîle d'oileau à un pied de quadrupede. I a Nature nésntmoins, en transformant l'aile en pied s'affiranchit de la loi qu'clle avoit fuivie auparavant dans la métamorphofe des menbres un peu diffemblables, favoir de fupprimer ces extrémités dans quelques animaux intcrmćdiuires, avant que de les reprocuire fous une nouvelle forme (*).

Oferoit - on avancer qu'elle a brufqué ici la métamorphofe, \& rapporter à cette précipitation les produetions irrégulières dont nous avons vu que le paffage des oifeaux aux quadrupedes ćtoit rempli ? cet animal à moitié nud, \& à moitié convert d’écailles, de plumes \& de poil, cet oifeau énorme qui reflemble au chameau par les pieds, par la longucur de fon cou, \& la petiteffe de fa tête $(\dagger)$, \& dont la ftupidité annonce les élémens contraires dont il eft compofe? ce volatile fans plumes, beaucoup plus petit \& plus monftrueux, que la Nature a condamné á ne quitter fare-

(*) Voyez ci-devant Chapitre LVI. nelus. 


\section{4

traite que dans les ténèbres, comme fi elle eût prćtendu nous cacher fes erreurs?

Ses erreurs, ou fes caprices, quelque nom qu'on leur donne, tendent toûjours au même but. Ses productions les plus difformes \& les plus bizarres nous offrent des traits humains que nous n'avions apperçus dans aucun des animaux les plus parfaits felon nos idées: l'œil de l'autruche, l'oreille de l'Ecureuil volant, la verge pendante de la chauve-fouvis mâle, $\&$ les mammelles rondes du chat volant femelle.

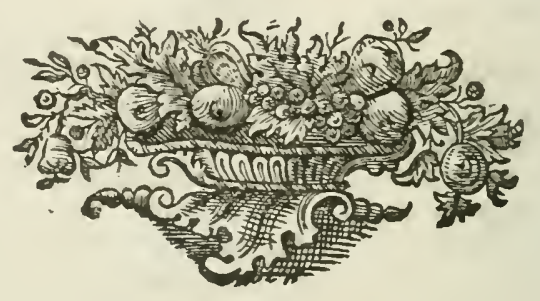




\title{
NEUVIEME PARTIE.
}

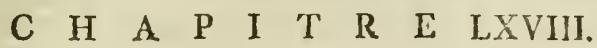

\author{
Les Céracies.
}

\section{Ie Renard marin.}

L

ES cétacées font de grands animaux marins qui ont le corps nud \& allongé, garni de membres charnus. Ils reffemblent beaucoup anx quadrupedes, quoiqu'ils foient, four la plûpart des efpeces de bimanes. Ils ont deux ventricules au cœur, refpirent par les poumons, s'accouplent $\&$ font leurs petits vivans. Les femelles qui les allaitent ont leurs mammelles placées au bas du ventre, ou fur la poitrine. Parmi ces animaux, les uns font amphibies, les autres ne font que plagiures. Ils n'ont pas tous des dents, mais jls ont tous fur la tête ou fur le mufeau un ou deux canaux pour rejetter l'eau. Entre ceux qui ont des dents, les uns, comme le marfouin, en ont auxdeux mâchoires. Le nar'whal n'en a qu'à la mâchoire fupéricure. Le cachalot n'en a qu'à la mâchoire inférieure. La balcine, qui n'a point de dents, a la mâchoire fupérieure garnie de chaque côté de lames de cornes qui s'ajuftent obliquement dans l'inférieure.

Le palfage des oifeaux aux cétacées eft rendu fenfible par le renard marin, dont les deux nageoires qui font auprès de la tête, repréfentent les aîles d'un oifeau plumé Ces aîles oflenfes \& charnues, très obtufes par les bords, femblent deftinées à former des dojgts dans les bimanes. (*).

(*) On trouve une defeription anatomique du renard mari! dans les Mémoires pour fervir à l'lliftoire des animaux. 


\section{II A P I T R L LIIX.}

\section{Les Bimanes.}

$\mathrm{E}$

NFIN les membres antéricurs de l'animal, après avoir revêtu \& quitté tour à tour tant de formes tingulières commencent à ćbaucher celle qu'ils doivent avoir dans l'homme. Il faut l'avouer, les premières mains font très groflières. Elles ont quelquefois jufqu'à fept \& huit dojgts: celles d'une efpece de baleine-cachalot en ont fept $(*)$, \& celles d'une efpece de diable-de-mer en ont huit $(\dagger)$. Sonvent clles n'en ont que quatre, comme dans le lamentin \& le finge de mer. Tantôt les dojgts font exceflivement courts, \& tantôt monitrueufement longs. Le poilton nommé l'Enfant de mer'enmailloté nous a pourtant fait voir deux petites mains plus régulières. Leur difformité dans les cétacées eft probablement une nécellité ou un avantage, eu égard à l'cxigence de leur's befoins; \& malgré les défauts de ces partucs envifagées comme des mains, on y entrevoit l'application de la Nature à les travailler, à en multiplier les eflais pour parvenir, à force de répétitions, à leur donner la jufte proportion qu'elles doivent avoir pour convenir au corps humain. Avant que de quitter le rivage de la mer, nous verrons fe promener fur fa furtace un animal à-moitié homme.

CHA-

(*) C'eft la Neuviéme efpece de baleine fuivant la divifion de Mr. Anderfon; \& la feconde clpece de Cachalot.

$(†)$ Celui dont parle Rochefort dans fon Hiftoire Naturelle \& inorale des Iles Antilles. 


\section{P II I O SOPHIQUES \&.c.}

\section{C $\begin{array}{llllllllll} & \text { H } & \text { P } & \text { I } & \text { T } & R & \text { E } & \text { LXX. }\end{array}$}

\section{La Baleine.}

I

L eft conftant que ia balcine eft bimane. Elle $\mathrm{a}_{2}$ au lieu de nageoires, des os articulés, figurés comme ceux de la main \& des doigts de l'homme, revêtus de mufeles \& de beaucoup de chair tendineufe, Er recouverts d'une peau affez épaiflé, fembiable à celle qui enveloppe le refte du corps. Cet énorme habitant des eaux falées, s'avance par le moyen de fa quene qui fait la fonetion d'une grande rame, \& ne fe fert de fes mains que pour tourner dans l'cau. La femelle, lorfqu'elle fuit, en fait auffi ufage pour emporter fes petits (*).

On apporta à Paris, il y a un peu plus d'un fiécie $(t)$ le iquelette d'une baleine propre à donner une idee de la grandeur de ces animaux marins. " Le " crâne avoit feize à dix-fept pieds d'ouverture, \& " quatorze pieds de longueur, pefant environ onze " cens livires; les nageoires qui reffembloient à des " mains, donze pieds de long, \& pefoient fix cens "livres; \& enfin les côtes, douze pieds \& demi de "longueur, \& chacune pefoit quatre-vingts livres."

Des mains de douze preds de longueur, garnies d’une quantité exceffive da chair \& de graiffe, penvent aifément paroître affez difformes \& monftrueufes pour être appellées des bras, des aîles, ou des nageoires. Leur figure véritable n'a pourtant pas échappé à ecux qui l'ont vue \& examinće de près.

land?

(*) Anderfon, Hiftoire Nat. d'Illande, \& Hift. Nat. de Groen$(t) \operatorname{En} 1653$ 


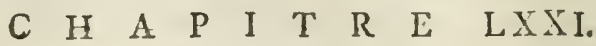

\section{Le Diable de mer.}

\section{$\mathrm{P}$}

LUSIEURS poiffons portent ce nom, parce que le peuple donne le nom de diable à tout ce outu a l'aspeet hideux un effrayant. Celui dont je veux parle: sci eft un cétacée de d uze pieds de long \& davantage. Quand il ouvre la gueule, il ćtale ume enorme quantité de dents qui garniffent fes deux mâchoires, fa langue \& le fond de fa gorge: c'eft tout ce qu'il a de diabolique. Outre quatre nagcoires, deux grardes latérales, \& deux plus petites, l'une fur le dos, \& l'autre près de l'anus, il a deux mains fous le ventre compofées chacune de cin a do:gts articulés.

On lit dans le Journal Encyclopéd que du $Y 5$ Jan. vier 1763 . une lettre au fujet d'un monftre marin échoué au fort de Kermorvan à quatre lienes de Breft; deux nageoires cn forme de mains placées à la partie antérieure de l'eftomac, lui firent donner le nom d'bomme de mer; ce n'ćtoit peut-être gu'un diable de mer.

Mr. Savary, Docteur en Médecine de la faculté de Paris, \& médecin de la marine à Breft, nous a donné la défeription d'un Diable de mer échoué dan - la rade de cette ville, qui n'avoit pas tout - à - fait cinq pieds. Je n'en rapporterai que ce qui regarde les mains.

"En renverfant ce poiffon, dit Mr. Savary, on פ" voit à un pied de diftance du rebord de la ma" choire inférieure deux autres petites nageoires, en " forme de mains, écartées l'une de l'autre d'environ "fix pouces. On pourroit les appeller nageoires ven"trales, quoique leur fituation reponde plûtôt au ", fond de la bouche qui eft énorme dans cet animal. , Elles font compofées chacune de cinq rayons carti- 
in lagineux femblab'es à cinq doigts; ce qui leur don$\Rightarrow$ ne beaucoup de reflemblance avec les mains ou les "pieds d'un homme: La peau qui les couvre eft "rougeâtre \& de couleur de chair, un peu rabo" teufe, \& même calleure; ce qui feroit croire qu'il is s'en fert pour s'appuyer contre les corps durs, \& " élever fa tête, ou peut-être pour fouiller \& creufer "I le fable dans lequel il s'enfonce \& fe cache pourten"dre fes piéges \& attraper fa proie (*)."

Mr. Savary croit que c'eft le Lopbius ore cirrofod'Artedi, \&t la défeription qu'il en fait cadre très-bien àvec ceile de ce Naturalifte. Sculement les rayons cartilagineux des mains font des oflelets, felon Artedi.

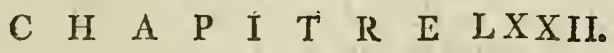

\section{Le Lion marin.}

¿ $\mathrm{N}_{\mathrm{N}}$ trouve dans, liIle de Juan Fernandez un פ, amphibie appellé Lion marin, qui reffemble un peu ig au veau marin, quoique beaucoup plus grand; nous "le mangions fous le nom de boeuf; \& comme c'eft פ, un animal tout - à - fait fingulier, je ne faurois me و difpenfer d'en donner ici la défcription.

"Les lions marins, quand ils ont toute leur taille, is peuvent avoir depuis douze jufqu'à vingt pieds de " long; \& en circonférence depuis huit pieds jufqu'a "quinze؛ ils font tellement gras qu'après avoir fait ", une incifion à la peau qui a environ un pouce d'é" paiffeur, on trouve au moins, un pied de graiffe э) avant que de parvenir à la chair ou aux os; 2 nous "times plus d'une fois l'expérience que la graiffe de ") quelques-uns des plus gros nous fourniffoit jufqu'à "2 cent-vingt - fix galons d'huile, ce qui revient à peu

(*) Journal de Médecine Tomc XXII. p. $5 \dot{\theta}^{\circ}$, , 
"prè à cing eurs Pintes mefuie de Paris. Ils font

, auffi fort fangruins, car, fi on leur faic de protondes

, bieflures dans une douzaine d'endroits, on verrt

, jaillir à l'inftane avec beaucoup de force, autant de

" tontaines de fang. Pour déterminel la quantité de

", leur fanç, nous en tuâmes d'abord un a coups de

$\because$ fufil; lui ayant enfuite coupé la gorge nous mefu-

"rames lc fang qu'il rendit, \& trouvâmes qu'outre

", celui qui reitoit encore dans les vaiffeaux \& qui

$\Rightarrow$ n'étoit pas peu de chofe, il en avoit rendu au moins

" deux barriques. Leur peau eft couverte d'un poil

- court, de couleur tannée claire; mais leur queue

- \& leurs nageoires qui leur fervent de pieds, quand

, ils font à terre, font noirâtres. Les extrémités de

\# leurs nageoires ne refiemblent pas mal à des doigts

"joints enfemble par une membranc. Mais cette "membrane ne s'étend pas jufqu'au bout des doigts "q qui font garnis chacun d'un ongle. Outre la gros"feur qui les diftingne des reaux marins, ils en dif"fèrent encore cn plufieurs chofes, \& furtout les , màles, qui ont une efpece de grofle trompe, qui " leur pend cu bout de la mâchoire fupérieure de la " longueur de cinq ou fix pouces; cette partic ne fe "trouve pas dans les femelles, ce qui les finit diftin. 9g guer des mâles au premicr coup d'œil, outre qu'el, les font beaucoup plus fetites.......

"Ces animaux font de vrais amplibies: ils pafiert tout l'été dans la mer \& tout l'hivel à terre; c'ct: alor's qu'ils travaillent à la génération, \& que les

, femeiles mettent bas. Leurs portíes fant de deux petits à la fois: ces animaux tettent \& font dès la , naillance de la grandeur d'un reau marin qui a " toute fa taille. Les lions marins, pendant tout le ", temps qu'ils font à terre, virent de l'herbe quicroit "fur les bords des caux courantes, \& le temps qu'ils , ne paiflent paś, ils l'emploient à dormil dans la "fange. Ils paroifient d'un naturel fort pefant $\& \tau$ "g font dificiles à réveiller, mais ils ont la précaution „ de placer des mâles en fintinelle autour de l'endroit 


\section{P II ILOS O PH I Q UES \&c. 10J}

"où ils dorment, \& ces fentinclles ont grand foin " de les éveiller dès qu'on approche feulement de la : horde. Ils font fort propres à donner l'allarme, " leurs cris étant fort bruyans, \& de tous fort difé"rens; tantôt ils grognent comme des pourceaux, \& "d'autres tois ils henniflent comme les chevaux les „o plus vigoureux. Ils fe battent fouvent enfemble, "furtout les mâles, \& le fujet ordinaire de leur's que"relles ce font les femelles. Nous fûmes un jour "furpris à la vue de deux de ces animaux qui nous "parurent d'une efpece toute nouvelle; mais en ap"grochant de plus près, nous trouvâmes que c'é"2 toient deux mâles, défigurés par les bleffures qu'ils "s s'ćtoient faitcs à coups de dents, \& par le fang dont „ ils étoient couverts.....

"Nous tuâmes quantité de ces animaux pour en manger la chair, \& furtout le cosur \& la langue, "que nous trouvions préférable à celle de bcuf. In , eft très facile de les tuer; car ils font prefque égaو lement incapables de fe défendre \& de s'enfuir; il "n'y a rien de plus lourd que ces animanx, \&, au. ") moindre mouvement qu'ils font, on voit leur graiffe " mollaffe flotter fous leur peau. Cependant il faut "fe donner de garde deleurs dents; car il arriva à un „, de nos malelots, dans le temps qu'il étoit tranquil"lement occupé à écorcher un jeune lion marin, que ;, la mère de cet animal fe jetta fur lui fans qu'il l'ap" perçût, \& lui prit la tête dans fa gueule. La morlure fut telle que le matelot en eut le crâne fracaffé en plus d'un endroit, \& quelques foins qu'on pût en prendre, il mourut pea de jours après (*)."

Telle eft la défcription du lion marin qu'on lit dans les voyages du Lord Anfon; mais fuivant la figure qu'on en voit dans le même livre, ces deux nageoires

(*) Voyage autour du Monde de George Anfon, p. Iro. Kolbe dans fa Défcription du Cap de Bonne-Efpérance, \& d'antres Au. teurs ont aufi parlé du Lion Marin.

\section{G 3}




\section{CONSIDERATION S}

qui lui fervent de pieds pour fe trainer quand il eft à terre, font des mains imparfaites, comme celles de la baleine \& des autres bimanes, avec cette différence que les doigts du ion marin font unis par une membrane jufịues vers la moitić de leur longueur, ce qu'on ne trouve pas genéralement dans tous les céta: cées à deux mains, mais dans quelques efpeces feu?ement.

La baleine, le diable de mer \& le Lion marin pourroient être appellés des bimanes eftropiés. Leurs mains font comme jointes immédiatement aux omoplates. 'Dans la buleine \& le diable de mer on ne voit ni l'humerus, ni l'avant-bras; la partic qui repond à ía main de l'homme fort immédiatement de la poitrinc. Les deux autres funt enfermées \& cachées danș le corps, fous la peau. Dans le lion marin une portion de l'arant-bras fe montre au dehors. Le bras fortira en entier dans les bimanes fuivans.

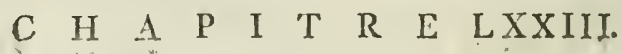

\section{Le Lamentin.}

L.

lamentin (Plancbe V. Fig. 3.) eft un des bi. manes qui mérite le mieux ce nom, quoiqu'en dife le P. I.abat qui n'a point vu cet animal, \& qui en a pris la figure dans l'Hiftoire Naturelle des Iles Antilles par Rochefort; \& cette figure, la même que je repete ici, fuffit pour combattre le fentiment de ce miffionnaire.

La Nature, fupprimant les nageoires, les cornes, \& la queue des auțres cétacées, a formé une maffe vivante de près de dix-huit pieds, qui n'a d'autres membres que deux bras courts \& ramafiés, auxquels font attuchées deux petites mains qui n'ont chacune que quatie doigts courts \& gonflés. Le lamentin a les yeux

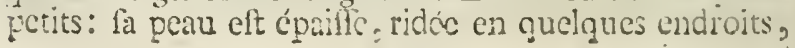


\& parfemée de quelques petits poils. Il a deux mammelles fur la poutrine, qui eft peut - être un caractère des cétacécs bimanes. Il s'accouple à la manière de l'homme. Ses bras font flexibles: la femelle s'en fert à tenir \& porter fes petits, à peu près comme lẹs tînges tiennent les leurs.

Mais, dit le P. Labat, comment a-t-on pu donner le nom de pieds ou de mains aux deux nageoires qu'il a un peu au deffous du cou, qui fe replient fous le ventre, \& dont quelques Auteurs prétendent qu'il fe fert pour fe traince fur la terre? Premièrement il s'en faut bien que ces prétendus pieds ou mains aient affez de force pour foutenir ou faire mouvoir un corps auffi psfant. En fecond licu, fuivant le rapoort d'tun très grand nombre de perlonnes, furtout des Flibuftiers qui n'ont fouvent d'autre reffource pour vive que la pêche du lamentin, \& des Indiens de l'Ifthène de Darien qui font lans contredit les meilleurs pêcheurs du monde, le lamentin ne vient jamais à terre; ainfi ce n'eft point un animal amphibie, ni un quadrupede, Ainfi parle le P. Labat,

Quoique le lamentin ne foit point un quadrupede; quand même il ne feroit point amphibic, cela empêche-t-il qu'on ne puiffe donner le nom de mains aux deux membres qu'il a aux deux côtés de la poitrine, fuffent-ils encore incapables de porter le poids du corps? C'eft la forme qui détermine leur nom; on y diftingue la main', l'avant-bras \& l'bumerus, Ces trois parties font raccourcies \& un peu monitrueufes, fil l'on veut; cependant elles ont du jeu \& de la flexibilité, ce qui les caractérife encore mieux (*).

(*) Mr. Klein (Difp. Qualr. p. 94.) après avoir comparé ce que les anciens \& les modernes ont dit du lamen in, après avoir réfuté furtout Clufius \& Artedi, donte fi cet animal a véritablement des mains, des afles, on des nageoires, \& conclut que l'hiftoire Naturelle, qu'on en a donnée jufqu'ici, eft très défcctueufe. Mr. de Buron le dit bimane dans fon Hiftoirs des finges. 
Mr. de la Condamine nous a donné la défcription \&x la figure d'un cétacée qu'ıl a lui-même defline d'après Nature (*). Les ESpignols \& les Portugais lui donnent le nom de Vacbe-marine, ou de Poifon-bourf. Ce favant Acidémicien croit que c'elt ie même qu'on nomme lamentin à Cayenne \& aux lles Françoiles de l'Amérique. Cette vache marine n'a que deux petites nageoires placées afféz près de la tête, \& qui lui fervent de bras \& de pieds. Je ne la crois pas le véritable lamentin. Mr. de la Condamine convient aufli que c"eft une efpece un peul différente; \& en effet on fait que les Efpagnols appellent le lamentin Manati, parce qu'il a des mains $(\dagger)$, \& non pas Vacbe marine.

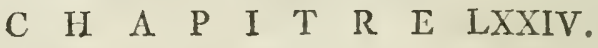

\section{Le Singe de mer Darois. Simia marina Danica.}<smiles>O</smiles>

${ }_{N}$ peut voir dans le Theatrum aniverfale omnium animalizun de lonfton publié par Ruyfch, la figure du linge de mer Danois, qui a deux mains, \& furtout deux bras unue l'on prendroit pour des bras humains, s'ils étoienc fur un autre corps. La forme de l'humerus, du coude, de l'avant-bras eft aufii parfaite que dans l'homme. La main n'a que quatre doigts, \& chaque duigt eft armé d’un petit ongle aigu.

(*) Relation de la rivière des Amazones.

(f) De Manati les Naturaliftes ont fait Manctus, nom Latin qu'ils domment au lamentin.

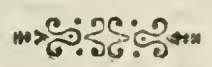




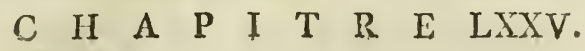

\section{L'Amlize.}

\section{I}

A MBIZE n'eft pas l'homme marin: il eft beaucoup plus grand, \& ne reffemble pas fi bien à l'homme terreftre. Suivant Dappcr (*), les ambifes fe trouvent dans les lacs d'Angola \& de Quibite. Ils ont pleinement huit pieds de longueur. Nicremberg dit qu'il y en a quelquefois de fi grands qu'ils pefent jusqu'à cinq cens livres. Ils ont deux bras fort courts, avec des mains qui peuvent fe courber un peu, mais qui ne fe ferment point comme celles de l'homme. Leurs doigts, qui ont une certaine longueur, font joints par une membrane. Ils ont les yeux petits, le riez plat, la bouche grande, fans apparence d'oreille \& de menton. Les parties naturelles du mâle reffemblent غ̀ celles du cheval. La femelle a deux mammelles bien formées fur la poitrine, mais qui ne paroiffent pas bien diftinguées l'une de l'autre, tandis qu'elle eft dans l'eau, parce que leur couleur' eft de gris-fané.

(*) Défcription de Ia IaTe Ethiopie.

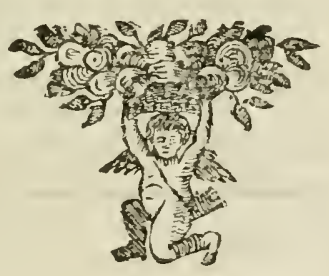

G 5 


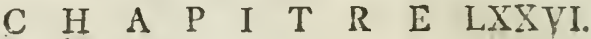

\section{L'Homine marin.}

N mes marin. 'Tant de témo gnages autentiques contatent l'exiltence des poiflons - hommes \& des poiftonsfemmes par la moitiz fupérieure du corps, qu'il y auroit plus que de "'opiniâtreté à cn douter. Voici ce que j'ai pu raliembler de plus avéré au fujet de ces hommes marins.

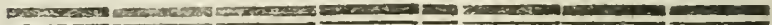

\section{II A P I T $\mathrm{R}$ E LXXVII.}

r

Homme marin pècbé d̀ Oxferd.

CARREY (*) rapporte qu'en II 8 ?. On pêcha à Oxford, dans le Duché de Suffolk, un homme marin qui le Gouverneur garda fix mois, deforte que chacun put le voir. Sa figure ctoit fi conforme à celle de l'homme, qu'il fembloit ne lui manquer que In paroic. Un jour s'étant échappé, il fe replongea dans la mer, \&i on ne le revit plus.

(*) IIfroire d'Angieterre. 
P H I L O S O P H I Q U E S \& rc. IO?

\section{H A P}

ESpece de Sirène fêcbée en WVelffrise.

N lit, dans les Délices de la Hollande, qu’en I 430 . après une furieufe tempête qui avoit lompu les digues \& donné paffage à la mer dans les prairies, des tilles d'Edam en Wefttrife, pafièrent en batteaux par Puxmerand pour aller traire des vaches, \& que l'eau s'étant retirée, elles apperçurent une femme marine dans la vafe. Elles l'emmenèrent à Edam où elle fe laiffa habiller \& ufa de nos alimens de pain \& de lait. On lui apprit à filer. On la mena à Harleni ; elle y vêcut quelques années fans pouvoir apprendre à parler, \& confervant toûjours un inftingt qui la conduiloit vers l'eau. D'où l'on peut conclure qu'elle fe feroit re. plongée dans la mer, ainfi que l'homme marin pêché à Oxiord, fi on ne l'eût gardée de près. Je me fouviens d'avoir vu de très anciennes figures de cette efpece de Néréide, dans lefquelles elle eit repréfencé filant, \& aflife fur fa queue de poiflon replićc fous elle $(t)$.

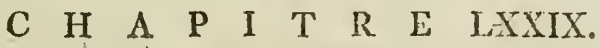

$L$

Sept bonmes marins \& neuffemmes mirins.

des péch T O R E générale des Voyages dit qu'en 1560 fur la côte occidentale de l'Ine de Ceylon, prirent d'un coup de filet fept hommes marins \& neuf femmes

(*) Defponde parle de cette femme marine dont il cft atrfi fait mention dans les E-tancrides des curieux de lit Nature. 
marines. Le médecin qui les examina avec foin, \& qui en fit l'anatomie, trouva toutes leurs partics intérieures \& extéricures très-conformes à celles de l'homme. Dimas l'ofquez de Valence, médecin du Viceroi de Goa, en fit l'ouverture en pretence de plufieurs Miffionnaires Jefuites, \& en particulier du Père Henriquez.

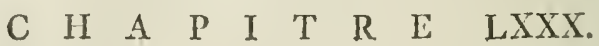

$\mathrm{U}$ Sirène d'une grande beauté. rlois de nation vit gleterre, une Syrène d'une grande beauté, qui ne le cédoit en rien aux plus belles femmes. Des cheveux d'un noir blcuâtre flottoient fur fes épaules; mais la partie inférieure, en commençant à la région ombilicale, refícmbloit à la queue d’un poiffon.

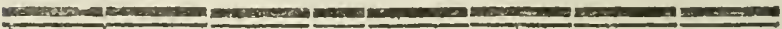

\section{$\begin{array}{llllllllll}C & H & A & P & I & T & R & E & \text { LXXXI. }\end{array}$}

\section{Témoignage de Monconys.}

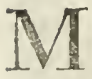

oNCONYS fait mention (*) de ceshommes marins femblables aux poiftons par la partie inférieure de leur corps, \& aux hommes par la partic fupérieure, à la referve des mains dont les doigts font unis cniemble par une membrane, comme les pieds des oies ou les aîies des chanves-fouris. Nous avons vu ectte forme dans quelques binanes.

(*) Dans fon Voyage d'Egyptc. 


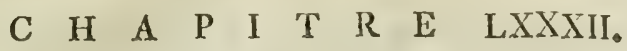

Cinq bornmes Marins, \& une femme marine.

$\mathrm{S}$ me marin. Sous l'Empereur Maurice, on vit dansle Nil un homme marin \& une femme marine qui fe laisfèrent voir pendant trois ou quatre heures hors de l'eau jufqu'au nombril.

En ${ }^{1526}$. on prit en Frife un homme marin qui avoit beaucoup de barbe \& de chercux. .

Un autre fût pris en 153 I. dans la Mer Baltique, \& envoyé à Sigismond, Rol de Pologne: il vêcut trois jours à fa Cour.

On en prit encore un autre jeune près de la Racca de Sintra $(*)$.

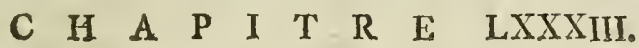

I

\section{Deux fesmmes marines.}

put en 1660. auprès du port de Coppenhague, une Syrène qui fut apperçue du rivage par plufieurs perfonnes dignes de foi $(t)$; quoiqu'elles ne fuffent pas d'accord fur la couleur de fes cheveux, toutes convinient qu'elle avoit le vifage d'un homme fans barbe \& la queue fourchue ( $\$$ ).

Lucas-Jacob Debes ( $\$ \Phi)$ dit qu'en I67\%o. fur la côte

(*) Dictionnaire des Animaux.

(t) Thomas Bartholin en parle.

(\$) Ephémerides des curieux de la Nature; Melanges d'Hiftoira Naturelle.

(S\$) Curiofités Naturelles obfervées dans les Illes de Féroé. 
méridionale de Suderoé, plufieurs habitans du village de Qualbié virent une temme murine. Elle refta pres de trois heures elevees au deflus de la furface de l'eau, tenant en fà main un poiflon qui avoit la tête en bas. Sa longue chevelure defeendoit jufqu'à la partie du corps qui étoit plongée dans la ner. On la voyoit à découvert jufqu'au nombril. Les habitans de Suderoe virent aufii ce monftre, \& Debes dit tenir ce fait d'un d'cux qui étoit a Coppenhague lorlquu'sl le lui saconta.

\section{C $\mathrm{H}^{\circ}$ A}

Poiffon-femme, appellé par les Espagnols Pecz-mumer.

\section{$\mathrm{R}$}

E D I parle d'un poifon, affez commun dans les mers du Bielil, que ies Efpagnols appellent Pece muger, parce qu'il a la face d'une femme. On dit que fes os ont la vertu d'arrêter toutc efpece d'hémorragie (*). Mais cette propricté n'eft pas aufli bien conltatée que l'exiftence du poiffon même dont nous allons donner une défcription plus détailléc d'après Ruyfih.

En certains temps de l'année, on pêche dans la mer des Indes Orientales, proche des Ifles Viffaies, yui font fous la domination des Elpagnols, un poifion anthropomorphe c'eft-à-dire poiffon à figure humaine, què les Efpagnols appellent Pece muger \& les étrangers. Duyon: Ii a la tère ronde, collée immédiatement fur les épaules, fans cou; fes oreilles, faites comme celles de l'homme, ont la conque tournée a peu près de la même façon, avec l'ouverture beaucouro plus grande. Ses yeux couverts de leurs paupières reftemblent pour

(*) Redi, Experimentr Naturalia, \&ce. 
Dlanche ri. Daqe 120.

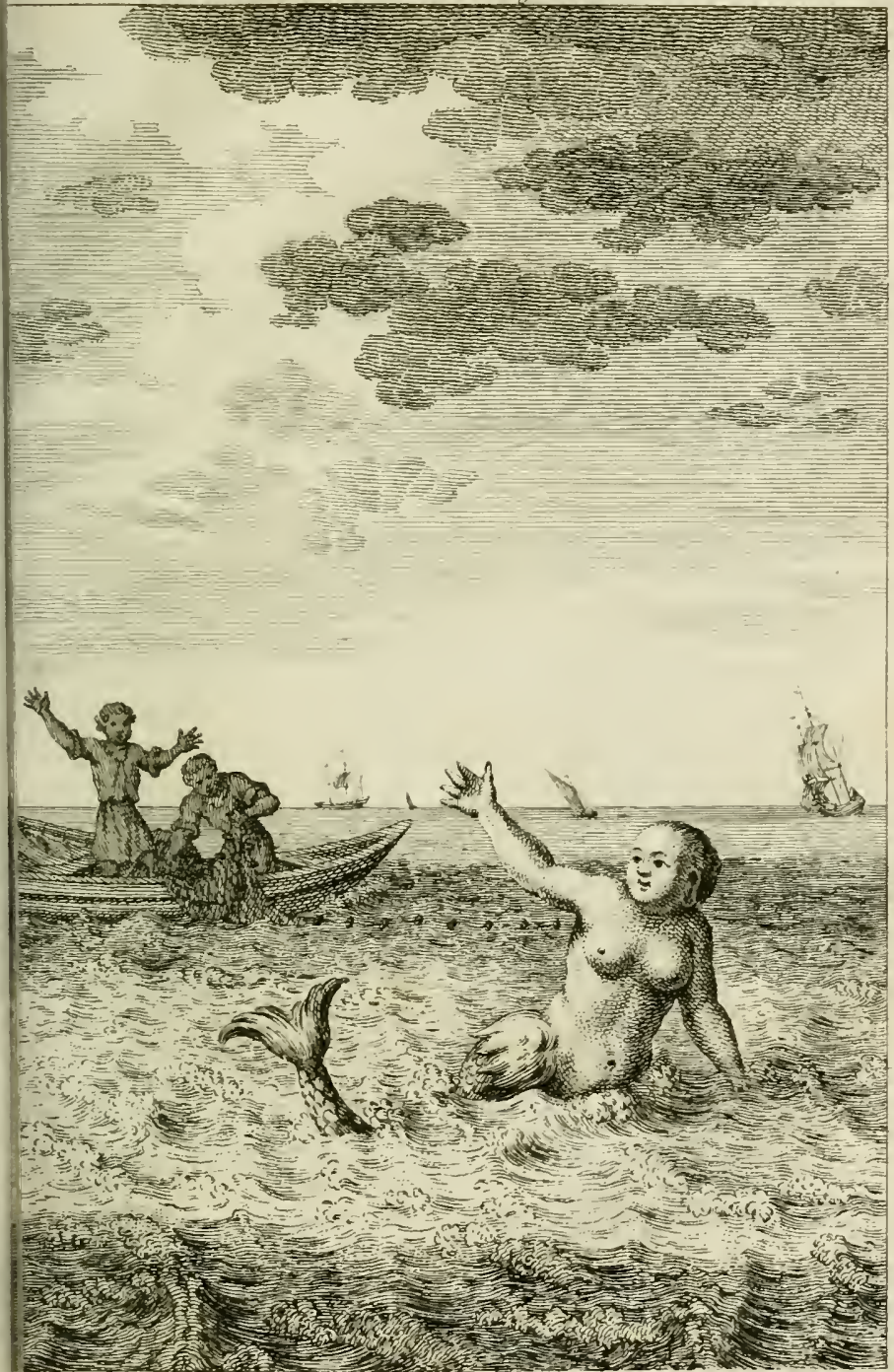

rischícy, del at jucto. 

la conleur \& pour la manicic dont ils font placés, non aux yeux d'un poiffon, mais à ceux d'un homme. Il a le nez plat, les levres comme les nôtres. Ses dents pleines \& très blanches fontrangées comme dans l'homme \& non comme dans les poiffons. Il a la poitrine large, blanche, délicate, les mammeiles rondes \& fermes comme les ont les vierges \& non pendantes comme les nourrices: elles font pleines d'un lait très blanc. Enfin fes bras font plus larges \& plus gros que longs, propres à nager, \& les coudes peu marqués: les mains portent de petits doigts pointus qui tiennent les uns aux autres par une menibrane (V oyez Plancbe $V I$.) Le mâle \& la femelle ont les parties fexuelles femblables à celles de l'homme \& de la femme; Le reite du corps finit en queue de poiffon. On ne fera pas fàché de trouver ici le paftage cntier rapporté par Ruyfch, que je viens de traduire en m'attachant plus à la figure qu'à la lettre:

Capitur certis anni temporibus in mari Orientail Indice ad Infulas Viffajas quas Infiulas Piclorum vocant, fub

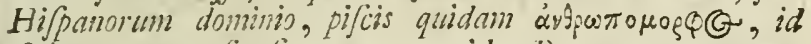
eft bumana prorfus figura, quam ideo Pece muger vocant, ab indigenis Duson. Caput babet rotundum, nulla co!li intercarpedine trunco conpactum. Fxtreme aurium fibie, que $E$ auricula noncinantur, ex cartilaginea carne ele. ganter vefita, quarum interior pars ampilifmis formato anfracibus, verun bominis refert culrem; oculos juis ornatos palpebris, fituque ô colon non pifcis fet bominis judicares; nafo won wibil aberrat: ma am inter utranques $120 n$ ufquequague enilint, fed levi tramite bipartitur; jub co vero labri magrnitudine jẹcieque noliris fimillima. Dentium 'non quales in int pifcium generi feriatilum, fed ple. norum \&E candidifjimorum continua feries. Pecilus alba cute cont.eilum, linc atque linc patild latius quam procorpore in maminas extuberans; neque eas ut feeminis pendiculas, fed quales virginibus globolas, plenas lactis candidefami. Bracbia non longa fed lata ad natandum apia. mullis tamen iffa cribtis, ulnis, manibus, articulisve dipincla. In adminifrris foboli pronagande membris in utitg. 
que fexu anlla ab bumanis diflinetio: polt bee in pifcem cauda definit (*).

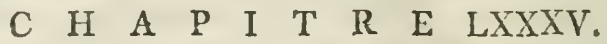

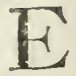

\section{Hlomme marin \& Femme marine defécbés.}

7755 on montroit a la foire Saint - Germain a Paris deux poiffons defféchés, l'un mâle l'autre femelle, qui refiembloient à un homme \& à une femme par lc haut du corps jufqu'à la ccinture, ayant la tête, le vifage, le fein \&r les mains femblables aux nôtres: ils fentoient la marcé. Celui qui les fáifoit voir les appelloit Triton \& Syrène.

\section{II A}

Defcription dime femme marine que l'cn voyoit wionte aे Paris $\mathrm{Cn} 17.58$.

Q

UELQUES années après $(t)$ on vit à la même foire une autre femme marine vivante quie l'on confervoit dans un grand baflin d'eau pleın d'cau où elle paroiffoit fe plaire beaucoup. Eille étoit vive \& agile. Elle avoit deux pieds de long. Elle plongeoit \& fautoit dans l'eau avec beaucoup de dexterité; lorsqu'elle étoit tranquille, fon attitude ordinaire étojt d'avoir le corps droit élevé fur la furface de l'cau jusqu'au deffous du fein. On lui donnoit du pain \& de petits

(*) Kircher. Art. Magnet, Lib. VI. p. 6\%5. Ruyfcl de Pifcibus Tit. III. Cap. I.

(t) En l'année 1758. 
jetits poiffons qu'elle mangeoit, fe fervant de fes mains pour les porter à fa boucha. Elle regardoit les lpeétateurs, les hommes furtout, avec une attention qui annonçoit la curiolité \&z le defii, \& qui ne pouvoit être que l'effet du pur inftinct. Elle avoit la peau rude au toucher, la tête ni:c à l'exception de quelques apparences écailleufes derric̀re la tête ver's la nuque, lcs oreilles longues \& larges, le vifage très laid, le cou épais \& honnêtement long, la main droite mal formée, aufli fe fervoit-elle plus ordinairement de la gauche, la poitrine large les mammelles grandes plcines \& arrondies. A l'égard du fexe, un clitoris fort gros fortoit de la vulve de la longueur d'un demipoucc. Elle avoit deux cfpeces de nagcoires aux ầnes, qui pouvoient fe fermer \& couvrir en fe fermant les parties fexuelles. Elle avoit la moitié inféricure du corps en quicue de poiflon couverte d'écailles. Une nageoire compofée de fix rayons defendoit en diminuant de grandeur \& d'épaificur depuis la vulve jusques vers l'extrémité de la queue. Cette quene fe terminoit d'une manière particulière qui, lorfyu'elle étoit ouverte ou épanouic, ne reffembloit pas mal au calice d'une fleur. Elle étoit formée d'une fẹule membrane de la même fubftance que les nageoires, \& attachéc fur dix rayons. Une moitié pouvoit s'abattre ful l'autre, \& cette queue ainfi fernée reflembloit à un double éventail. Six portions de la menubrane, favoir trois portions correlpondantes de chaque côté, po:toient une marque extérieure. La première du côté gauche étoit un point blanc furmonté d'un petit arc de même coulcur: Les deux autres étoicnt compofées chacune de deux ares blanes qui fe regardoient, $\&$ dont l'inférieur, c'eft-à-dire le plus éloigné du bord de la queuc, ćtoit plus petit que l'autre. Les trois taches du côte droit ctoient à peu près femblables. - Tcl étoit cet anmal fingulier. Mr. Gautier, fi connu par fes planches anatomiques colorées, le vit \&x le deflina dans le temps; c'eft d'après lon deflin que nous en donnons la tigure ( Plancbe V. Fig. 4.) 
Cette femme marine differe en plufieurs points de celle dont parle K : $*$ her; celle-là n'avoit point de cou; celle ci cn avoit un erais \& affez long L'une avoit une nageoire furchaque hanche $\&$ les hanches étoient ger) es \& bien marquées; l'autre avoit les hanches prefque cffacies, dcux nageoires ver's les aînes, \& une plus longue fous la queuc. La conformation des oreilles, des mains, du fexe, \& de l'extrémité de la queue différoir dans l'une \& dans l'autre, ainfi que le derrière de la tête qui portoit de petits cheveux dans la première, \&x des apparences écailleufes dans la feconde. lue corps n'aroit pas la même délicatelie de peau dans les deux.

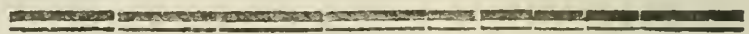

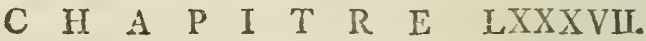

\section{M}

Homme mariin ou par Mr. Glower. ctions de la Virginie (*), dit qu’il y a reu de pays au znonde où il $y$ ait un li grand nombre de fleuves, que l'on y voit fouvent des monures marins, qu'il en a vu un qui parut comme il defcendort fur un de ces Heuves; que ce monftre avoit une figure humaine, avec la tête, les bras, l'air \& le vifage d'un Indien; que fon regard terrible jetta la terreur dans l'âme de tous ceux qui étoient dans fon batteau, jufqu'à ce que plongeant dans l'eau il fit voir a queue de poisIon qui étoit cachée, tandis qu'il fe tenoit debout, la tête \& la moitié du corps élevées âu-deffus des eaux.

(*) Tranfections Philofophiques, \& Journal des \$2vans 2n, $20-6$. 
CDlancke III. CPage 115.

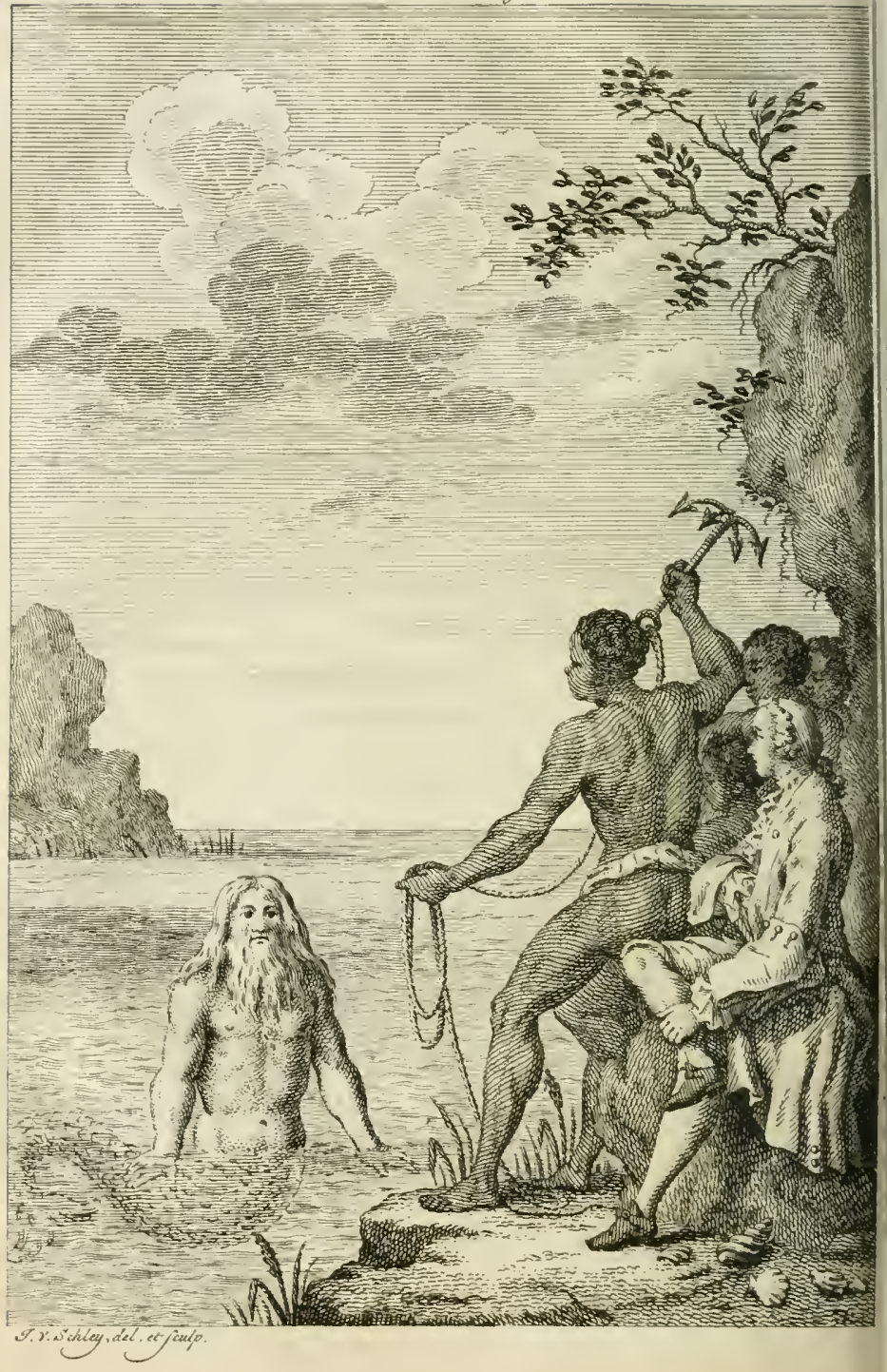




\section{C $\quad \begin{array}{lllllllll} & \mathrm{I} & \mathrm{A} & \mathrm{P} & \mathrm{I} & \mathrm{T} & \mathrm{R} & \mathrm{E} & \text { LXXXVIII: }\end{array}$}

Extrait d'une Lettre écrite de la Martinique, par Mr. Chretien, à un Licentié de Sorbonne, contenant la Relation d'un bomme marin qui a paru aux côtes de cette Jje le 23 de Mai I67 I. (Planche ViI.)

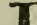

פ2 Le diamant eft un grand rocher fitué au fud de

on la Martinique \& fépare de l'Ine par un détroit d'u-

g, ne licue. Les rus des marées contraires qui cou-

go rent furieufement entre les pointes des montagnes

" voifines, le rendent prefque inacceffible. Les oi-

g, feaux s'y retirent comme dans un lieu ot̀ les dan, gers de la mer \& les précipiccs les rafiurent contre

פ, les courfes des chaffeurs. Il y en a en fi grande

"2 quantité qu'ils font comme de grands nuages au-

" deffus des batteaux qui en approchent; \& ceux qui

9, ont la hardieffe de monter au haut de ce rocher; rempliffent fouvent de grands canotsde petits, qu'ils prennent à la main, dins les trous \& dans les herbes d'alentour: de forte que la ftérilité dé ce defert produit, àvec une fécondité admirab c, le grand nombre d'oifeaux qui peuplent nos bois; \& qui font une partie de notre nourriture. Mr. le Général de Baas, ayant fagement remarqué que les habitans des côtes voifines enlevoient les œuf́s \& les petits, \& ruinoient la chaffe de l'Ille par ce pillage, a défendu à toutes fortes d'habitans d'aborder cette Ifle durant le temps que les oifeaux y couvent leurs petits: \& le Sieur de la Paire, Capitaine Commandant de ce quartier, a pris un foin particulier de faire obferver cette ordonnance fi utile au Public, jufqu'au 23 Mai, qu'il commanda un canot pour reconnoître la fécondité de ce petıt defert. Le Maí:

is tre du canot; s'étant acquitté de fa commiflion, retourna fur une pointe avancée de dix ou douze pas

H 2 


\section{6

„, dans la mer, élevíc ce huit ou dix pieds au defius

"2 de l'cau, ou un autre François \&x quatre Negres,

29 qui compofoient fon equipage, l'attendoient. Iis demeurçient fur cette pointe jưfiu'à une heure a, vant le foleil couchant (c'eft environ cinq heures

, \& un quart, à la fin de mai, dans les Illes), pour

", attendre que le vent d'eft, contraire à leur retour, s'abaiffât comme il a cotitume de faire tous les foirs.

,Ils fe divertifloient, lorfqu'un jeunc François cfirayé

g, fit un grand cri qui leur fit auffi-tôt tourner la tête de fon côté, pour apprendre le fujet de fa crainte; \& tous enfemble voyant en même temps un homme marin à huit pas d'eux, qui avoit la moitié du corps bors de l'eau, ils furent faifis d'un etonnement qui, partagcant leurs efprits entre la crainte

, \& l'admiration, Jes arrêtoit fans favoir s'jls devoient

2) fuir, ou confidćrel à loifir ce monftire. Il avoit la ,2 figure d'homme depuis la tête jufqu'à la ceinture,

" la taille petite telie qu'ont les cnfans de quinze ou

9, fcize ans; la tête proportionnce-au corps; les yeux

, un pell gros, mais fans difformité; le nez un peu

, large \& camus; le vifage large \& plein; fes cheveux

פ gris mêlés de blancs \& de noils étoient plats \& ar-

9 rangés comme s'ils euffent été peignćs, \& lui flot-

" toient fir le haut des épaules; une barbe grife, éga-

; lement large partout, lui pendoit fept ou huit fou-

$\Rightarrow$ ces fur l'eftomac qui étoit couvertede poil gris com-

"g me aux Vieillards, le vifage, le cou \& le refte du

„2 corps étoit médiocrement blanc; on n'a rien remar-

פ, qué de particulier au cou, aux bras, aux mains,

„2 aux doigts, ni au refte du corpsqui fortoit de l'cau,

"fi ce n'eft qu'il n'étoit pas couvert d'écailles, ou de э poil, \& qu'il paroifloit avoir la peau affez délicate.

"La partie inférieure depuis la ceinture, que l'on

", voyoit cntre deux eaux, étoit proportionnce au פ, refte du corps \& femblable à un poifion, \& elle fe g, terminoit par une queue large \& tourchue, conme is vous le voyez dans la figure ici jointe (Piancbe $V I J)$ „s L'étonncment que cettc vuc caufa d'abold aux 
"Francois \& aux Negres, ne leur permit pas de la bien diltinuruer la premic̀re fois; mais s"ćcant remis de ce premier trouble, \& le monttre s"etant montré "fur l'eau plufieurs fois, \& fort longtemps, ils eu"rent le loifir de remarquer diftinctement toutes les , parties dont il étoit compofé. Le plus jeune des "François, à qui les dangers continuels ont appris ì , ne rien craindre, fe tammliarifant peu à peu avec פ lui, l'appella en le fifflant, comme on appelie les , chiens. Un des Negres voulut jetter une grolie li"gne pour le prendre. Il fe montra la première fois à "2 huit pas du rocher. Il fe montra plus près la fe" conde fois, \& vint enfuite tout proche de la poin, te, où les François \&z les Negrès étoicnt aflis; \& \& פ puis fe retirant vers l'eft le long d'un herbage quí , eft au pied de ce rocher, il fe tourna plufieurs tois, 2, \& s'arrêta longtemps fur l'eat, comne s'il ê̂t pris g, plaifir à voir \& à être vu, fans s'effàroucher ni tć"moigner aucun ćtonnement; \& enlin il difparut au , commencement de la nuit.

2, Ce recit avant été fait premiérement à un Pere "Jefuite, qui faifoit mıfion dans les côtes du voifi"nige, où la mort de Mr. Rozel très-fervent Eccléפ fraftique, a laifté une Erlife de plus de mille per„2 fonnes fans pifteur; \& énfuite la même chofeayant " été rapportée au Sieur de la Paire Capitaine de ce grand Quarticr ; fa nouveauté la leur rendit fu"fpeete, \& les obligea d'en faire une information avec و toute l'exartitude que peut donner la crainte d'ĉtre "publiquement trompé. Ils prétendoient au com"mencement en détromper le peuple qui a toûjours $\Rightarrow$ trop d'inclination à croire les chofes extraordunai, res, \& qui peuvent felvir d'entretien; mais ayant ", vu que les témoins répondoient à cent queftions " qu'on leul faifoit, fans fe contredire, ils turent à "la fin obligés de croire ce recit comme veritable, "qu'ils n’avoient conlidéré d'abord que comme une " fable. Le Sieur de la Paire fit recevoir juridiquement "leurs dépolitions par un Notaire, en préfence des $\mathrm{H}_{3}$ 
, Officiers \& des Perfonnes les plus confidérables du

g quartier (*).

"Il feroit difficile de faire une recherche plus ri"goureufe. Un Religieux \& un Capitaine de méri, te, à qui plufieurs campagnes ont donné de l'ex"périence, y ont employé toute leur adreffe, en fé"parant les témoins les uns des autres, pour les in, terloger, en leur faifant des demandes conceltées ", entre eux pour les faire couper. Auffi Mr. le Gé* néral de Baas, a qui l'efprit, l'expérience, \& la " leeture donnent une merveilleure vivacité pour juger des chores, 11'a pas cru qu'on y dût rien ajou-

* ter pour la rendre plus autentique.

". Le témoignage de deux François eft confidéra"b.c , en ce qu'ils n'ont rien qui les oblige de faufler g, le ferment folemnel qu'ils ont fivit de dire la vérité. g Miais ce qui duit rendre, cette hiftoire encore plus 9, certaine, eft le témoignage de quatre Negrès qui, ¿ étant féparés les uns des autres, ont tous conttam"ment dépofé la même chore. Ceux qui connoiffent g, leur naiveté \& leur frupidité, jugeront aifément "qu'ils ne pourloient convenir dans le même témoi", gnage, s'ils n'avoient vu la même chofe; \& qu'ayant 9) affez peu de mémoire, il leur feroit impoffible d'ap-

g, prendre en fi feu de temps à feindre une fi longe g, hiftuire. De plus ce n'eft pas une vifion paffagère, g, \& d'un moment, ou confufe \& de nuit; ils ont vu و, ce monfre en plein jour, \& pendant une lieure; و, ils l'ont confidéré à loifir; ils s'en font entretenus, "g \& ont diftinctement remarqué toutes ces particula9, rités qu'ils ont dépofées. Ajoutez à cela que ce g n'eft pas le premier homme marin qui a paru .... \% $(t)$. Celui qui parut il y a quelques années aux 3, cûtes de Bretagne, proche de Belle-Inle, étoit tout

(*) On en trouvera le proces-verbal à la fat de cette Relation.

$(t)$ Ici Mr. Chrétien cite quclques-uns des hommes marars dont nous ąvons parlé ci-dellus. 
פg fembiable à celui qui s'eft fait yoir cette année dans "l’Amérique.

„On s'eft informé fi les bras étoient proportionnós " au corps, s'ils ćtoient plats, \& $x$ fi les doigts de la "main étoient attachés enfemble; s'ils avoient des aî", lerons, comme on a fouvent remarqué en ces for$\rightarrow$ tes de monftres, qui avec cela font plus propres à 9) nager. Mais les témoins n'ayant pas fait ces réэ) flexions, n'ont pu fatisfarre la curiolité de ceux qui эg les interrogeoient; ils ont tous affuré qu'ils l'avoient 32 oui fouffler du nez, \& qu'ils lui avoient vu paffer "g la main fur le vifage \& fur le nez, comme pours'es" fuyer \& fe moucher. II n'a frit aucun bruit de la "g bouche qui ait pu faire connoître s'il avoit de la 9) voix (*).

"Il eft croyable que ce monftre s'étant fouvent vu ", dans l'eau, comme dans un miroir, ou en ayant و vu d'autres femblables dans les mers, regardoit ceux פ, qui compofoient l'équipage du canot, avec un plai-" fir que la reffemblance fait naître. Les témoins lui פ, trouvèrent le vifage farouche; mais peut-être qu'un "refte de frayeur le leur faifoit paroitre plus fier qu'il " n'étoit en effet.

"On laiffe aux curieux à conjecturer fi c'eft un monftre, ou une efpece féconde; \& fuppofé que ce " foit un monftre de quelle manière il a pu être engendré. Nicolas Rimber rapporte que la famille " des Marinis en Efpagne eft venue d'un Triton \& "g d'une fille dont il eut la compagnie. Mais de favoir "2 s'il eft auffi femblable à l'homme dans les parties "intérieures que dans les traits du vifage, s'il peut "2 vivre \& engendrer dans l'eau; c'eft aux favans à " decider ces queftions, \& à nous à rapporter fidéle"ment ce que nous en avons appris $(t)$."

$\left(^{*}\right.$ Les hommes marins ont une forte de voix, ou de cris, \& fe plaignent, au rapport de quelques modernes: ce que les an. ziens, n'ont par ignoré, comme on le lir daps Pline.

$(t)$ Jourual des Savans Aanée 1672. 
Nous allons joindre à cette Relation la copie du Pro. cè-verbal qui en attefte la verité. Quoiqu'il toit déja rapporte dans d'autres ouvrages (*). Nous croyons qu'il efí clientiellement nécelfaire ici: c'eft pour yuuoi nous ne fuifons aucune difficulté de le repéter.

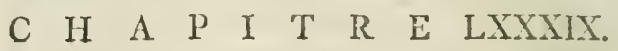

COPI I'un F'erbal fait is la Martinique de l'apparition d"unb bomme maring fir les bords de l'Ijle dis Diamant.

39

2)

99

93

95

92

49

25

99

ง)

99

99

97

5)

99

(2)

29

y9

(3)

29

9<smiles>C1=CCCCCC1</smiles>

Ejourd'hur 31. jour de Mai I67I. nous Pierre Lue Sieur De Lavaire, Capitaine commandant les quarciers du !iamant; fur l'avis qui nous a été donné par le Sicur le Gras, Enfeigne de notre Compi gnic. que les gens que nous avions envoyés à l'Ifle du Diamant auroient vu apparoitre \&x diftingué véritablement un monlite marin en figure c’homme, lequel fï leroit arrêté plutieurs fois auprès d'cux, \& regardé fixèment, ce qui les auroit obligés, n'ayant aucune arme, de fe rembarquer dans leur canot qui les aroit portés aux îfles du Diamant, pour reveqir à la grande anfe d'où ils étoient partis; ce qui nous auroit obligés de partir du quartier de la Rivière-Pilote pour nous rendre all quartier de la grande anfe du Diamant, auquel lieu étant arrivés, nous aurions rencontré le R. Pcre Julıen-Simon, trc̀s-digne Religieux de la Compagnie de jefus, pour tiarre la miftion ordinaire de temps en temps, lequel nous auroit aufli dit qu'il en avoit éte pareillement averti, \& qu'il teroit a propos d'en faire une exalte inquifition pour en favorl la pure $\&$ fincère vérité. "Four à quoi vaquer nous aurions appellé aupies

(*) Tellímed, ou Entretiens d'm Philofophe Indien fur le dimmution de la mer avec un Hilionnaire Frauçois. 
an de nous Me. Pierre de Beuille Notaire des quarticers " de notre Compagnie, \& le dit Sieur le Gras, \& en "prélence du R. P. Julien-Simon, après arvir fair venir Cyprien Poyer habitant au dit quartier, $\int 1+$ "lien Vattemar aufi habitant, André Negre du sieur "Dc:forges aufii habitant du quartice, Abraham Ne"gre du nommé Alexandre Defchamps, \& Pierre э Negre d'un nommé Noël le Moulle dit la Roziere, " tous enfemble étant ceux qui avoient vu la dice ap" parition, \& les ayant fóparément \& à part ouis, go d'eux pris ferment de dire vérité, ont dit,

\section{PREMIÉRE IIENT.}

" dit \& dépofé ce qui fuit: Qu'étant amrve le matin و aux Illes du Diamant fur les fept à huie heure du "matin, le famedi vingt-troifieme du mois prefint, " \& voulant s'en retourner fur le $\int$ sir $^{2}$, environ une " heure avant folcil couché, le temps, étant clar \& „ ferein, il auroit vu diftinctement un montite ma"rin ayant la figure d'homme depuis la tête jufqu'à " la ceinture, \& cepuis la ccinture jufues en-bas la "figure d'un poiffon, ternine par une queue foulפs chue femblable à celle d'une Carangue. Lit ayant "été interrogé des particularités, il a dépofé ce qui 9 fuit: la tête étoit femblable à celle d'un homme, " les yeux, la bouche de même, le nez, camus, le „ vifage large \& plein, la barbe grife mêlée de bian. "2 \& de noil', pendante d'environ fept à huit pouces و \& fort lirge, les cheveux gris, pendans fur l'extré") mité des épaules, \& fort plats, unis comme s'is ", avoient ćté peignés, la gorge \& le lefte du corps " médiocrement blancs, ou il n'a remarqué aucunes "9 particularités, la foitrine poilue à la façon des vicil" iards, la taille petite \& comme d"un jeune homme $\because 2$ de feiza à dix-fept ans: il s'eft montré trois firis; la g première, environ à huit pas du rocher; la feconde 27 environ à quatre pas; \& la troifiéme à tros pieds H 5 
${ }^{2}$ près d'ellx, fe tournant pour le regarder, quiétoit tout près dudit Inct, fortant moitie du cores hors de la mer, ayant la mine fière, portant la main plufieurs fois fur le nez \& fur le vifige comme pour s'effuyer; ce qui épouvanta le dit dépofant \& fes Compagnons, lequel n'ayant point d'armes, fe rembarqua apres avoir vu ledit monftre s'ecarter vers la Savane dudit Inlet, \& les regarüer dittinftement les uns apròs les autres; après quói il fe plongea en mer, fans qu'ils l'aient revu. C'eft tout ce que le dit Dépolant a dit fçavoir, \& a polé fa marque, déclarant ne favoir écrire ni figner ; de ce enquis fuivant l'ordonnance, après Lesture à lui faite, a perfifté: \& fur la minute eft appofée une croix, marque ordinaire du dit Cyprien Poyer.

\section{SECONDEMENT.}

, Julien Vattemar, âgé de äix-fept ans, a de92 pofé en préfence de fon père, ce qui fuit: Qu'étant "fur le dit Inet avec le dit Dépofant, il a vu un " monftre marin ayant la figule d'homme jufqu'à "moitić corps, le refte en façon de poiflon. Il n'a "pas diftingué la queue; la tête, le vifage, les joues, les mains, la poitrine n'ont rien de different de lá. "figure humaine; le nez étoit gros, la barbe gristatre, longue partout également; fe tenant non fort , loin de la terie: fes oreilles étoient fort larges. Le ") dit dépofant appella le monftre en fiffant, \&x difant , tais, tais, comme à un lbarbet, \& s'étant appro$\Rightarrow$ ché par trois fois, fe retira tournant fouvent la tête pour les regarder; \& quand il lui entroit de l'cau

, dans le nez, il la fouffloit, comme un chien qui ¿reniffle. Ce font tous les propos terus \& dont le dit dépofant s'eft fervi; \& tout vis-à ris la Savane alla ", au fond fans qu'il l'ait revu. C'eft tout ce que le ", dépolant a dit favoir, \& a mis lit marque en pré, fence de fon père, à qui il a fouvent fait la même " déclaration; \& fous la dépofition, à la minute eft 
P H L I O S O P II I Q U E S \&c. $\quad$ Iथ3

59 93 lien Vattemar, \& figné Vattemar.

\section{TROISIEMEMENT.}

29 ABRAHAm, Negre du dit Alexandre Defchamps, , d'environ dix-neuf ans, a depofé ce qui fuit: Qu'il و a vu un homme bâti comme un homme, la tête 2) groffe comme une Perfonne, les cheveux gris \& la "g barbe grife, large, \& le nez gros, la poitrine poilפ lue de poil gris, la queue large \& fendue comme و une caranguc. Il les regardoit entre deux yeux; g, le Dépofant voulut le prendre avec une ligne, ayant 29 pourtant bien peur, fe tenant fur les rochers pour 9 Je regarder. Il a reniffé comme une perfonne; il " a fait trois plongeons, \& ils ne l'ont plus vu, la 22 mer étant devenue trouble, ils ne l'ont point vu و depuis; c'eft la manière dont il a fait fa depofition; g, à quoi il 11 'a rien voulu changer.

\section{QUATRIEMEMENT:}

"ANDrÉ, Negre du Sieur Desforges, a dépofé ce - qui fuit: j'ai vu bĉte faite comme homme dans la g, mer; cheveux longs, épaules, un poil gris; barbe 2. ly gris, large comme main; par devant le corps g, tout de-méme comme lomme, le cou blanc, poil 2) gris fur le fein, la queue tout de même comme caو, rangue: ly veny trois fois fur l'eau, \& gardé nous 9) toûjours avec fes gris yeux; my teny mouche per 2) ly faire; autre Negre coury après ly pour prendre g, comme ligne, luy cacher dans la mel", \& puis pu g) voir lui.

\section{CINQUIEMENENT.}

9 Pierre, Negre du dit Noël le Moulle de la Roو, zière, a dépolé ce qui s"enfuit, \& dit: noi miré $\Rightarrow$ un homme en mer du Dianant, moi miré lui trois 
"fois; lui teny tête, bon vifige de ly comme mon-

"de; ly teny grand barbe gris, ly forty hors de

"l'eau, regarje nous. Je vaus moi prenáre lui dans

g, ains poul prendie lui, moi teny petit peur, non

29 pus grund, non; \& puis lui, \& puis lui cache : lui

9g buvent gardé nous, \&x puurtant lui teny queue

" comme poilion. Ce font les cermes du dit Dépo-

פg lant.

"Et Pierre, Negre du dit Sr. le Gras, âgé d'enviroll 22 ou 23 ans, a dépoté ḋ̀ dit: Moi miré bûte,

") lui teny yeux, teny barbe, teny mains, teny

פ, cpaulestout comme homme, teny cheveux \& bar-

,2 be grife, non pas blanc: moi non pas miré bien lui,

, paree que lui étoic dans l'yau, lui fembloit poui-

, tant poiflon, mol teny peur, autre dire, c'cit un

${ }^{2}$ ange monde; lui regarde pituteurs tois : lui allé con-

, tre Savanne, \& puis lui caché dans l'yau, \& moi

"non miré lui davantage: \& c'ét la manière de par-

"ler du dit Dépofant.

${ }_{92}$ Ce font lesdépofitions de tous ceux qui étoient g dans le dit Canot, qui ont perfilté plufieurs jours dans

"2 leur's dépoficions; favoir depuis le vingt-trois du dit و prefent mois jufques à ce jour.

"Fait à ia grande anfe du viamant le jour $\& x$ an „و que defius, en prélence des témoins ci-deflus fig2) nés. Ainfí figné fur la minute, Julien-Simon de la "Compagnie de Jefus, la Paire, le Gras, J. Galteau, "Alex. Barbier, Claude Barbe, Martin de J. N. Du2, puy, \& de Beuille ave paraphe, Greflier. "Collationné fur la minute par le Notaire Royal, 2, en cette llle de la Martinique loufligné, ayant celle "des plícèdens Notaires du quartier du Diamant \& "autres quartier's circonvoifins. Delivré ces préfen9 , tes à M. de II ruterive, au Diamant de ladite Ine, 32 Etude du dit Notaire foufligné, le 6 juin 1722 . Sig né 


\section{P H I L O S O P H I Q UES \&c. $\quad 225$}

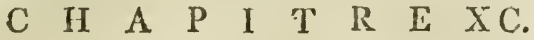

Honwne marin pêcbéen 1737 , près d' Exeter en Devonshire.

Extrait du Wonderfal Magazine for September 1764 .

$\mathrm{E}$

1737, des pîcheurs jettant leurs filets près d'Exeter, furent furpris en le retirant, d'en voir fortir une efpece d'animal à figure humaine qui refauta dans l'eau. aufi-tôt \& fe mit à nager. Les pêcheurs lui donnèrent la chaffe à force de rame; \& ne pouvant le prendre vif, ils lui portèrent plufieurs coups de perche, \& le prirent à-demi-mort: il foupiroit comme un homme. Ils avoit deux efpeces de pieds antérieurs, ou de mains, dont les doigts étoient unis enfemble par une membrane comme les pattes d'un canard. Du refie il avoit les yeux, le nez \& la bouche parfaitement reffemblants aे ceux de l'homme: feulement il avoit le nez écrafé \& aplatti. La partie inférieure de fon corps fe terminoit en une queue femblable à celle d'un faumon. La longueur de ce poiffon-homme étoit de quatre pieds deptis l'extrémité de la queue jufqu'au fommet de la tête.

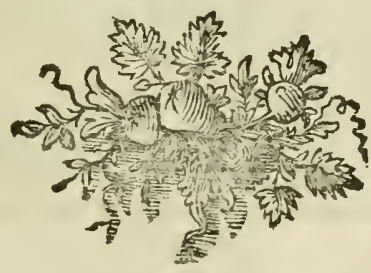




\section{H A P I T R E XCI.}

Extrait des Uialogues faits a l'imitation des Anciens par Oratus Tubero (Limotic-le.Vayer), au luget des bommes marins: Dialogue II. intitube, le Banquet Sceptique. Es Portugais ont tiouré anx Inites Orientales leur Pefcadomuger (*) î reflemblant à la femme, qu'ils lui en ont donné toutes les fonetions. C'eft le même poiflon avec lequel les Negres du Mozanmbique difent fe rafliaichir grandement, $c n$ en abufant même étant mort. Ce qui une fait encore douter

و qu'il pourroit être aufli le même qu'Agatarchides , appelle Fitbiops $(t)$, \& lequel au commencement 9 les pêclicurs ne vouloent ni vendre ni manger, à 9, caufe de fa forme \& reflemblance humaine A quoi les Syrènes \& Néréides des Anciens (t) femblent pouvoir êtrc rapportćcs; \& peut-ĉtle ce que $\mathrm{Ni}$ colo Conti nous contc, qu'en la rivièrc qui pafle à

"Cochin, il fe trouve des poiflons de forme fi lut9, maine, qu'étant pris, comme ils font fouvent, on 29 y remarque jufqu'à la difference du fexe aux mâles \& aux femelles, toute pareille à la nôtre; ajoutant qu'ils unt bien l'induftrie, lortant de l'cau la nuit, de tirer du feu des cailloux qu'ils trouvent, \& en alluiner du bois, à la lucur duquel ils prennent les autres poiffons qui accourent.

, Les Uros d'Acofta $(\S)$, qui habitent la grande „2 Lagune Titicaca, fe diloient n'être pas hommes,

(*) Poiffon-femme.

(t) Apud Photium.

(t) Plin. Hift. Na . Lib. TY. Cap. V. Ce pafiage eft rapportế en enticr dans le Chapitre ́nivant.

(\$) Liv. III. Chapitre Xlil. 
gg mais Uros feulement; \& à la vérité il nous les décrit, comme une différente efpece d'hommes aquag, tiques. Sur quoi je ne puis me tenir de vous ex9, pofer ici la penfée d'un des plus fublimes \& méta- phyfiques efprits de ce temps (*), qui s'ćtoit per" luadé que le genre humain étoit originaire de quel" ques Tritons ou femmes marines; foit qu'il cût "g égard à l'opinion de Thalès qui tenoit l'eau pour le $\Rightarrow$ feul élément de toutes chofes.

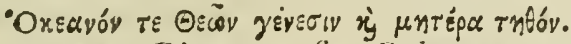
Oceanum Divum genefim L'etbymque parentem.

Homer.

و Soit qu'il regarde les cataclifmes \& déluges univer"fels, après lefquels ne reftant plus que les animaux " aquatiques, il crut que par fucceffion de temps, ils 3) fe faifoient amphibies, \& puis après terreftres tout" à fait: fon opinion fe trouvant auffi fort authorifée " de celle des ligyptiens dans Diodore de ficile, $(t)$, "g qui tenoient l'homme, iacuftre animal \& paludibus "cognatum."

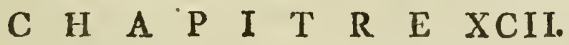

Extrait du netroieme Livre de Hifoire Noturelie is Pline.

\section{$\mathrm{E}$}

NFIN les anciens n'ont pas ignoré l'exiftence des hommes marins \& des femmes marines. Ce font leurs Tritons, leurs Syrènes, leurs Néréides, \& quoiqu'its aient mếlé beaucoup de fables à ce qu'ils en ont dit, le tout n'eft pas fans fondement.

(*) D. Polo,

(t) Lib. I. 
On lit dans Pline ce qui fuit: ,Du regne de l'Em2 preur Tibère, ceux de Lisbonne lui envoyèrent 2 des Ambalideurs exprès, pour l'averiir qu'en leur " côte de mer on avoit decouvert un Triton jouant "du cornec en une caverne, \& qu'il étoit tel qu'on "les depeint ordinair ment. Quant aux Néréides ou jyrenes, elles unt véritablement le colps tel qu'on es dépeint: hormis qu’elles font apres \& ćcaillées, ès parties eliguclles clles retirent à la ligure bumaine; car un en a vĩ en la même côte \&r plage; \& même les gens du pays en ont ouj plaindre une de loin lorfúculle mourut.

"D'ailleurs le Gouremeur des Gaules a certifié à l'Empereur Augufte par lettres expreflesqu'on avoit trouve fur la paage plufieurs Néréides mortes. Item, j'ai pour témoins pluficurs hommes d'armes Romains, gens d'honneur \& de crédit, qui m'ont af"f frrmé avoil vu en la côte d'Efpagne un homme "marin, ayant entiérement forme d'homme, \& di"givient qu'il fe jettoit de nuit dans les fuftes \& brigantins, \& qu'il étoit fi pefant \& fi actif qu'il les faifoit enfoncer la part où il étoit.

"Du temps de l'Empareur Tibère, ès côtes de Bre. tagne, la mer fe retirant laiffa fur lagreve, en une certaine Ine, plus de 300 bêtes marines, de grandeur \& variete admirables, \& on en trouva quafi autant ès côtes de Saintonge fur la Rochelle: entr'autres bêtes on y trouva des éléphans \& des bcliers qui avoient les cornes comme les terieltres, hormis qu'elles étoient blanches, \&r même y avoit plufieurs Néréides (*)."

$\mathrm{CHA}$.

(*) Traduction de Dupinet.

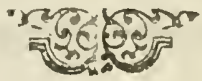




\section{$\begin{array}{llllllllll}C & H & A & P & I & T & R & E & \text { XCIII. }\end{array}$}

Homme marin \& femme marine vus dans le Nil en 592.

I

L s'en faut bien que j’aic épuifé toutes les relations des hommes marins \& des femmes marines. En voici encore quelques-unes auffi-bien conftatées que les précédentes.

9. En l'anncé 592. le I 8 du mois de Mars, un O "ficier d'une des villes du Delta, ou de la Bati"e"Egypte, fe promenant le foir avec quelques-uns de " fes amis fur les bords du Nil, ils apperçurent aflez " proche du rivage un homme marin fuivi de fa fe" melle, le mâle s'élevant fouvent fur l'eau jufícu'à "fes parties naturelles, \& la femelle feulement jus"qu'au nombril. L'homme avoit l'air féroce \& le „g regard affieux, les cheveux roux \& un peu héris. " fés, la peau brune; il étoir femblable à nous par " les parties que l'on appercevoit. Au contraire l'air g du vifage de la femme étoit doux; elle avoit les " cheveux longs, noirs \& flottans fur les épaules, le " corps blanc, les mammelles enflées. Ces deux mon"ftres reftèrent près de deux heures à portée de la "vuc de cet Officier, de fes amis, \& de tous ceux du " voifinage accourus au bruit d'un fait fi cxtraordi" naire. Ils parurent une heure avant le coucher du "foleil; \& il n'y eût que les ténèbres de la nuit qui "les dérobèrent aux yeux des fpeetateurs. On en " dreffa une atteftation fignée de l'Officier \& de plu; fieurs autres témoins; \& elle fut envoyée à l'Em" pereur Maurice qui régnoit alors à Conftantino9 ple (*).

La defcription de la femme marine s'accorde fort bien avec celle du Puce muger dont il a été parlé ci-deffus

(*) Telliaked, Tome II. 
(*): une figurc douce, un corps blanc, des mammelles laroges, pleines \& enflées. Seulement celle-ci avoit de longs cheveux noirs \& flottans fur ces ćpaules, comme celle que vit le Capitaine Schmide en I6I $4(t)$, au lieu que celle dont Redi, Kircher \& Ruyfch font mention les avoit plus courts.

Du refte ces deux poillons à figure humaine fe montrèrent une heure avant le coucher du folcil, ainfi que l'homme marin vu fur les bords de l'llle du Diamant.

\section{C $\quad$ H}

Homme marin ou par le Sr. Larcher, babitant du Fort-Royal.

J

'A JOUTER A I un fait notoire à la Martinique, \& poftérieur de plus de trente ans à celui de 167 I. que j'ai rapporté.

g Le Sr. Larcher, habitant du lieu, revenant un joul' au Fort-Royal de l'habitation qu'il avoit aux 9) trois Ifles, \& étant dans fon canot armé de huit "Negres, la têtc tournée à la mer d'un côté, \& les "Negres de l'autre, ceux-ci s'ćcrièrent tous à la 9 fois: Un Bequet d la mer; ce qui dans leur langage 9, fignifie, un bomme blanc à la mer. A ce cri, le Sr. "Larcher ayant tourné la tête ver's eux, n'apperçut "plus que le bouillonnement des flots à l'endroit où 9g le monftre avoit difparu. Les huit Negres atteftèפr rent feparément qu'ils avoient vu un homme tel g, que les blancs élevé fur la mer, de la ceinture en ", haut, \& les regardant; ajoutant qu'il s'étoit enfon-

(*) Chapitre LXXxiv.

(t) Vojez ci-dellus Chapitre LXX.Y. 
PII ILOSOPH I Q UES \&c. I3I

jo cé dans la mer au noment qu'ils avoient crié, thi "Brequet (*)."

\section{$\begin{array}{lllllllll}C & \text { H } & A & P & \text { I } & T & R & \mathrm{E} & \mathrm{XCV} \text {. }\end{array}$}

Une fenme \& the fille marines.

A tions au fujet des hommes \& des femmes aquatiques, on voit que, ,es exemples ne font pas aufil rares "qu'on pourroit fe l'jmaginer; \& s'il fe rencontre "de ces hommes marins dans les mers les plus fré"quentées, n'eft-il pas vraifemblable qu'ils doivent " fe rencontrer encore en plus grand nombre dans " celles qui baignent des côtes defertes? "On lit dans l'Hiftoire de Portugal \& dans les Relations des Indes Orientales, que s'étant fait un jour "I une pêche à la pointe de l'Inde d'une troupe de "Tritons, ou hommes marins, on ne put en faire " parvenir au Roi Dom-Emmanuel qui régnoit alors, "qu'une femme \& une fille, tous les autres au nom") bre de quinze étant morts, ou aufi-tôt après leur "fortie de la mer, ou dans le trajet des Indes à Lis"bonne. Cette femme \& cette fille étoient d'unc "g trifteffe extrême: rien ne pouvoit les rcjouir; \& el"les mangeoient fi peu qu'elles diminuoient à vue "d'œil. Le Roi touché de lcur état, \& peut-être و, pouffé d'un efprit de curiofité, ordonna qu'après les " avoir attachées d'une chaîne lègere, on leur lais. פ fàt la liberté de retourner à la mer dans quelque "9 endroit de peu de fond. On ne les eut pas plûtôt " mifes en ćtat de le faire, qu'elles s'y jettent avec " empreffement, \& que, s'y étant plongćes, elles jouè"2 rent enfemble, \& firent dans l'eau, où on les re-

(*) Telliamed, Tome Ii. 
99

39

?

93

99

99

93

$\because$

;9

29

99

Ainfi les favans de Harlem entreprirent inutilement de faire parler la Svrène prife en IV ettrite, laquelle conferva aufit un inftinct marqué pour l'eau, comme les deux dont on vient de parler.

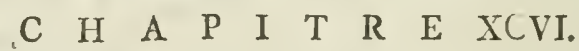

\section{Homme marin conduifant une petite, barque.}

" L E fait que je vais rapporter eft d'une autre es"pece, \& encore plus fingulier. Sur la fin du fiecle " dernier, un vailfeau Anglois de la ville de Hull, "ficuce à foixante milles de Londres fur la côte fep" tentriunale d'Angictcre, étant à la pêche de la ba" leine dans les mer's de Groenland, a cent cinquante " licues de terre, fe trouva environné vers le miäi פ, de foixante ou quatre-vingts petites barques, dans " chacune defquelles il y avoit un homme. On ne ., Jes cut pas plûtôt découvertes, que les chaloupes du "vaifleaufirent force de rames four en joindre quel"ques unes: mais ceux qui montoient ces barquettes, "qu'jls conduifoient avec deux petites rames. s'en " etant afpercus, \& voyant que les chaloupes les "gagnuient, plongèrent tous à la fois dans la mer avec

(*) Là-mème. 
„ lcurs barques, fans que de tout le jour il en reparut

"une feulc. Celle-ci revint fur l', au un inftant après,

"parce qu'en pioncesant une de fes ramess'étoit cafféc.

"A Arès quatre heures de chaffe, \& cent nouveaux

17 plongeons que faifoit la barquette à mefure que les

, chaloupes: approchoient, elle fut prife enfin avec ce-

"Iui qui la conduifoit. Un le mena à bord du vaiffeau,

"ou il vecut vingt ours, fans jamais avoir voulu pren-

" dre aucune nomriture, \& fans jetter aucun cri, ni

" pouffer aucun fơn qui pût donner à connoìtre qu'il

" cût l'ufige de lat parole, foupirant purtant fans

" cefle, \& les larmes coulant de fes yeux. Il étoir

"fait comme nous avec des cheveux \& une barbe as-

" lie I ngue; mais de la ceinture en bas fon corps

" cetoi tout comvert d"icailles.

,A l'eg rd 3e la barcnette elle avoit huit à neuf

, pids de hinueur, \& etoit fort ćtroite furtout aux extremites. les membres cn étrient d'os de poislin, julyu'au liege fur lequel l'homme étoit placé. E le étoit couverte en dedins \& en dehors de peaux de chien marin bien coufues les unes aux autres. Cette efpece d'embalage ćtoit ouvert au milieu de la grandeur nécelliure pour y introłure le rameur; \& cette ouverture ćtoit garnie d'une efpece de bourfe ou de lac de la miene peau, dont'homme introduit dans la b.i"que jufqu'a mi-corps le ceigno:t fi parfaitement avec des bundes auffi de peau de chien marin, que l'eau ne pouvoit y entrer Devant lui etoient deux morceaux de la même peau atcachés fur la couverture, où ils formoient deux efpeces de poches. Dans l'une on trouva des lignes \& des hameçons faits aunli d'os de poiffon; \& dans l'autre des poiflons qui paroiffoient avoir été pris depuis peu. A côté du rameur étoient deux petites rames, attachees au batteau ou panier par deux bandes taites auffi de peau de chicn marin. Tout cet attirail, avec l'homme defféché, fe voit encore aujourd'hui à Hull dans la falle de 1'Amirauté; \& le Procès-verbal de cette découverte, dûment atte. 
,g ftée par le Capitaine du vailleau \& par tout l'Luui, page, fe trouve dans les arehives de cette Jurisg diction."

Quoique la relation de eet homme marin ne dife point que la partie inféricure de fon corps fît terminée en queue de poilion, on peut raifonnablement le conjefturer d'après ces paroles, que de la ccinture en bas fon corps étoit tout couvert d'eccillies, lefquelles m'autorifent à lc mettre au nombre des bimanes, \& ù le croirc de la même efpece que le monftre vu fur les bords de l'llle du Diamant. J'avoue nćanmoins que fans cette circonitance, celle du procès-verbal, \& l'exiitence des piéces confervées encore aujourd'hui à Hull dans la falle de l'Amirauté, je ferois tenté de prendre cet homme marin pour un pêcheur, de ceux dont il ett parle dans l'Hiftoire Naturelle \& morale des liles Antilles, par le Sr. de Rochefort, dont nous allons donner un extrait. La forme \& la matière des batteaux de ces pêcheurs font abfolument les mêmes que. la forme \& la matjère de la barquette de cet homme marin; \& quant au grand éloignement de terre, on fait que ces pêcheurs font des courfes confidérables. l.a crainte den impofer au Leeteur dans la moindre chofe, \&x de mêler des récits faux ou douteux à des faits avérés m'oblige de tranferire ce qui fuit.

\section{$\begin{array}{lllllllll}C & H & A & P & I & T & R & E & \text { ICVIII. }\end{array}$}

Extrait de PHifloire Naturelle \& morale des Ijles Antilles, par le $S r$. de Rocbefort, Livre $I$. Cbapitre XVII.

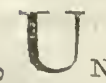

N Capitaine étant parti de Zclande fur la fin $\Rightarrow$ du printemps de l'an 1656 , en intention de décou" vrir quelque nouveau commerce dans les terres du. ¿Nord, arriva fur la fin du mois de Juin dans le Dó. 
कs

$\Rightarrow$

troit dz Davis, d'où étant entré dans une rivière qui commence au foixante quatriéme degré \& dix minutes de la Ligne en tirant vers le Nord, il fit voile jufques au feptante-deuxiéme....

"Des que les habitans du pays qui ćtoient à la pêche eurent apperçu le Navire, ils le vinrent reconnoitre avec leurs petits efquifs qui ne font faits que pour porter une feule perfonne. Les premiers, qui s'étoient mis en ce devoir, en attirèrent tant d'autres après eux, qu'ils compoferent en peu de temps une efcorte de foixante \& dix de ces petits vailicaux qui n'abandonnèrent point ce navire étranger, jusques à ce qu'ıl eût mouillé à la meilleure rade, où ils lui témoignèrent par leurs acclamations, $\&$ par tous les fignes de bienveillance, qu'on peut attendre d'une nation fi peu civilifée, la joie extraordinaire qu'ils avoient de fon arrivée. Ces petits vaisfeaux font li admirables, foit qu'ils foient confidérés en leur matière, foit qu'on ait égard à la mer. veilleufe induftrie dont ils font façonnés, ou à la dextérité incomparable avec laquelle ils font conduits, qu'ils méritent bien de tenir le premier rang: dans les deferiptions que cette agréable digreflion nous fournira.

„Ils font compolés de petits bois déliés, defquels la plûpart font fendus en deux comme des cercles. Ces bois font attachés les uns aux autres avec de fortes cordes qui font faites de boyaux de poiflons, qui les tiennent en arrêt, \& leur donnent la firure qu'ils doivent avoir, pour ĉtre propres aux ufages auxquels ils font deftinés. Ils font couverts en dehors de peaux de chien marin, qui font fi proplement coufues enfemble, \& fi foigneufement enduites de refine à l'endroit des coutures, que l'eau ne les peut aucunement pénétrer.

", Ces petits båteaux font ordinairement de la lon, gueur de quinze à feize pieds, \& ils peuvent avoir 9, par le milieu où ils ont plus de groffeur, environ cing pieds de circonférence. C'eft aufli dès cer enI. 4 
$\Rightarrow$ droit quils vont en diminuant, deforte que les cx. $\Rightarrow$ trémités aboutifient en pointes, qui font munics ", d'os blancs, ou de dépouilles de Licornes. Le des2) fus eft tout plat \& couvert de cuir de-même que le "refte, \&x le deflous a la forme du ventre d'un gros

", poifion: de forte qu'ils font trc̀s-propies à couler „ fur les caux. Ils n'ont qu'une feule ouverture qui \% eft directement au milieu de tout l'édifice. Elle eft , rélevée tout à l'entour d'un bord de côte de ba, leine, \& elle clt faite à proportion, \& de la gros"reur du corfs d'un homme. Quand les fauvages qui , Ont inventé cette forte de petits vaifieaux s'en veu", lent fervir, foit pour aller à la pêche, ou pour fe ", divertir fur la mer, ils paffent par cette ouverture 9) leurs jambes \& leurs cuifes, \& s'étant mis fur leur ", fíant, ils licnt fi ferrément la cafaque qui les couפ, vic avec le bord de cette ouverture, qu'ils femblent , être cntés fur cet efquif, \& ne faire qu'un colps 9, avec lui.

"Voilà pour ce qui conccrne la figure \& la matière , de ces petits vaiffeaux. Contidérons à-préfent l'é" quipage des hommes qui les gouvernent. Quand " iis ont deflein d'aller lur mer, ils fi couvrent par "g defius leurs autres habits d'une Calaque laquclle "n'cft deftince à aucun autre ufage. Cet habit de " mer eft compofé de pluficurs peaux, dénuées de , leur poil, qui font fi bien préparces \& unies enfemو. ble, qu'on le crojroit être fajt d'une feule piéce. Il $\because$ les couvre depuis le fommet de la tête jufuues au , deflous du nombril. Il eit enduit partout d'une g, gomme noirâtre, laquelle ue fe diffout point dans ,2, l'eau, \& quil l'empêche de percer. Le capuchon, פ, qui courre la tête ferre fi bien fous le cou \& fur le , front, qu'il ne leur laifie rien que la face à décou9 vert. Les manches font liées au poignet, \& le bas 2 de cette cafaque eft aufí attaché nu bord de l'ou, verture du vaificau, avec tant de foin, \& avec une g, tolle indultrie, que le corps qui elt ainfi convert, 9. fe trouve toûjours à fec au milieu des flots qui ne 

fage \& les mains.

9. Encore qu'ils n'aient ni voiles, ni mât, ni gou, vernail, ni compas, ni ancre, ni aucune des pié, ces de tout ce grand attirail qui eft requis pour , rendre nos navires capables d'aller fur la mer; ils entreprennent néanmoins de longs voyages, avec ces petits vaificaux fur lefquels ils femblent cetrecoufus. Ils fe comnoifient parfaitement bien aux étoiles, \& ils n'ont befoin d'autre guide pendant la nuit. Les rames, cont ils fe fervent, ont une largeur à chaque bout en forme de palette; \& afin qu'elles puifient couper plus aifément les flots, \& qu'clles faient de plus grande duréc, ils lesenrichisfent d'un os blanc qui couvre les extrémités du bois, ils en garnifient aufi les bords des palettes, \& ils y attachent cet ornement avec des chevilles de corne qui leur fervent au lieu de cious. Le milieu de ces rames, eft embelli d'os, ou de corme précicufe, demême que les bouts, \&x c'eft par-là qu'ils les tiennent de peur qu'clles ne leur coulent des mains. Au refte, ils manient ces doubles rames avec tant de dextćrité $\&$ de vitefle, que leurs petits vaiffeaux devancent aifément les Navires qui ont deployé toutes leur's voiles, \& qui ont le vent \& la marée favolrable. Ils font fi afturés dans ces petits efquifs, $\&$ ils ont une fi grande adreffe à les conduire, qu'ils leur font faire mille caracoles, pour donner du divertiffement à ceux qui les regardent. Ils s'efcriment aufi quelquefois contre les ondes avec tant de force \& d'agilité, qu'ils les font écumer, comme fi elles étoient agitées d'une rude tempête, \& pour lors on les prendroit plûtôt pour des monftres marins qui s'entrechoquent que pour des hommes. Et même pour montrer qu'ils ne redoutent point les dangers, \& qu'ils font en bonne intelligence avec cet élement qui les nourrit \& les carefle, ils font le moulinet, fe plongeans \& roulans en la mer, 
2) par trois fois confécutives, die furte qu'ils peuvent

, pafter pour de vrais amphibies.

"Quand ils ont defiein de faire quelques voyages , plus longs que les ordinaires, ou quand ils appré:, hendent d’être jettés bien avint en pleine mer par "quelque tempête, ils portent daus le vuide de leur "Valleau, une velfic pleine d'eau douce pour citan", cher leur foif, \&r du poifion feché au foleil ou à la "geléc, pour s'cn nourrir à faute de viandes fraîches, "Mais il arrive rarement qu'ils foient réduits à re, courir à ces provilions: car ils ont certaines fleches 2, en forme de petites lances qui font attacliecs fur "leurs bateaux \& lefyuelles ils favent darder fi vive" ment fur les poillons qu'ils rencontrent, qu'il n'ar"rive prefuue jamais qu'ils fojent fans ces rafrâichis"femens. Ils n'ont pas buloin de feu pour cuire leurs " viandes, parce que fur la mer \& fur la terre, ils "font accoûtumés à les mangel toutes crues; ils pol", tent aufli certaines dents de gtos poittons, ou des ", broches d'os fort pointues qui leur tiennent lieu de ") couteaux, car ils s"en fervent pour éventrer \& tran2 cher les poifons qu'ils ont pris. Au relte il ne peut ", point y avoir de debats dans ces vailfeaux, pais2, qu'un feul homme en eft le maitre, le matelot, le "pourvojeur, \& le pilote, qui le peut ariêter quand ") bon Íui femble, ou l'abandonner au gré du vent \& " de la maree, lorfqu'il veut prendre le repos qui lui "eft néceffaire pour réparer fes forces. Ln ce cas il 2, accroche la rame à des courroies de cuir de cerf qui 2) tont préparées à cet ufige, $\&$ qui font attachées par „, bandes au deffus de ce batteau; ou bien il la iie à "sue boucle laquelle pend au derant de fa cafaque." Si le récit du Chapitre précédent n'eit point une altération de celui-ci, la comparaifon de ces deux fuits rapproche l'homme marin de l'homme fauvage non foulement pour la figure extericure, mais, ce qui eft pius fingulier, pour l'induftrie, \& les mocurs. C'es hommes marins, vus à cent-cinquante lieues de terre, arvient ciu fourtant y conitruire !curs barquettes, \& 
prendre le bois néceflaire pour faire les rames dont ils fe fervoient. Il étoit encore néceffiare qu'ils raccommodaffent leurs petites barques dans les lieux ou ils les avoient conftruites: ils avoient par conféquent des connoiffances pour retourner dans ces mêmes lieux, foit qu'ils les tirafient de la difpofition desétoiles, comme les fauvages pécheur's dont nous venons de parler, ou du fond des mers fous lefquelles ils pouvoient refter, \&t où reut.être ils avoient leurs femelles \& lenr famille. Mais ces circonftances ne font pas de mon fujet aetuel (*).

\section{C $\quad$ H $\quad A \quad P \quad I \quad T \quad R \quad E$ XCVIII.}

Queiques animaux marins, de refpuce des cétacées, de la fois bimanes 80 bipodes.

Le veau marin: paffage des Cétacées aux Quadrupedes.

L

E veau marin marque le paffage des cétacées aux quadrupedes. Les autres cétacées, prefque tous bimares, ont la portion infërieure de leur corps terminée en queue de poiffon, c'eft même la forme des hommes marins \& des femmes marines. Dans le veau marin, cette queue partagée en deux parties égales \& digitées à leur extrêmité, eft ainfi transformée en deux pieds offeux \& charnus. La croupe eft même tout-àfait femblable à celle d'un quadrupede, les jambes font raccourcies, \& le pied' eft terminé parquatre doigts articulés, \& liés enfemble par une membrane ćpaiffe \& fouple. Les cuiffes \& les jambes allongées, ferrées $\&$ collées l'une contre l'autre, adhèrent enfemble \& la féparation ne commence qu'un peu au deffus des pieds:

(*) Voyez Telliamed, Tome II. 


\section{I40 CONSIDERATIONS:}

ce qui indique affez vifiblement que dans l'efpece fupérieure, elle formuient une queue de foiflon. Les bras cachés fous la peau ne 'aiffent voir que les mains qui n'ont, comme les pieds, que quatre doigts articulés. Ces mains ne font pas fi parfaites que celles de quelques-uns des cétacée dont nous avons fait mention ci-deflus; comme fi la Nature occupéc à travailler les pieds, avoit négligé les membres antérieurs. $\mathrm{Ce}$ pendant es doigts des mains font féparés, funs menlfirane qui les unifle enfemble, comme ceux des rieds. Cet animal n'a aucune apparence de nageoire; mais il porte une queue longue d'un peu plus d'un pouce, qui ne tient rien de la queue d'un poillon, mais fort femblable à celle d'un cerf. La peau dure \& épaiffe eft garnie d'un poil court très reflembiant à celui du vear terreftre. La tête a quelque reffemblance avec cclle du veiu fụtout par le mufeau. Cct animal eft amphibic.

\section{C $\begin{array}{lllllllllll} & \text { H } & \text { A } & \text { P } & \text { I } & \text { T } & \text { R } & \text { E } & \text { XCIX. }\end{array}$}

Ifpece particulière de Poiffon a pieds bumains.

\section{(T) \\ E trouve dans le fupplément à la Defeription de} 300 animaux, publiće en Anglois à Londres, il y a plufienrs années, la figure d'une efpece particulière de poiffion beaucoup plus homme par la partic inférieure de fon corps que par la partie fupérieure La grandeur \& la proportion du corps font celles d'un netit homme de quatre pieds \& deni : la peau eft blanche \& polie, fans poil ni écailles. La tête n'a rien d'humain: elle eft groffe portée fur un cou court, gonfé \& fortement mufclé. Les éfaules font chargées chacune d'une nagcoire épaife en forme d'aìle de Cherubin: les hanches ont auffi chacune une nageoire plus petite, dont les fommets ne font ni auffi marqués ni aufí élevés que ceux des, nageoires fupérieu- 


\section{PHILOSOPHIQUES \&c. 14I}

res. La queue auffi grande que tout le corps y compris la tête, reflemble à celle du Dauphin. Tout cela n'a prefque aucun rapport avec la figure humaine; mais immédiatement au deflous des petites nageoires, les hanches fe prolongent, prennent la forme de cuisfes, auxquelles font attachées deux petites jambes terminées chacune par un pied d'homme, aufii bien fait qu'il puiffe l'être, ayant un talon, \& une forme toutà-fait femblable à nos pieds, excepté qu'on n'y remarque à l'extérieur aucune apparence de doigts; mais ces doigts font cachés fous la peau, \& on les fent au toucher. Le fexe, tant du mâle que de la femelle, n'eft pas entiérement femblable à celui de l'homme \& de la femme, quoiqu'il en approche beaucoup. Le ventre \& la poitrine ont aufi quelque chofe d'humain dans l'un \& dans l'autre. Cet animal peut fe tenir élevé au-deffus de l'eau à mi-corps, comme les hommes marins \& les femmes marines dont nous avons fait mention; il eft aufli viviparc.

Voilà une efpece très particulière de triton \& de fyrène, qui nous offre un poiflon cnté fur la partie inférieure d'un homme, au lieu que les autres nous ont montré un homme enté fur la queue d'un poiflon.

La Nature n'eft pas parvenue tout d'un coup à cette grande perfection des pieds. Le poifton que les Anglois nomment Kingffone eft une ébauche du Mermaid, nom qu'ils donnent a la femelle du poifton à pieds humains. Le Kingftone a deux prolongemens offeux \& charnus au même endroit, c'eft-à-dire fous les na*. geoires inférieures; ce font deux efpeces de membres informes, à peu près de la même groffeur dans toute leur longueur, fans diftinction de cuiftes ni de jambes, \& furtouc fans apparence de picd, mais tcrminés cn pointe fort obtufe. 


\section{ONZIEME PARTIE.}

\section{$\begin{array}{llllllllll}C & H & A & P & I & T & R & E & C\end{array}$}

Des Quadrupedes. I. Les Solipedes.

$L_{\text {s }}$

Es quärupedes remplifent l'intervalle qu'il y a des bimanes aux quadrumanes. Les mains, que le prototype avoit acquifes par tant de changemens \& de métamorphofes, fe refierrent; les doigts s'unifent: la matière des ongles furabonde, fe dureit, s'étend, \& fe gonfle; ainfi ie forment le fabot \& le pied du Chevai. Sous cette enveloppe groffiere, l'anatomic a retrouvé les os du carpe \& du métacarpe; \& en remontant plus inaut clle a reconnu l'analogue du poignet de l'homme, puis le bras qui répond ì l'avant-bras humain, $\&$ entin l'humerus \& l'omoplate qui comporent l'épaule du cheval, \& répondent au bras \& à l'épaule de l'homme: le coude eft placé en arrière, comme dans l'homme. Les pieds antérieurs du cheval \& des autres folipedes font done les mains des bimanes altérees ou dégénérées, auxquelles on a donné le nom de pieds, parce que l'étrange altération qu'elles ont foufferte par le prolongement de certaines parties, le raccourcifement de quelques autres, \& furtout par l'union des doigts en un feul, \& le renflement exceflif de la fubltance des ongles, leur a fait perdre leur ancien ufage, deforte que dans cet état l'animal ne peut plus s'en ferrir qu'à marcher.

Les iambes de derrière du cheval comparées à celles de l'homme offient des fimilitudes aufi fiappantes. La fefle du cheval qui renferme le fémur, correfpond à la cuifie de l'homme; ce qu'on appelle la cuiffedans le cheral, faroir cette partie de la jambe de derrière, 
Ia première qui foit détaehée du corps, laquelle depuis ic bas des fefles jufqu'au jarret, correfpond à la jambe de l'homme, auffi clle a urie partic charnue qui eft l'analogue du gras de notre jambe, \& qu'on nomme pour cela le graffet. Le jarret eft la jointure qui eft au bas de la cuifie: cette articulation a rapport au coude-pied de l'homme, c'eft-à-dire au tarfe. La partic du jarret qui oft on arrière, \& que l'on appelle la pointe du jarret, eft proprement le talon: ce que l'on appelle vulgairement le gros nerf du jarret, qui fe termine à la pointe du jarret, eft un tendon qui correspond au tendon d'Aclillie, attaché au talon de l'homme. Au deflous du jarret on trouve le canon dont les os repréfentent ceux du metatarfe de l'homme.

Ce ne font pas-là les feules refemblances du fquelette du cheval avec celui de l'homme. Qu'on life l'excellente Defcription que Mr. Daubenton a faite de cet animal, \& dont j'ai extrait ce que je viens de dire, on y verra que le baifin y eft compore des mêmes osque celui de l'homme, feulement avec des proportions \& une fituation différentc qu'exigeoit l'attitude du cheval: par excmple, les os des lies ou des hanches font en avant, les os pubis en deffous, \& les os ifchions en arvière; on verra que la tête du cheval eft compoféc à peu près du même nombre d'os que celle de l'homme, que ces os fe correfpondent \& ont beaucoup de reffemblance par leur figure \& leur pofition dans l'un \& dans l'autre, quoiqu'il y ait de grandes différences dans leur's proportions, \& dans la figure totale qui réfulte de lcui allemblage; on fera frappé de la vérité des rapports \& de leur multitude, l'on s'étonnera que la première efpece des quadrupedes réuniffe déja tant de formes humaines; on remarquera „, dans les partics même qui contribuent le plus à la "2 varieté de la figrure exterieure, une prodigicufe res"femblance gui nous rappelle réceffairement l'idée "d"un premier deficin fur lequel tout femble avoir "été conçu: le corps du cheval, qui du premier coup "d'œil paroît lì different du corps de l'homme, lors- 


\section{I44 CONSIDERATIONS}

"qu'on vient à le comparer en détail \& partic par

„, partic, au lieu de furprendre par la difiérence, n'ć-

, tonne plus que par la reflemblancelingulière $\&$ pl'cs-

"q que complete qu'on y trouve: en ellet pienez le

"fquelette de l'homme, inclinez les os du ballin, ac-

, courciffez les os des cuilles, des jambes \& des bras,

" alongez ceux des picds \& des mains, foudez en-

"femble les phalanges, alongez les mâchoircs en rac-

, courciflant l'os frontal, \& enfin alongez aulí l'épine

"du dos, ce fquelette ceffera de repréfenter la dé-

"pouille d'un homme, \& fera le fuuelette d"un che

9 val; car on peut aifément fuppofer qu'en allongear,

") l'épine du dos \& les mîchoires, on augmente en

"même temps le nombre des vertebles, des côtes \&

"des dents, \& ce n'eft en effet que par le nombre de

, ces os qu'on peut regarder comme accefloires. \&

"par l'alongement, le raccourciflement ou la jontion

, des autres, que la charpente du corps de cet ani-

" mal differe de la charpente du corps humain. On

"vient de voir dans la defeription du cheval ces faits

"trop bien établis pour pouvoir en douter ; mais pour fuivre ces rapports encore plus loin, que l'on confidere feparément quelques parties eflentielles à la forme, les côtes, par exemple, on les trouvera dans tous les quadrupedes, dans les oifeaux, dans les poiffons, \& on en fuivra les veftiges jufque dans , la tortue, où elles paroiflent encore deflinée par les fillons qui font fous fon écaille; que l'on confidere, comme l'a r'emarqué Mr. Daubenton, que le

", picd d'un cheval, en apparence fi diflérent de lat

,g main de l'homme, cft cependant compoí des mê-

"mes os, \& que nous avous à l'extrémité de chacun

", de nos doigts le même oflelet en fer à cheval qui

", termine le pied de cet animal; \& l'on jugera fi cette

,reflemblance cachée n'eft pas plus mervcilleufe que

"les diftérences apparentes, fi cette conformité con-

,g tante \& ce deflein fuivi de l'homme aux quadru-

פ, pedes, des quadrupedes aux cétacés, dis cétacés

„2 aux oifeaux, des oifeaux aux reptiles, des reptiles 
9, aux poifons, \&c. dans lcfquels les parties efientici-

9) les, comme le cœur, les inteitins, l'épine du dos,

"Ics fens, \&c. Re trouvent toûjours, ne femblent pas

"Indiquer qu'en créant les animaux, l'Etre fuprême

" n'a voulu employer qu'une idée, \& la varier en

"même temps de toutes les manières pofîbles, afin

" que l'homme pût admirer également, \& la magni-

"ficence de l'exćcution \& la fimplicité du des.

$"$ fein (*)".

Paffons à de nouvelics variations de cet exemplaire original.

\section{$\begin{array}{llllllllll}C & \mathrm{H} & \mathrm{A} & \mathrm{P} & \mathrm{I} & \mathrm{T} & \mathrm{R} & \mathrm{E} & \mathrm{CI} & \end{array}$}

2. Des Qunadrupedes pieds-fourchus.

$\mathbf{L}$

A claffe des pieds-fourchus eft beaucoup plus nombreufe que celie des folipedes. Ceux-ci n'ont qu'un feul doigt: les pieds-fourchus en ont deux; mais la dernière plaalange de chacun de ces doigts eft encore enveloppée d'une matière de corne, comme dans les folipedes, deforte, par excmple, que le taureau a réellement deux fabots à chaque pied, quoiqu'on leur donne vulgairement le nom d'ongles, puifqu'ils renferment la dernière phalange de chaque dojgt, au lieu que les ongles véritables n'en couvrent que la partie fupérieure dans tous les animaux.

Dans quelques efpeces de pieds fourchus, comme dans le taureau, les ergots n'ont que deux offelets qui répondent à deux phalanges des doigts; mais dans le cerf, antre pied-fourchu, les ergots ont trois petits os attachés bout à bout comme les trois phalanges des doigts. Cette particularité indique les nuances par lefquelles la Nature transforme le pied-fourchu en

(*) Hiftoire naturelle de l'âne par Mr. de Bufiono 


\section{$1+46$

fifipede: car cet eroot articulé eft l'annonce d'un troifiéme doigt.

Le cochon eft une autre nuance du paffage des piedsfourchus aux fiflipedes, \& qui approche encore plus de ceux-ci que le cert. On l'a mis au rang des animaux à pied-fourchu, dit Mr. Daubenton (*), parce qu'il n'aà chaque pied que doux doigts qui touchent la terre, que la dernière phalange de chacun des dojgts eft enveloppée dans une fubftance de corne, \& que, fi l'on n'oblerve les pieds du cochon qu'à l'extéricur, ils paroiffont très rellemblans à ceux du taureau, du bélier, du bouc, \&c. mais dès qu'on a enlevé la peau, on les trouve très differens; car il y a quatre os cans le métacarpe \& dans le métatarfe; \& quatre do:gts dont chacun eft compofé de troi- phalanges bien fornées. Les deux doigts du milicu font plus longs que les autres, \& ont chacun un labot qui porte fur la terre: les deux autres font beaucoup plus courts, \& leur dernière phalange eft revêtue d'une corne pareille à celle des fabots, mais elle fe trouve placée plus haut à l'endroit où font les ergots des animaux de l'efpece du taureau, du belier, du bouc, \&cc. On peut dire que ce font deux doigts véritables, comn:e les autres, quoique plus imparfaits qu'cux.

Le cochon qui tient, aux pieds fourchus parla pofition des intettins, \& par les parties extérieures de la génération, s'cn éloigne pour fe rapprocher des fiffipedes par la forme des jambes, par l'habitude du corps, \& par le produit nombreux de la génération: car on fait que de tous les quadrupedes les fifipedes font ceux qui produifent le pius $(t)$.

(*) Defcription du Cochon,

(t) Hiftoire Naturelle du Cochon, par Mr. de Buffow. 


\section{$\begin{array}{llllllllll}C & H & A & P & \text { I } & \text { T } & R & \text { E } & \text { CII. }\end{array}$ \\ 3. Des Filipedes.}

Tes fiffipedes ont '́es pieds divifés en quatre ou cinq doigts, \& quelques-uns, même dans les plus petites efpeces, ont des mains très reffemblantes à celles de l'homme: telle eft la taupe \& d'autres. Les premières efpeces des fifipedes, comme le tigre, le lion, le léopard, le loup, le renard, \&c. font de véritables quadrupedes, en ce que leurs pieds antérieurs ne peuvent leur fervir de mains, quelle qu'en foit la forme; mais il y a aufi un grand nombre de fiffipedes, qui fe fervent de leurs pieds de devant comme de mains pour faifir \& porter à leur gucule: tels font les ours, les écureuils, les marmottes, les agoutis, \& pluficurs autres. Cette feconde claffe de fiflipedes, compore une fuite de quadrupedes ambigus qui conduit aux quadrumanes dont nous parlerons bientot.

Parmi ces fiflipedes, il faut encore diftinguer, ceux qui aiment à fe tenir le corps élevé, affis ou accroupis fur leurs feffes qui peuvent même, quoique plus difficilement ${ }_{5}$ fe tenir \& marcher fuî les deux pieds de derrière feulement. Ce font autant de nuances qui nous marquent les perfeetionnemens gradués de l'animal prototype. En fuivant ces gradations, on voit la Nature déformer le fquelette du folipede, redreffer peu-à-peu les os du baffin, alonger les os des crivifies, des jambes \& des bras, \& au contraire raccourcir ceux des pieds' \& des mains, divifer des piéces unies, articuler des piéces foudées enfemble, refferrer l'épine, fupprimer des vertebres $\&$ des côtes, \& le rapprocher ainfi graduellement de la charpente du corps humain.

Si dans les opérations la marche de la Nature nous paroit quelquefois incertaine \& mal-afiurée; s'il nous K 2 


\section{I48 CONSIDERATIONS}

femble qu'elle opere en tâtonnant, par une voie détournée, ambigue, c'cft une fauffe apparence qui ne vient que de notre ignorance $\&$ de nos préjugés, Nous oublions qu'elle ne doit \& ne peut laifler échapper aucune nuance, aucune variation $f \mathrm{n}$ s le réalifer: nous ne voyons point les différences trop fubtiles des formes contignis: nous faififons mal les rapports de celles qui funt plus éloignées: nous ne connoiflons point affez la génération cies formes pour juger de ce qu’il falloit piécifément pour en amener une particulière, \& de ce que celle-ci doit produire néccflairement \& immédiatement. Si nous ne voyons par pourquoi les mains des bimanes deviennent des pieds antérieurs dans les quadrupedes; pourquoi les doigts déja developpés \& divifés, fe refferrent, \& s'uniffent dans les folipedes, pour fe développer \& fe redivifer de nouveau dans les fiflipedes, pourquoi ils perdent leur ufage dans cette métamorphore pour le reprendre dans une autre; s'il nous 1emble-bizarre qu'à des bimanes fuccedent des quadrupedes, \& qu'à des quadrupedes fuccedent des quadrumanes; fi nous jugeons plus fimple que la Nature, ayant une fois atteint une forme, celle des mains par exemple, l'eût confervée dans tontes les efpeces fuivantes fans la déguifer, l'altérer, la déformer pour la rétablir enfuite arec de nouveaux fraix, gardons-nous de prononcer fur ces conjectures hazardées, vains phantômes de notre efprit, qui ne repréfentent point la réalité des chofes. La Nature ne fait rien d'inutile: fa marche eft nuancéc, \& chaque nuance eft néceffaire dans le plan total. Les formes que nous prenons fi mal-à-propos pour des irrégularités, des redondances, des inutilités, rentrent dans l'ordre infini des Etres, \& rempliffent une place qui feroit vuide fans elles. 


\section{PH I L O S O P H I Q U E \& \&. I49}

\section{DOUZIEME PARTIE.}

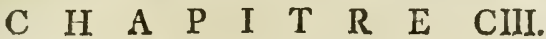

\section{Les Quadrumanes.}

\section{O}

Es T ici la dernière grande divifion des animaux, qui par des gradations très fines doit nous conduire jufqu'à l'homme. Les extrêmités des quatre membres des quadrumanes ont la forme de mains, d'où leur vient le nom qui leur a été donné par les modernes. Le gros doigt de pied qui répond à l'orteil dans l'homme eft très court \& fort éloigné des quatre autres doigts: c'eft un véritable pouce; \& les quatre autres doigts font aufi ceux d'une main plûtôt que d'un pied: outre qu'ils en ont la forme \& les proportions refpectives, la partic, qui répond à la plante du pied eft encore la paume d'une main allongée \& resferrée.

Les premiers quadrumanes, c'eft-à-dire les plus bas dans l'ćchelle, font ceux qui ont un mufeau mince $\&$. alongé, une queue aufli longue ou plus longue que le corps, les mahis, les loris, les fapujous, les fagoins, \&rc. A mefure que l'on remonte les échellons fupéricurs, cette longue queue fe raccourcit: ce n'eft qu'un petit bout de peau dans le magot, \& il n'y en a plus aucun veftige dans le gibbon ; le mufeau fe resferre aufli, \& la face s'applatit graduellement dans les efpeces de quadrumanes, à melure qu'elles s'élevent vers l'homme. Le farigue a le mufeau long \& poin$\mathrm{tu}$, le magot l'a plus large, \& relevé comme celui du dogue, le pitheque a la face plate.

Toutes ou prefque toutes les femelles des quadrumanes font fujettes à un écoulement périodique du

$$
\text { K } 3
$$




\section{:50 CONSIDERATION S}

fang, comme les femmes. Nous aurions déja du re. marquer plus haut que la chaleur des chiennes fe ma nifefte par un écoulement femblable.

La plûpart des quadrumanes peuvent marcher à quatre ou à deux mains, quoiqu'ils n’aient pas tous uuse égale aptitude pour ces façons de marcher. Il y en a qui ne peuvent fe tenir que difficilement fur leurs doux mains de derrière, deforte que le marcher à quatre niains femble leur être feu! naturel: obfervation confirméc par l'inclinaifon des os dubalin. D'autres paroiffent marcher plus aifément à quatre, quoiqu'ils puiffent aufit marcher à deux mains fans beaucoup de gêne. Quelques elpeces femblent marcher de l'une \& l'autre manière avec une égale fàcilité, \& une agilité femblable. Dans les efpeces les plus élevées les os du baflin redıeflés, \& les cuiffes alongées donnent à l'individu beaucoup plus d'aptitude à marcher à deux qu'à quatre mains. Enfin les quadrumanes les plus voifins de l'efpece humaine, ne marchent jamais que fur les mains de derrière, \& aufli droits que l'homme narche fur fes pieds: ce qui eft attefté par ceux qui ont vu des jockos \& des pitheques.

A ces remarques générales faifons fuccéder des détaiis plus particuliers en contemplant le plus parfait des quadrumanes.

(*) Voici, la defoription de cette jeune femelle de 'a pe:ite efjece, celle du grand mâle eft détaillée dans le texte.

Animalis rarioris, Chimpanfée dicti, ex Regno Angola Londinum advecti brevior delicriptio.

Spectandum in Tabula, quam hic aljecimus, Lectori noftro exhibetur miri \& valde tetrici adipectus, forme \& ftature humanam referentis, nacure ferocifime, animal, vix ulli civium noltrorum vifum unquam, auditum forte paucifimis. Patriam agnofeit Angolam, Africanum Regnum, a cujus incolis nomen Chimpanfée accepit. Ex illis oris allatum eft anni $1738 \mathrm{menfe}$ Auguito Londinum ab IIenrico Ilowero, Magiltro navis Specker dicte. Sexus eft freminei, altum pedes duos quatuor pollices, incedens corpore crecto, aliqua membrorum parte hirfutum, catera robuftum \& mufculolim. Ex ltercore fuo alimenta petit; 
$+7+2$

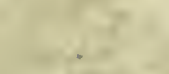

$-1 . \quad 7$

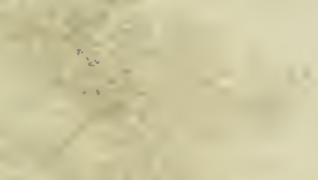

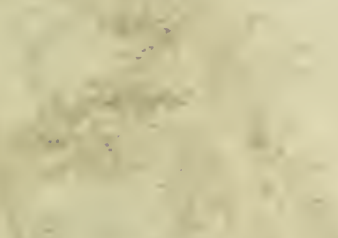

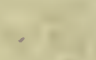

1.9. $3-2$

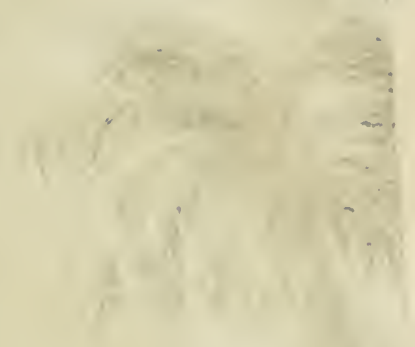

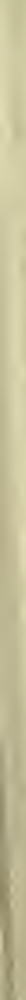

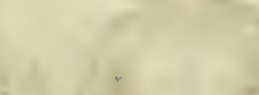


Ilanche VIII. Page 151.

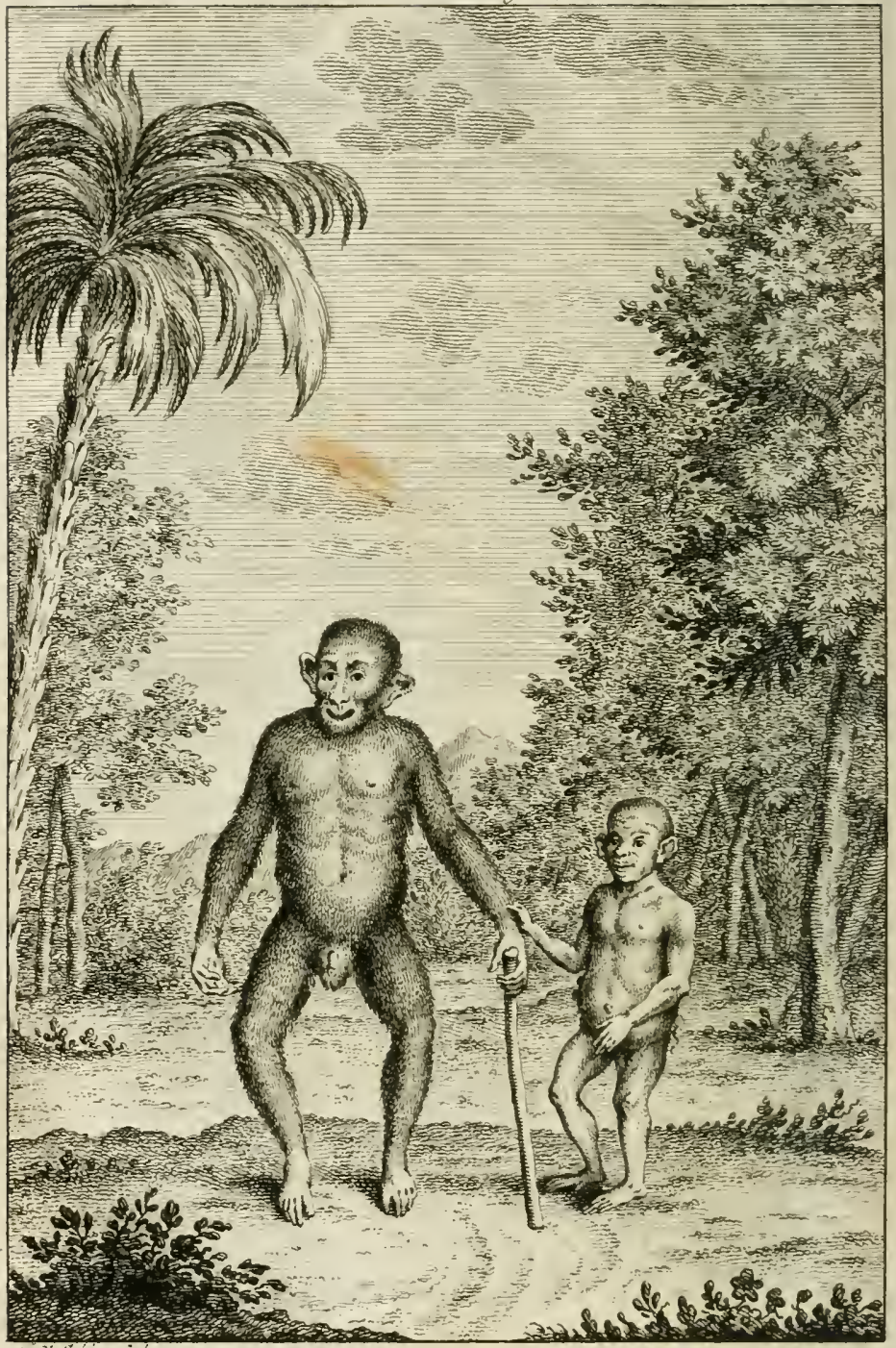

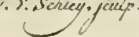




\section{$\begin{array}{lllllllll}\text { C } & H & A & P & \text { I } & T & R & E & C I V .\end{array}$}

L'Orang-Outang, le Pongo, l'bomme des bois, le Sittyre, le Barris, le Climpancée, le . Focko, l'bomane de inuit, le Troglodite, éc.

$\mathrm{T}$

o us ce noms défignent le même quadrumane, \& lui ont étć donnés par différcns voyageurs ou naturaliftes. C'eft celui que l'on voit reprétenté à la Plancb̉e VIII. ayant à cûté de lui une patite femelle de la même efpece, qui n'a encore que quelques poils fort rares fur les hanches (*).

L'Orang-Outang n'eft pas véritab'ement un homme; mais il en approche de très près. Il n'eft pas non plus un finge, oll une guenon, car il en differe beaucoup plus qu'il ne differe de l'homme. On peut done le prendre pour une efpece intermédiaire qui remplit le paflage du finge à l'homme, \& c'eit ainfi que nous l'envifigeons.

Un des plus favans \& des plus célèbres Naturaliftes de ce fiécle vient de recueillir avec beaucoup de foin $\&$ de difecrnement ce que les voyageurs les plus véridiques \& les anatomiftes les plus exacts ont écrit fur

fed amat etian potun Theæ, quam hominum more ex vafculo bibit. Horun preterea fomum imitatur, nec prorfus ingenio caret, ipfa etiam voce garrulitatem humanam exprimens. NIares, cum ad retatem adultam venerunt, fœminas humanas ftupro petunt, \& viros etiam armatos ad pugnam provocaut. Idem fixpiffime ab hujus, in are expreffi matre, pedum quinque altitudi. nem requante, fact:m, quan nifi telo fuftuliffet Maurus quidam, vix in ejus unquam manus foet!!s lic veniffet. Hujus, menfes unum \& viginti nati, imaginem Londini affabre in are infculpfix Scotinus, artifex peritus, confilium fi recte fufpicamur, fecutus Yoamis Sloanii, Regire fcientiarum Societatis præfidis, cujus etianı nomini, quicquid eft peregrini hujus monitri, infcriptum videmus. Cujus imaginis nuper esemplum nacti, ut regni etian animalis hiftoria linc lucem acciperet, eam dextra quadam manu repetendan hic curavimus. Nova aita ernditorum $6 m$ imo 1739 \$trblicata Lypfia. Menf. Sepiemb. pas. $5^{64} \& 565$. 
l'extérieur \& l'intérieur de cet animal; nous ne faurions mieux faire que d'en rapporter ici le réfultat. Ainfí c'elt d'après Mr. de Buffon que nous allons expofer en abregé les ciifférences qui diftinguent cette efpece de l'efpece humaine, \& les conformités qui l'en approchent.

L'Orang-outang differe de l'homme àl'extéricur par le nez, qui n'elt pas proéminent, par le front qui eft trop court, par le menton qui n'eft pas relevé à la bafe; if a les orcilles proportionncllement trop grandes, les yeux trop voifins l'un de l'autre, l'inrervalle entre le nez \& la bouche eft aufli trop étendu: cefont là les feules différences de la face de cet animal avec le vifage de l'homme, \& l'on voit combien clles font legeres.

Le corps \& les membres différent en ce que les cuisfes font relativement trop courtes, les bras trop longs, les pouces trop petits, la paume des mains trop longue \& trop ferrée, les pieds plûtôt taits comme des mains que comme des pieds humains: nous verrons bientôt que cette dernière différence fouffire quelque modification.

Les parties de la génération du mâle ne font différentes de celles de l'homme qu'en ce qu'il n'y a point de fiein au prépuce; les parties de la femelle font à l'extéricur fort femblables a celles de la fenme. Une particularité remarquable c'eft que le mâle defire aufli ardemment la compagnie des femmes que de fa femelle. Ces aninnaux tacheni de furprendre les negrefies, \& s'ils en peuvent attraper, ils les gardent pour en jouir, les nouriflant bien \& ne leur faifant aucun mal.

$\Lambda$ l'intérieur cette efpece differe de l'efpece humaine war le nombre àes côtes: l'homme n'en a que douze, I'orang-outang en a treize; il a auffi les vertebres du cou plus courtes, les os du bafiin plus ferrés, les laanches plus plates, les orbites des ycux plus enfoncées; il $n^{2} y$ a point d'apophyle ćpineute à la première verrebre du cou; les reins font plus ronds que ceux de 
P H I L O S O P H J Q U E S. S c. I5s

l'homme, \& les uretères ont une forme diffërente, auffi-bien que la veffie \& la veficule du tiel qui font plus étroites \& plus longues que dans l'homme.

Toutes les autres parties du corps, de la tête \& des membres, tant extérieures qu'intérieures, font fi par. faitement femblables à celles de l'homme, qu'on ne peut les comparer fans admiration; \& fans être étonné que d'une conformation fi pareille \& d'une organifation qui elt abrolument la même, il n'en refulte pas les mêmes effets. Par exemple, la langue \& tous les organes de la voix font les mêmes que dans l'homme, \& cependant l'Orang-outang ne parle point; le cerveaul eft abfolument de la mêmc forme \&̀ de la mêne proportion, \& il ne penfe pas. Il faut convenir néanmoins que la penfée \& la parole que nous refufons à cet animal fingulier, lui font accordées par Mr. Linnæus d'après Kjoep \& quelques autres voyageurs. Ce favant Naturalifte Suédois dit exprefiëment que l'Orang-outang penfe, qu'il parle \& s'exprime en fifflant:

Homo nociurnus. Homo filvelris Orang-Outang Bottii. Corpus album, inceffic erechum, pili albi contortuplicati, oculi orbiculati, iridi pupillaque aurea. Palpebric antice incumbentes cum membrana nicitante. Vifis naturalis, nociurnus. Die crecutit; nochu videt, exit, fuFatur. Loquitur fibilo, cogitat, credit fui caufa faciam tellurem, fe aliquando iterinn fore imperantem, $f i$ fides peregrinatoribus... babitat in Fave, Amboine, Ternate Speluncis (*).

L'Orang-Outang a des fefies \& des mollets, comme l'homme, \& par confequent il eft fait pour marcher debout comme nous: il a la poitrine large, les épaules applaties, \& les vertebres conformées comme nous: il a le cerveau, le cour, les poumons, le foie, lit rate, le pancreas, l'eftomac, les boyaux abfolument pareils aux nôtres: il a auffi une appendice vernicu-

(*) Lin. Syftema Naturx Edit. X. p. 24.

K 5 


\section{CONSIDER $\triangle$ T IONS}

laire an crecum; enfin l'orang-outang refiemble plus far le phylique à l'homme qu à aucun des animaux, plus même qu'aux babouins \& aux guenons, nonfeulement par toutes les parties que je viens d'indiquer, mais encore par la largeur du vilige, la furme du crâne \& des mâchoires, par la forme \& lc nombre des dents, par les autres os de la tête \& de la face, par la groficur des dojgts \& du pouce, par la figure des ongles, par le nombre des vertebres lombaires \& facrées, par celui des os du coccix, \& enfin par la conformité dans ies articulations, dans la grandeur \& la figure de la rotule, dans celle du fternum, \&c.; en lorte qu'en comparant cet animal arec ceux qui lui reffemblent le plus, comme avec le magot, le b:sbouin ou la guenon, il fe trouve encore avoir plus de conformité avec l'homme, qu'avec ces animanx dont les éfpeces cependant paroilfent être fi voifines de la fienne qu'on les a toutes défignées par le même nom de finge, mais dont nous jugeons que l'Orang-Outang doit être diftingué, comme formant une efpece intermédiaire entre elles \& l'efpece-humaine. Si l'on devoit le réunir à quelqu'autre efpece, fa forme extéricure lui mériteroit un rang parmi les hommes; \& les Indiens font excufables de l'avoir aflocié au genre humain par le nom d'orang-outang, homme-fauvage, puifqu'il resfemble à l'homme par le corps plus qu'il ne reffemble aux autres finges ou à aucun autre animal: ce nom a été adopté par les voyageurs ¿ ¿ les Naturaliftes qui l'ont nommé bonn nocturnus, bomo filveltris, l'bomme des bois, the man of the woods; \& pour le moins, il mérite tout autant commencer l'efpece humaine, que l'homme mérite de terminer l'efpece des quadrupedes à la tête de laquelle on fait que Mr. Linnaus l'a viacé.

L'Orang-Outang a la face plate, nue \& bazanćc, les oreilles, les mains, les pieds, la poitrine $\&$ le ventre auffi nus; il a des poils fur la tête qui defcendent en forme de cheveux des deux còtés des tempes, du poil fur le corps \& fur leslombes, mais en petite quan- 



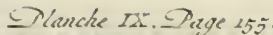

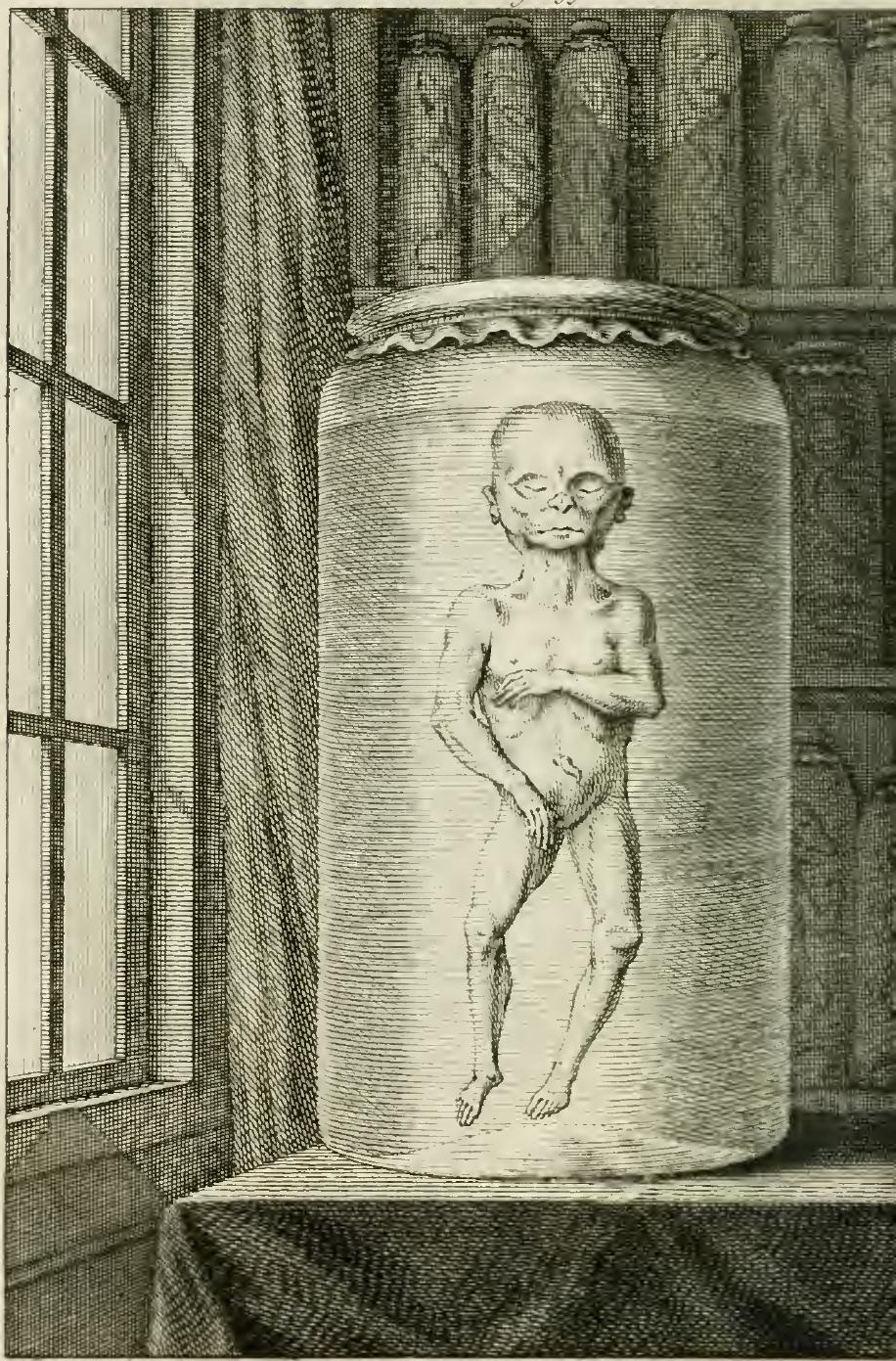


tité; \& il y a des hommes qui en ont beaucoup plus que lui. Il a cinq ou fix pieds de hauteur, avec un corps aufi bien proportionné que celui de l'homme. Quoiqu'il foit conformé pour marcher debout, comme les doigts de fes picds font fort longs \& que fon talon pofe plus difficilement à terre que celui del'homme, il court plus facilement qu'il ne marche, \& il au= roit befon de talons artificiels, plus élevés que ceux de nos fouliers, fil l'on vouloit le faire marcher aifément \& longtemps.

On peut inférer de ces détails que les feules différences eflèntielles entre le corps de cet animal \& celui de l'homme, fe réduifent à deux, favoir, la conformation des os du baffin \& la conformation des pieds; ce font-lì les feules parties confiderables par lefquelles l'orang-outang reffemble plus aux autres finges qu'il ne rellemble à l'homme. Encore la dernière différence n'eft-clle pas auffi marquée \& aufí conftante qu'on pourroit le croire par l'infpection de quelques individus feulement. Elle eft très fenfible dans le Jocko dont on voit la figure dans l' Hiffoire N'aturelle générale \&O particulière avec la Defcription du Cabinet du Koi. Eille l'eft également dans la petite femclle que l'on voit ici (Plancbe VIII.) Mais le pongo ou grand Orang-Outang, celui qui eft égal en ftature à l'homme, a le gros doigt de pied plus femblable à l'orteil du pied humain, \& le talon plus bas. Je puis afturer avoir vu le pied délleché d'un pongo dont les doigts reffembloient encore plus à ceux du pied de l'homme, qu'on ne le voit ici fur la figure, quoique déja ce picd ne foit plus celui du jocko, ou orang-outang de la petite efpece. Je reçus aufii en 1762 . de la côte d'Angole un fœetus-pongo que l'on voit à la Plancbe. $r X$. \& dont les pieds font tout-à-fait humains. L.C front y paroît moins court que dans le jocko, le menton eft un peu plus relevé, les oreilles relativement moins grandes, \& mieux à leur place, les cuiflè \& les bras plus proportionnés; deforte que le pongo, qui reffemble plus à l'homme par la ftature \& la gran- 
deur que le jocko, lui reffemble aufi davantage par les formes \& les proportions particulières de la face \& des membres, La longueur des cuiftes indiqueroit peut-être que les os du baflin y ont plus de conformité avec ceux du fquelette liumain, que les os du bafin du petit orang-outang.

Si ces obfervations étoient fuffifamment confirmées par la vue \& l'anatomie de plutieurs pongos, on auroit un prefqu'homme qu'il feroit difficile de diftinguer, par la forme extérieure, de l'homme véritable; \& le grand vuide du finge à l'homme paroîtroit rempii. On auroit après les, fugoins, les fapujous \& les guenons qui ont de longues queues, les babouins à queue courte; puis le magot qui n'a qu'une apparence de queue, le grand \& le petit gibbons, avec le pitheque qui n'ont point du tout de queue, \& qui marchent à deux mains, le corps droit; enfuite le jocko ou petit Orang-outang; le pongo ou le grand Orang-outang; \& enfin l'homme, dont nous allons diftinguer plufieurs races, finon plufieur's efpeces.

\section{$\begin{array}{llllllllll}C & H & A & P & I & T & R & E & C V\end{array}$}

D'une efpece particuliere d'bomme-marin, peut-être quadrumane.

A tés, je vais rapporter le relation d'un nouvcau monftre marin.

"EN l'année I720. le 8 Aon̂t, jour de jeudi, les g, vents variables étant à l'cit-ludd-eft, à vingt-huit ou " trente brafles d'eau, fept navires en vue mouillant "fur le banc de Terre-neuve, il parut fur les dix "s heures du nıatin à bord d'un vaiffeau François nomg mé la Marie de grace, commandé par Olivier Mo29 rin, un homme marin qui premièrement fe mon23. tra à bas-bord fous le theux ou baril du Contre- 
20 Maître, appellé Guillaume l'Aumone. Auffi-tôt " celui-ci prit une gaffe pour le tirer à bord; nais le "Capitaine l'en empêcha, de clainte qu'il ne l'en" traînât avec lui. Par cette raifon, il lui en donna 2) feulement un coup fur le dos fans le piquer.

". Lorfque le monitre fe fentit frapper, il prêta le 9, vifage, au Contre-Maître, comme un bomme en " colère qui eût voulu faire un appel. Malgré cela il " ne laiffa pas de paffer dans les lignes en nageant, " pour faire le tour du vaiffeau. Quand il fut derrière " il prit le gouvernail avec fes deux mains: ce qui "obligea l'équipage de mettre deux palans, de peur " qu'il ne fit quelque dommage. Il repaffa enfuice " par ftribord, nageant tôtjour's conıme eût pu faire " un homme véritable; \& lorfqu'il fut à l'avant dur. "vaiffeau, il s'arrêta à regarder la figure qui étoit ", celle d'une très-belle fcmme. Après l'avoir long"temps confiderée il prit la foubarbc du Beaupré, \& " s'éleva hors de l'eau pour tâcher, à ce qu'il fem"bloit, de faire tomber la figure. On attacha une mo. " ruë à une corde, \& on la laiffa pendre à côté du "vaiffeau. Il la prit \& la mania, fans la rompre.

"Il nagea enfuite au vent du vaiffeau environ la longueur d'un cable; \& paffant par derrière, il prit

"de nonveau le gonvernail. Le Capitaine ayant fait " préparer un harpon, cflaya lui-même de le har" ponner; mais parce que le coldage n'ćtoit pas paré, "il manqua fon coup. Le manche frappa feulement "fur le dos de l'homme marin, qui à ce coup prêta "long temps le vifage au Capitaine, comme il avoir "fait au Contre-Maitre, \& avec les mêmes geftes. "A Arès ccla le monftre paffa à l'avant du Navire, \& "s’arrêta encore à confidérer la figure: ce qui enga"gea le Contre - Maître à fe faire apporter le harpon. "Mais craignant que cet homme Marin ne fùt la vifion و d'un matelot nommé la Commzme, qui l'année précé" dente le I8 du mois d'Août s'étoit défait à bord du " même vaifleau, fa main tremblante adreffa mal le a) coup; en forte que pour la troiliéme fois le monftre 
„2 ne fut fiappé que du bâton auquel le harpon étoit " attaclé. Alor's il préfenta encore le vifage d'un air "menaçant, comme il avoit fait les deux premières

" fois. Cela ne l'empêcha pourtant pas de fe rappro-

" cher encore davantage du bord, \& de prendre une

, ligne avec laquelle pêchoit un matclot nommé Jean

"Marie; après quoi il nagea de nouveau au vent en-

"viron la portée d'un coup de fufil. "Il revint enfuite à bord très-proche, \& s'éleva z encore hors de l'eau jufqu'au nombril ; enforte que פ, tout l'équipage remarqua parfaitement qu'il avoit , le fein auffi plein que celuid'aucune fille ou femme, "quoique ce fût un mâle, comme on le vit auffi-tôt. "Car il fe renverfa enfuite fur le dos, \& prit avec , fes mains fes parties naturelles, d'une groffeur \& "d'une figure pareilles à celles d'un cheval entier, "2 après quoi il fit de nouveaul le tour du navire, \&r " prit cncore le gouvernail. De-là nageant lente"ment, il s'éleva hor's de l'eau, \& tournant le dos, פ, il fit fes immondices tout contre le vaiffeau. Après "sela il s'éloigna de forte qu'on le perdit de vue. "Ce manege avoit duré depuis dix heures du ma${ }^{2}$ tin jufyu'à midi, le monftre ayant toûjours été , pendant ce temps-là proche du vaiffeau, fouvent à deux ou trois pieds de diftance; en forte que l'équipage compofé de trente-deux-hommes eut le plaifir \& la commodité de remarquer les particularités fuivantes: qu'il avoit la peau brune \& bafanée, fans écailles; tous les mouvemens du corps, depuis la tête jufqu'aux pieds, tels que ceux d'un véritable homme; les yeux fort bien proportionnés; la bouche médiocre eu égard à la longueur du corps, qui fut eftimée par tout l'équipage, de huit pieds; le nez fort camard, large \& plat; les dents larges \& blanches; la langue epaiffe; les cheveux noirs \& plats; le menton garni d'une barbe mousfeufe, avec des mouftaches de-même fous le nez; les oreilles femblables à celles d'un homme; les pieds „2 \& les mains parcils, excepté que les doigts étoient 
9, joints par une pellicule telle qu'il s'en voit aux patg, tes des oies \& des canards. En général c'étoit un "2 corps d'homme aufli bien fait qu'il s'en vore ordi, nairement.

3. Ce détail eft tiré d'un procès-verbal qui en fut פ, dreflë par un nommé Jean Martin Pilote de ce vaisפ feau, figné du Capitaine \& de tous ceux de l'équi", page qui favoient écrire, \& qui fut envoyé de "Breft par Mr. d'Hautefort à Mr. le Comte de Mau"repas le \& Septembre 1725 (*)."

Je foupçonne que cet homme-marin, plus grand que l'homme ordinaire, pouvoit être auffi quadrumane, en ce que les doigts de fes pieds étant unis par une membrane comme ceux de fes mains, ils devoient être beaucoup plus longs que ceux du pied de l'homme, s'étendre \& s'écarter comme ceux de la main pour fervir de rame \& faciliter l'action de nagcr. Il eft probable auffi que le talon devoit être fort élevé, peut-être entièrement effacé \& ces formes devoient donner naturellement à un tel pied, la figure d'une main marıne.

Quoi qu'il en foit de ces conjectures, ce fait fuffifamment attefté nous montre dans la mer un presqu'homme qui répond à l'Orang-outang terreftre, \& mérite d'être placé à côté de lui dans l'échelle des Etres, comme un animal très-voifin de l'homme véritable.

(*) Telliamed, Tome II.

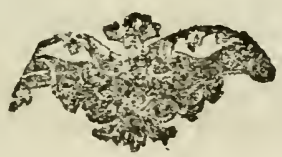




\section{TREIZIE ME PAR T IE.}

\section{$\begin{array}{lllllllll}\mathrm{C} & \mathrm{H} & \mathrm{A} & \mathrm{P} & \mathrm{I} & \mathrm{T} & \mathrm{R} & \mathrm{E} & \mathrm{CVI} \text {. }\end{array}$}

De l'Homme 8 des diferentes races bumaines.

I. Les Hommes à queze.

A la vue de l'Orang-outang on eft tenté de deman. der, que lui manque $t$-il pour être un homme? En voyant certaines races d'hommes, on oferoit prefque dire, quels animaux font-ce-là ? Le pongo n'a point de queue; le gibbon \& le pitheque, efpeces inférieures au pongo, n'ont point de queue. Ce fuperflu, plolongement exceflif de l'épine, paroìt un caractère diftinetif de la brute; \& dès qu'il manque, on voit l'animal prototype prendre la forme humaine. Cependant il y a des hommes, reconnus pour tels, qui ont une queue. La marche de la Nature feroit-clle retrogade? non: mais elle elt finement nuancée. Le pongo tient à l'efpece humaine par une infinité de res. femblances: l'homme devoit tenir, par d'autres traits, à des efpeces fort au deffous du pongo.

On tlouve dans l'lfle de Manille des noirs qui virent dans les rocher's $\&$ les bois, menant une vie de brutes; on en a vu plufieurs qui avoient des queues de quatre i cinq pouces, comme les Infulaires dont parle Ptolémee. (*) Le loyageur qui rapporte ce ce fait, dit que les temmes de ces Satyres accouchent dans les bois, comme les chevres, \& vont aufli tôt fe laver

(*) Gemelli Caveri, Voyage du Tour du Monde, Tome V. paris $1,2 \% \cdot$ page 65.66 . 
laver \& leur fruit auffi dans les premières rivières, $0 u$ autre eau froide: ce qui feroit mourir une fenme d'Europe. Il ajoute que des Mifionnaires léfuites, dignes de foi, lui ont affuré que les Manghiens qui habitent le cœur de l'Ille de Mindoro voifine de wanille ont auffi une queue de quatre à cinq pouccs, qu'ils n'ont aucune forme de gouvernement, qu'ils vont nuds, qu'ils fe nourriffent de fruits fauvages; que quelques-uns pourtant du territoire de Nauhan ont embraflé la foi catholique (*).

Jean Struys $(\dagger)$ dit avoir vu de fes propres yeux dans l'Ille Formole, un homme qui avoit une queue longue de plus d'un pied, toute couverte d'un poil roux, \& fort femblable à celle d'un bœuf; cet homme à queue affuroit que ce défaut, fuppofé que c'en fût un, venoit du climat, \& quie tous ceux de la partie méridionale de cette Ine avoient des queues comme lui. Cette queue eft fort différente pour la forme \&s les dimenfions de celle que portent les noirs de $M a$ nille, les habitans de Mindoro, de Lambry, \&c. Il pourroit donc y avoir plufieurs races différentes d'hommes à queue, qui cifférafent par la longuéur de cette partie, comme nous avons diftingué les guenons \& bes fapajous à longue queue, des babouins à queus courte.

2. Les hommes qui ont des queues peuvent-ils être "les fils de ceux qui n'en ont point? Comme les "g finges à queue ne defcendent certainement point de " ceux qui font fans queue, ne feroit-il pas naturel " de penfer de-même, que les hommes qui naiffent ", avec des queues font d'une efpece différente de ceux 9, qui n'en ont jamais eu? Auffi font-ils encore ca-

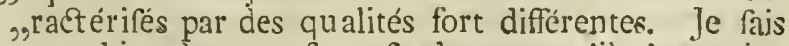
", que bien des gens fe perfuadent ou qu'il n'y a point g d'hommes avec des quenes, ou que s'il s'en trouve

(*) Page $8 \%$.

(f) Voyages de Jean Struys, Rouen 17 Ig. Tome I. p. 100. L 
פ, quelques-uns, c’eft une erreur de la Nature, Oii

" bien un eflet de l'imagination cies mères. Niais cenx , qui penfent de la forte fe trompent certainement

\%, en fuppofant que jes hommes \& les femmes decette

" efpece, ou bien n'exiltent point, ou du moins font

", fort rares. Il eft vrai que la turpitude attachée z̀

" cette difformité, le caractère farouche $\&$ de peu

" d'efprit de tous ceux qui y font fujets, leur pilofité

, naturelle, les oblige à fe cacher des autres hommes

g, avec lefquels ils vivent. Ils prennent le même foin

g pour leur's enfans; \& ceux-ci inftruits par leurs pa-

9, rens, en ufent de-même à l'égard de leur poftérité.

2, Du refte il eft confant que cette lace d'hommes à

פ, queue eft beaucoup plus nombreure qu'on ne ie l'i-

" magine; \& que ce proverbe fi commun parmi

", vous $\left(^{*}\right)$. Homines caudati, pour défioner des gens

" fans efprit, n'eft nullement métaphorique. Il eft

"fondé fur la vérité. Il y a beaucoup de ces lom"mes en Ethiopie: il y en a aux Indes, en Egypte,

, en Angleterre, furtout en Ecofle; toutes vos rela-

g tions en font foi. On en trouve même en France,

" où j'en ai vu plufieurs. Mais je me contenterai fur

, cet article de quelques faits récens \& affez voifins

פ, de vous pour que vous foyez à portée de les vé-

$\Rightarrow$ rifier.

„, Le Sr. Cruvillier de la Croutat qui fit avec fuccès \& avec courage la courfe concre les Tures \& qui péric en Caramanic dans un vaiffeau qu'un des Officiers de fon bord, pour fe venoer de fon Capitaine, fit fauter en l'air en mettant le feu aux pou.

2, dres, a été auffi connu par la queue avce laquellc

", il étoit né, que par fẹs aétions de valeur. Il n'étoit

פ, encore qu'Ecrivain d'un vaiffeau marchand, lors-

9, qu'un jour ce vaiffeau mouillant au port d'Alexan.

99

9g

drie, un Bacha qui paffoit au Caire, \& qui fut inftruit des exploits de ce jeune lomme, lui fit pro-

(*) Il faut fe fouvenir que c'elt un Philofoplıe Indien qui parle a tun Nilìionnaire François. 
92

pofer de lutter contre un noir qu'il avo't à fon fervice, \& lui promit trente fequins s'il fortoit victorieux de ce combat. Ce nuir avoit tué ouinze ou feize hommes dans cet exercice. Quoique le Sr. Cruvillier en tût bien informé il accepta la propofition dit Bacha, \& fe rendit à la lutte fans aucune préparation. Le noil au contraire fe prefenta le corps froté d'huile, \& nud, ainfi que le pratiquoient les anciens athletes, n'ayant qu'une fimple ferviette pour couvrir fa nudité. Ils fe mefurèrent d'abord l'un \& l'autre pendant quelque temps, avant de s'aborder. Enfin après quelques feintes, le noir fe jetta tout - à - coup fur le Si. Cruvillier dans la réfolution de le faitir; mais celui-ci qui avoit les bras tendus, dans l'efperance de l'en empêcher, lui enfonça fi rudement de part \& d'autre fes doigts au défaut des côtes, qu'ils entrèrent dans le corps du noir, comme s'il eût été de beurre. Par-là il luí ôta la refpiration \& la force; \& le ferrant entre fes mains il l'étouffa. Enfuite, l'élevant de terre, il le jetta par deffus fa tête avec tant de force, que la tête du noir, entra toute entière dans le fable. le Bacha témoin avec tout le peuple \& tous les étrangers, qui fe trouvoient à Alexandrie, d'une force fi extraordinaire, quoique touché de la perte de fon noir, ne laifla pas de faire compter au Sr. Cruvillier lestrente fequins, qu'illui avoit promis. Ce Cruvillier, lorfqu'il étoit en courfe, \& qu'il s'agiffnit d'appareiller, laiffoit à fon équipage le choix, ou de lever les ancres tandis qu'il haufferoit les humiers, ou de haufier ceux-ci, tandis qu'il leveroit feui les ancres. Il avoit un frère d'une force égale à la fienne. Celui - ci étoit à Tripoli de Barbarie, où les Turcs l'obligèrent de fe faire Mahometan. On prétend qu'il avoit auffi une queue.

פ, Lorlque je paftai dans cette dernière ville, an commencement de ce ficcle, je vis un noir nommé Mahammed, d'une force extraordinaire. Il me. noit feul une grofle chaloupe à l'aide de deux 
" mes, avec plus de vîtefle que vingt autres n'au"roient pu faire. D'une feule main, il renverfoit " ceuz à trois hommes, \& portoir des fardeaux d'u, ne peinteur étonnante. Il ćtoit velu \& couvert " de poul contre l'ordinaire des noirs, \& avoit une " quencén demi-pied de longueur qu'il me montra.

9 le m'informai de fon pays, il me dit qu'il étoit du ") côte de Bornco. Il maltura que fon père avoit une ", queue comme lui, ainlì que la plûpart des hommes $\Rightarrow$ de fa contrée, qui vont tout nuds, \& chez lefiucls " cette queuc n'a rien de deshonolant, comme en 2 Europe. Les Marchands de Tripoli qui trafiquent ", en efclaves noirs, m'afluierent aufil que ceux de ce pays étoient plus farouches, plus forts $\&$ plus diffi2, ciles à dompter que ceux de tout autre; qu'ils a"voient prefque tous des quenes, les femmes com"me les hommes; \& qu'il leur en palloit pluficurs " par les mains qu'on vendoit bien à la côte de $\mathrm{Ca}-$ "ramanie, où ils étoicnt employés à couper des bois. "Il n'ef̂́ point honteux à un Naturalitte d'approfondir des faits qui peuvent l'inftruire des fecrets "de la Nature, \& le conduire à la comnouflance de ", certaines vérités. Etant à Pife en l'annéc 1710, je "fus informé qu'une Courtifane s"ćtoit vantćc d'avoir " connu un ćtranger qui y avoit paffe trois ans aupa, ravant, \& qui ćtoit de l'efpece de ces hommes à " queue dont je parle. Cela me donna la curiofité de la voir, \& de la cuctionner fur cette avantule. Elle n'avoit pas encore alors plus de dix-huit ans, \& etoit for belle. Eile me conta que revenant de Livourre à Pife en 170 ? dans un bateau de voiture, elle y rencontra trois Officiers François, dont un devint amoureux à'cl c. Cet homme ctoit grand $\&$ bien fait, \& pouvoit avoir trente-cinq ans. Il ćtost fort blane de vifage, ayant la barbe noire \& epaifie, les foucis longs \& garnis. 'Il paffa la nuit avec elle, \& approcha tort de ce travail par lequel Hrcule n'eft pas moins fameux dans la fable que pur fes autres exploits. Il ćtoit fi velu que les ours 
"ne le font pas davantage; le poil dont il étoit tout " couvert, ávoit près de demi-pied de longueur. "Comme cette femme n'avoit jamais rencontré d'hom"me de cette efpece, la curiolité quil lui fit porter les " mains de tous côtés fur le corps de celui-ci, les lui " ayant fait étendre fur fes feffes, elle y trouva une "queue de la grrffeur du do:gt, \& de la lonqueur d'un demi - pied, qu'elle empoigna en lui demandant ce que c'étoit. Cette queue étoit velue comton brufque \& chagrin, que c'étoit un mol'ceau de " chair qu'll portoit de naiffance, par le clefir que fa "s mère avoit eu, étant groffe de lui, de manger d'une "queue de mouton; \& depuis ce moment elie remar"g qua qu'il ne lui témoigna plus le même amitiś. "L'odeur de fil fueur etoit fi forte \& fi particulière, " elle fentoit tellement le fauvage, que cette femnie g, fut plus d'un mois à en perdre le fentiment, qu'olle "s'imaginoit trouver par-tout. "Une perfonne de votre pays m'a affuré que feu "Mr. de Barfabas \& fa four Religieure, tous deux "fameux par plufieurs traits qui marquent en eux 3) une force extraordinaire, avoient une queue. " J'ai connu à Parıs une Limonadière qui cn avoit "une, que cinquante autres perfonnes ont vue: aufifi , avoit-elle i'air hommaffe \& les bras fort velus. "Je vis à Orlçans, lorfque j'y paffai, un hommequi "s avoit une queue. Il étoit aulfi très-fort \& très"velu. J'ai fu depuis qu'ayant voulu faire couper" " cette queue, il mourut de cette opération, dont le "Mercure du mois de Septembre 1718 fait mention. „. Il y a à Aix, dans la rue Courtiffade une fem„, me du peuple, nomméc Louife Martine, qui à "l'âge de trente-cinq ans fut attaquée de la conta"gion, lorfqu'elle affligea cette ville. Ceux qui la "foignorent dans fa maladie découvrirent qu'elle :1„2 voit une queue, \& la firent voir à diverfes autres "s perfonnes, enforte que l'hiftoire en devint publique. 9 Cette femme qui a du poil au menton, grofle \& $\mathrm{L} 3$ 
9, puifante, ayant les foucils \& les cheveux fort פ, noirs, a une force cxtraordinaire \& porte fur les " épaules deux facs de bled, comme une autre pourroit porter un fagot. Un jour elle donna un fouf"flet a un homme qu'elle etendit par terre du coup, פ, lequel refta demi - heure évanoui. Il y a cneore à , Aix un certain Bernard, procureur, nomme Queue„و de-porc, parce qu'il eft connu pour avoir réellement 
"Il peut être velu \& n’avoir point de queue, ou avoir une queue $\&$ n'être pas velu."

Comme la queue des finges, très longue dans les premières races, diminue dans les fuivantes, pouL difparoitre entièrement dans les races fupérieures; il fe peut que la queue de certaines races d'hommes, longue d'un pieci, comme celle des fauvages de l'Jile Formofe dont parle Struys, n'ait qu'un demi-pied dans d'autres races dont ćtoit le noir Mahammed de Borneo; puis feulement quatre pouces, comme dans les noirs de Manille \& de Mindoro; \& qu'elles'efface toutà-faic dans la fuite des générations. Tontes les formes animales changent \& fe perdent de-même graduellement \& fuccelfivement, par la variation néceffaire des produits de la Nature. Pnifqu'elle ne fe répete point; chaque géneration doit amener quelques différences, $\&$ ces différences fans ceffe multipliées \& accumulées doivent produire des altérations confidérables dans le modele prototype: elles doivent fupprimer d'ancienrres parties, ou les multiplier, en engendrer de nouvelles, transformer les combinaifons, varier les réfultats, \& rendre à la fin ce modele original très-différent de lui-même. Elles peuvent déguifer certaines parties, les envelopper, les cacher, pour les remontrer fous une autre face dans de notnveaux produits. A près tout, cette quene, qui nous paroit fi étrange, n'eit que la multiplication des vertebres \& le prolongenent de la peau du dos: elle n'a rien de plus fingulier" que ce fixiéme doigt commun à prefque toute une fimlle de Berlin (*), quoiqu'il difparoiffe dans quelques in. dividus.

(*) Jacob Ruhe, Chirurgien à Berlin, né avec fix doigts à chaque main \& à chaque pied, tient cette fingularité de fir mère Jilifabeth Ruhen qui la tenoit de fa mere Elifabeth Hortsmann, de Roftock. Elifibeth Ruhen ha tranfinit à quatre enfans de huit qu'elle etit de Jean Chrifian Ruhe qui n'avoit rien d'extraordinaire aux picds ni atx mains. Jacob Ruhe, l'un de ces enfans fexdigitaires, époufa à Dantfic cn 1733 . Sophie Louife de Thungeh qui n'avoit ticn d'extraordinaire: il en a eu fix enfans; deux L 4 


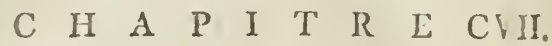

\section{Les Negres.}

T.

I y a des Negres à queue: nous venons d'en voir plufieurs excmples. Cependant la plus grande partie des races negres n'en ont point. Cette large bande gui ceint le giobe terreltre d'orient en occident, n'cft prelque toute habitée que par des peuples noirs qui one des nez larges \& écrafes, de groffes levres, de la la ne au lieu de cheveux, \& un efprit très borné qui s'ileve à peine de quelques degrés au delfus de l'inftinet de la brute. Mr. de Buffón ne compte parmi les véritrioies noirs que ceux de Nubie, du Sénćgal, du CapVerd, de Gambie, de Sierra-liona, de la côte des Dents, de la côte d'Or, de celle de Juda, de Congo, d'Angola, \& de Benguale jufqu'au Cap-Negre. Les plus laids \& les plus itupides font ccux d'Angola, qui cit auffi le pays des Orang-outangs. Outre lcur diffor mité \& leur ftupidité, ils ont encore la force en partarce, \& ils fentent ti mauvais lorfuuils font échauffes, que l'air des cndroits par où ils ont paffé en eft infecté peidant plus d'un quart-d'heure.

I es Negres n'ont pas toụs la même laideur, ni la nêne teinte de noir, ni la même future. Ceuxd'AnFy ia ${ }^{2}$ de Congo font les plus.noirs, les plus laids, les pilis petits, les plus dégon̂tans. Ceux du Cap-verd furt bien auffi noirs, mais ils ont le corps micux fait, les traits du vifage moins durs, le naturel moins ftupide ir moins féruce. Les Sénégallois font peut-être les micux fiits de tous, \& les plus aifés à difcipliner, mais

:? ons on: s-é fexdigitaires. I'un d’eux, Jacob Erneft, à fix Shints an piez gtuclye \& cinq au droit, il avoit à la main droite

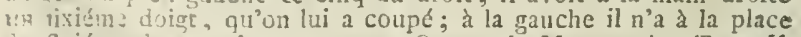

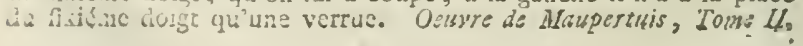




\section{PHILOSO PH I Q U E \& \&. 169}

ils font moins forts que les autres. Les Bambaras font les plus grands, \& les Negres créoles les plus fpirituels \& les plus adroits. Pour la couleur, les Jalofes qui habitent le bord méridional de la rivière du Senégal font tous fort noirs, au Nord du même fleuve, on en trouve qui ne font que d'un brun foncé; ceux des Ifles du Cap-verd font plûtôt jaunâtres que noirs. Les Negres de Serra-Liona ne font pas tout-à-fait auffi noirs que ceux du Senćgal, mais ils le font plus que ceux du Cap-Verd. Én étudiant les variétés de la couleur des races negres, on y trouvera toutes les teintes intermédiaires du noir au brun; en comparant leurs traits, leur taille, les proportions de leurs membres, on verra la Nature perfectionnant fans ceffe, mais lentement, l'efpece humaine en multipliant les générations, réformant chaque fois quelque trait. Combien lui a-t-il fallu de fiécles pour laver la peàu du Sénégallois, je ne dis pas par le mêlange avec le fang du Blanc, mais par la gradation néceffarre des formes qui embrafle également la couleur des furfaces \& la texturc des parties $\left(^{*}\right)$ ?

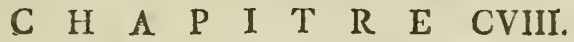

\section{Les Hottentots.}

N ne connoit gucre les peuples qui habitent "les côtes \& l'intérieur des terres de l'Airique depuis

(*) "Le Blanc avec la Noire, ou le Noir avec la Blanche " produifent également un Mulàtre dont la couleur eft brune, ") c'eft-à-dire mêlée de blanc \& de noir, ce Mulatre avec un Blanc " produic un fecond Nulâtre moins brun que le premier; \& fi ce " fecond Mulatre s'unit de même à un individu de race blanche, "2 le troifiéme Mulâtre n'aura plus qu'une muance légère de brup $\because$ qui difparoltra tout-à-fait dans les générations fuivantes: il no * Eut donc que cent-cinquante ou deux cens ans pour laves lo L5 


\section{FiO CONSIDERATIONS}

, le Cap-Negre jufqu'au Cay des Voltes, ce qui fair 9 une étendư d'erviron quatre cens Lieues: on fait क) feulement que ces hommies fort beaucoup moins 2, noirs que les autrés Negres, \& ils seffemblent affez , aux Hottentots, defquels i!s font voifins du côté du g, ninidi. Ce's Hottentots au contraire font bien connus, \& prefque tous les voyageurs en ont parlé: ce ne font pas des negres, mais des Caffies qui ne ferroient que bafunés s'ils ne fe noirciffoient pas la peau avec des graiffes \& des couleurs. M. Kolbe qui a lait une deficription fi exacte de ces peuples, les regarde cependant comme des Negres, il aflure qu'ils ont tous les cheveux courts, noirs, firfés \& laineux comme ceux des Negles $(t)$, \& qu'il n’a jamais vu un feul Hottentot avec des cheveux longs: cela feul ne fufit pas, ce me femble, pour qu'on doive les regarder comme de vrais Négres; d'abord ils en different abfolument par la couleur. M. Kolbe dit qu'ils font coulcur d'olive, \& jamais noirs, quélque peine qu'ils fe doment pour le devenir; cnfuite il me paroit aflez difficile de prononcer fur leurs cheveux, puifqu'ils ne les peignent ni ne les lavent jamais, qu'ils les frottent tousles jours d'une très grande quantité de graiffe \& de fuie mê̂lées enfemble, \& qu'il s'y amalfe tant de pouffic̀re\& d'ordure que fe colant à la longue les uns aux au-

פ, peau d'un Negre par cette voie du mèlange avec le fang du , Blanc, natis il faudroit pent-être un aliez grand nombre de fié- cles pour produire ce méme effet par la feule infuence du cli, mât. Depuis qu'on tranfporte des Nenres on Amérique, c'eft, atrire depuis environ deux cens cinquante ans, l'on ne s'eft " pas appercu que les familles noires qui fe font foutemes fans y, mêlarıgc, áient perdu quelques nuances de leur teinte originelke : " il cft vrai que ce climát de l'Arrérique méridionale étant par "Ttil-mène afiez clatid ponir brunir fes habitans, on ne doit pas , s'etonner "que les Negres y demeurent noïs : poür faire l'expé"rience da changemét de 'cotiteur dans l'efpcce hitmaine, il fau-

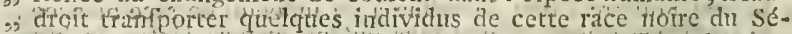
, négl ten tortnemarck, où l hohme ajant cómmunéñent la penu.

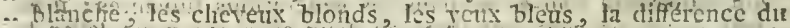

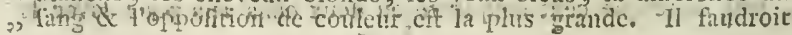



" the; \& par la même raifon combien il en a fallu pour la chan "ger du blanc au noir." En tentant l'expérience inverfe, on pourroit connoitre combien il faudroit de temps pour roürcir la peau des zaces blanches par la feule influencc du climat, ou des autres caufes naturelles.

(*) Defćription du Cap de Bome-Efperance par M. Kolbe, Amfterdain 1741. page 95.

(t) idem, pag. 93.

(*) Voyez l'intone générale des Voyages, par M. l'Abbé Preo vôt, Tome 1. p. $2 s$.

(t) Ibideris. 
"Les voyageurs Hollandois difent que les Sauvages qui font au Nord du Cap, font des hommes roux-brun, quelques - uns plus roux \& d'autres moins, qu'ils font fort laids \& qu'il cherchent à fe rendre noirs par de la couleur qu'ils s'applicjuent fur le corps \& fur le vifage, que leur chevelure eft fembable à celle d'un pendu qui a demeuré quelque temps au gibet (*). Ils difent dans un autre endroit que les Hottentots font de la coulcur des mulâtres, qu'ils ont le vifage difforme, qu'ils font d'une taille médiocre, maıgres $S z$ fort légers à la courfe; que leur langage eft ctrange, \& qu'ils glousfent comme des cogs d'Inde $(t)$. Le Perc Tachard dit que, quoiqu'ils aient communement les cheveux prefqu'auffi cotonneux que ceux des Negres, il y en a cependant plufieurs qui les ont plus longs \& quiles laiffent flotter fur leurs épaules, il ajoute

" même que parmi eux il s'en tlouve d'auffi blanes ", que les Europecens, mais qu'ils fe noircillent avec ", de la graiffe \& de la poudre d'une certaine pierre ", noire dont ils fe frottent le vifage \& tout le corps; "que leurs femmes font naturellement fort blanches, " mais qu'afin de plaire à leurs maris elles fe noir, ciffent comme eux (\$). Ovington dit que les Hot") tentots font plus bafanés que les autres Indiens, ", qu'il n'va point de peuple qui reflemble tant aux \$, Negres par la couleur \& par les traits, que ecpen" dant ils ne font pas fi noirs, que leurs cheveux ne "font pas fi crêpus, ni leur nez fi plat (\$j).

- "Par tous ces témoignages il cit aifé de voir que "les Hottentots ne font pas de vrais $N$ egres, mais des

(*) Voyez le Recueil des Voyages de la Compagnic de HolLande. $p_{.} 218$.

(t) Idem, Voy. le Voyage de Spitzberg. p. 443.

(S) Voyez le premier voyage du P. Tachard, Paris 1686, 8. 108.

(SS) Voyez le Voyage de Jean Oviugton, Paris 3725, p. 194 
,

Voilà un fort vilain peuple dont l'Afpect hideux prouve que la Nature, qui en s'éloignant de l'equateur a éclairci le noir des races negres, en a pourtant

(*) Voyez la Defcription du Cap. par M. Kolbe Tonse I. page 91. Voyez aulfi le Voyage de Courlai, page $29 \mathrm{r}$.

$(t)$ Hiftoire Naturlle générale \& particulière avec la Defcripkion du Cabinet du Roi. Tome VI. Edit. in-12. page 245 \& fuiv, 


\section{4

chargé la laideur dans les Hottentots. Cettc excroisfance de la peau du pubis, particuliere aux femmes, $\&$ beaucoup plus étrange que la queue des Negres de Manille \& de Mindoro, leur ftature petite \& mul proportionnée, leur malpropreté, leur ftupidité, leur naturel indifciplinable, leurs grofles levres, leur nez plat \& large qu'ils s'efforcent d'uplattir encore davantage, leur vie pius courte de moitié que celle de l'homme, \& leur voix femblable au cri du cuq d'Inde ou à des foupirs, qui paregt faire li nuance du cris des jockos a la voix humaine; tout ccila rapproche les Hottentors des brutes. On a ditque l'Orang outang ćtoit un animal. Sous un mafque humain. On pourroit dire qu'un Hotentot eft un homme dćguifé fous les traits, la voix \& les mœurs d'un animal.

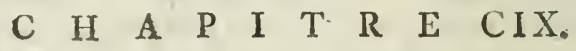 \\ 4. Des autres Caffres.}

L.

A nouvelle Hollande nous offre des races Hottentutes aflez femblables pour la couleur \& la figure à celles que nous venons de décrire. Les Caffres de la côte orjentale d'Afrique, par excmple, ceux de la terre de Natal, de Soffala, du Monomotapa, de Mofambique, de Melinde, de Madarafear \& des Ines voifines; ainfi que les habitans des Maldives, de Ceylan, de la pointe de la prefqu'ille de l'Inde, de Sumatra, de Malaca, des Yhilippines, $\mathcal{S}_{0}$ c. font un peu débarbouillés. Ils font plus grands, moins laids \& moins mal-propres, que les Hottentots: ils ont en général le nez mieux proportionné, 'eś membres moins menus, \& quelques uns ont une mine affez agréable quoiqu'ils foient cxtrêmement bruns. Ainfi les traits de l'humanité s'adoucıffent fenfiblement \& prennent de la regularite, en remnntant vers l'orient: c'eft tout le contraire vers le nord. 


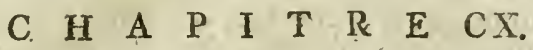

5. Les Lappons d" Europe, les Samö̈edes d" Afie, los Saurvages du Détroit de Davis en Amérique..

A v Nord de l'Europe, de l'Afie \& de l'Amćrique, on trouve des hommes que l'on prendoit volontiers pour une race d'avortons contrefaits, tant ils font petits \& laids! Leur face eft-celle de l'Orang-outang, fi elle n'eft pas plus difforme: Un vifage large \& plat, un nez fi peu proéminent qu'il ne s'éleve prefque pas au deflus de l'os de la machoire fupérieure, une bouche extrêmement grande, des joules très élevées, un menton étroit \& prefque entièrement effacé, l'ouverture des yeux petite \& retirée vers les temples, une groffe tête, des cheveux prefque anffi durs que des crins, des oreilles grandes \& rehauffées, enfin l'iris de l'œil jaune \& le teint d'un brun jaunâtre: que l'on compare ce portrait à celui de l'Orang-outang, \& que l'on décide lequel eft le plus difforme $(*)$. . Your achever cette caricature, figurez-vous un cou extrêmement coult, un corps dur \& nerveux, de quatre pieds de hauteur, quelquefois moins, une ftructure large \& quariée, des menibres courts, gros \& trapus : une voix grêle, peut-être femblable au fifflement que Mr. Linnæus donne à l'homme-des-bois; du refte paffant toute fa vie fous terre ou dans des cabanes enterrées dans les tenebres d'une nuit de plufieurs mois, \& connoiffant peu les maladies qui affigent l'humanité. Eft. ce-là un homme?

A fin que l'on ne foit pas tenté de m'accufer d'avoir chargé les traits de ce portrait, je vais appuyer ce que je dis de quelques autorités refpectableș.

${ }^{*}$ ) Voyez ci-devant Chapitre CIV. 
On trouve en Laponie \& fur les côtes feptentrio. nales de la Tartarie, dit Mr. de Buffon d'après des relations autentiques, une race d'hommes de petite ftature, d'une figure bizarre, dont la phyfionomie eft auffi fauvage que les mœurs. Ces hommes paroifient avoir dégénéré de l'efpece-humaine, ajoute ce favant Naturalifte. Tous ces peuples, favoir les Lappons, les Samoïedes, les Tartares feptentrionaux, les (iroenlandois, \& le fauvages au Nord des Efquimaux, ont le vifage large \& plat (*), le nez camus \& cerrafe, l'iris de l'œil jaune-brun \& tirant fur le noir $(t)$, les paupières retirées vers les temples $(\mathbb{S})$, les joues extrêmement élevées, la bouche très grande, le bas du vifage étroit, les levres groffes, \& relevées, la voix grêle, la tête grofle, les cheveux noirs \& liffes, la peau bafanée; ils font très-petits, trapus quoique maigres; la plüpart n'ont que quatre pieds de hauteur, $\&$ les pus grands n'en ont que quatre \& demi. . Cette race eft comme l'on voit, bien différente des autres, il femble que ce foit une efpece particulière dont tous les individus ne font que des avortons (c'eft toûjours Mr. de Buffon qui parle); car s'il y a des différences parmi ces peuples, elles ne tombent que fur le plus ou le moins de difformité; par exemple, les Borandiens' font encore plus petits que les Laiffons, ils ont l'iris de l'œil de la même couleur, mais le blanc eft d'un jaune plus rougeâtre, ils font aufi plus bafanés, ils ont les jambes groffes, aulieu que les Lappons les ont menues. Les Samoïedes font plus trapus que les Lappons, ils ont la tête plus grofte, le nez plus large, \& le teint plus obfcur, les jambes plus courtes, les genoux plus en dehors, les cheveux plus longs \& moins de barbe.

(*) Voyage de Renard Tome I. de fes Oeuvres, p. 169. Voyez auti il Genio Vagante del conte Aurelio degli Anzi in Parma 69r. \& les Vovages du Nord faits par les Hollandois.

(t) Y. Linnai Fauna Suecia I746. p. I.

(S) Voyez la Martiniere page 39. 


\section{P H I O S O PHI Q UES \&c. $17 \%$}

de barbe. Les Groenlandois ont encore la peau plus bafannce qu'aucun des autres, ils font couleur d'olive foncéc; on prétend même qu'il y en a parmi eux d'auffi noirs que les Ethiopiens. Chez, tous ces penples, les femmes font auffi laides que les hommes, \& leur reffemblent fi fort qu'on ne les diftingue pas d'abord; celles de Groenland font de fort perite taille, mais elles ont le corps bien proportionné, clles ont auffi les cheveux plus noirs \& la peau moins douce que les Samoïedes; leurs mammelles font molles \& fi longues qu'elles donnent à teter à leurs enfans par delfus l'épaule, le bout de ces mammelles eft noir comrne du charbon, \& la peau de leur corps eft couleur olivâtre très-foncée. Quelques voyageurs difent qu'elles n'ont de poil que fur la tête \& qu'elles ne font pas fujettes à l'évacuation périodique qui eft commune à leur fexe; nous verrons bientôt ce qui a donné lieu à cette méprife. Elles ont le vifage large, les yeux petits, très-noirs \& très-vifs, les pieds courts aufiibien que les mains, \& elles refiemblent pour le refte aux femmes Samoïedes. Les Sauvages qui font au Nord des Efquimaux, \& même dans la partie feptentrionale de l'llfe de Terre-neuve, reflemblent à ces Groenlandois; ils font, comme eux de très-petite ftature, leur vifage eft large \& plat, ils ont le nez camus, mais les yeux plus gros que les Lappons ( $\because$ ).

Les Samoïedes, dit un tavant qui en a vu plufieurs $(t)$, font pour la plûpart d'une taille au deffous de lia moyenne: ils ont le corps dur \& nerveux, d'une firueture large \& quarrée, les jambes courtes \& menues, les pieds petits, le cou court \& la tête groffe à proportion du corps, le vifige applati, les yeux noirs $\&$ l'ouverture des yeux petite, mais alongée, le nez

(*) Voyez le Recueil des Voyages du Nord I7I6. Tome Is p. I30 \& Tome III. p. 6.

( $t$ ) Mémoire fur les Samoïedes \& les Lappons., Quant à l"é, tymologie du nom de Samö̈edes, dit l'Auteur de ce Mémoire, 2) ceux qui en ont ćcrit font peu d'accord entre-eux. Les uns 


\section{CONSIDERATIONS}

tellement ćcrafé que le bout en eft à peu près au niveau de l'os de la mâchoire fupérieure qu'ils ont très forte \& élevée, la bouche grande \& les levres minces; leurs cheveux noirs comme le jais, mais extrêmement durs \& forts, leur pendent comme des chan. delles fur les épaules; leur teint eft d'un brun fort jaunâtre, \& ils ont les oreilles grandes \& rehauffées.

Les hommes, continue le même obfervateur aufi cxact que judicieux, n'ont que fort peu ou prefque point de barbe, \& ils ont ceci de commun avec leurs femmes, que non plus qu'elles ils n'ont du poil fur aucune partic de leur corps, excepté ì la tête. Cependant il jeite encore à examiner fi c'eft par un défaut naturel qu'ils fe trouvent fans poil, ou plûtôt par une qualité particulière à leur race, ou bien par le foin que prennent les deux fexes de fe l'arracher partout où il pourroit en paroître, y attachant peut-être quelque idée de honte \& de difformité. Ce qu'il y a de certain, c'eft que les femmes ont un intérêt tout particulier à n'en point avoir, quand même la Nature leur en donneroit, puifqu'un mari, fuivant les ufages de ces peuples, feroit en droit de rendre à fes parens la fille qu'il auroit prife pour femme, $\&$ de leur demander la reftitution de ce qu'il leur en auroit donné, s'il lui trouvoit un poil fur d'autres endroits du corps que fur la tête. Cependant, c'eft là un cas qui,

פ, eroient que ce nom-lì répond à celui d'anthropophages, \& qu'on

" le leur a donné à l'occafion de ce qu'on les a vit manger de la

" chair crue que l'on a prife pour de la chair humaine; d'où l'on

", avoit inféré qu'ils mangeoient les corps morts de leurs propres

, gens, auffi-bien que ceux de leurs ennemis, à la façon des

9, Cannibales. Mais il y a long-temps que l'on eft revenu de cette

" opinion; ¿t l'on fait même, par la tradition de ces peuples,

"que pareil ufage n'eut jamais lieu parmi cux. D’autres difent

"que le mot de Semoz̈e fignifie en lenr langue un IIabitant, \&

"que c'eft delà que leur nom tire foll origine. Cette dérivation

, feroit, ce femble, la plus naturelle, fi la fuppofition fur la-

", quelle elle repofe, n'étoit pas deftituéc de fondement. Mais

" comme il eft certain, qu'il ne fe trouve guere dans toute leur

"langue de mot qui approche de celui de Samoïe, \& qu'ils fe

2. conuent eux-même dans leur propre langue le nom de Ninez 
fuivant les apparences exifte fort rarement, quand mêrne la Nature ne les auroit pas elle-mêmı garantie à cet égard, parce que les Samoïedes ont coûtume de les époufer fort jeunes, dès l'àge de dix ans. La Phyfionomic des femmes reffemble parfaitement àcelle des hommes, excepté qu'elles ont les traits tant foit peu plus fubtils, le corps plus mince, les jambes plus courtes, \& les picds très-petits; d'ailleurs il eft fort difficile de diftinguer les deux fexes par la phyfiono. mie. Ceux qui ont prétendu que les fenmes Samoïedes ne font point fujettes aux évacuations périodiques, fe font trompés; c'eft une particularité fur laquelle j'ai pris des informations exactes: cependant il eft vrai qu'elles ne les ont que très-foiblement \& en petite quantité. Une autre particularité également conftatee, c'eft qu'elles ont toutes les mammelles plates \& molles en tout temps, lors-même qu'elles font encore pucelles, \& que le bout en eft noir comme du charbon, ce qui leur eft commun avec les Lapponnes:

Quant aux fauvages qui habitent les terres du Détroit de Davis ils font fort femblables aux Lappons d'Europe \& aux Samoïedes d'Afie, Ils font petits, trapus, d'un teint olivâtre: ils ont des jambes courtes \& groffes. Les Sauvages de Terre-neuve font aufi de petite taille, comme on l'a dit plus haut, ils n'ont

, \& celui de Chafowe, on voit bicn que c'eft-lì une étymologie "o chinérique comme tant d'autres. 11 vaudra donc nieux, á mour , avis, en chercher une qui ait du rapport avec la langute des "nations voifnes. Fit conne il eft certain que les Finnois ont "habité dans les temps reculés la plus grande partie des contrécs " du Nord, le mot de Sooma, qui fi gnifie ci langue Finnoife un ,Marais peut bien avoir fervi d'origine at nom de Samoïede, " comme il eft vraifemblablement aufí l'étymologie du nom dé "Samalantfil que les Lappons fe donnent dans leur propre lunt. " gue, \& encore celle du non de Somameites qute les Careliens "affectent à leur Nation. Dans les Chanceleries Ruffiennes, les "Samoiedes portent le nom de Sirogıeszi qui défigne des gerig " qui mangent des choles crutes. Voilà tout ce que j'ai pu dé" couvrir cle moins incertain fur la dérivation du nom de cẹs "s peuples:"

M 2 
que peu ou point de barbe, leur vifage eft large \& plat, leurs yeux gros, \& ils font généralement alicz, camus. Le voyageur qui en donne cette defeription dit qu'ils reffemblent affez bien aux fauvages du continent feptentrional \& des environs du Groenland (*). On en peat conclure que tous les habitans du Nord tant de l'Europe que de l'Afie \& de l'Amérique font les plus miferables, les plus laids \& les plus ftupides de toute l'efpece. Ces peuples fi grofliers, menant une vie dure, trifte \& prefque toute fouterraine, parviennent néanmoins à une très.grande vieilleffe.

\section{$\begin{array}{llllllllll}C & H & A & P & I & T & R & E & C X I .\end{array}$}

\section{Saurages au corps \& au vifage velus.}

Q

UE le prototype a de peine à quitter les formes hideures de la brute pour revêtir les belles formes de l'homme! Les Sauvages de la baie d'Hudfon \& du Nord de la terre de Labrador, ainfi que ccux du pays d'Yeço au Nord du Japon dans l'ancien continent, reffemblent aux Lappons d'Europe \& d'Amérique en ce qu'ils font laids, petits \& malfaits comme eux; en ce qu'ils paflent l'hiver fous terre, \& l'été fousdes tetes faites de peaux de bêtes, en ce qu'ils couchent tous pêlemêle fans diftinction comme eux, en ce qu'ils fe nourrisfent de chair crue ou de poiffon cru, \& qu'ils vivent longtemps comme eux; mais ils en différent en ce que les Lappons \& les Samoiedes n'ont que peu ou point de barbe, au lieu que ces fauvages-ci ont non-feulement une barbe très épaiffe, mais encore pręfque tout le vifage \& le corps aufi velus, qu'un ours. Cette par-

(*) Voyez le Recueil des Voyages au Nord. Rouen $1-16$. Tome III. page 7 . 


\section{P H I L O S O P H I Q E S \&C. 181}

ticularité les fuit regarder, avec raifon, comme une race feparée des autres.

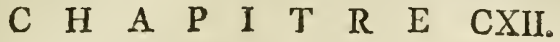

\%. Les Oftiaques \&ै les Tongufes.

\section{I}

E S Oftiaques \& les Tongufes font la nuance cntre les Lappons dont on vient de parler, \& les Tar. tares dont il fera queftion dans le Chapitrefuivant. Les Samoïedes \& les Lappons font environ fous le 68 ou

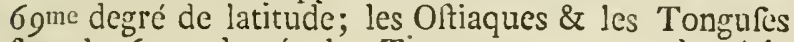
fous le 6ome degré; les Tartares au $55^{\mathrm{me}}$ degré le long du Volga. Les Oftiaques quoique petits \& nial faits, lont peut-être un peu moins raccourcis \& un peu moins laids que les Samoïedes. Les Tongufes font un tant foit peu moins petits \& moins laids. Ils vivent de poiflon ou de viande crue, ils mangent la chair de toutes les efpeces d'animaux fans aucun apprêt, ils boivent plus volontiers du fang que de l'eau. Ils font errans, groffiers, ftupides \& brutaux (*).

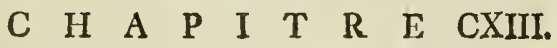

\section{Les Tartares.}

L

A Nation Tartare prife en général, occupe des "pays immenfes en Afie, elle eft répandue dans toute

$\left(^{*}\right)$ Hiftoire Naturelle générale \& particulière, \&c. Tome VI。 Edit. in-I2. 
"g l'étendue de terre qui eft depuis la Ruflic jufqu'à

"Kantichatka, c'eft-à-dire, dans un efpace de onzo

"ou douze cens licues en longueur, fur plus de fept

", cens cinquance lieues de largeur, ce qui fait un

, tcrrein plus de vingt fois plus grand que celui de

" la Irance. Les Tartares bordent la Chine du côté

„, du Nord \& de l'Oueft, les royaumes de Boutan,

"d'Ava, l'emp.re du Mogol \& celui de la Perfe jus-

"g qu’à la mel Calpienne du côté du Nord, ils fe font

, auffi répandus le lorg du Volga \& de la côte occi-

, dentale de la mer Cafpienne jufqu'au Dagheftan,

, ils ont pénetré jufqu'à la côte fepientrionale de la

, mer noire, \& ils fe lont ćtablis dans la Criméc \&

9, dans la putite Tartarie près de la Moldavic \& de

g, l'Ukraine.

"Tous ces peuples ont le haut du vifage, fort large

" \& ridé, même dans leur jeunefie, le nez court \&

"gros, les yeux petits \& enfoncées (*), les joues

9) fort élevées, le bas du vifage étroit, le menton long

פs \& avancé, la machoire fupéricure enfoncée, les

э) dents longues \& féparées, les fourcils gros qui leur

y, couvrent les yeux, les paupic̀res épaifies, la face

y plate, le teint bufanm i \& olivâtre, les cheveux noirs;

9) ils font de ftature mediocre, mais très-forts \& très-

„robuftes, ils n'unt que peu de barbe, \& elle et par

" petits épis cumme celle des Chinois, ils ont les

s, cuilles groffes \& les jambes courtes; les plus laids

פ, de tous font les Calmuques dont l'afpect à quelque

s chofe d'effiovabie: ils font tous cirans \& vaga.

5, bonds, habitans fous des tentes de toile, de feutre,

, de peaux; ils mangent de la chair de cheval, de

", chameau. \&e. crue, ou un peu mortifiée fous la

; felle de leurs chevaux, ils mangent aufli du poiffon

g deffeché au folcil. Leur boifton la plus ordinaire

s) eft du lait de jument fermenté avec de la farine de

(t) Voyez les Voyages de Rubrufquis, de MInrc-Paul, de Jcart struys, du Père Avril, \&. . 

cette efpece....

millet; ils ont prefque tous la tête raféc, à l'cxception du toupet qu'ils laiffent croître affez pour en faire une treffe de chaque côté du vifage. Les fenmes, qui font aufit laides que les hommes, portent leurs cheveux, elles les treflent \& y attachent de petites plaques de cuivre \& d'autres ornemens de

„Pour reconnoitre les différences particulières qui fe trouvent dans cette race Tartare, il ne faut que comparer les defcriptions que les voyageurs ont faites de chacun des différens peuples qui la compofent. Les Calmuques, qui habitent dans le voifinage de la mer Cafpienne, entre les Mofcovites \& les grands Tartares, font, felon Tavernier, des hommes robuftes, mais les plus laids \& les plus difformes qui foient fous le ciel; ils ont le vifage fi plat \& fi large que d'un œil à l'autre il y a l'elpace de cinq ou fix doigts, leurs yeux font extraordinairement petits, \& le peu qu'ils ont de nez eft fi plat qu'on n'y voit que deux trous au lieu de narines, ils ont les genoux tournés en dehors \& les pieds cn dedans. Les Tartares du Dagheftan font, après les Calmuques, les plus laids de tous les Tartares: les petits Tartares ou Tartares Nogais, qui habitent près de la mer noire, font beaucoup moins laids que les Calmuques, mais ils ont cependant le vifage large, les yeux petits \& la forme du corps femblable à celle des Calmuques. Les Tartares Vagoliftes en Sibérie ont le vifage large comme les Calmuques, le nez court \& gros, les yeux petits, \& quoique leur langage foit différent de celui des Calmuques, ils ont tant de reffemblance qu'on doit les regarder comme étant de la même race. Les Tartares Blatski font, felon le Père Avrill, de la même race que les Calmuques. A mefure qu'on avance ver's l'orient dans la Tartaric indépendante, les traits des Tartares fe radouciflent un peu, mais les caractères effentiels à leur racc reftent toûjours; \& enfin les Tartares Mongoux qui ont conquis la Chine, \& 
"qui de tous ces peuples étoient les plus policés, font

, encore aujourd'hui ceux qui font les moins laids \&

"les moins malfaits, ils ont cependant, comme tous

"les autres, les yeux petits, le vifage large \& plat,

" peu de basbe, mais toûjours noire ou rouffe (*),

"le nez écrafé \& court, le teint bafanné mais moins

"Olivâtre Les peuples du Thibet \& des autres pro-

"vinces meridionales de la Tartaric, font, aufí bien

" que les Tarares voilins de la Chine, bcaucoup moins "laids que les autres $(t)$."

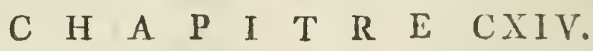

L

9. Les Chinois EO les .Faponnois, Ec. quels ils reffemblent par plufieurs traits marqués. Les Chinois ont en général le vifage large, les ycux petits, les fourcils grands, les paupières plates \& élevées, le nez camus, quelques épis de barbe à chaque levre \& fort peu au menton. 1ls ont affez ordinairement la taille épaiffe, le teint bafanné \&x la ftature commune: les femmes chinoifes font mieux faites que les hommes, au rapport des voyageurs, la taille plus dégagée, mais le nez également écraié \& les autres traits du vifage à la Chinoife.

Les Japonnois font affez, femblables aux Chinois: feulement ils font plus jaunes, ou plus bruns; mais du refte, ils ont la taille ramafféc, un vifage large \& plat, le nez écrafé, de petits yeux, \& peu de barbe.

Nous mettrons ici les Cochinchinois, les Tunquinois, les Siamois, les Péguans, les habitans d'Aracan, de Laos,

(*) Voyez Palafox, p. 444 .

(†) Hiftoire Naturelle générale \& particulière $\mathbb{E}$ \&. Tome VL, Edit. in-12. 


\section{P H I L O S O P H I Q UES \& 185}

\& autres contrées voifines, qui ont tous des firures chinoiles un peu variées; les Cochinchinois \& les Tunquinois n'ont pas le vifage auffi plat, ni le nez auffi camus que les Chinois. Les Siamois ont le corps mieux fait, mais leur front fe rétrécit liubitement \& fe termine autant en pointe que leur menton: ils ont aufi de petits yeux placés obliquement. Les habitans des Royaumes de Pégu \& d'Aracan ont la forme du curps \& la phyfionomie chinoifes, ils font feulement plus noirs.

\section{$\begin{array}{lllllllll}\text { C } & H & A & P & I & T & R & E & C X V \text {. }\end{array}$}

Io. Les Indiens. Hommes à grofles jambes.

L

Es peuples qui habitent la prefqu'ifle de l'Inde font tous plus ou moins olivâtres ou jaunes. A cela près ils reffemblent affez aux Européens pontr la taille \& les traits du vifage. Les corps y font peut-être plus petits, fur tout dans les femmes, mais pour dédomnagement les jambes \& les cuiffes font fort longues.

Je dois pourtant diftinguer parmi les Indiens, les habitans de Calicut qui forment comme deux races particulières, différentes entre elles, \& difiérentes des autres races Indiennes. Les Naires de Calicut, qui font les nobles, font bien faits: ils ont une taille cievée; mais on voit parmi eux de certains hommes \& de certaines femmes qui ont les jambes auffi groffes que le corps d'un autre homme. Cette difformité n'eft point une Maladie, dit Mr. de Buffon ( $t$ ), elle leur vient de naiflance; il y en a qui n'ont qu'une jambe \& d'autres quil les ont toutes les deux de cette groffeur monftrueufe; la peau de ces jambes eft dure \& rude comme une verrue: avec cela ils ne laiffent pas d'être

(*) Au même cudroit, 
fort difpos. Voilà un étrange écart de la Nature dans le temps qu'clle commence à donner une plus belle forme à l'efpece humaine. On trouve encore deshommes à grofles jambes à Ceylan Pour les Moucois, qui font les Bourgeois de Calicut, ils femblent être d'une race inférieuru à celle des autres Indiens: car ils font, lrommes \& femmes, plus laids, plus jaunes, plus malfaits \& plus petits (*).

\section{$\begin{array}{lllllllll}C & H & A & P & I & T & R & E & C X V I .\end{array}$}

Ir. Les Perfans, les Arabes, les Egyptiens, les Maures.

\section{1}

1 ous ces peuples font des nuances intermédiaires entre les Indiens \& les habitans des climats les plus tempérés où font les plus beaux hommes. Du vingtićme degré de latitude feptentrionale, au trente-cinquiéme, les corps, quoique d'une couleur brune \& bafannée, font beaux \& bienfaits:-ils preparent par degrés le beau teint \& les belles proportions, On trouve chez les Maures des femmes d'une extrême blantheur, d'un teint de lys \& de rofes, d'une taille grande \& dégagée.

$\left(^{*}\right)$ Voyages de François Pyrard. Recueil des Voyages qui ont fervi à l'établiffement de la compagnie des Indes de Hollande, Voyage de Jean Huguens.

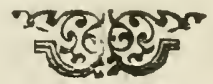


PIILOSOPHIQUES \& I I8?

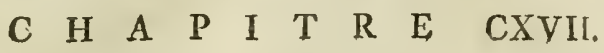

12. Les Ffpagnols, les Portugais, les Francois, les Anglois, les Hollandois, les Aliemands, les Suedois, les Polonois, les Danois.

\section{P}

Es peuples Européens font bienfaits, ils ont les traits réguliers, les membres bien proportionnés, mais ils ne nous offient point encore le chef dœuvre de la Nature, cette beauté noble \& fublime, qui plait par clie-même, \& non par les mignardifes de l'art, ni par la reffource des paffions, ni même par le preftige des graces, le fupplément de la beauté. Ce qui marque la marche graduée \& varice de la Nature, ce qui prouvé d'une manière fenfible par combien de nuanceselle s'éleve lentement au fuprême degré de la beauté, c'eft que tous ces peuples ont un air nacionnal qui fait que chacun eft différent des autres, \& eft auffi aifé à ditimguer par la phyfionomie, que par le langage uu l'habillement. Les Efpagnols ticnnent beaucoup des habitans de la Barbarie par une taille maigre \& arlez petite, par un teint jaune \& bafanné; cependant ils ont une belle tête \& de beaux yeux, Aux environs de Bidaffou ils one les orcillesd'une grandeur exceflive. Les Portugais tiennent des Efpagnols. Les François, les Argiois, les Hollandois \& les Allemands font plus blancs que les Efpagnols \& les Portugais, ils ont aufi une taille plus avantageufe. Ils font cncore éloignés de la perfection de l'efpece humaine. Er comparaneles individus, on trouve que la plûpart font audefious de la beauté médiocre. On rencontre partout des traits à demi-ćbauchés, les nez aplatis, ou aquilins, des têtes communes, des figuresqui ne fignifient rien, des membres mal-afiortis, des corps grêles ou trop chargés de chair, des ftatures raccourcis, des jambes malfives, des mains groflièrcment tournées; dans quelques pro= 


\section{CONSIDERATIONS}

rinces dè la France \& ailleurs près de la motié de l'espece eft contrefaite. Chez tous ces Européens, on compte les beaux hommes \& les belles femmes: encore ce ne font que des beautés nationales, c'eft -àdire des beautés fuivant les idées qu'ont produites les plus belles formes du pays (*) parmi lefquelles on en trouveroit bien peu qui fuffent dignes de fervil de modeles aux peintres du vrai beau. Les Danois font les plus blanes de tous les peuples. Mais ce blane de lait trop éblouiffint n'eft pas tavorable à la beauté: il eft fade: il devroit ĉtre légérement bruni. Aufti, tout le refte égal, une blonde n'eft pas aufli belle qu'unc brune.

\section{$\begin{array}{llllllllll}C & H & A & P & I & T & R & E & \text { CXVIII. }\end{array}$}

3. Les Italiens, les Turcs, les Grecs, les Circafiens E les Géorgiens.

1u centre des différentes nations nommécs dans les deux Chapitres précédens, on trouve les Italiens, les Turcs, les Grecs, les Circafliens \& les Géorgiens. Ces peuples font, fans contredit, les plus belles races de l'efpece humaine. Ils jouiffent de tous les avantages naturels. C'eft chez eux qu'il faut aller contempler le chef-d'œuvre de la Nature, les plus belles formes \& la ftructure la plus excellente lous le plus beau ciel.

Dans les belles Provinces d'Italie, dit Mr. Winckelnann, on voit peu de ces figures ignobles que l'on rencontre à chaque pas au delà des Alpes. Les traits

(*) Ces iłkes de la beauté nationale font fi fortement cmprein. tes dans l'efprit des Artiftes que Rubens mime, après avoir demeuré pluficurs années en Italie, n'a pu leur cu fubftituer de plus parfaites, \& a toujours deffinc fes figures comme s'il n'eut jamais vil guc les formes de fon pays. 
y font partout nobles \& bien marqués; la forme din vifage y eft ordinairement grande \& pleine, \& parfaitement proportionnée dans toutes fes parties. Cette beauté de forme eft frappante jufques dans le bas peaple. La tête du dernier artifan pourroît-être placée dans les compofitions héroïques; \& il ne feroit pas difficile de trouver parmi les femmes de la delnière claffe du peuple, même dans les villages les moins confidérables, un modele pour faire une Junoti. Naples, qui jouit, plus que les autres provinces d'Italie, d'un ciel doux \& temperé, produit en quantitc de ces formes dignes de fervir de modele au beau ideal, c'elt-à-dire ail beau naturel, épuré, ćlevé jufqu'à la perfection divine (*). Si les Italiens, dit un Anglois, font feuls capables, parmi les modernes, de peindre la beauté, c'eft qu'ils ont la bafe de ce talent dans les belles figures qu'ils ont continuellement fous les yeux: cette contemplation affidue du beau naturel fait qu'ils le copient avec tant de vérité $(t)$. On voit peu de vifages grêlés en Italie.

C'eft dans leur propre pays que les Artiftes Grecs prirent les modeles de ces ftatues dont nous admirons les fragmens, \& qui, toutes mutilées qu'elies font, ferviront éternellement de regle pour les belles proportions. Dans l'ancienne Grece, il y avoit des jeux publics où les jeunes-hommes venoient difputer le prix de la beauté. Les prêtres de plufieurs Dieux, ne pouvoient être que des adolefcens qui eufent mérité ce prix (\$). Il y avoit de femblables fêtes inftituées pour les jeunes filles à Sparte, à Lesbos, à Paros. Poly be dit qu'aucune Nation ne pouvoit être égalée aux Girecs pour" la beauté $(\$ 5)$. Le fang des Grecs modernes quorque fort melange eft cncore renommé pour fa beauté.

(*) Hiftoire de l'Art clez les Anciens, Tome I. Traduction Francoife.

(†) Là-mêine.

(5) Paufanias Lib. VII. \& LY.

(Sं๋) Polyb. Lib. V. 
On ne trouve print parmi eux de nez écrafé, celui de tous les défauts qui défigure le plus un vifage. Un célèbre Anatomifte a obfervé que les têtes des Grecs $\&$ des 'Tures ont la forme de l'ovale d'une plus belle proportion que les têtes des Allemands \& des Flamands (*). Les Artiltes Grees fixèrent les idées de la beauté d'après les modeles de leur nation, \& ces idćes ont été univerfellement adoptées partout où les arts ont fleuri. On en retrouve les traits dans les mê. mes contrées, ainfi que dans la Circaflie \& la Géorgie. On y retrouve le profil Grec, le premier caractère de la buiuté du vifage, qui n'admet qu'un enfoncement très doux \& très léger entre le front \& le nez; on y retrouve les fourcils des Graces, ce font ceux des femmes Circafliennes, qui, par la finefle \& la fubtilité des poils, ne femblent être qu'un filet de föe recourbé; ce front moderément grand, poli, \& également courbe dins tous les points qui fe répondent; les yeux \& les mains de la Pallas de Phidias; la taille riche \& noble de la Venus Grecque; cette fublime harmonie de toutes les parties du corps qui frappe dans l'Antinoüs \& dans Niobé. Un trait de beauté remarquable dans les temmes Georgiennes, Circalliennes \& Turques, c'eft la rondeur pleine du menion fans apparence de forietre. Cette follette n'eft en effet qu'un agrément accidentel qu'on ne trouve ni dans Niobé, ni dans fes filles, ni dans la Pallas que poffede le Cardinal Albani, ni dans l'Apollon du Belvedere $(t)$.

Le fang de Georgie eft fi univerfellement beau qu'on ne trouve pas un laid vifage dans ce pays, \& la $\mathrm{Na}$ ture a répandu fur la plûpart des femmes des graces qu'on ne voit pas ailleurs, elles font grandes, bienfuites, extrêmement délićes à la ccinture, elies ont le vifuge charmant $(t)$. Les hommes font aufi fort

(*) Vefal. de Corp. hum. fabrica, Lib. I. Cap. V.

(†) Hiftoire de l'Art cliez les Anciens, par Mr, Winckelmann.

(t) Voyages de Chardin: Hiftoire Naturelle générale \& particulière \&c. 
beaux $(\Omega)$. Les femmes, dit Struys, font fort belles $\&$ fort blanches en Circaffic, \& elles ont le plus beau teint \& les plus belles couleurs du monde; le front grand \& uni, les yeux grands, doux \& pleins de feu, le nez bienfait, les levres vermeilles, la bouche riante $\&$ petite, \& le menton comme il doit être pour achever un parfait ovale; elles ont le cou \& la gorge parfaitement bienfaits, la taille grande \& aifée, les cheveux du plus beau noir: Il eit rare de trouver en Turquie des boffus ou des boiteux; les hommes y font auffi beaux que les Géorgiens ou les Circaffiens, les femmes y font belles bientaites \& fans défaut. Il n'y a femme de Laboureur ou de payfan en Afie, dit Belon, qui n'ait le teint frais comme une rofe, la peat delicate $\&$ blanche, fi polie $\&$ fi bien tendue qu'il femble toucher du velours. Cette peau douce, fatinée \& tranfparente eft un don précieux de la températuro du climat. Les femmes Grecques font peut être encore plus belles que les Turques; ou plûtôt il faudroit avoir des idées bien pure de la beauté pour décider laquelle de ces nations mérite la pomme. Les habitans de Ine de l'Archipel partagent auffi les avantages de la beauté avec leurs voifins.

\section{$\begin{array}{lllllllll}\text { C } & H & \text { A } & \text { P } & \text { I } & \text { T } & \text { R } & \text { E } & \text { CXIX. }\end{array}$}

\section{Les Patagons, ou Géants.}

A l'extrémité auftrale de l'Amérique j'apperçoi une nouvelle race d'hommes. Leur taille eft le double de la nôtre, \& leur corps a plus de huit fois le volume du nôtre.

(\$) Il genio vagante deli Cónte Aurelio degli Anzi, 
"En 1522. Magellan étant proche du détroit ap. פ) pellé de fon nom, fit defeendre au port nommé de, puis Saint-Julien, clivers foldats \& matelots. Ceux, ci étant entrès fort avant dans les terres, trouvè"rent une maifon, féparéc en deux logemens. Dans "l'unc étoient tiois hommes de la hauteur de dix "pieds, \& dans l'autre leurs femmes \& leurs enfans. "Ils amenèrent par adrefle un deceshommes à bord; ") les deux autres fe fauvèrent. Ce Guant avoit le "gofier li large qu'il y faifoit entrer une fleche de la و, longueur d'un pied \& demi. Il étoit fi fort qu'il و fallut huit hommes pour le licr. Il mangeoit une 9 corbeille de bifiuit, \& buvoit un fceau-de vin. פCette terre fut appellée terre des Géants ou des $\mathrm{Pa}$ tagons \& conferve encorc aujourd'hui ce nom. Magellant trouva que les côtes de l'un \& de l'autre. côté du detroit étoient habitées par des peuples gigantefques; voici comment l'Auteur s'en explique.

"Les habitans de l'un \& de l'autre rive font exceffivement grands, prefque tous de douze à treize pieds, mêne davantage. Ils ont la couleur blanche de-même que nos peuples feptentrionaux, \& la voix fi grolle \& ii horrible, qu'ils femblent plûtôt meugler comme les bcufs \& les éléphans, que formel une voix humaine. Ils font fi vifs \& $\mathrm{ti}$ agiles à la courfe, qu'ils devancent les cerfs; ce qui eft caufe que dificilement nos arquebufes peuvent les attraper \& atteindre, fi ce n'eft qu'ils cheminent en troupe, ou qu'jls foient pris à l'improvifte. Une marque de leur grande force, eft qu'un feul homme leve \& porte un tonreau de vin dans les batteaux, \& que trois ou quatre pouflent à la merun bâtiment qu'à-peine trente de nos hommęs peuvent remuer. Ils ont des arcs très-grands dont les cordes font de boyaux de bêtes fauvages de la groffeur du pouce. Le même Hiftorien parlant des peuples du Chili voifins des Patagons dit qu'ils égalent ceux- 
9, ci en groffeur \& en grandeur , \& qu'ilsfont de douze go pieds (*).

C'eft à l'extrémité du Chili, vers jes Terres Magellaniques, dit Mr. de Buffon, que fe trouve, à ce qu'on prétend une race d'hommes dont la taille eft gigantefque. Mr. Frezier dit avoir appris de plufieurs Efpagnols qui avoient vu quelques-uns de ces hommes, qu'ils avoient quatre varres de hanteur, c'eltà-dire neuf ou dix pieds; felon lui, ces Géants, appellés Patagons, habitent le côté de l'eft de la côte deferte dont les anciennes relations ont parlé.... En 1709 les gens du vaiffeau le Jaques, de Saint-Malo, virent fept de ces Géants dans la baie Grégoire, \& ceux du vaiffeau le Saint-Pierre, de Marfeille, en virent fix dont ils s'approchèrent pour leur offrir du pain, du vin \& de l'eau-de-vie qu'ils refufêrent quoiqu'ils euffent donné à ces matelotsdes fleches, \& qu'ils les euffent aidés à échouer le canot du Navire $(t)$.

Mr. de Buffon paroît douter qu'il exifte en effet une race d'hommes toute compofée de Géants, \& il regarde toute grandeur au delà de fix pieds comme un accident, \& non une différence conftante dansl'efpece humaine. Plufieurs favans ont nié tout-à-fait l'exiftence des Géants, c'eft-à-dire d'homme de dix à douze pieds $(\$)$.

Mr. de Maupertuis difoit, dans fa lettre fur le progrès des Sciences, que cette terre des Patagons fituce à l'extrémité auftrale de l'Amérique méritoit d’être examince. Tant de Relations dignes de foi, ajoutoit-

(3) Hiftoire Univerfelle des Indes Occidentales par Witffict; Telliamed, Tome II.

$(t)$ Voyez le Voyage de Mr. Frezier, Paris 1732. page $75 \&$ fuiv. Hiftoire Naturelle générale \& particulière \&.c. Tome VI. Edit. in-12。

$\left(^{*}\right)$ Au Ier. Livre de Moïle Chap. III. vers 1. On lit. La "I4me Année Kedorlnomer vint avec les Riois fes alliés, \& il " défit les Rephrïns dans le Pays d'Aftharoth, les Zuzimes dans "le pays de Ham, \& les Emimes dans le pays de Kiriat/äim." L'Interprete grec prend la liberté de traduire ainfi la fin du 
il, nous parlent de ces Géants qu'on ne fauroit guère raifonnablement douter qu'il n'y ait dans cette region des hommes dont la taille eft fort differente de la nôtre. Les Tranfactions Philofophiques de la focieté Royale de Londres parlent d'un crâne qui doit avoir appartenu à un de ces Géants, dont la taille par une comparaifon très-exacte de fon crâne avec les nótres, devoit être de dix ou douze pieds (*). A examiner philofophiquement la chofe, on peut s'étonner qu'on ne trouve pas entre tous les hommes que nous connoiffons la même varieté de grandeur que l'on obferve dans plufieurs autres efpeces: pour ne s'écarter que le

verfet, it il difit les Géants qui étoient dans le pays of Aftarot. On eft éconné de trouver des Géants dans la veŕlion Grecque, des Géntints dont l'Original ne dit mot. Les Interprétations, que les Rabbins font des noms Rephaim, Zufin, Nephilim, Enakim, Emisz, ne prouve nullement que ce fuffent des peuples de Grans, mais f'culement des hommes courageux, crucls, intrćpides, forts \& robuftes, qui avoient l'air menaçant \& l'œil ardent comme lc Lion, ainfí qu'il eft écrit au Chap XII. de Nombres.

Les Elpions que Nö̈fe envoya a la découverte de la terre promile rapporcèrent, qu'ils avoient vil les peuples de Niphélin, э, illus des anciens" Onckins, \& que les Iliä̈lices anprès d'enx " "n'étoient quc des Cigales."

? Suppofons que la taille des Ifraëlites étoit audefrous de cinq pieds, \& que celle des peuples de Nephilin fut de cinq piés cinq pouces; il n'en faut pas davantage pour qu'ils parufient des Geans aux yeux d'm efpion lache \& timide à qui la fraieur groffit les objets. Les petiples du pays de Canaan étoient par xapport au peuple Juif, comme aujourd'hui. Cenx de la Zone zeinpérée par rapport al ceux de la Zone glaciale ou de la Zone zorride: comme les germains que Tacite appelle homines inmenfa procéritctis, ̇̀ l'égard des Lappons qui ne fout auprès d'cux que des Cigales.

Il y a dans chaque nation des hommies cxtraordinaires cu force ef en hauteur at paris on vit en $1-56$. un homne de 7 pieds 5 pouces 6 lignes. Tel étoit Goliatl parmi les philiftins l'hiftoire finte nous a laifré la mefure exacte de fa taille: il avoit 6 cou. dées \& trois palnes de haut. La palme écoit la largeur de quatre doigts. La Condée revient à peu près au pié de Roi. Goliat awoit donc environ 6 piés huit pouces, taille alfez extralordinaire pour le peuple Juif qui n'avoit gucere plus de cinq piés.

Le Chevalier Hans Sloane donna le 10 Decembre 1727 une disfertation Critique, imprimće dans les memoires de l'Acadenie des Sciences de Paris ou il fait voir que les dents \& les os des 


\section{P II I L O S O P HI I Q U S \&c. 195}

moins qu'il eft poflible de la nôtre, d'un Sapajou à un gros Singe, il y a plus de différence que du plus petit Lappon au plus grand de ces Géants dont les voyagcur's nous ont parlé.

Ces hommes mériteroient fans dotite d'être conrus, continue Mr. de Maupertuis: la grandeur de leurs corps feroit peut-être la moindre chofe à obferver: leurs idées, leurs connoiflances, leurs hiftoires, feroient bien encore d'une autre curiofité $(t)$.

On ne tardera peut - être pas long-temps à être à même de faire ces recherches. Les derniers vaiffeaux Anglois, qui ont paffé le détroit de Magellan, ont en-

prétendus géants ne font en effet que les dents \& lès os des Ële. phans, des Baleines, de l'Hipopotame ou d'autres bêtes femblables. Il en eft de même des fquelettes de 12 de 20 , de 30 coudées dont parle Philoftrate, celui de 46 coudées qu'on trouva. felon Pline dans la Caverne d'une montagne en Eréte; celui de 6o Coudées dont parle Strabon, qui fut trouvé en Mauritanie , \&. qu'on prit pour le fquelette d'Anthée. Tel eft encore le fquelette Eléphantin qui fut trouvé près de Trapani en Sicile, \& qu'on prit pour Poliphéme lui-même.

En I630. Un Gentilhomine de Tunis aiant decouvert un fquelette d'une grandeur prodigieufe, en envoya une dent au favant M. Peyrelch : tous ceux à qui il lá montra la prirent pour la dent d'un Géant. Quelque tems après un Elephant en vie aiant éte montré à Toulon, Mr. Peyrefich donna ordre de l'amener à fi maifon de Canpagne, dans le deffein d'en cxaminer ì loifir les dents, dont il fit prendre l'impreffion en cire, \& trouva que la pretenduë dent de Géant qui lui avoit écé envoyée de Tunis , étoit la dent nolaire d'un Elephant.

En 1678. On envoya de Conftantinople à Vienne une dent quo l'on difoit avoir été trouvée aux environs cle jerulalen dans une caverne fouterraine fort fpacieufe, oll il y avoit le tombeau d'un Géant avec cette inlicription en caractères Caldaïques, $\mathrm{C} i$ git le Géant Hog. d'où l'on conjecturoit que c'avoit été la dent de Hog: Roi de Bafan qui fut defait avec tout fon peuple ies Rephaims par Moïfe: Mais on trouva que c'étoit la dent d'un Elephant. L'Emperenr a qui on vouloit la vendre deux mille écus la fir renvoyer à Conftantinople.

Voila à peu près tout ce qu'on a dit pour prouver qu'il $\mathrm{n}^{\prime} \mathrm{y}$ a point de Géants; mais ces raifonuemens ne peuvent rien contre. İa réalité des faís.s.

(*) Tranfact. Philof. No. 168 \& 169 .

(t) Lettre fur le progrès des Sciences, dans les Oeuyres des Mr. de DIaupertuis Tome II. 
fin reconnu la verité de ce qu'on n'avoit jufqu'ici regardé que comme donteux ou feulement vraitemblable. On n'a pas vu feulement quelques uns de ces Géants, on en a vu une horde de plus de trois cens. On en a amené en Europe; \& nous fommes à la veille de découvrir bien des particularités concernant les terres auftrales \& ces grands hommes qui les habitent. L'exiftence d'un nombre auffi confidérable étant une fois conftatée, on ne peut plus dire que leur grandeur extraordınaire eft un fimple accident. Ce doit être une varieté conftante dans l'efpece. Une fimple différence individuelle ne pourroit pas porter la grandeur de l'homme au double, \& fon corps à un volume huit fois plus confidérable que le volume ordinarre.

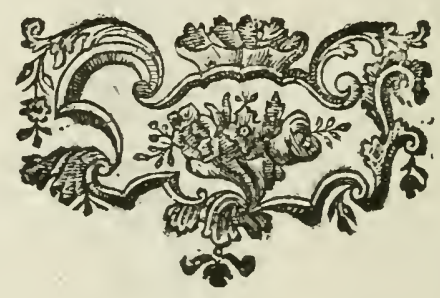




\section{QUATORZIEME PARTIE.}

\section{C $\begin{array}{llllllllll} & \text { H } & A & \text { P } & \text { I } & \text { T } & \text { R } & \text { E } & \text { CXX. }\end{array}$}

\section{T}

Les Monftres.

L manqueroit quelque chofe au Traité de la grada. tion naturelle de l'Etre, fi j'oubliois de parler de certaines formes particulières, que nous appellons monftrueufes parce qu'elles femblent s'éloigner de la régularité \& de l'uniformité des autres productions naturelles. Ces combinaifons bifarres des élémens de l'animalité, que l'on attribue affezz communément à des accidens, font diftribués le long de la chaine des Etres, \& me femblent entrer dans le plan général. Ces variations de la forme prototype, qui, en comparaifon des autres, admettant un excès, un défaut, une difformité oul un déplacement de parties, n'ont point la conftance des autres formes: elles ne font fouvent que fe montrer \& difparoître, fans engendrer des formes analogues. Car fi la monftruofité eft à un certain degré, c'eft-à-dire, fi elle apporte de tels changemens dans l'organiration du fujet qu'elle affecte, que cet individu ait plus de traits de différence, que de rapports dé conformité avec les autres Etres, il fe trouve ifolé, fans pareil auquel il puiffe s'unir avec fuccès, \& conféquemment incapable de produire. Mais la difformité ne va pas toûjours jufqu'à ce point, \& lorsqu'elle ne fe trouve que dans les extrémités, ou avee un tel tempérament qu'elle n'occafionne point de defordre confidérable dans l'ćconomie organique, loin de nuire à la génération, elle fe perpétue, elle fe transmet de proche en proche, quelquefois avec des caprices \& des changemens qui ont quelque chofe d'é- 
trange. La famille des fexdigitaires, dont nous avons parlé plus haut, en eft une preuve fuffifante.

Les Pierres, les plantes \& les animaux ont leurs monftres, c'eft-à-dire des individus qui s'éloignent des formes ordinaires, felon l'idée que nous nous en fommes faite: car le mot de monflre, comme celui d'efpece, exprime un fimple rapport qui n'a d'exiftence que dans notre façon de concevoir. A près avoir circonfcrit les œuvres de la Nature dans de certaines bornes de régularité \& d'uniformité, nous appellons monftre tout L'e qui s'en écarte; tout comme après avoir divifé fes productions, nous appellons efpece diffërente chaque collection d'Etres que produit cette divifion de l'enfemble, Etendons la fphère de nos idces: ne formons point de petits fyftèmes dans un grand. Croyons gue les formes les plus bizarres en apparence, à quelque degré qu'elles le foient, appartiennent néceffairement \& effentiellement au plan univerfel de l'Etre; que ce font des métamorphofes du prototype aunfi naturelles que les autres, quoiqu'clles nous offient des phénomènes différens; qu'elles fervent de paftage aux formes voifines; qu'elles préparent \& amenent les combinaifons qui les fuivent, comme elles font amenées, par celles qui les précédent; qu’elles contribuent à I'ordre des chofes, loin de troubler. Ce n'eft peutĉtre qu'à force d'êtres que la Nature parvient à produire des Etres plus réguliers, \& d'une organifation plus fymmétrique. Qui nous répondra qu'au commencement il n'y a pas eu beaucoup plus de ces produits monftrueux, que de formes plus régulièrement organifées? Si c'eft le contraire aujourd'hui, c'eft que ces monftres manquent des facultés néceffaires pour fe ieproduire, la faculté générative étant attachée à une certaine combinaifon d'organes plus régulières, ils ont du périr, \& laiffer la place aux Etres mieux organifés. Les formes néanmoins n'en font pas tout-à-fait perdues, \& nous en voyons reparoître quelques-unes de temps à autre. Ce n'eft point un vice dans la Nature, que dans la multitude infinic des combinaifons 
de la matière il y en ait qui ne djivent que fe montrer \& diffaroît:e, parce qu'clles ne fauroient fubfifter par elles-mémes.

Les Etres éloignes dans l'échelle font des monftres les uns par rapport aux autres, parce que leur forme eft très diffemblable foit pour le nombre, l'elpece, ou la fituation des parties. Sans comparer des Etres éloignés, prenons des individus de la même efpece, mais de race différente: un homme à queue de Borneo, ne feroit-il pas un monftre à Paris? Une fẹme Hottentote avec fon tablier de chair ne feroit-elle pas un monitre dans un férail de Conftantinople? 11 y a des races d'hommes dont la tête eft fi enfoncée entre les épaules, qu'elle femble occuper la place de la poitrine $11 \mathrm{y}$ en a d'autres dont une jambe grofle comme le corps, fait difparoître l'autre qui eft grêle \& menue, de forte que ces hommes femblent n'avoir qu'une jambe \& un pied. Toutes ces conformations monftrueufes ne le font que comparativement \& fuivant les idées que nous nous fommes forgées d'après les formes qui fe préfentent le plus communément à nos yeux, \& que, nous voyons fe fuccéder avec le plus d'uniformité.

Peut être que, dans quelques - uns des mondes qui roulent fur nos têtes, les Etres qui font réputés informes dans le nôtre, compofent des races conftantes parmi lefouelles nous ferions des monftres. On n'y voit pas de contradiction.

\section{$\begin{array}{llllllllll}\text { C } & H & \text { A } & \text { P } & \text { I } & T & R & \text { E } & \text { CXXI. }\end{array}$}

\section{Des Monftres foljiles.}

$\mathrm{O}$

N ne peut guère douter que parmi les pierres \& les métaux, il n'y ait de ces Etres bizarres \& ambigus qui s'écartent de la conformation ordinaire de leur

$N_{4}$ 
efpece. 11 peut y en avoir parmi les fels, dans le re= gne aqueux. Mais comme le plan des premières combinaifons de la matière, elt moins régulier dans fes proportions relativement aux Etres fupérieurs, les monftres folliles doivent nous être moins fenfibles: ce qui fait que nous ne fommes pas en état d'en juger. Ces conerétions pierreufes, les fralaetites, les préten. dues petrifications ne feroient-elles point autant de developpemens monftrueux des germes lapidifiques, ou de combinaifons vicicufes des élémens des pierres?

\section{$\begin{array}{llllllllll}C & H & A & \text { P } & \text { I } & T & R & \text { E } & \text { CXXII. }\end{array}$}

\section{Des conformations monftrueuses parmi les oégétaux.} I

Es monftres ne font pas rares parmi les végétaux: ils le feroient cncore moins, fi l'on y faifoit plus d'attention. Un citron qui en renferme un aure; une poire qui en enfante un feconde, \& celle-ci jettant par fa tête une branche \& plufieursteuilles; une autre poire dont la partie fupérieure porte prefqu'au milicu du calice un bouton duquel fortent deux petites feuilles \& cinq fleurons auprès des feuilles, garnis chacun de leurs étamines \& piftils; une rofe du centre de laquelle s'éleve une branche de rofier, telle que les nouvelles pouffes ou bourgeons des rofiers; trois rofes qui s'élevent graduellement l'une fur l'autre le long de la même tige (*), font autant de productions végćtales ou le cours ordinaire de la Nature paroît dérangé \& même renverfé.

(*) Voyez les Mrémoires de l'Academie Royale des Sciences de paris. Le Jourual des Savans, an. I679. Les Nouveaux Comwentaires de l'Académie Impériale de Petersbourg. Tome VI. \& le Liyre intitule: de La Nature Tome IV. 


\title{
$\begin{array}{llllllllll}C & H & A & P & I & T & R & E & C X X I I L\end{array}$
}

\author{
Animalsx Monftrueux. \\ Quatre efpeces de Monftres.
}

$O_{N}$ divife les Monftres en quatre efpeces fuivant la nature de leur difformité qui peut fe rapporter a quatre chefs principaux.

\section{Première espece.}

La première efpece comprend les monftres qui le font par la conformation extraordinaire de quelquesunes de leurs parties, quoique du refte le nombre \& la place de ces parties foient comme dans les autres in. dividus.

\section{Seconde efpece.}

On met dans la feconde efpece des monftres tous ceux qui ont quelque partie déplacée, eût-elle d'ailleurs la conformation qu'elle doit avoir,

\section{Troifiéme espece.}

La troifiéme efpece de monftres renferme ceux a qui il manque quelque partie foit extérieure, foit interne; \& on les nomme monftres par défauts.

\section{Quatriéme efpece,}

Les monftres de la quatriéme claffe font ceux qui ont plus de parties que l'état naturel ne le comporte, qui, par exemple ont deux têtes fur un corps, ou deux corps fous un tête, fix doigts à une main, ou à un pied, ou aux deux mains \& aux deux pieds, \&c. On nomme ceux-ci Monftres par excès.

N 5 
Il y a des monftres qui n'appartionnent qu'à une de ces quatre clalfes; il y en a aufi qui appartiennent à deux claftes, à trois clafles, ou même aux quatres, ayant des traits de difformité de plufieurs ou de tous les genres: car il y en a qui ont quelques partics d'une conformation monftruenfe, qui ont d'autres parties déplacées, qui manquent de certains membres, \& qui en ont d'autres fuperfius.

En Gćomètrie, entre deux figures regulières, telles que le triangle équilatéral \& le quarré ou le cercle, il y un très-grand nombre de figures irrégulières. C'eft la même chore dans les formes de l'Etre; \& ceux qui ont regardé les monftres comme des intermédiaires entre les productions plus régulières, par où le prototype a du pafler avant que de revêtir des formes mieux ordonnées, ont foutenu un fentiment très.conforme à la marche de la Nature, qui a du rumplir toutes les nuances, \& conféquemment faire bien des monftres tant par défaut que par excès, tant pul la conformation extraordinaire que par le déplacoment de leurs parties, avant que de produire des fyltèmes organiques aufli bien fymmétrifés que ceux qui nous ont fourni la matière de cet ouvrage. Combien d'effais ont du précéder le jufte nombre \& la proportion exacte des parties, qui nous frappent dans les œuvres de la Nature?

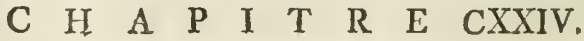

Monfres qui font tels par la conformation extraordinairs de quelques-unzes de leurs parties, foit intérieures ou extérieures.

L

Es premier's monftres de cette efpece font les mulets dont la conformation totales'ćloigne plus ou moins de celles des deux individus dont ils proviennent. Le 
mulet ne reflemble ni à l'âne ni au cheval, \& n'eft réellement ni âne ni cheval, quoiqu'il participe de la nature de l'un \& de l'autre. Le mulct provient ou d'un cheval \& d'une ânefle, ou d'un ânc \& d'une cavalle, ou d'un onagre \& d'une jument. Le mulêt provenu d'un âne \& d'une cavalle, reffemble beaucoup à l'âne par la forme du corps, la longueur des oreilles \& la brieveté de la crinière, mais il reffemble plus à la cavalle par la grandeur. Comme l'âne, il a une queue longue qui n'a de crins qu'à fon extrémité. Sa couleur la plus ordinaire eft le noir, on un brun noirâtre, Il braic comme l'âne, \& comme lui, il a fur le dos une croix d'une'coulcur plus foncée que celle du refte du corps (*).

Il eft très rare que le mulet \& la muleengendient, quoiqu'ils foient fort chauds \& ardens pour l'accouplement: cependant on vit en $17 \odot 3$ une mule à $\mathrm{Pa}$ lerme, en Sicile; qui à l'âge de trois ans engendra un poulain; elle le nourrit de fon lait dont elle avoit une afrez grande abondance $(t)$.

Le mulet qui provient de l'accouplement du coq avec la femelle d'un canard, eft une efpece de $\mathrm{Ca}$ nard qui a les pieds parfaitement reffemblans à ceux du coq.

On peut mettre au nombre des mêmes monftres les deux œufs fuivans qui n'avoient d'autre monftruofité que les marques fingulières empreintes fur leur coque. Le foir du Lundi 2 Decembre 1680. lorfque la comete fe voyoit au ciel, une poule qui n'avoit point encore fait d'œufs, après avoir chanté d'une façon \& d'un ton plus aigu qu'à l'ordinaire, \& fait beaucoup de bruit, fit un œuf d'une groffeur au-delà de la groffeur naturelle, marqué non d'unc comete, mais de plufieurs étoiles. Quelques années auparavant on avoit montré à Mr. Cafini à Boulogne une coque d'œuf'

(*) Dictionnaire d'Hiftoire Naturelle an mot Mulet.

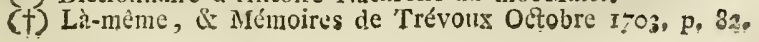




\section{MO4 CONSIDER ATIONS}

fur laquelle étoit empreint en relief'un folcil parfaite. ment bien formé, \& on l'allura que cet œuf avoit été pondu tel pendant le temps d'une éclipfe de foleil (*).

On doit langer encore dans la même clafle un enfant aflez bien conformé à l'extéricur mais à qui toutes les articulations manquoient. Tous fes os étoient foudés enfembie, deforte qu'ils ne formoient qu'un feul os continu $(t)$.

\section{$\begin{array}{lllllllll}\text { C } & \text { H } & A & P & \text { I } & T & R & \text { E } & \text { CXXV. }\end{array}$}

Monflres qui font tels par le déplacement de quelques-umes de leurs parties, tant externes qu'intérieures.

N

1. feconde efpece de monftres. I. Un enfant dont la partie inférieure du corps étoit tournée à contle-fens, c'eft-à-dire le devant derrière, \& le derrière devant. L'épine du dos étoit contournée de telle forte que la face, la poitrine, \& le ventre étoient vus par devant, tandis que les parties extérieures de la génération, les genoux \& les pieds fe trouvoient tournes vers le derrière du corps. 2. Un Soldat invalide, mort à 72 ans, dont toutes les parties internes de la poitrine $\&$ du basventre étoient tranfpolées, celles du côté droit étant fituées au côté gauche, \& celle du côté gauche occupant le côté droit, mais fans aucune confution. Ce déplacement ne nuifit en rien aux fonctions vitales: ce qui prouve que cette tranfpofition eft indifférente cn elle-même. Peut-être que ce Soldat l'avoit héritée de fon père, \& qu'il l'auroit tranfmife à fes enfans s'il en avoit eu. Cet homme avoit donc le cœur à

(*) Journal des Savans An. 168I,

(t) Mémoires de l'Académic Royale des Sciences de Paris, An. 1716 . 


\section{PHILOSO PH IQUES \& 205}

äroite \& le foie à gauche. Ce Soldat fut difféqué à Paris en 1688 par Mr. Lemery. On avoit vu dans la même ville en 1650 une tranfpofition de parties femblables dans le meurtrier qui tua un Gentilhomme croyant tuer le Duc de Beaufort, \& dont le corps après avoir été roué fut ouvert \& difféqué par Mr. Bertrand, Chirurgien. Le Cadavre du Sr. Audran, Commiffaire du Régiment des Gardes à Paris, ouvert après fa mort en 1657 . Offrit un déplacement pareil des vifcères. Frederic Hoffinann, avoit eu auffi occafion d'obferver ce phénomène dans un fujet qu'il avoit difféqué. Ces excmples font voir que la fituation ordinaire de ces parties n'eft pas abfolument néceffairc à la vie, \& que la fituation contraire ne s'obferve fi rarement que par le petit nombre des diffections que l'on fait. D'ailleurs ces monftres peuvent engendrer, \& en fe multipliant perpétuer leur conformation fingulière (*). 3 . Un foetus monftrueux qui avoit lc cœur en dehors, pendu au cou. Voilà un déplacement des plus bifarres que l'on puifie voir.

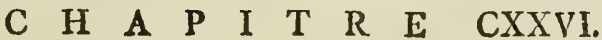

\section{Monfores par defauto}

AgNEAU foetus, fans tête, fans poitrine, fans ver-
tebres \& fans queue: il avoit feulement une efpece de
ventre au bout duquel étoient les cuiffes, les jambes
\& les pieds de derrière.
A Quimper-Corentin en Baffe-Bretagne, en 1683 .
nâquit un petit monftre fort fingulier: un chien de la
longueur \& de la groffeur d'une belette, avec des
pieds de taupe, fans gueule \& fans yeux.' La Nature
n'avoit rien fait pour fuppléer au défaut de ceux-ci;

(*) Là-même, Année 1733 . 


\section{CONSIDERATIONS}

mais à la place de la gueule, elle lui avoit donné une efpece de petite trompe pour fuccer, \& fe nourrir à la façon des infettes qui ont une trompe. Il vecut trois jours (*).

Un autre chien n'avoit qu'un ail, \& point de nez ni de gueule. Sa tête difforme n'étoit qu'une maffe à peu près ronde ou oblongue, fans autre accompagnement que deux oreilles \& un ceil. Le refte du corps n'avoit rien de monftrueux.

Nous avons parlé d'hommes à fix doigts à chaque main \& à chaque pied. Un autre homme n'avoit à chaque main que le feul doigt index, fans qu'il parût aucun veftige de tous les autres doigts, excepté une portion du pouce que l'on fentoit fous la peau en touchant ces mains difformes $(\dagger)$.

Un enfant venu à terme, bien formé \& bien nourri, mourut prefque en naiffant, il fut ouvert: on trouva qu'il n'avoit que la bafe du crâne, \& point de cerveau ni de cervelet. C'étoit une fille. Un autre enfant mâle vecut douze ou quinze heures, quoiqu'il n'en̂t aucune trace de cerveau ni de cervelet, mais feulement un grand efpace vuide à leur place. Un foetus monftrueux n'avoit ni cervelle ni cervelet, ni moëlle épinière. Un enfant venu à terme, n'ayant aufi ni cerveau ni moëlle épinière, a pourtant vecu $2 \mathrm{I}$ heures. Mr. de Littre difféqua en 1701 un foetus monftrueux qui avoit veeu huit mois dans le fein de la mère où elle l'avoit fenti, remuer jufqu'à ce temps. Il n'avoit que la bafe du crâne. Cette bafe étoit couverte d'une membrane qui étoit double, d'un tifiu fort ferré, \& qui ne contenoit dans fa duplicature aucun veftige de moëlle, mais feulement les nerfs \& les vaiffeaux fanguins, qu'on trouve ordinairement à la bafe du crâne. Les nerfs avoient fenfiblement leur commencement à la fuperficie inférieure de la partie

() Journal des Savans, An. I683.

(t) Mémoires de l’Acriémie Royale des sciences de París 217. 173.3 . 
fupérieure de la membrane qui les renfermoit \& ils faifoient trois lignes de chemin dans la duplicature, avant que de fortir de la bafe du crâne pour s'aller dittribuer aux autres parties du corps. Enfin le canal de l'épine de ce fœtus monftrueux, étoit ouvert par derricre dans toute fa longueur, de la largeur de neuf lignes. Il étoit tapiffé de la même menibrane que la bafe du crâne; elle étoit de même vuide de moêlle \& contenoit fculement les nerfs, \& les vaiffeaux fanguins particuliers à l'épine. Ses deux parties étoient tellement colécs enfemble ou avec les vaiffeaux qui étoient dans fa duplicature, qu'il ne reftoit entre elles aucune apparence de canal (*).

En 1709. Mr. Mery reçut d’un Medecin Danois la defeription d'un fotus à terme monftrueux par la tête. Elle étoit plus petite qu'à l'ordinaire, \& la face prefque toute couverte de poils avoit quelque chofe d'affieux. Au milieu du front, il y avoit une petite protubérance charnue, \& directement au-deflous un œil de figure triangulaire, revêtu de fes paupières garnies de leurs cils; mais la fupérieure n'avoit point de fourcils. Ce foetus n'avoit que ce feul œil dont on diftinguoit parfaitement bien la conjonctive, la cornée tranfparente \& la prunelle. Il n'avoit ni bouche, ni nez; de-ià vient, dit-on, qu'il ne pouvoit pas refpirer, ce qui lui a caufé la mort peu de jours après être forti du fèin de fa mère. Les oreilles occupoient la place du menton, mais clles n'avoient point de conduit extérieur. Nous avons dit que ce petit monftre n'avoit point de nez; il ne faut pas oublicr aufi qu'il n'avoit point de nerf olfactif, \& que l'os etlimoide étoit fans trous; il auroit donc été privé de l'odorat s'il eût vécu $(t)$.

Un autre fœetus fans nez, \& avec un feul œil placé au milieu du front, offre des circonftances un peu

(*) Hiftoire de l'Académie Royale des Sciences de Paris.

(t) Là-même, An. I7\%9. 
différentes. La place du nez, étoit unie, plate \& de niveau avec le refte de la face: la peau n'en étoit percée d'aucune ouverture; le deffous de cette peau étoit folide, n'ayant point les creux néceffaires pour former les deux foffes nafales, \& pour loger les lames offeufes avec la membrane qui les tapifle; auffi tout cela manquoit, \& on n'en obfervoit aucun veftige. Le vifage portoit un feul œil placé au centre de la partic inférieure du front, comme on nous depeint celui des Cyclopes. Il y avoit pourtant deux fourcils qui avoient confervé leur place ordinaire ainfi que les deux paupières denuées de cils. Le globe de l'oil étoit rond à Iordinaire, \& compofé de la conjonetive, de la fclérotique \& d’une cornée de figure ovale. Au travers de cette cornée on diftinguoit deux petits corps ronds. Le globe ouvert, on n'y vit point de choroide, mais on reconnut que les deux petits corps ronds étoient les deux yeux renfermés fous une même enveloppe \& polés l'un à côté de l'autre. Quoiqu'ils n'euffent qu'un globe commun, ils avoient chacun fon nerf optique, fa rétine, fes ligamens ciliaires, fon iris, fon humeur vitrée, fon cryftallin. Il n'y avoit que l'humeur aqueufe qui leur fût commune. Toutes leurs parties étoient fort petites, excepté les deux cryftallins qui, à peu de chofe près, avoient leur grandeur naturelle (*).

En I7 I6. une femme accoucha d'un enfant mort qui n'étoit ni garçon ni fille, car il ne paroiffoit fur fon corps, aucune marque de fexe, \& il n'y avoit au dedans aucune des parties néceffaires à la génération. Il n'avoit point aufii d'anus; \& les feffes avoient la même rondeur en devant que par derrière. Il fortit du fein de fa mère avec une exomphale où le foie, la rate, l'eftomac \& tous les inteftins étoient renfermés.

(*) Là-même. 
Les feffes n'étoient féparées en devant \& en derrière que par une petite ligne peu profonde $(\dagger)$.

Le même Académicien de Paris, que je viens de nommer dans l'inftant, vit \& difféqua en 1720 un monftre humain parfait en défaut. C'etoit une file qui vint à fix mois, fans tête, fans bras, fans cœur, fang pounions, fans cftomac, fans reins, fans inteftins grêles, fans foie, fans veficule du fiel, fans ratte, tans pancréas. Une autre fille nâquit avec elle du même accouluchement: clles étoient toutes dèux enveloppées dans les mêmes membranes, \& n'avoient à elles deux qu'un feul placenta, d'où fortoit un cordon unique qui, dans le milieu de fa longueur fe divifoit pour s'aller terminer au nombril de chaque fœtus.

Je ne puis me difpenfer de parler encore d'un autre foetus monftrueux par défaut dans le même genre. Celui-ci étoit un petit mâle fans tête, fans pootrine, fans bras, n'ayant que le bas-ventre, les lombes, les hanches, les cuiffes, les jambes \& les pieds, en un mot n'ayant qu'environ la moitié inféricure d'un corps humain. La hauteur de ce demi-corps n'étoit que de fept pouces, mais fa groffeur étoit énorme. Le haut ou le fommet en étoit arrondi \& couvert également par la continuation uniforme de la même peau. qui en couvroit tout le refte, \& qui étoit partout à l'ordinaire, fans aucune altération extéricure. Les plantes des pieds étoient tournées l'une ver's l'autre les talons en-haut $\&$ les orteils cn-bas. Environ à la diftance d'une ligne \& demic au deffus du nombril, il $\mathrm{y}$ avoit une petite éminence cutance, en forme de bouton mollalfe, inégal, \& garni par en-haut de petits poils clair-femés. Sur un des bords faillans de ce bouton, on voyoit une autre petite eminence cutanée plate, peut-être femblable à une très petite oreille informe, fans ouverture. Immédiatement au deflous

(*) Là-même. Année I7ı16. 
de la portion unfericure de la circonférance duboutous; étoit un petit enfuncement en forme d'cmbouchure, dont la largeur \& la protondeur n'- toient pas tout àfait d'une ligne. Voila tout l'ćquivalent d'une tête, des bras, \& de toute la partic fupericure du corps qui manquoit a ce toetus $\left({ }^{*}\right)$.

\section{C $\quad$ I}

Monfires par excès.

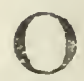

N lit dans ie Journal des Savans du Lundi 23 Juin 168I. la Relation fiuvante lous ce tître.

פ, Ie Poulet de Mr. Hevin Avocat au parlemunt de Erełagne, enouyé d l'Auteur du Fournal avec une Relativn exacie de fon Hifoire.

„2 Parmi plufieurs poulets qui furent éclos fur la fin g, de l'éte dernier dans un village à trois lieues de Renפ, nes, il s'en trouva un d'une forme extraordinaire gs ayant quatre pieds \& quatre aîles. Le payfan chez 9 qui ce petit monftre parut, eut le plaifir de la roir 2) courir \& manger, avec les autres poulets pendant 2 que'que temps; mais un jour la poule trappec plus os qu'à l'ordinaire à la vue des pieds qu'elle voyoit en¿haut en ce petit poulet, \& s'imaginant fans-doute $\Rightarrow$ qu'il étoit renverfé par terre \& hors d'état de fe re$\Rightarrow$ lever, le tourna plufieurs fois de part \& d'autres "fens deffus-defous; mais voyant des pieds \& des "aîles de tous les côtés, comme fi l'horreur du mon"ftre l'eût emporté fur la tendrel:c maternelle, elle "g le tua à grands coups de bec. Un Médecin de vil-

(*) Hiftoira \& Mémoire de r.Académie Royale des Scicnces. 

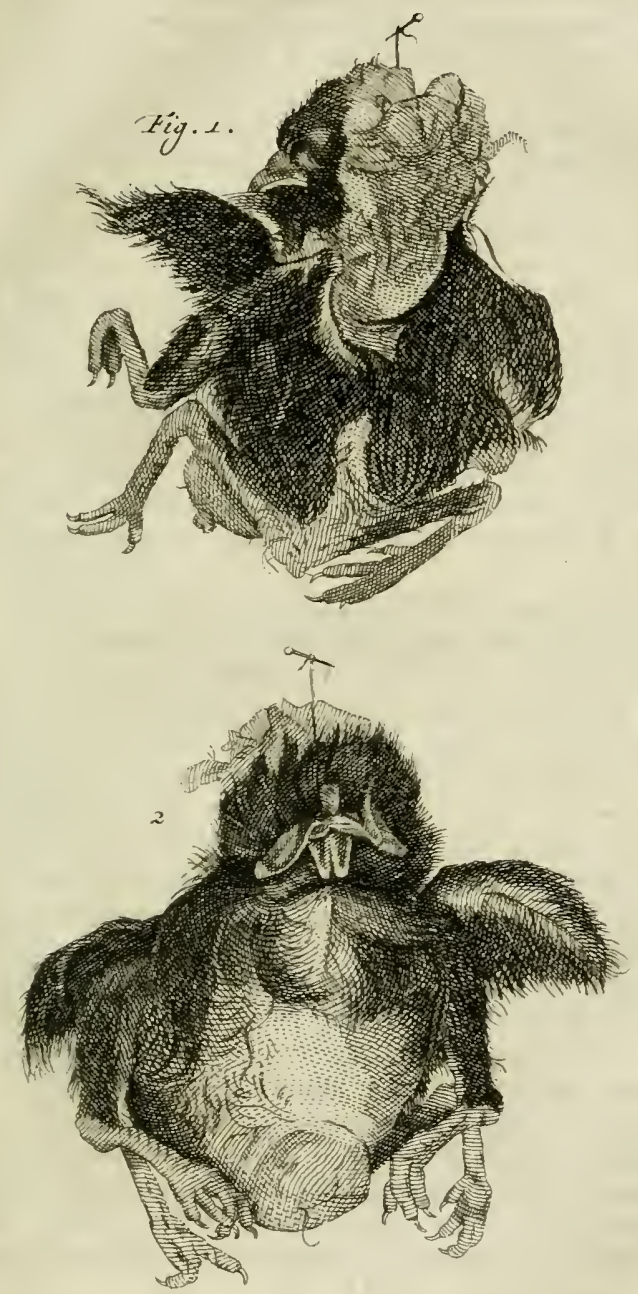

S. de Batkor feat 


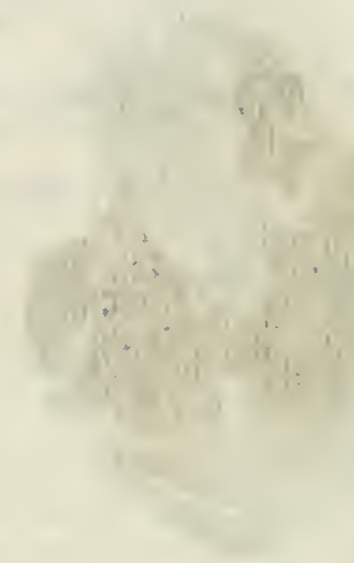

3

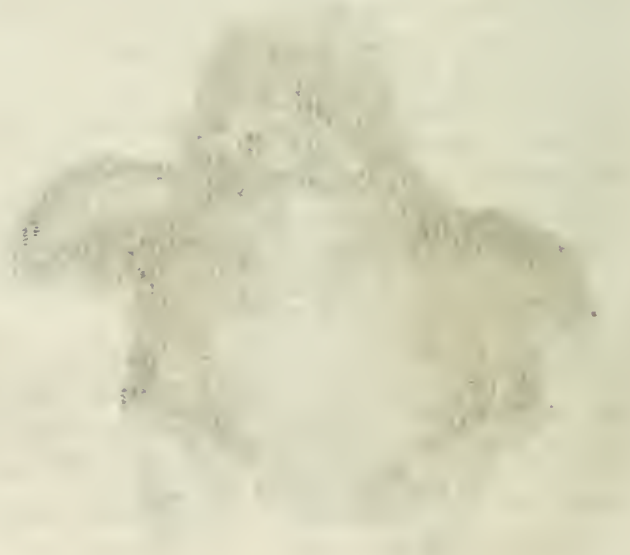

.

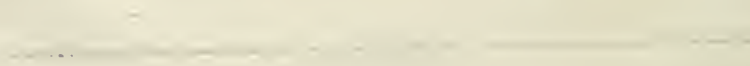

- 
\$) lage ayant eu la curiofité d'arracher le gizier pour

$\Rightarrow$ voir sil etuit double (ce qui ne fe trouva pas) rom.

פ, pit pill malheur le croupion, en introduifant le

" doigt dans le corps.

"Mr. Hevin l'ayant reçu de la part de Madame de "2 Launay Commat fa tille à qui le paylan l'avoit lni" même apporté à fa Maifon de Campagne qui n'eft $\because$ pas bien éloignée de ce village, il fit appeller le Sr. "Moreau, l'un des plus celèbres (hirurgiens de Ren$"$ nes, pour l'ouvrir. On vuida le ventre, \& on ne "laifia dans le corps du poulct que le cœur, le foie "\& \&es poumons attachés. Mr. Hevin vuida enfuite " la tête \& mit le poulet dans de l'efprit de vin, où ¿, il s'ett partaitement bien confervé, à la réferve du " plumage, car étant de l'efpece de ceux que l'on ap" pelle en Bretanne, de la grand' race, dont le plu" mage eft gris moucheté, il eft devenu d'un roux "fort pâle."

Le poulet monftrueux, confervé dans de l'efprit de vin, accompagnoit cette Relation envoyée à l'Auteur du journal des Savans. Il paroît que ce pullet n'avoit' d'autre monftruofité, que fes quatre pattes \& fes quatre aîles. Celui dont je vais parler, que j'ai vu \& poffédé, avoit d'autres difformités, comme on le voit Planche X. fig. I \& 2.

En 1763 un payfan demeurant à une lieue, ou environ d'Amfterdam, du côté de porte d'Utrecht, apporta ce poulet à un Chirurgien de la ville, en lui difant qu'il avoit vecu cinq jours entiers, \& que le fixiéme la poule l'avoit tué à coups de bec. Il fe tenoit fur deux pattes, marchant avec peine \& d'une manière mal-adroite. Ce Chirurgien l'acheta le mit dans de l'efprit de vin, \& me le vendit quelques jours après. Ce petit monftre a quatre pattes bien formces, deux de chaque côté : deux font à leur place ordinaire, les deux autres font plus haut, prefque fous les aîles, une de chaque côté. Il n'a que deux aîles fans aucune monftruolité. Le corps eft extrêmement gros à pro.

02 
portion du relte. Il n'y a çu'une tête, mais cille femble compofee de trij tites; aufli on remarque trois becs très-fenfibles \& très diftinets quoique tort près les uns des autres, \& prefque fur la même ligne horizontale: feulement celui du milieu eft un peu plus bas que les deux autres: on voit auffir trois ycux, l'un eft ouvert \& place au milieu de la tête, au deftus du bec le plus bas auquel il répond: les deux autres yeux, couverts de leurs paupières, font placés de chaque côté de la tête. Voilà ce que cet animal a de plus monftrueux à l'exterieur. Comme il n'a point été ouvert, \& qu'il eft paffé aujourd'hui en des mains étrangères, je ne puis rendre compte de la confurmation des parties internes.

La Figure I. fait voir le poulet par derrière; la Fig. 2. Le montre par devant.

A l'occalion de ces deux poulets monftrueux, je rapporterai un facus poulet bien plus ćtrange que ceux-là. J'en trouve cncore la Relation dans le Jourmal des Savans du Lundi 28 Juillet I68 I. où l'on peut en voir la figure.

\section{Extrait d'une Lettre contenant l'bifoire \& la defcriptions d'un petit Monflin, écrite d'Avignon le 22 du mois de Fuillet $168 \mathrm{I}$.}

"Il y a deux jours qu'un chirurgien de cette ville 9, qui nourrit chez lui des poules avec un coq, eng, tendant fur les onze heures du matin un bruit de , cris extraordinaires que faifoient enfemble \& toutà-la fois le $\operatorname{coq} \&$ i les poules, eut la curiofité d'aller , voir le fujet de leurs cris. Il trouva tous ces animaux perchés fur des piéces de bois. Il les chaffa d'abord, \& puis cherchant quel pouvoit être l'objet qui les avoit determinés à crjer if fort, jl trouva en cet endroit un ouf de la grandeur ordinaire " de ceux des poules. Cet œuf n’avoit point de coو que, \& le Chiruroien, l'ajant confideré au jour, 
"s'apperçut qu'il n'avoit point de jaune. Il fe fit ap„ porter une affiette, \& ayant percé l'enveloppe ou ") membrane qui contenoit la fubftance de l'œuf, il

" la verfa fur l'affiette, \& vit d'abord avec furprife au-

פ, lieu du jaune de l'œuf une fubltance glaireufe affez

"folide de la couleur d'une chair morte, \& duns

و cette fubftance la figure de la tête d'un petit hom-

"me. Je l'ai vue \& examinée fort foigneufement.

"On y diftingue parfaitement le front, la cavité

و des deux yeux, fans que j'aic pu appercevoir les

g yeux. Le nez y paroit diftunctement, \& avec une

"grande lentille de verre on le voit boutonné. La

"levre d'en haut eft à proportion plus grinde que

" celle d'en bas, la bouche fort fendue, \& enfin on

"y voit le menton au deffous duquel il n'y a plus de

"matière: tout ce vifage n'eft point une figure, mais

„, un vrai relief.

פ. Je confiderai fort foigneufement le deffus de la g, tête où l'on diftingue tort bien \& fans peine une

"fubftance femblable à une cervelle; dont une partic

") fur le nilieu a la forme d'un triangle. 'ai apperçus

" des fibres dans ce cerveau qui eft a découvert.

"Toute cette tête eft de la grandeur pour le moins "d'une petite noix, \& le vifage à peu près comme ", une piéce de quatre fols. C'cit une Relation de vifir "que. je vous envoie. On doit tenter la diffection de " cette petite tête. Si je puis m'y trouver, je vous " en ferai favoir le fuccès. En attendant il ne faut " pas oublier de vous dire que cette téte ivnit deux "affez grands lobes de glaire figée, l'un à droite \& "l'autre à gauche $(*)$."

$\left({ }^{*}\right)$ Journal des Savans all. I68I. Tome Li, page 2?-2. Edit. de Irollande. 
7)ifection de ce Monfre.

". . Dans le deffein d'embaumer ec petit monftre ", on refura d'abord de le laiffer ouvrir. Mis trois "jours après on le donna enfin à difféquer, parce 9, uu'ayant ćte expofé au foleil pendant ce temps là, "bien loun d'v mieur diltinguer toutes chnfescomme ", on l'avoir cru, la chalcur avoit liquefié affez toute פ, cette matière pour la rendre méconnoiffable.

"Mr. Luflin le fils, chirurgien \& très habile $\Lambda$ nag, tomile, fit done cette dillection en prefence de $\mathrm{Mr}$. „, Guifony, Churdon, \& Olivier le tils, Méłecins „, d'Avignon. Il fépara d'abord la première glaire qui , paroiffoit \& qui ctoit tort vifqueufe, après laquelle "il s'en trouva encure une deuxiéne interieure jau"nâtrce, telle qu'on la voit dans un œuf couvé. On 9 découvrit alor's cinq petites cavités dans l'endroit "où l'on défignoit le cerveau, dont l'entrée de cha9, cune réfiftoit à la pointe d'une lancette. Le Long " de la prétendue épine du dos on remarquoir plu: ficurs petits cercles, comme ceux qui dans les vers 2. tiennent lieu de vertebres. Mais à la fin on trouva "une membrane qui enveloppoir généralement le ", tout, dans laquelle ces Meffieurs ayant fait fouffier "avec une paille, on vit s'élever une peau qui for9, ma une cavité affez confidérable à l'endroit ou doit ", être l'abdomen, dans laquelle on diftinguoit une פg forte de matière graiffeufe; \& tout cela fe termınoit , 9 en une queuc ou petit cordon.

,2 La délicatefle d'un fi petit fujet ne permit pas à " ces curieux d'en obferver davantage, même avec " les inftrumens qui grofliffent les objets, dont ils s'ég, toient précautionnes (*)."

On ne fe feroit guère attendu à trouver un effai de la figure humaine dans un œuf de poule: ce qui eft aufi

(*) Lì-meme, page 330 . 


\section{P HIL O S O P H I Q UES. \&c. 215}

Etrange . c'eft ce qu'ajoute Mr. Guifony Auteur de la Relation précedente, au fujet du coq de ec poulailler. Ce coq ayant ete facrific à la haine pubique \& à la fuperftition parce qu'il fut regardé comme la caufe prochaine de ce prodige monftrueux, on en fit diffequer les bas-ventre ou l'on trouva fur la région des lombes un telti:ule unique de la grofleur de celui d'un homme; \& l'un a affuré que jamais on ne l'avoit vu cocher les poules dont l'une avoit pondu un œuf is extraordinaire (*).

Je me fouviens d'avoir vu dans l: livre de Fortunio Licetis fur les Monftres, la repréfentation d'un œuf qui contenoit une petite maffe a figure humaine à la place du jaune $(t)$.

Une femme d'un petit village à trois quartsde liene de Rumılly, ville de Savoic, tira le I 3 Ma! I683 d'une chevre qui venoit de faire un chevreau bien conformé, un fecond chevreau qui étoit monitrueux. Il avoitle mufeau \& un des pieds de derrière d'un chien, \& à ce pied répondoit un pied de chevre tournécomme fi l'animal dût marcher en arrière. Cesdeux pi¿ds étoient accompagnés de huit autres, dont il y en avoit deux la moitic plus petits que le refte. Ce monftre avoit aufli deux anus \& deux queues, dont la fupérieure étoit placéc au lieu ordinaire audeffus du premier anus; \& la feconde fort au deflous du fecond an!is fortoit d'entre les deux dernières jambes, fans qu'on vît à l'extériéur aucune partic fexuclle. Le refte du colps ne différoit de celui des autres animaux de cette cfpece, qu'en ce qu'il étoit un peu plus gros \& que le poil reflembloit aflez à celui du chien $(\mathbb{0}$.

On prit à Ulm, dans le dernier fiecle, un lièvre montrueux qui fut prefenté au Duc d'Hanovie Il

(*) Lì-mème, page 335 .

(t) Fortunii Liceti de Monftrorum Caufis, natura \& differentiis, cum Iconibus, Petavii, I6 34.

(\$) Journal des Savains, an. $169 ;$ 
aroit deux têtes, quatre oreilles, huit picłs, \& res= fumbloit à deux lièvres collés l'un fur l'autre dos à dos. Mais, ce qu'il y avoit de plus plaifant \& de plus curieux. C'eft que, ij l'on en croit l'hiftoire, quand il etoit pourfuivi, \& qu'il étoit las de courir d'un côté, i. fe toumoit adroitement de l'autre \& couroit ainfi fur noureaux frais. Sans-doute l'honneur de tomber entre les mains de ce Prince le flatta ti fort qu'il né. gligea en cette occafion de fe fervil d'un avantage qui devoit le mettre à couvert des pourfuites de tous les chaffeurs (*).

A u mo:s u'Août I683. une femme de Bourg en Brefie accoucina de deux jumeaux au terme ordinaire de neuf mois. Le premicr enfant qui rint au monde etoit parfaitement bien formé \&z proporionné dans rous fes membres. Mais il ne recut que fort peu de temps. Le fecond étoit montrusux. Le Chirulgien le tira mort du ventre de la mère. Il y a des entans qui naifient coëffés: celui ci nàquit tout habillé; car il avoit une efpece de peau en forme de tégument ou de membrane qui lui couvroit tout le corps, \& resfembloit à ure efpece de robe charnue, travaillée par la Nature, mouvante \& plifiée par delfus la chair jusgu'aux cxtrémités des mains \& des piełs. Le vifige feul étolt découvert; \& les traits étoient plûtôt ceux d'un vieillard decrépit \& raccoulci, que d'un cnfant qui vient de naître. Les plis de la membrane étoient furtout fentibles fur le corps, \& même très amples fur les bras, à peu près comme les manches d'une chemife; ils étojent moindres fur les feffes, les cuifles \& les pieds: ce qui ne donnoit que plus de refiemblance à cette membrane avec des bas $\&$ des caleçons. La peau de l'enfant, fous ce tégument, étoit lifle \& polie partout à l'ordinaire. Mass ce qu'il y avoit de plus

(*) Toyez la figure \& la defeription de ce monfte dans les Evhémúrides d'Allcmagne. 
fingulier, eft que cet enfant portoit une forme de capuce de la même nature que la membrane qui pouvoit être ou abattue fur le dos, ou relevée fur la tête pour la couvrir, comme le capuchon d'un moine. Cet enfant étoit de la moitié plus petit que fon frère jumeau, \& néanmoins fa tête garnie de cheveux \& quatre dents très apparentes, avec lefquelles il vint au monde, font conjecturer qu'il pouvoit avoir plus de neuf mois, \& que la Nature avoit employé à l'liabiller la matière propre à fon accroiffement.

Une femme accoucha en 1706 dedeux enfans mâles joints enfemble par la partie infërieure du ventre. Leurs corps jufques-là n'avoient rien d'extraordinaire. La partie moyenne du ventre qu'on nomme ombilicale n'avoit point de nombril ; \& au licu que ces deux jumeaux en devoient avoil chacun in, il $r^{\prime} y$ en aroit qu'un feul pour tous les deux; il étoit précifément au milieu de la partie la plus baffe du ventre, iaquelle leur étoit auffi commune. Ces enfans n'avoient point d'anus, \& de l'endroit où il eft ordinairement, on voyoit fortir les verges dont l'une étoit tournée d'un côté, \& l'autre de l'autre. A chaque côté de ces parties on voyoit un repli de peau qui repréfentoit affez bien la moitié d'un ferotum vuide \& applati. Ces enfants vecurent fept jours.

On lit dans lẹs Mémoires de l'Académie Royale des Sciences de Paris qu'un fœetus venu à fept mojs \& demi, \& mort en naiflant, avoit deux têtes très-bien formées, pofées chacune fur fon cou, \& auffi groffes que s'il n'y en avoit eu qu'unc. Intérieurement il avoit deux efophages, deux eftomacs, deux trachées, deux poumons, les deux fexes, deux épines, mais féparées par une troifiéme efpece d'épine, un cœur unique à une feule oreillette \& un feul ventricule. On prétend qu'il y a quelques exemples de monftres humains.à deux têtes qui ont vecu plufieurs années. S'il s'en prefentoit de nouveaux exemples, une recherche également curieufe \& intéreffante feroit d'obferver 
la différence des penfées \& des volontés ou leur conformité dans chaque tête, d'examiner comment le monitre total fe prendroit à les accorder, oll a facrifier les unes aux autres en cas de contrarieté, où refideroit l'indıvidualité d'un tel Etre \& cn quoi elle confifteroit.

Le Ig du mois de Mai de l'Année i677 le Sr. Deschamps Maìtre Chirurgien à Bonneval près de Chartres, accoucha à 10 heures du matin la femme d'un laboureur nommé Chaudegrin, demeurant à Migrandi Paroilfe de S Maurice L'enfant étoit un monftre. Il avoit une tête à deux vifages l'un devant, l'autre derrière: l'un avoit la face humaine, l'autre avoit quelque chofe d'affieux \& approchant de la face d'un lion. Il avoit deux bras de chaque côtés attachés à une même fouche depuis la tête jufqu'au deffous des omoplates. Depuis ces parties jufqu'au dos, il n’y avoit nulle feparation; mais le bas de l'épine fembloit fe partager en deux, poul former deux corps dittinets \& adoffes derrière cintre derrière, avec deux jambes à chaque corps, oppofies les unes aux autres. Le fère s'etant oppofe à l'ouverture de ce monftre, le Chirurgien ne put obferver les parties internes.

On rapporte plutieurs exemples de monftres humains compofés de deux corps avec toutes les parties dou. bles, tel que ce monitre formé de deux filles dont les corps bien dift nets \& bien conformés étoient joints I'un à l'autre poftérieurement depuis les épaules jusqu'aux feffes *). Mais ordinairement un des deux corps eft defectueux. Un Italien d'environ dix huit ans avoit au deflous du cartilag de la troifiéme côte, du côté gauche, une autre têre beaucoup plus petite que la fienne $(t)$ : Il reffentoit les Impr.fions frites fur cette tête lorfqu'on la touchoit: ce qui prouve

(*) Hiftoire e Mémoires de l'Académie Roynle des sciences de Paris, an. I724.

(t) Li-meme. 
qu'il y a une communication du fentiment du toucher entre deux corps joints enfemble d'une manière unonftrucufe. On difoit à Paris en 1733 . qu'une tille âgée de douze ans avoit deux corps

Mr. Winflow la vit \& l'examina. Elle avoit réellement à la réğion épigaftrique; un peu vers le cô:é gauche, la moitic inferieure d'un corps plus petit à proportion, qu'on prenoit auffi pour celui d'une fille. On n'appercevoit dans le petit corps aucun veftige de tête, ni de bras, ni de poitrine, excepté une rangée de vertebres, dont la portion fupérieure étoit comme foudée à la moitié inféricure du fternum du grand corps. Le refte s'avançoit peu-à-peu fur le devant en s'éloignant de plus en plus du corps entier, de forte que les deux bas-ventres étoient entićrement féparés l'un de l'autre \& tournés l'un vers l'autre, avec les baffins \& les extrémités inférieures. D'ailleur's la conformation dú bas-ventre, des cuiffes, des jambes \& des pieds du corps furnuméraire étoit très-naturelle. Ces parties quoiqu'elles ne donnaffent aucune marque de mouvement, paroiffoient bien nourries, graffes \& dans un état ordinaire d'embonpoint. La peau dont elles étoient couvertes, étoit comme la continuation de celle du grand corps.

Nous terminerons-là cette lifte de monftres: el'e fuffit pour donner une idée des formes irrégulières de l'Etre. Ne pourroit-on pas les regarder comme des effais que la Nature ne ceffe de faire encore aujourd'hui, \& qui annoncent des nouvelles efpeces compo. fées de plus ou de moins de piéces que les animaux ordinaires? Suivant cette conjecture, que le lecteur appréciera, les monftres feroient des degrés par lesquels le prototype s'élève infenfiblement à de nouvelles métamorphofes qui n'acquéreront leur perfection que dans les âges futurs, felon l'ordre immuable des manifeftations. 


\section{$\begin{array}{lllllllll}C & H & 4 & P & I & T & R & E & \text { CXXVIII. }\end{array}$}

\section{Les Hermapbrodites bumains.}

$\mathrm{I}$

A Nature eft parvenue à produire un hermaphroditine affez parfait dans certaines efpeces animales; elle l'a fait même arec une magnificence qui annonce fa fécundité, \& l'aifance de fes pioductions (*). Nous la voyons s'ctudier fans ceffe a produire le même phénomène dans l'efpece humaine; \& les effais, qu'elle a donnés jufques ici tout imparfaits qu'ils font, en marcua it fon but, nous promettent quelque chore de mieix pour la fuite.

Si tout ce que l'on rapporte des Hermaphrodites étoit fuffifamment conftaté, on pourroit compter quatre efpeces d'Hermaphrodifmes récls, favoir celui des fujets qui ont un fexe parfait dont ils peuvent ufer avec fitccès, avec l'autre fexe imparfait; celui des fujets qui ont quelque chofe des deux fexes \& qui ne font puiffans nı dans l'un ni dans l'autre; celui des individus qui ont les deux fexes affez parfaits pour produire comme mâles ou comme femelles, fans néanmoins pouvoir produire feuls, fans s'unir à un autre mâle ou a une autre femelle; enfin l'hermaphrodifme le plus parfait de tous, celui de ceux qui, pouvant $s^{\wedge}$ unir efficacement à un mâle ou à une femelle, peuvent encore engendrer feuls par l'union des deux texes qu'ils poffederit. Il n'y a guere que la première \& la feconde efpeces dont nous ayons des exemples bien prouvés, \& la feconde eit la plus commune de toutes.

(*) Voyez ci-devant Chapitre LII. 


\section{Premiere efpece d' Hermapbrodites.}

On voit quelques individus humains qui, ayant un fexe dominant \& affez bien conforme pour' s'en fervir utilement, ont encore une ébauche informe de l'alltre fexe. Ces efpeces d'hermaphrodites peuvent être de deux fortes: mâles ou femelles, mâles lorfque le fexe nafculin eft dominant; \& femelle, lorfque le fexe feminin eft le parfait. C'eft peut - être le premier pas de la Nature vers l'hermaphiodifme; elle commence par unir à un fexe partait quelques appartenances fimulées de l'autre. Les loix Romaines font mention de ces hermaphrodites manqués \& décident qu'il faut les regarder comme appartenant au fexe qui domine dans eux (*). Dans les temps plus reculés ils ctoient rejettés de la focieté, ou mếme jugés indignes de voir le jour $(\dagger)$. Les Naturaliftes, qui ont eu occafion d'obferver plufieurs de ces conformations, en ont cherché la caufe; mais ils n'ont point été afiez heureux pour percer ce myftère naturel $(\$)$.

\section{Seconde efpece d'bermapbrodites.}

Les hermaphrodites de la feconde efpece, loin $d^{\prime} \hbar$. voir les deux fexes, n'en ont véritablement aucun: ils ont quelque chofe de l'un \& de l'autre, mais dirs un tel état d'imperfection, qu'ils ne peuvent engendrer ni comme mâles ni comme fimelles. Ces Litros ftériles, trop \& trop peu avartagés de la Nature, ne pouvant ni agir ni permettre, font un mêlange com. biné des deux fexes, dans lequel l'un nuit réciproquement à l'autre. On voit errer de ces fujets d'un texe mi-parti, qui vont de ville en ville, de pays en pays, montrer aux curieux l'inutile prodigalite de la Nature

(*) Plin. Hutt. Natur. Lib. VII. Cay. III.

(†) L. X, ad Dig. de Statu hominum.

(\$) Voyez Grauf \& Bartholin, \&c. 
envers eux; je dis inutile, en ce qu'elle ne produit rien dans les individus qui polledent ces apparences trompeufes. Du lelte ce font des chainons eflenticls dans la chuine univerfelle des Etres. Il clt à croireque ces eftais ie pertectionneront avec les générations. J'ai vu pluficurs de ces hermaphrodites, \& j'ai obfervé qu'en genéral la verge n'elt point percée à l'extrémité, defirteque, quoiqu'clle fuit capable d'une érection voluprueufe, elle ne peut cependant répandre aucune femence. 'Tel etoit l'hermaphrodite dont il eft fait mention dans les Mlémoires de l'Academic Royale des Sciences de Paris \& que Mr. Morandexamina: tel étoit celui que je vis à Amfterdam en 1764 . Tel eft celui dont le muriage fut déclaré abufif par arrêt rendu en la chambre de la Tournelle du Parlement de Paris, le Io Janvićr I765. La vulve ćtoit, dins ces trois fujets, un petic trou entre la verge ex l'anus, dans lequel on auroit pu à peine introduire le petit doigt, \& qui n'avoit une apparence extéricure de vulve qu'autant que l'on rapprochoit les chairs des deux côtés pour en former deux efpeces de levres. Du refte ils avoient plus de gorge qu'un homme n'en a ordinairement, \& moins qu'une femme, une peall-affez délicate $\&$ une voix d'eunuque. $\mathrm{Ni}$ les uns ni les autres n'étoient fujets aux ćvacuations périodiques, n'éprouvoient rien en prefence des femmes, \&r leur inclination dominante étoit pour les hommes. J'en ai vu qui n'avoient prefuque pas de poil même aux parties fexuelles, \& d'autres qui avoient des jambes fort velues \& de la barbe comme un homme, mais tous avoient une gorge affez délicate \& point de poil fur l'eltomac.

Les Artiftes Grecs fe font excrcés dans un gुenre de beauré mélangée de celle des deux fexes; \& le temips en a épargné quelques modeles; telle eft la figure connue fous le nom dibermaplodite, \& les $\Lambda$ ntiquaires en citent d'autres exemples. Une opération cruelle forma cette beauté cu privant de jeunes hommes des 
appanages de la virilité. Ce que l'art ne put faire que par une privation, la Nature l'exćcute par la voie contraire. Les hermaphrodites réuniflent les qualités du tempérament de l'homme \& de celui de la femme. Ils les réuniffent imparfaitement, parce que ce font des hermaphrodites tres-imparfaits; quand la $\mathrm{Na}$ ture fera parvenue au point d'allicr dans un même individu les organes parfaits des deux fexes, ces nouveaux Etres réuniront avec avantage la beauté de Venus à celle d'A pollon: ce qui clt peut-être le plus haut dégré de la beauté humaine.

\section{Troiféme espece d'bermaphrodites.}

Un célèbre Médecin rapporte qu'une homme avoit époufé une femme hermaphrodite dont il eut des cnfans, tant mâles que femelles (*). Voilà done un hermaphrodite de la troifiéme efpece, qui avoit les deux fexes, \& pouvoit engendrer comme homme \& comme femme. On dit qu'à Surate au Mogol, il y a beaucoup de ces hermaphrodites, qui, avec des habits de femme portent le turban pour faire connoître qu'ils ont les deux fexes. Si ce fait étoit bien avére, l'ouvrage de la Nature, feroit beancoup pius avancé qu'on n'ofe le croire, faute de témoignages fuffifans,

\section{Quatrieme espece d"bermapbrodites.}

On parle d'un moine qui s'engroffa lui-même. Ce fait a été traitéde fable, \& pourroit bien en être une, Mais il y auroit de la témérité à affirrer qu'une pa-

(*) Viro nupferat cui filios aliquot \& filias peperit; nihilnminus tamen ancillas comprimere, \& in his generate foleba:. schenck Ob Sery. 
reille fécondation elt impoffible. Un hermaphrodite; qui auroit les organes des deux fexes dans un tel degré de perfection, \& dans une telle fituation qu'il pourroit fe féconder lui-même, feroit un Etre fort étrange, felon les idées vulgaires; j'en conviens. Cet Etre eft-il impoflible? Je le demande envain aux $\mathrm{Na}-$ turalites: la Nature eft feule capable de décider la queftion.

Je m’étois propofé d'étudier la gradation naturelle des formes de l'Lire. Je cede la plume à un pius habile que moi.

\section{F I N.}

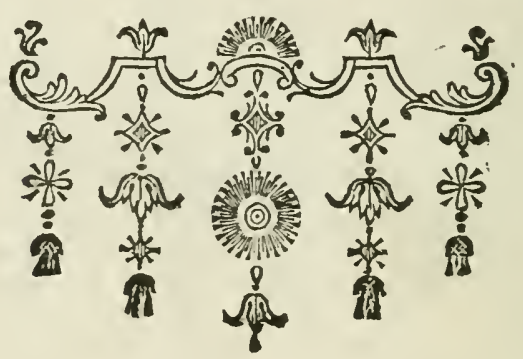




\section{T A B L E ANALYTIQUE \\ D E S \\ C $H A P$ P T R E S.}

PREMIERE PARTIE,

CHAPITRE I. Tous les Etres ont été concus \& formés d'après un feul defein primitif dont i's font des variations graduées a l'infini. Du prototype, \& de fes métamorpholès conficterées coinm aittant de progrès vers la forme la phus excellente de l'Etre, qui efl la form bumaine. $\quad$ - page I

Marche nuancée de la Naturé : enchainement univerfel des Etres. Acte unique dans la Nature: la permanence. Desfein unique, exenplaire original de tous les Etres. L'homme le plus parfait de tous, formé comme les autres, d'après ce prenier modele perfectionné dans une infinité de variations. Bipedes, bimanes, quadrupedes, folipedes pieds - fourchus, fiffipedcs, quadrumanes, l'homme feul animal bimane \& bipede. Le magot. L'Orang - outang plus reffemblant à l'homine qu'à aucun antre animal. On appelle prototype le deffein unique d'après lequel toris les Etres ont été conçıs \& formés. Chaque variation de l'enveloppe du prototype coufidérée conme une étude de la forme humaine. La Nature occupée à travailler ces études ou ébauches de l'loumme. Rapports du prototype avec l'homme. Du principe de continuite, fondement de la nouvelle manière de contempler la Nature \& fes productions.

CHAPITRE 11. Oì l'on recberche foc'ell la matidr out la force qui conflitue le fond de l'Etre.

Problême univerfel que la Nature avoit à refondre \& dont elle 2 donné uue infinité de folutions. Matières \& netivité. Etres inférieurs où la matière domine. Etres mitoyens ou la ı2- 
tière \& laćtivité femblent fe difputer l'cmpire, \& l'eun porter tour-i-iour. Litres liupéricurs oì la matière u'ett que l'accelpoire, l’organe par lequcl le principe actif déploie fes facultés. Gradation de la puiffance active. Conjectures fur cette gradation. Cette aćtivité, ou force, conçuc comme une tendance à un changement cn micus, qui s'exerce fans ceffe nécefhirement. Monde matériel, pur affemblage de phénomencs. Monde invifible, linjer ou foutien du monde vifible. Ce monde invifible eft 12 collection de toutes les forces. Génération de ces forces. Prototype compofé de la force prototype jointe a la forme prototype. Particularités it oblerver clans la proyreffion univerlelle de l'Erre, qui font fentir la raifon pourquoi, dans la partie inférieure de l'échclle, les Etres femblent tenir plus de la matière que de la force, tandis que c’eft le contraire dans la partie fupéricure.

\section{CHAPITRE 111. De la première ébauche de la For-} me Humaine dans les Folfiles.

Comparaifon tirée de la marche \& des progrès le l'Art. Ses foibles commencemens. Trente Idoles adoríes en Gréce, fans aucuns traits de la figure humaine. C'étoient des blocs irréguliers, des pierres quarrées ou des colomnes. Têtes groffièrement ébauchées mifes fur ces pierres ou colommes. La partic inférieure de ces inaffes léparcéc en deux pour indiquer les cuifles \& les jambes. Par combien d'ébauches l'Art s'éleva de ces formes groffières aus belles formes de la Venus Grecque, de l'Apollon du V'atican, du Génic aîlé de la Vigne Borghefe, modèles éternels du vrai bcau. Differens ttyles : leur fucceffion. Pcrfection de l'Art dans Praxiteles, Lyfippe \& $A$ pelles.

Application ta la marche de la Nature dans la production des Etıes. Premières réalifations du Prototype par lesquelles la Nature préparoit de loin fon clief-d'ceuvre. Corps foffiles premières ébauches de la macline en tant que compofés de folides \& de fluides. Premiers types du tronc ou corps de l'honme, du cour \& des poumons. Dégradation de ces parties efienticlles. Inlećtes; polype; plantes; minéraux. Economic ritale de ceux - ci. De quelle fineffe \& de quelle fimplicité ne doivent pas être les organes d'une vie fi fumple dons des Etres aufli purs que l'or \& le Diamant? Ces organes, quelque forme qu'ils aient, font un progres de l'Etre vers la forme de leurs analogues dans les végétaux, dans les infectes, dans les srands animaux, \& finalement dans l'homme.

CHAPITRE IV. Des Litbocardites \& Boucardites. Des Antbropocardites ou pierres qui ont in fio re d'un ceur bumain. 


\section{DES C IA A I T RES.}

Ori conmoit un grand nombre d'efpeces différentes de T.ithocarlites. Defcription \& figure d'une Anthropocardite rare \& fingulière.

CHAPITRE V. Dss Encepbabiödes ou Encepbribithes, pierres qui imitent le Cerveau bumain. .

Efpece particullerc rapporte par le Dr. Plott \& qu'il dit avoir vue.

CHAPITRE VI. Carnioïdes ou pierres qui reprefentent le crâne bumain.

Sentiment du Dr. Leyel fur une de ces pierres, refuté par uri autre foffile dont parle le même Autenr. Efpece de Carnioïdes mentionnce par Schenchzer \& dont on trouve quantité aux environs de Bafle. Autre efpece, crue mal-à-propos un crâne pétrifié. Hyppocephaloïdes ou pierres qui repréfentent la tête d'un clieval. On en donne la figure \&. la defcription.

CHAPTIRE VII. Pierres qui repréentent la Machoire bumaine.

CHAPITRE VIII. Os bumains folfiles.

ibid.

CHAPITRE IX. Andropodites, ou pierres qui imitent le Pied bustain.

I. Première efpece.

Celle que le Dr. Plott a trouvée dans une carriçre au pied du mont Shotover, qui repréfente le pied humain coupé un peu au defius de la cheville. Les doigts $n^{\prime} y$ font point niarqués. On en donne la figure.

2. Seconde efpece.

Le pes humants fexeus dont parle Wormius, qui repléfente le pied gauche d'un jeune homme avec les articulations, les doigts \& l'os de la jambe.

\section{Troifiéme espece.}

Eelle-ci repréfente la figure d'un pied humaị, 2u poínt d'y" reconnoftre les rotules \& les petits os. 
Voyez la Defeription \& la figure de cette pierre fingulière dont parle le Dr. Brookes dans fon Iniftoire Naturelle.

CHAPITRE XI. Olites ou pierres Auriculaires. ibid. Elles repréfentent la tornue catéricuse de l'nreille de l'homme.

CHAPITRE XII. Pierres qui repréfentent un eil.

1. Pramière elpece.

Ic Leizcoptatchiäos de Pline. Sa defcripion. Méprife de Mr. Dargenville au fujet de cette pierre.

2. Seconde efpece.

L'Ocyophtaimos on Acyophtalnzos qui fait voir un petit eil faillant \& pointt?.

3. Troifiérie espece.

La pierce nominée Triophtalmos qui porte Ia figure de trois yeux.

4: Quatriessie elpuce.

Celle dont on donne la figure, qui repréfente un ceil clargé d'une taie ou cataracte. C'eft peut-être l'œil de Belus, Oculus Beli, mentionné par Boot.

\section{Cinquieme efpece:}

Une belle Onyx qui repréfente deux yeux, nommée pource. lis Diophitalinos.

\section{CHAPITRE XIII. Pierres Mammillaires. 26}

Elles repréfentent la mammelle d'une femme.

1. Première efpece.

Celle dont on donne ici la figure \& la defcription. C'eft fa plus reffemblante.

2. Seconde efpece.

Ce!le dont parle le Dr. Brookes dans fon Hiftoire Ninturelle. 
CHAPITRE XIV. Pierre nommie. Lapis Chirites, repréfentant une Main bumaine. • . 27

Elle repréfente la paume de la main avec des formes de doigts \& d'ongles de couleur de chair.

CHAPITRE XV. Pierres qui repréfententun Mucle. ib.

I. Premiere efpece.

C'eft la grande cfpece: elle oft allonge \& un peu applatie d'un cơté.

2. Seconde efpece.

La petite efpece dont l'ovale p'eft point applati,

CHAPITRE XVI. Pierres qui repréfentent le Nerf olfacioire.

On en donne la figure et la defcription.

CHAPITRE XVII. Des pierres appellées. Orchis, Diorchis \&f Triorchis.

Réflexions fenfées d'un Auteur moderne fur la faufe délicateffe des perfonnes qui s'imaginent qu'on fait une infulte à leur inodeftie en leur préfentant des defcriptions anatomiques \& des figures des parties nobles de l'homme \& de la femme, appellées auffi parties honteufes par une bizarre contradiction. On n'en trouve ici que des modeles folfi!es.

I. Orcbis.

Cette pierre reprefente un tefticule de l'homme ou d'un animal quelconquic.

\section{Diorcbis.}

Cellc-ci repréfente les deus tefticules. Diorchis d'me gros. feur extraordinaire.

\section{Triorcbis.}

On la nomme ainfi, parce qu'elle reprefente trois tefticules. CHAPITRE XVIII. De la pierre nommée Scrotum humanum. 
Glle reprefente le Scrotum ou la bourfe contenant les tefti: cules.

CitaPITRE XIX. Des Priapolites, Colites \& Pbazlëdes.

\section{Premiere efpece.}

Elle repréfente. I.e membre viril enfté, avec les tefticules: prinpolites Saromire cum uppenfis teftibus. On en donie la figure,

2. Seconde efpece.

Colle-ci eft un fimple cylindre allongé imitant le membre yiril, mais fans teficules.

3. Troifiéme efpece.

C'eft une variation de la prúcédente qui n’en differe que par 1: coulcur.

On ne peut s'empêcher de faire ici une réflexion fur les fos: files des trois d rniers Cluapitres. On y voit la Nature travailler d’alond féparémnnt les tefticules, les loger enfuite dans la bourle ou Scrotum, puis les fufpendie ainfi a la riscine de lo verse.

\section{CHAPITRE XX. Pierre nommée Hifterapetra.}

Cette picrre repréfente la vulve de la femme: Voyez la figure \& la defeription.

\section{CAAPITRE XXI. De l'Hifterolithos, ou Diphys,} ou Liphrys,

C'eft un foffile qui repréfente d'uu côté la partie naturelle de la femme, $\&$ de l'autre côté les parties de l'bomme. Eft-ce un type des hermaphrodites?

CHAPITRE XXII. Caillou comnu fous le nom de Puer in fafciis.

i] reprefente la figure bleutre d'un enfant en maillot.

CHAPITRE XXIII. Autre caillou repréfentant les fefles d'un enfant. 
CHAPITRE XXIV. Figures bumaines empreintes fur des Agatbes \&O autres pierres. . .

Portrait naturel dans la manière de Rembrant. Deux petits portraits de Negres. Autres pier̃es, rapportées par Wornius \& Bartholin, repréfentant le corps lumain avec toutes fes parties,

CHAPITRE XXV. D'un Rocber appelié le Moine pendu.

CHAPITRE XXVI. Conchufron des Chapitres précedens. . . . . ibid.

Cette quantité de pierres que l'on vient d'expofer fous les yenx du Lecteur, fuffit pour faire voir que la Nature, en travaillant les folliles, modéloit véritablement les différentes formes du colps humain. Elle les préparoit même dans lcs Etres inférieurs aux picrres.

\section{SECONDE PARTIE.}

CHAPITRE XXVII. De l'intérieur des foffiles confideré comme un type de l'organifation

Les foffilcs font des tiffus de fibres \& de veines, lesquelles font très finfibles dans plufieurs efpeces. Ces veines it ces fibres font des organes. Raifons fur lesquelles eft appuyé le fyftème qui tefufe une vie particulière aux fosfiles, nne vie convenable à lcur efpece. Réfutation de ces raifons. Preuves directes qu'il y a dans les pierres un fluide qui nourrit les parties folides. Eau qui diftille des voutes des grottes. Pierres qui augmentent de poids \& de volume daus l'eau. Pierres grafles \& huileufes au toncher. Pierres qui donnent plus on moins de liqueur' it la diftillation. Pierres dont le poids dininue $\&$ dont la furface devient concave après la fufion. D'où vient la couleur des pierres précieufes. Pierres quí femblent ałes éponges pleines du fluide électrique. Deftination des fibres \& des veines. Analogic des fibres pierreufes $\mathbb{E}$ métalliques avec les fibres animales. La ftructure des pierres eft plus ou moins uniforme. Gradation d'appareil fibrillaire dans les fofliles.

CHAPITRE XVIII. Pafage des Minéraux aux Plantes.

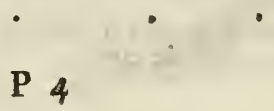




\section{$33^{2}$ TABLE ANALYTIQUE}

Ce panige e? rempli par les pierres fenfiblement fibreuies dont iI eft queftion dans les Chapitres fuivans.

CHAPITRE XXIX. Les Mica.

page 43

Les caracteres de ces picrres. On compte ici huit cfpeces fuivant la figure, la coufitance \& l'arrangement de leurs partics.

I. Première efpece: Mica roide; Mica rigida,

2. Seconde efpece: Mica fexible, blanc argenté; mica flexilis argented.

3. Troifiéme efpece: Mica écailleux à lames pointues: mica particulis tenuiorıbus acuminatis.

4. Quatriéme efpece: Micabrillant; mica femi-pellucida.

5. Cinquiéme efpece: Verre de Mofcozie; vitrum Molcovitum.

6. Sixiéme efpece: Mica firié; mica particulis oblongis.

7. Septieme efpece: Mica demi-phériqne; mica hremifpherica.

8. Hutitiéme efpece: Mica irrégulier; mica fquammulis inordinatè mixtis.

CHAPITRE XXX. Les Talcs.

plus on compare la fructure des mica \& des talcs à celle des 03 , plus on fe convainc que l'unc eft une étude de l'autre.

CHAPITRE XXXI. Des Pierres Ollaires. ibid.

Caractères \& fructure de ces pierres,

CHAPITRE XXXII. Les Roches de corne.

1.a fubfance de ces pierres eft cornée, ce qui les a fait ap. peller roches de corne. 


\section{DES C H A P I T R E S.}

\section{CHAPITRE XXXIII. Les Amiantes.}

Paffige de Mr. Wallerins, dans lequel le Naturalifte reconnoît l'analogie des aniantes avec les fubltances des règnes végétal \& animal.

I. Première efpece: Amiante de Cbypre, lin ou laine foffile; lana montana.

2. Seconde efpece: Cuir folfile; corium montanum.

3. Troiféme efpece: Cbair fofjile; caro montana.

Rapport de la ftructure des aminates avec les chairs.

CHAPITRE XXXIV. Les Asbefles.

Les asbeftes ont avec les nerfs \& les mufcles, les meines rapports organiques que les amiantes ont avec les cliairs. Asbefte mur; asbefte qui n'eft pas encore inùr.

CHAPITRE XXXV. Si les Amiantes \& les Asbefes doivent être mis au rang des minéraux, ou des végetaux?

La queftion eft bientôt décidée fi l'on confidere que les amiantes \& les asbeftes participent plus de la Nature \& des propriétés de végétaux que de celles des minéraux,

\section{TROISIEME PAR TIE.}

CHAPITRE XXXVI. Sommaire des rapports org'a. niques de la Plante avec i'Homme.

Truffe, 110 toch, cliampignons, lichens, plantes lierbacées, arbriffeaux, grands arbres. Multitude immenfe des plantes; variété infinie de leurs figures. Rapports organiques de la plante avec l'homme. Diftinction de fexes. Parties fexuelles. Etamines furmontées de gouffes fpermatiques, tnalogues it la verge \& aux tefticules. La bafe du piftile, fes conduits \& fon fommet, quỉ répondenc à la matrice, aे fes trompes, \& a la vulve de la femme. Fœtns plante, fes filets ombilicaux, fon double placenta, fes enveloppes, \& la manière dont ils fe nourrit. Divifion de la plante en tronc \& extrémités, comme colle de l'homme. parties folides de denx fortes dans un arbre comme dans un homme. Ecorce de l'arbre compofée de trois meis, 
branes, comme la pean humaine. Deux fluides généraux Jans l'écononie végétale de daus l'économic animale. La feve eft le fang des plantes; une liqueur, vifqueule particuliere, leur tient lieu de fymphc. Nutrition de la plante E aflimilation dus parties propres : excrétion des pattics hécérogènes. Ses poumons \& fa refpiration. Sa tranfpi ration. Son temps de veille \& de fommeil, Scs maladies.

\section{CHAPITRE XXXVII. De la circulationde la Seve} lion les plantes.

Syftema da Mit. Frew fur la circulation de la feve clans les plates, exuraic de fon Ancionic des Plantes. Syftême d. If: Desu extrait de fon Trsite de Plume des plantes.

I) 1 : a $p$ sint de cire'slatiun proprement dite dans les Plantes, il $n^{2} y$ in a qu'm ctiai.

fa APIIR! XXXVIIL. Nevet fingulier reprisen-

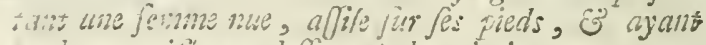
d: brits croijès au depous de la poitrine.

CHAPITRE XXXIX. Cbampignon repréfentant $\int n_{0}$ figures bumaines.

flveil a une, dont la tête de profil fait voir nu œil, le nez la bouche, le menton anfii exastement deffinés que l'anrinit pu faire une main habile. Les cinq autres figures ne montrent que le dos.

CHAPITRE XL. Mandragore repréentant la figure d'une fenmone.

CH APITRE XLI. Rave ayant la forme d'une main bumaine.

CHAP!TRE XLII. Les Zoopbytes, ou Plantes animales. Infectes aquatiques.

Zooplivtes rapportes par Aldrovande \& après lui par Ruyfcl. j)ivition de ces animans felon la Méthode de Ml. Linnzus. Divilion de M1. Donati. Nature \& organifation des Zoophytes. Leur analogie avec les plantes. Zooplyytes branchus on rancux, dont l'intéricur n’ofle que les vifcères tcls ì peu près qu'ils font dans les végétaux. Autres clpeces dans qui la Nature a lupprimé les extrémités, \& qui ont nuc or anifation intérieure plus avancée vers colle des grands animanx. 


\section{1) LS CII A P T R E B. \\ QUATRIEME PARTIE.}

CHAPITRE XLIII. De quelques formes du corps bumain ébauchées dans les Zoophytes. La main de mer: Manus marina.

C'eft l'Alcyonium rameux, mou, dont les ramifications font en forme de dloigts, \& qui eft entièrement étoilć. Aíyo.

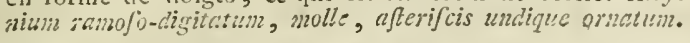

CHAPITRE XLIV. Le Poumon marin, ainfinommé parce quili reffemble de nos poumons tant par Ja forme externe que par fa fructure interne. ib.d.

CHAPITRE XLV. Le Rein de mer.

CHAPITRE XLVI. Des Holothuries ou Verges ma. rines; en Latin Holothurium. • isis.

I. Première efpece. Mentula marina. Sa defcription,

2. Seconde Efpece. Epipetrum. C'eft la plis beile. S.h defcription.

3. Troifiéme espece. Mentula alata pifcatorum.

CHAPITRE XLVII. Cbampignon marin, dont la partio fupérieurs repréfente la vulve d'une feimme.

\section{CINQUIEME PARTIE。}

CHAPITRE XIVIII. Les Infecties terreftres.

Rapports des ver's d'ea!! douce avec les vers de terre. Analogie des infectes avec les plantes, qui préfente unc iniage figurative de la métamorphofe d'une plante en infećtes. L'intérienr, l'enveloppe, les formes faillantes. Chenilles épineufes; efpece de bıifions ambulans. Les aîles, la tête, les yeux: leır nombre \& leur ftructure. Leeuwenhoek a calculs qu'il y en avoit $318 \mathrm{r}$ fur une fenle cornée d'un fcarabéc, \& qu'il y en avoit plus de 800 fur chacune de celles d'une monche. Mobilité de la tête des infectes. Leurs organes de la génération. Digreffion cu farme de note fur les hommes préţndus acépliales. 


\section{$=3^{3}$ TABLE ANALYTIQUE}

CHAPITRE XLIX. Les Cogtiillages.

Les coquillages ne font, aux youx de plufieurs Naturaliftes, que des vers de mer, de rivière, ou de terre, logés dans des coquilles univalves, bivalves, ou multivalves.

CHAPITRE L. Buccin de mer appellé Oreille de mer. Auris marina.

Un en donne la figure \& la defcription.

\section{CHAPITRE LI. Conque de Venus. Concha Venerea.}

Elle repréfente la vulve d"une femme d'tme maniere beatcoup plus parfaite que les deux autres modeles rapportés dans les Clapitres XX. \& MLVIl. On en donne la figure \& la defcription.

\section{CHAPITRE LII. Do Hermapbrodifine de quelques} coquillages.

Il y a trois efpeces d'hemaplirodifme dans les coquillages.

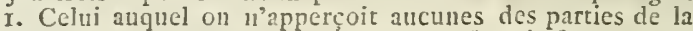
génération, foit mâles, toit femelles; \& qui, fans aucune efpece d'accouplenent, produit fon femblable: il eft particulier aus conques. 2. Cului qui, reunilant en foi les deux efpeces de parties lexuelles, ne peut fe fuffire à luimême; inais a befoin du concours de deux individus qui Se fécondent réciproqueinent \& en même temps, l'un fervant de mâle à l'autre, pendant qu'il fait à fon egard les fonctions de femelle: cet hermaphrodifme fe voit dans les limaçons terreftres. 3. Celui qui, poflédant les deux efpeces de parties génitales, a befoin de la jonction de deux individus, mais qui ne peuvent fe féconder en méme temps, à caufe de l'éloignement de leurs organes. Cette ficuation defavantageufe les oblige de monter les uns fur les iautres pendant l'accouplenent. Si un indiridu fait à l'égard de l'autre la fonction de mâle, ce mâle ne peut-étre en inême temps fécondé par fa femelle quoique hernaphrodite; il ne le peut-être que par un troiliéme individu qui fe met fur lui vers les côtes en qualite de inile.

\section{SIXIE M E PARTIE.}

CHAPITRE LIII. Pafage des Animaux Tefacés oux Crufutces. 
La Cancre nommé vulgairement. Le Soldat ou Bernard l'Hermite. Cancellus macroufus, cauda molli tefta cochlex inclufa, chela dextra majore. Linn. Syft. Nat.

Les Amimaux cruftacés font aufi des infectes inarins ou fllviatiles, recouverts d'une enveloppe moins dure que celle des teftacés. Parallele autre les uns \& les autres. Les écailles, les coquilles \& les croutes font les os des infectes terreftres \& des infectes aquatiques. Ils ont done leurs os à l'extéricur comme les grands animaux les ont t̀ l'intéricur. Premiers traits du fquelette des grands ani. malux.

CHAPITRE LIV. Les Serpens.

On tache d'expliquer d'une manière naturelle le paffage des cruftacés aux Serpens, par la fuppreffion gradiée des parties faillantes, le déplacement des os de l'extérieur a l'intérieur. Squelette du ferpent premiere ébauche du: fquelette humain.

CHAPITRE LV. Serpent des Indes Orientales, appelle par les Portugais Cobra de Capello, portaint fur le dos un mafque ou une figure bumaine.

Sa Defcription. Conjecture fur les Serpens à Lunette.

CHAPITRE LVI. Réflexions fur les animaux qui n'ont point de membres, E fur leur diflribution dans l'écbelle des Etres.

I] s'agit d'expliquer pourquoi la Nature, toutes les fois qu'elle veut donner une forme neuve aux extrémités, elle commence par les fipprimer peu-à-peu, \& que, quand elle eft parvenue à les fare évanouir, elle produit quelques Etres intermédiaires qui n’en ont point du tout, anxquels fuccedent enfuite les animaux avec de nouveanx niembres. Comparaifon de lis métanorpliofe concinuelle de l'Etre univerfel avec la métamorphofe ordinaire des infectes âles. Différence entre l'une \& l'antre unétamorphofe.

\section{SEPTIEME PARTIE.}




\section{T A B L E AN A L Y T I U E}

Scrpens marins, les congres, \& les murenes. Les petits ailerons de quelques efpeces anuoncent les nageoires. De. fcristion abrénée de l'Ophidion. Combien l'action de magel" a de rapport avec l'aition de ramper on ferpenter. Quelques Auteurs penfent que c'elt parler plus jufte de dire que les poitions rampent que de dire qu'ils nagent. Ils s'atutorifent d'un paffage de la Genefe I. 20.

\section{CIIAPITKE LVIII. PoifJons Antbropomorphes. page $8 \mathbf{z}$}

\section{Curpe is figure bumaine. Cyprinus Anthropomor-} phos.

Deferipion de cet animal fingulics. Première carpe à figure lntrntine apportée furr le marché public de Lyon où elle fitt vue de tout le peuple, au rapport de Rondelet. Seconde carpe femblable prifée en $\mathbf{5} 5$ t. dans l'étang de Noze.et. cnvoyse par Gilbert Voifin à Gefner qui en parle. Tro:fíme carpe femblable prife dans le lac de Conftance en 1:45. Ouatriéne carpe de la mẻme efpece préfentée à Cliarles V. at Ausbourg.

CHAPITRE LXI. Poiffon d' Amboine, fort rare, nemúe. Anac lafet jang terbougkoes, c'eft- $\vec{\partial}-$ dire P Enfant de mer enmailloté.

Il a véritablement la figure d'un enfant dans fon maillot, a. voc les bials \& les mains lortis.

CHAPITRE LX. Poiffon dans le corps duquel il s'entendre une pierre qui a la figutu d'une tête bumaine.

Il eft de la grandenr de notre merlu ou merluche. On le nom:ne poillon de St. Pierre.

\section{CHAPITRE LXI. Le Poifon volant.}

C'eit l'exocet. Il y en a plufieurs efpeces qui ne different pourtant que par leurs aîles \& les couleurs de leur robe: car pour le corps elles ont toutes la forme d'un liareng.

\section{HUITIEME PARTIE.}

CHAPITRE LXII. Les Oifeaux, ou Bipedes ailés. 8:

Oifenux aquatiques palmipedes. Oifeaux terreftres ou ä̈riens fiflipedes. 
CHAPITRE LXIII. L'Autrucbe.

Comme nous nous attaclions particuliérement it ce qui a quelqtic rapport avec l'homne, nous remarquerons dans l'autruche fes yeux prefiute linbiables a ceux de l'homme.

CHAPrTRE LXIV. La Chauve-Souris. La Rousjette.

La Chauve-Souris malle a la verge pendante \& détacliée, ce qui ne la!i eft commun qu'avec le finge \& l'honme. Ia femelle a deux mamelles fur la poitrine, comme la femnue.

Eir quoi la rouffette differe de la chanve-fouris.

\section{CIIAPITRE LXV. Ecureuil volant. Singe volant.} Chat volant.

L'écureuil volant a de petites oreilles arrondics \& tournées comme celles dn finge \& de l'homme.

L'exittence du finge volant dont parlent quclques Autcurs n'eft pas bien conftaté : ils pourroicnt bien avoir pris un finge pour un écureuil.

Le Clat volant femelle a fur la poitrine deux tettes grandes \& rondes, femblables aux manmelles d'une femme.

CHAPITRE LXVI. Le Lézard volant oupetit Dragुon ẩlé.

Defeription de ce nouvel effai de quadrupede volant.

CHAPITRE LXVII. Obfervation fur le paffage des Oifeaux aux Quadrupedes.

On demande pourquoi, dans ce paffage, la Nature n"a point fupprimé dans quelques efpeces intermédiaires les membres qu’elle transforme, conme elle les a lupprimés en paffant des plantes aux infectes, des infectes teriefres aux cruftacés, des cruftacés aux poifluns.

\section{NEUVIEME PARTIE.}

\section{CHAPITRE LXVIII. Les Cétacés.}

\section{Le Renard marin.}

Les célacés font de grands aimmaux marins qui ont le corps nud \& allonge, garni de membres chratus. Ils reffem- 
blent beancoup aux quadrupedes, quoiqu'ils foient pour la plupart des efpeces de bimanes. On les nomme cétacées, parce que les Naturaliftes les ont rangés dans $l_{2}$ claffe de la baleine nommée cete.

Le Renard marin a deux nageoires auprès de la téte qui repréfentent affez bien les aîles d'un oifeau plumé. Ces â̂les offenfes $\mathcal{E}$ charnues, très obtufes par les bords, femblent deftinées à former des doigts dans les bimanes.

\section{CHAPITRE LXIX. Les Bimanes. . pageg6}

Première ébauche des mains très groffière. Elles ont quelquefois jufqu'at fept ou huit doigts. Celles d'une efpece de baleine - cachalot en ont fept: celles d'une efpece de Diable-de-mer en ont huit. Celles du lanentin \& du finge de mer n'en ont que quatre. Doigts exceffivement courts, doigts monftrueufement longs. Raifon de toutes ces différences.

\section{CHAPITRE LXX. La Ealeine.}

Il eft conftant que la baleine eft bimane. Elle a, aulieu de. nageoires, des os articulés, figurés comme celix de la main \& des doigts de l'homme, revétus de mufcles \& de beaucoup de chair tendineufe \& recouverts d'une peau Épaiffe femblable à celle qui enveloppe le refte du corps, leur maffe énorme les déguife \& les a fait appeller des bras, des âlles, des nageoires; leur figure veritable de mains n'a pourtant pas échappé à ceux qui l'ont vue \& confiderée de près.

\section{CHAPITRE LXXI. Le Diable de mer.}

Plufieurs poiffons portent ce nom. Le Diable de mer dont il s'aglt ici eft un cétacéc de douze pieds de long \& davantage, qui a deux mains fous le ventre, compofées chacune de cinq doigts articulés.

Diable de mer échoue au fort de Kermoryan ì quatre lienes de $B r \in f t$.

Autre Diable de mer échoué dans le rade de Ereft, décrit par Mr. Saycry.

\section{CHAPITRE LXII. Le Lion marin.}

On trouve dans l'Ine de Juan Fernandez un amplibie ap. pellé. Lion majin. Defcription de cet animal, extraite des voyages din Lord. Anfor.

La baleine, le Diable de mer \& le lion marin pourroiene être appellés des bimanes eftropiés. Leurs maains font comme jointes imúdiatement aux orzoplates. Dans la 
baleine \& le diable de mer ont ne voit ni l'lumerus ni l'aveint-bras; la partic qui répond à la main de l'homme fort immédiatement de la potrinc, les deux autres font enfermées ex cachées dans le corps, fous la peau. Uans le lion marin, une portion de l'avant - bras fe inontre at delors. Le bras fortita en entier dans les bimatnes qui fuivent.

\section{CHAPITRE LXXIII. Le Lamentin。 . page 102}

La Nature fupprimant les'nageoires, les cornes et la queue des autres étacées, a formé. une malfe vivante de près de dix-huit pieds, qui n'a d'autres nembres que deus bras courts ex ranafiés, auxquels font attichées denx petites mains qui n'ont chacune que quatre doigts ciourts «t gonlés. C'eft le lanentin. Cet animal à les yenx qetits: fa peau eft épaile, ridéc en quelques cndroits, d parfeméc de quelques petits poils. Il a deux manmelles fur la poicrine qui eft peut-èce un caractère des cétacées bimanes. Il s'accouple à la maniere de.l'homme. Ses bras font flexibles : la femelle s'en fert at tenir \& porter fes petits, à-peu-près conme les finges tiennent les leurs. On en dunne la figure.

CHAPITRE LXXIV. Le Singe de mer Dano's Simia marina Danica.

Je finge de mer a deux mains \& furtout deux bras que l'on prendroit pour des bras humains s'ilsétoicnt fur un autre corps.

CHAPITRE LXXV. L'Ambize.

Cet animal, qu'il faut bien diftinguer de l'homme marin a deux bras fort courts, avec des mains qui peuvent fe courber un peu, mais qui ne fe ferment point comme celles de l'homme: les doigts qui ont une certaine lonsueur fort jo its par une nembrare, $E$

\section{I X I M E P A T IE.}

\section{CHAPITRE LXXVI. L'Homme marin. . I06}

Tant de temoignages autentiques conftatent l'exiftence des poilfons-honynes \& des poifons-femmes par la moitis fupérieure du corps, qu'il y auroit plus que de l'opiniz. rreté à en douter.

CHAPITRE LXXVII. Homme marin pêché di $O x-$ ford, dans le Ducbé de Suffilck. . . ibid. 
Sa figure étoit fi conforme à celle de l'homme, qu'il fenbloit ne iui manguer que la parole. Le gunverijeur le garda fix mois; mats un jonr s'étant échappé, il fe r'splongea datıs $12 \mathrm{mcr}$, \& on ne le revit plus.

\section{CHAPITRE LXXVIII. Elpece de Sirene pêcbée en} We elfrije.

C'eft cette fille marine dont il cft parlé dans les Delices de la Hollande, qui fe laitia habiller, apprit à filer, ufa de nos alimens, de pain \& de lait \& qui ne put jamais apprendie à parler.

CHAPITRE LXXIX. Sept bommes marins \& neuf . femmes marines. $\quad$ : : : ibid.

Ils furent pris près de l'Ifle de Manar daus les Indes. Di. mas Bofquez, de Valence, Medecin du Vice-roi de Gea en fit l'ouverture \& trouva toutes leurs parties intéricures $\&$ extérieures trés conformes it celles de l'homme $\mathbb{\&}$ de 12 femmc.

\section{CHAPITRE LXXX. Sirene d'une grande beauté.}

Cette belle firenc fut apperçne en 6 r q,par leCapitaine Schmidt dans Ia nouvelle Angleterre. Elle ne le cédoit en rien aux plus belles femmes par lia partie fupérieture de fon corps, mais la moitié infúrieure, en commençant à la région ombilicale, refiembloit it la quete d'un poiffon.

CHAPITRE LXXXI. Témoigizage de Monconys. ibid.

CHAPITRE LXXXII. Cinq bommes marins, \& ane femme marine.

Homme marin pris fous le Pontificat d' Eugente IV.

Homme snarin \& femme marine ous dans le Nil fous l' Empereur Maurice.

Homme marin pris en Frïe en 1526.

Homme marin pris en $\mathrm{I} 53 \mathrm{I}$, dans la Mer Baltiqus

. Feune bonme marin pris près de la Racca de Sintras 
CHAPITRE LXXXIII. Deux. jemmesmarines. pag. 109

L'une le montra en x(rig): auprès du port de Coppenhague; l'autre fiur la cóte méridionale de Suderoé.

CH PITRE LXXXIV. Poiforn-jerrme appellépar les lifpagncis Pece-muger.

Ce poiffon a la tếte rnude, collée inmédiatement fur les. épaules, lans cou; fes rireilles faites comme celies de l'inomme ont la couque tourice a peu près de la inene façon avec.l'ouverture beaucoup plus grande. Ses yeux couverts de leurs paupieres reffemblcht pour la conleur \& pour la inaniere dout ils font placés, non aux yeux d'un poifon, mais a ceux d'un homme. Il a le nez plat, les levres comme les, nòtres. Ses dents très blanches funt rangées comme dans l'homin: Il a la poitrine large, blanche, délicate, les mammèlles rondes \& formes. Enfin fes bras tont plus larges \& plus gros que longs, propres à nager: les matio portent de petits doigts pointus qui tiennent les uns aux autres par une mumbrane. Le matle \& la finelie ont les partics fexuclles femblables à celle: de l'homme \& de la femme. Le rette du corps finit en queue de poifton. On cn donnc la figurs.

CHAPITRE LXXXV. Homme marin \& femmo marine defjécbés.

On les nontruit aux curieux ea $\mathbf{2 7 5 5}$. 1 la foire saint-Germain a Paris.

CHAPITREL LXXXVI. Defcription d"uns fem. me marine aue l'on voyoit vivante o Paris en I $75^{\circ}$.

Flle avoit la peall rude au toucher, la tête nue a l'exception de guelques appatences écaillcules derribre ia tctc vers !a ruque, les oreilles longues \& larges, le vilage tres-laid, le cnu épais \& honnetement long; la main droite mal fomí, la poitrine large, les mammclles gran: des pleines \& aruindies. A l'egard du fexe, un Clicoris fort gros fort it de la vulve de la longucur d'un denipoucc. Elle avoit deux efpeces de nareoires aux ànes, qui pouvoient fe fermer \& couvrir en fe fermant les par ties fexuclles. Elle avoit la nioitie inférieure du corps en queue de poiffon couverte d'Ecaille. Defcription de cette queue Comparaifon de cette Sirene avec cell dont on 2 donné la Delcription au Chapitre ICXXXIV. 


\section{CHAPITRE LXXXVII. Homme marin $» u$ par $^{\circ}$ Mr.Glower.

Ce monftre avoit une figure limnaine, avec la tête, les bras, l'air \& le vilage d'un Indien, avec une queue de poiffon.

CHAPITRE JXXXVIII. Extrait d'une Lettre écrite de la Martinique, par Mr.Cbretien, dे tur Licentie de Sorbonne contenant la Relation d'un bomme marin qui a paru aux côtes de cette ifle be 23. de mai I671.

I. 23 du mois de mai 1671 , deux Frauçois \& quatre negres étant allés le matin au!x Ifles du Diamant avec un bateau pour pìclier, of voulut s'en revenir un peu avalse le coucher du folcil, ils apperçurent près du bord d'une petite Inle ol ils étoient, un monftre inarin aynut la tisure humaine de la ceinture en haut, \& fe terninant par le bas en poiffon. Sa queue étoir large \& fendue comme celle d'une Carangue, poillon fort commun dans cette mer. Il avoit la tête de la groffeur \& de la forme de celle d'un lomme ortinaire, avec des clıeveux unis, noirs, mẻlés de gris, qui lui pendoient fur les épaules; le vifige large di plein, le nez gros \& camus, les yeux de forme accoutunéc, les oreilles larges; une barbe demême pendante de fept i huit pouces, \& mêlée de gris comme les cheveux́; l'eitonac couvert de poil de la méme couleur; les bras \& les mains femblables aux notres, avec lefquelles, lorlqu'il fortoit de l'cau, il paroiffoit scefluyer le vilage, en les y portant à plufieurs reprifes; \& reniflant au fortir le l'eau comme font les chiens barbets. Le corps qui s'elevoit au deflus de l'eau juf́qu'à la ceinture étnit delié comme d'un jeune - homme de quinze it feize ans : il avoit la peau médiocrement blasıche, \& la longueur de tout le corps pouvoit être d'unviron cing pieds, fon air étoit farouche. Cet homme fe montre a quatre pas, de forte qúil ne peit pas y avoir d'illufiou des yeux dans cette Relation. On en dome la figure.

CHAPITRE LXXXIX. Copie d'un Nerbal fait a la Martinique de l'apparition d"un bomme marin Jir les bords de l'Jfe du Dirmant.

Dépefition de Cyprien Roger natif de Rozé en Caux. Dépoofition de Yullien Vattemar, âgé de dix-fept ans. Dépofition d' Abrabam, Negre du Sr. Alexandre Descbamps.

Dépofition d"André, Negre du Dr. Desforges. 
Dépofition de Pierre, Negre dis Sr. Noël be Mulle de la Rozière.

Ce procès - verbal dans 'la meilleure forne attefte le vérité de ee qu’on vient de lire dans le Chapitre précéslent.

CHAPITRE XC. Homme marin pîcbé en 1737 près d' Exeter en Devonsbire. Extrait du Wontderfut Magazine pour Septembre 1764. . page 125

Cet homme marin pris id demi-mort, foupiroit comme unc perfonue. Il avoit deux mains dont les doigts étoient unis cufemble par une membrane comme les patres d'm canard. Du refte, il avoic les yeux, le nez \& la bouche parfaitement reffemblans a ceux de l'homme: feuleinent il avoit le nez écrafé \& aplatti. 'La moicic inféricure de fon corps fe terminoit en une queue femblable aे celle d'un Famoñ.

CHAPITRE XCI. Extrait des Dialogues foits a bimitation des Anciens par Oratius Tubero ( La motte-le-Vayer), au fujet des boimmes marins: Dialogue .11. intitulé, le Banquet Sceptique. I26

poifon-fenme avec lequel les Negres du Mozambique difent fe ralfraichir grandement en en abufant mêne étant mort. Syrenes \& Néréides des anciens. Homnzes marins ¿x femmes marizes de la riviere qui paffe à Cochin. Les Vros d'Acolta, qui habiteat la grande Lagune Tiricaca, autre efpece d'hommeśs aquatiques. Sentiment d'un moderne qui a penfé que le genre humain étoit originaire de quelques Tritons \& femmes marines. Les Egyptiens eftimoient l'homme un animal aquatique.

CHAPITRE XCII. Extrait da neuroiéme lipre de 'T Hifoire Naturelle de Pline.

Triton ou fous R Empereur Tibere par les babitans de Lisbonne.

Plufieurs Néréides mortes trouvées: fur la plage par lo Gourverneur des Gaules, fous Augufte.

Homme marin ou für la câte d' Êpagne.

Néréides jettées par la mer fur la greve, aux côtesclo Bret ague fous l' Empereut Tibere.

Q 3 
CHAPITRE XCIII. Homme marin \& femms marilie vas dans to Nil en $592 . \quad$ page I 29

L'lromme s'élevoit fonvent fur l'eau jufqu'd fe:s parties naturclles, la femelle feulcinent jufqu'su nombrit. L'hoinme avoit l'air fero:e \& le regard farouche, les cheve' $x$ roux \&̈ un peu hériliés, In pean brune; il, śtoit fait conine nous par les parties que l'on appereuvit. $A u$ contraire l'air de la femme étoit doux; elle avoit les cheveuk longs, noirs, \& flottans fur les épaules, le corps blanc. jes mammelles enflées.

\section{CHAPITRE XCIV. Homme marin ou par le Sieur} Larcher, babitant du Fort-Royal.

CHAPITRE: XCV. Une femme \& wne fillo marines. Ig I

On lit dans l'Hiftoire de Portugal \& dans les Relations des Ind:s Orientaies que, s'etant fait un jour une pëche t la pointe de i'Ine d'une trompe de Tritons, ou hommes marins, on ile put en faire pirvenir au Roi Dom Emannuël qui régnoit alorsqu'une femme \& une fi le vivantes, to:s les aures, au nombre de quinze, étant morts, ou auli-tót apres fenr fortie de la mer, ou dans le trajet des Indes al Listonna. Defription de cetre femme \& de cette fille marines.

CH 1 ITTRE X CVI. Homme marin conduifant whe petite barque.

Defcription da cet homme marin. De la ceinture en bas fon corps étoit tout couvert d'écailles; du refte il resfembloit a un homne ordinaire.

Defcription de la petite barque qu'il conduifoit \& dans laquelle il fut pris. Cette barque \& l'honnme defiéché, fe voient encore aujou d'hui à Hall dans la Salle del'Amiranté; \& ie pricess-verbal de cette découverte, duemont attefté par łe Capitaine \& par tout l'équipnge du vaifeau qui le prit, fe trouve dans les archives de cetre Jurisdiaion.

CH IPITRE XCVII. Extrait de l'Hifoire Naturelle of Morale des Jles Aratilles. par le Sr. de Rocbefort, Livre I. Cbapitre XIII.

Petic eqquif ou hateau fait pour porter fulement une perfonne. Defmiption de ce bateau de pecheur; dimenfions,

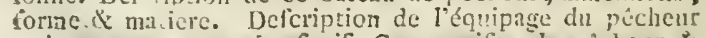
qui gouverne ce pecit efquif. Comparaifon du pécheur at de fa barque avec l'homme marin couduifint une petite barque, dont il eft parlé dans le Chapitre précedent. 
CHAPITRE XCVIII. De quelques animax $x$ marins, de l'ejpece des cétacées, dे la fois bimanes \& bipedes.

Le veau marin: paffage des Cétacées aux Quadrupedes.

Le veau marin marque le paffage des cétacées aux quadrupedes. Les antres cétacées, prefque rons bimanes, ont la portion inféricure de leur corps temnince én queue te poiffon, e'elt nuêne la forme dẹs hommes marins \& des ficmmes marines. Dans le veau mariu, cette queue partagée en denx parties égales \& digitées à leur extrémité, eft ainfi transformée cn deux pieds nfieux \& charnus. La croupe eft meme tout-il-fait lemblable a celle d'un quadrupede.

\section{CHAPITRE XCIX. Efpece particuliere de Poiffon} a pieds bumains.

Cette efpece particuliere de poiffon u'a ricu d'humain par la tête ni par la partic fupérieure de fon corps. Il a quatre nageoires, deux antérieures fort grandes \& étendues en forme d'ailes, \& deux poftérieures plıs petites: il a unc qusue de damphin. Mais fous les deux petites nageoires, on voir deux lianches qui fe prolongent \& prennent la forme de cuifies, auxquelles font attachées deux petites jambes terminées chacmue par un pied d'bonme auffi bicn fait qu'il puiffe l'être, ayant un talon \& une forme tollt - à - fait lemblable à nos pieds, excepté qu'on n'y rematque à l'extérieur ancume apparence de doigts; unais ces doigts font cachés fous la peatu, \& on les fent au toucher. Voilà un poifion enté fur la partie inféricu. re d'un homnze, conme nous avous vu un houme enté fur la quene d'un poifton. La femelle de ce poifton eft appellée par les Anglois Afermaid. Le Kingltone, autis poiflon, cft line ébauche du Mernaid.

\section{ONZIEME PARTIE.}

CHAPITRE C. Des Quadrupedes. I. Les Solipedes. 
Sle renflement excofif de la fubftance des ongles, leur a fait perilre leur ancien ufage, detorte que dans cet état latnimal we peut pius s'en fervir qu'à marcher. Rapports du fquelette clin clieval à cèlui de l'lomme.

\section{CHAPITRE CI. 2. Des Quadrupades pieds-four- clibs.}

Ee taureau, le cerf, le cocbon.

On obferve les progrès du prototype dans la fuite tes piedsfourchus.

CHAPITRE CII. 3. Les Fifipedes.

Les fiffipedes ont les pieds divifés en quatre ou cinq doigts, ¿i quelques-uns, mene dans les plus petites efpeces, ont dés miains très reffemblantes à celles de l'homme: telle eft la taupe \& d'autres. Lcs prenières elpeces de fiffipedes, comme le tépre, le lion, "le liopard, le Inup, Ec. font de veritables quadrupedes en ce que ieurs picds antérienrs ne peuvent leur fervir de mains. D'autres liflinedes, favoir les ous, les écurcuils, les agoutis $\mathbb{a}$ antres, fe fervent de lcurs pieds de devant comine de mains pour faifir ef porter d leur gueule : ce font ites quadrupedes ambigus qui forment lc pallage aux quacrumanes. Il fant cucore diftinguer parmi ces dermiers liiipedes ceux qui aiment à fe tenir le corps clevé, aflis ou accrounis lur leurs fefles, qui peuvent-mene, quoique plis difficilement fe tenir of marcher fur les deux pieds de derrière femlement. Ce font autant de nuances qui 1mus marquent les perfectionnemens gradués de l'animal prototype. En livivant ces gradations, on voit la natu re reformer le fquclette du folipecte, redrefler peu-à-pen les os du bafin, alonger les os des cuiffes, dus jambes $\&$ des bras, $\&$ an contraire raccourcir ceux des picds $\&$. des mains, divifer des pieces unics, articuler des pieces foudées enfenble, reflerrer. l'épine, fupprimer des vertebres $\&$ des cótes, $\&$ le rapproclier ainfi graduellement de la charpente du corps humain.

\section{DOUZIEME PAR TIE.}

\section{CHAPITRE CIII. Les Quadrumanes.}

Les extrémités des quatre membres des quadrunanes ont 12 forme de mains, d’où vient le nom qui leur a été donnế par les modernes. Gradation des quadrumanes. 
Qundrumanes au muleatu mince \&o alongé, \&̊ d quetro langrue.

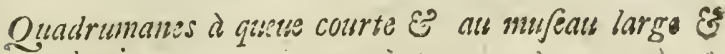
aplatti.

\section{Quadrumanes fans queue.}

Toutes on prefque toutes les femelles des quadrumanes font fujettes à l'écoulement périodique du fang, comme les fenmins.

Autre divifon des Quadrumanes par rapport d lo. maniere de marcher.

CHAPITRE CIV. L'Orang-Outang, Ibomme des bois, te Satyre, le Barris, le Clbimpanfée, lo Focko, l'bomme de nuit, le Troglodite, EC.

L'irang - outang n'cit pas véritablement un homme, mais il en approche de très près. Il n'eft pas non plus un finge, ni une guenon, car il en differe beaucoup plus qu'il ne diflere de l'homme. On peut clonc le prendre pour une clpece intermédiaire qui reinplit le paffage du finge à l'homme, ex c'eft ainf que nous l'envifageonts.

Differences qui difinguent cette efpece animale de l'Bljece bumaine, EO conformités qui l'en approcbent, taint pour les parties cxtérieures que pour l'organifation interne.

Deux efpeces d'Orang-Outang , favoir la petite efpece Eे la grande: celle-cieft plus voifne de l'bomme que i'autre.

1)'apres les obfervations fur les Quadrumanes on peut dresfer un cecte manière la titble des efpeces animales immédiatement au defous de l'homme.

I.es Sagoins, les Sapajons oै les Gurnoris qui ont det longues querves.

T.es Babouins à queue courte.

Te Magot qui u'a qu'uns apparsnce de queus.

Q 5 
Ie Grand Gibbon, le petit Gibbon, के le Pitbeque qui n'ont point du tout de queue \& qui marclient d aeux mains le corps droit.

Le Focke ou petit Orang-Outang.

Le Pongo ou le grand Orang-Outang dont les mains de derrieire je rapprocbent bcaucoup des pieds de l'bomme.

\section{L'Homme dont il y a plufieturs races.}

CHAPITRE CV. D'une efpece particuliere d'bonzme marin peut-être quadrumane. $\quad$ page ${ }_{56} 6$

J.a relation sle cet homme marin fingulier porte qu'il avoit la peau brune \& balince, funs écailles; tous les monvemens du corps, depuis la tête jufqu'anx pieds, tels que ceux d'un véritable homme; les yeux fort bien proportionnés, la bouche médiocre eu égard \&̀ ln longueur du corps eftimée de huit pieds; le nez fort camard, large of plat; les dents larges \& blanches; la langue épaife ; les cheveux noirs \& plats; le menton garni d'une barbe nousfeufe, avec des mouttaches de-méme fous le nez, les oreilles fomblables à celles d'un homme; les pieds \& les mains pareils, excepté que les doigts étoient joints par une pellicule, tolle qu'il s'cn voit anx pattes des oies \& des canards: ce qui fait croire que les doigts des pieds alongús leur domoient la forme de mains niarines.

\section{TREIZIEME PARTIE.}

CHAPITRE CVI. De l'Homme EO def diffirentes races bumaines.

I. Les bonmes à quteuse.

Noirs de l' Jfle de Manille qui ont une queuse de quatre à cing pouces de longrueur.

Mrarinthiens babitans de l'Ifle de Mindoro, voijune de Wanille, qui ont une queue pareille.

Ifomme de it the formose qui avoit ane curcue longtue de p!us d"un pied, toute converte d'un poil roux \& for: fesizblabie à celle d'un brexf. 
Il $y$ a des bommes a queus en Etbiopic, aux Indes, on Egypte, en Angleterre \& furiout en Liolle.

Ite Sr.Cruviliar de la Cisutat né avec une queue. aing que fon frère.

Noir nommé Mabammed, natif do Borneo qui aroit zine queute d'un demi-pied de longurur. Il étois fort velu contie l'ordinaire des nzgres.

Officier François qui nooit une quetse.

Mr. de Barfabas \& fa four Religioufe avoient sbacun une quetse.

Limonadiere de Paris qui avoit auffi une queue.

Homme d'Orléans qui, ayant voulu faire couper une quese qu'il avoit, mourut de cette opération.

Louife Martine, fenme d" Aix, groffe \&ु puilfante, portant poil au inenton, avoit unze quelue.

Procureur de la même sille, nommé Bernard \&8 furnommé Quelue - de Porc, parce qu'il acoit réellement une queus.

Réflexions fur les races d'bonmes dq queute.

CHAPITRE CVIII. 2. Les Negres. - page I58

Ces peuples noirs qui ont dos nez plats \& écrafés, de groffés levres, de la laine fur la tête aul lieu de cheveux, \& un efprit très borné z peine de quelques degrés audeflus de l'inftinet des brutes, forment une race particuliere très nombreufe. Les plus laids \& les plus ftupides font ceux d'Angola; Angola eft auffi la patric des Orangs - outangs. Les Negres nle font pas tous du même noir, ui de la même difformité. On trouve chez les races negres toutes les tcintes intermédiaires du noir au brun.

CHAPITRE CVIII. 3. Les Hottentots. - $\quad 169$

Ies Hotte tors ne font pas des Negres, mais des Cafies, ils vivent errans \& font de la plus affreufe mal-propreté. Ils font flıpides, indifciplinables. Leurs vilage eft fideux, leurs levres grolles, leur nez plat \& large, lekr 


\section{$22^{\circ}$ TABLE ANALYTIQUE}

voix femblable au cri d'un coq d'Inde, leur vie plus courte de moitié que celle de l'homme. Lesfemnes llottentotes, beaucoup plus petites \& plus laides que les hommes ont une excroifiance inonftrueufe de la peau qui courte l'os pubis, laquelle defcend en furme de tablier julqu'au milieu des cuifies.

\section{CHAPITRE CIX. 4. Des autres Caffres.}

Les autres Caffres font un peu noins laids que les Hotten? zots. Ainfi les traits de l'humanité s'adeucillent fenfiblement \& prenneut de la régularité en remontant vers l'orient. C'eft le contraire vers le Nord.

\section{CHAPITRE CX. 5. Tes Lappons d' Europe, les} samoiedes. d' Afie, les Sawoges diu Détroit de Davis en Amérique.

Les Lappons ont le vifage large \& plat, le nez camus \& écrafe, l'iris de l'nil jaunc brume \& tirant fur le noir, les paupieres ratirécs vors les teinples, les joues extrêmement élevées, la voix. grĉle, la tête grofie, les cheveux noirs \& lities, la peau bafanéc; ils font traptss quoique maigres, d la pltpart "n'ont que yuatre pieds de hauteur, les plus grands u'ont que quatre pieds \& demi. Les Lapponnes font aufi taides que leurs maris.

Les samoïedes font d'une taille au-deffous de la moyenne: ils ont le corps dur \& nervenx, d'une ftructure large \& quarrée, les jambes courtes \& menues, les pieds petits, le coucourt \& la tête grofic à proportion du corps, le vifage aplatti, les yeux noirs, \& lowverture des yeux petite mais allongée, le'nez tellement écrafé que le bout en eft à-pen-près an niveau de l'os de la machoire fupéricure qu'ils ont très forte \& ćlevée, la bouclie grande, \& les le. vres minces; feurs cheveux noirs comme le jais, mais extrémenent durs \& forts lemr pendent conme des chan. delles fur les épaules; leur tcint eft d'un brin jaunatre, \& ils ont les oreilles grandes \& rehauffées. Etymologies du nom de Samoïedes.

Les Sauvages, qui habitent les terres du détroit de Davis, font fetits, trapus, d'un téint olivitre; ils ont les jam: bes courtes \& groffes. Les Sauvages de Terre-nenve font aufli de petite taille, \& auffi mal faits que les Groenlandois. Ainf on peut conclure que tous les habitans du fiord tant de l'Europe que de l'Afie \& de l'Amérique, font les plus petits, les plus miferables, les plus laid's \& $\&$ les plus ftupides de toute l'efpece. 
CHAPITRE CXI. 6. Scuvages au corps 80 als vijage velus. - - - page 180

Jes Sauvages de la baie d'lludfón \& du Nord de la terre te L.abridor, ainfi que ceux du pays d'Feço au nord clu Japon dans l'aucien contiucut, reflicmbleut aux Lappous d'lurope $\mathbb{E}$ d'Amérique en ce qu'ils font laids, petits \& mal faits comme eux, mais ils en différent en ce qu'ils ont le corps \& le vifage aufi velu qu'un ours, au lieu que

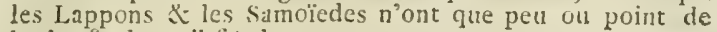
barbe \& de poil fur le corps.

CHAPITRE CXII. 7. Les Ofiaques \& les Tongujes.

Les Grtingutes \& les Tongufes fout la Nuance entre les Jappons dont nous avons parle \& les Tartares toht il jera queftion daus le Chapitre fuivant.

\section{CHAPITRE CXIII. 8. Les Tartares. - ibid.}

Tous les peuples compris fous le nom de Tartares ont le hauk du vilage fort large \& ridé, mème dans leur jeuneffe, le nez court \& les yeux petits \& enfoncés, les joues fort Elevées, le bas du vifage étroit, le menton long \& avancé, la måchoire fupérieure enfoncée, les dents longues de féparées, les fourcils gros qui leur couvrent les yeux, les paupières Epaiffes, la face plate, le teint bafanć \& olivâtre, les cheveux noirs; ils font de ftature médiocre, mais très forts \& très robuftes; ils n'ont que veu de barbe, $\mathbb{E}$ elle eft par petits épis comme celle des Chinois, ils onc le cuiffes groffes \& les janbes courtes. Ils font tous errans d Vagabonds. Divifion des Tartares.

Les Calmuques, les plus laids de tous les Tartares: dont l'ajpect a queique cbole d'effrayant.

Tes Tartares du Dagrbefam.

Tartares Nogais, ou petits Tartares.

Tartares Vagolijes en Sibérie.

Tartares mongoux, qui ont conquis la Chine.

Peuples duTbibet $\&$ des autres provinces méridionales

de la Tartarie, les moins laids de tous les Tartares. 


\section{CHAPTTRE CXIV. 9. Les Cbirois of les fapon-} nois, Éc. - page I8!

Les chinois ont en genéral le vifage laţe, les yeux petits, les tourcils grands, les prupiepres plates \& élevées, le nez camns, quelques épis de $t t^{-j}$ e à channe lcvre, $\&$ fort peu an menton. I's ont aifiz ordinairement lil taille

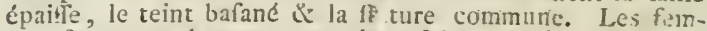
mes font peut-être un peu niéur faites, mais aufli laides de vifage.

Les Japonmois font afiez femblables atix Chinois, feulenent jls font plus jaunes ou plus bruns, durelte, ils ont bo taille ramaliéc \& le nez ecrafe. Susvent

\section{tes Cocbincbinois.}

\section{Les T'unquinois.}

\section{Les Siamois.}

\section{Les Peguans.}

Les babitans d" Aracan, de Laos, \&o autres contrécs voisunes, qui ont des figures Cbinoijes un peusariess.

CHAPITRE CXVi. IO. Les Indiens. Hommes à grofjes jambes.

Les Indiens font tous plus ou moins, olivitres on jaunes: cette couleur ne fe perd qu'en approchant des climats tempérés. A cela près ils reffemblent affez auxi Européens pour la taills \& les traits du vilage.

Il fant pourtant diftinguer parmi les Irdiens les Nobles de Calicut, tant hommes que femmes, parmi lefquels or trouve des familles entieres qui ont les jambes aufi grosfes que le corps d'um autre homme. On trouve encore de ces hornmes it grolles jambes a Ceylan. Les bourgeois de Calicuz forment auff une race purticuliere d'hommes plus laids, plus petits \& plus mal faits que Ies autres Indiens.

CHAPITRE CXVI. II. Les Perfans, les Araves, les Egypitiens, les Maures.

Tous ces peuples font des nuances intermédiaires en:re les Indiens \& les Européens des climats tempérés. 
CHAPITRE CXVII. 12. Les Elpagnols, les Porturgais, les I'rancois, bes Antriois, des Hollunduis, les Allemands, les Siuédois, les Polonois, les Da. nois.

Tous ces Peuples Europécns font beiux \& bien fairs, mais ils ne nous oflrent point le chef-d'xule de lis Nature. Les Efpagnols tiennent beaucoup des habitans de la Barbarie par une taille maigre \& aflez petite, par un teine jaune $\&$ balanć; cependant ils ont une belle tête $\&$ de beaux ycux. Les portugais tiennent des Elpagnols. Les François, les Anglois, les Hollandois \& "les Allemands font plus blancs que les Efpagnols of les Portugais; ils ont aufli une taille plus avantageufe : ils font encore éloiznés de la perfećtion de l’efpece humaine. Les Danois, ies plus blancs de tous les peuples, ue font pas pour ce. la les plus beaux.

CHAPITRE CXVIII. T3. Les Italiens, les Turcs, les Circafjiens ô les Géorgiens. • • - I 88

C'eft dans les belles Provinces d'Italic, \& dans l'Afie mineure qu'il faut chercher les plus belles races hmmaines. C'eft - la que la Nature après avoir paffé par tous les de. grés du froid \& du chaud, a fixé la plus jutte temperature. C'eft - lì l'empire de la beauté. Onl y trouve à la fois le plus beau coloris, les plus exaltes proportions, les formes les plus nobles ze les plus élégantes. On y voit rarement des corps contrefaits, prefique point de laids viliges, ni de figures ignobles. Détails fur les Italiens, les Grecs anciens \& modcrnes, les Turcs, les Circaffiens \& les Génrgiens, qui prouvent que ce font les plus beaux hommes de la terre.

\section{CHAPITRE CXIX. I4. Les Patagons on Géants. I9l}

Première découverte des Patagons ou Géants d l'extrémité Austarale de l"Amériquge, Leur force \&O lear grandeur extraordinaires.

Sept Giants vus dans la baie Grégoire, par les gens d'un Vaifeaus Malouin, nommé le faques.

Six autres Géants vus par les gens d'un Vaifleau Marfeillois, nommé le Saint-Pierre.

Doutes de Mr. de Buffon fur lexilence des races a'bommes toutss composées de Géants. 
Recbercbes propolées par Mr. de Maupertuis au /bijet des Patagons.

Nouroelles décoivertes de la Nation des Patagrons faites par des Vaifleaux Anglois.

Note qui contient tout ce qu' on a dit jusques - ici pour prouver qu'il n'y a point de Géants.

Les raifonnemens we peurent rien contre les faits.

\section{QUATORZIEME PARTIE:}

CHAPITRE CXX. Les Morifires. - page I9?

Définition d'un monftre. Les monftres entrent dans le plan général de l'Etre. Monftres qui engeudrent: autres qui nont pas la faculté générative. Raifon de cette différence. Les pierres, les plantes \& les animaux ont leurs monftres. Le mot de Monfre n'exprime qu'un rapport. Ce qu’on doit penfer fur les Etres appellés monftrueux. Leur néceffité \& leur utilité dans la cbaine univerfelle des productions naturelles. Les Etres éloignés dans l'échelle font des monftres les uns par rapport anx autres. Il y a même des races entières qui fenblent monftruenfes, comparées à d'autres races de la même efpece. Tel eft le Nère à queue comparé d̀ l'Européen, \& la femme Hottentote comparće à ume femme Turque. Peut-être qu'il y a des mondes ou les Etres reputés nonftrneus dans le notre, compofent des races conitautes.

CHAPITRE CXXI. Des Mongtres foffiles. igg'

Raifon ponrquoi ils femblent rares, \& gịils nous font peu fenfibles.

CHAPITRE CXXII: Desconformations monfrusethfes parmi les végétaux.

Citron qui en renferme un autre.

Poire qui en enfante ane feconcle, \& celle-ci jettant par fa tête une brancbe \& plufieurs feuilles.

Autre poire monfriterufe. 
Rose monftrueufe.

Autre rofe monftrueufe.

CHAPITRE CXXIII. Animaux monftrueux. Quatre efpeces de Monftres. • . page $20 \mathrm{~F}$

Premiere efpece: Monftres qui font tels par la conformation extraordinaire de quelques-unes de leurs parties, foit intérieures, foit extérieures.

Seconde efpece: Monftres qui ont quelque partie déplacké, foit à l'extérieur, foit dans l'intérieur.

Troifieme efpece: Monftres auxquels il manque quel. que partie: on les nomme Monftres par défaut.

Quatrieme efpece: Monftres par excès, ou qui ont des parties furmuméraires.

CHAPITRE CXXIV. Monftres qui font tels par la conformation extraordinaire de quelques-unes de leur's parties, foit extérieures, foit intérieures. 202

Le mulet qui provient ou d'uncbeval छ d'une änege, ou d'un âne E̊ d'une cavalle, oud'un onagre \&' d'une jument.

Mulet qui provient de l'accouplement d'un coq avec la femelle du canard.

Oeuf monftrueux dont la coque étoit marquée de plufieurs étoiles.

Autre cuf monftruezx qui portoit la figure d'un foleil en relief.

Enfant dont tous les os foudés enfemble ne formoient qu'un Seul os contimu.

CHAPITRE CXXV. Monftres qui font tels par le déplacement de quelques-unes de leurs parties, tant externes qu'intérieures. 


\section{TABLE A N A Y T I Q UE}

Enfant dont le corps étoit tourné à contre-Jens, le devant derriere, E le derriere devant.

Soldat qui avoit toutes les parties internes de la poitrine \& dic bas-ventre tranjpofées.

Trcis autres exemples d'une nonftruofité femtlable.

Fæutus qui avoit le caur en debors pendu au cou.

CHAPITRE CXXVI. Monfres par iéfaut. page zos

Agneau foetus fans tête, fans poitrine, fans vertebres है Jans queue.

Petit cbien fans yeux, Ẽ fans gueule, n'ayant à la place de la gueule qu'une petite trompe.

Homine qui n'avoit qu'un doigt à cbaque main, avoir l'index.

Enfant qui n'nvoit que la bafe du crâne, fars cer. veau, ni cervolet.

Autre foetus monftrueux à-neu-près femblable.

Fotus bumain qui n'avoit qu'un ail au milieu du front, fans boucbe, ni nez.

Autre foutus fans nez, E avec un feul cil.

Enfant fans parties fexuelles, ni à l'extérieur, nid lintérieur.

Monflre fans tête, Ėc. n'ayant que la moitié inférieure d'un corps: c'étoii une fille.

Autre monftre mâle dans le méme genre, Eo presque semblable.

CHAPITRE CXXVII. Monfres par excès. - 210

Poulet monftrueux, ayant quatre pieds E̊ quatre aţ. les. 
Autre poulet monftrueux, ayant quatre pattes, trois becs \& ${ }^{2}$ trois yeux.

Figure d'une tête bumaine, trouvée dañs un ceuf. Autre exemple femblable, rapporté par Fortunio Li. ceti.

Cbevreau monftrueux ayant dixpieds, deux anus E deux queues.

Lievre monftrueux, ayant deux corps adodés, deux têtes \& buit pieds.

Linfant tout babillé d'une espece de furpeau, en forme de tégument ou d'enveloppe.

Deux enfans mâlesjoints enfemble par la partie infé. rieure du ventre.

Foctus bumain à deux tétes, deux cefopbages, deux eftomacs, deux poumons, E'c.

Autre monftre bumain ayant deux vifages \& quatre pieds.

Deux filles jointes enfemble pofteriaurement, depuis les épaules jufqu'aux felfes.

Italien d'environ 18 ans, ayant une seconde tête plus petite que la fienne au-dedous.

Fille âgée de $\mathrm{I} 2$ ans qui avoit deux corps.

CHAPITRE CXXVIII. Les Hermapbrodites bu. mains.

- page 220

Quatre efpeces d'Hermapbrodites.

Premiere efpece: ceux qui ont l'un des deux Jexes parfait है l'autre imparfait.

Seconde efpece: ceux qui ont les deux fexes imparfaits. 
Troifieme espece: ceux qui peuvent engendrer comme mâles \& comme femelles, mais Seulement avec un autre individu.

Quatrieme efpece: ceux qui peuvent engendrer avec un autre individu comme mâles ou comme femel. les, peuvent encore. produire Seuls parl'union des deux Jexes qu'ils podjedent.

Conclufion.

\section{FIN DE LA TABLE.}

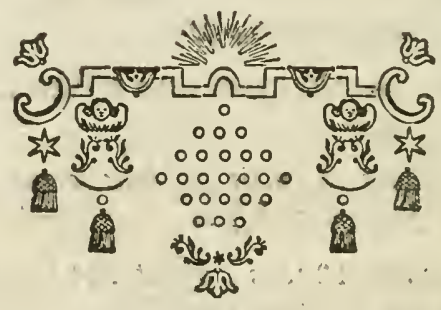





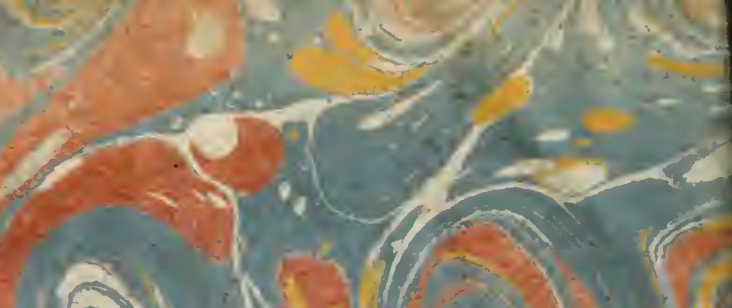


if

$x^{2}$

1

$3=$

nes

Y. 